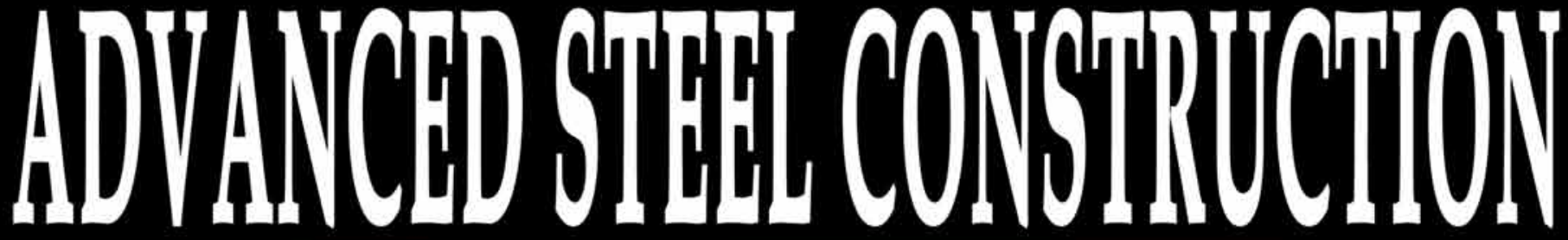

an Intenuational ] ounal

Volume 1 Number 1 June 2005

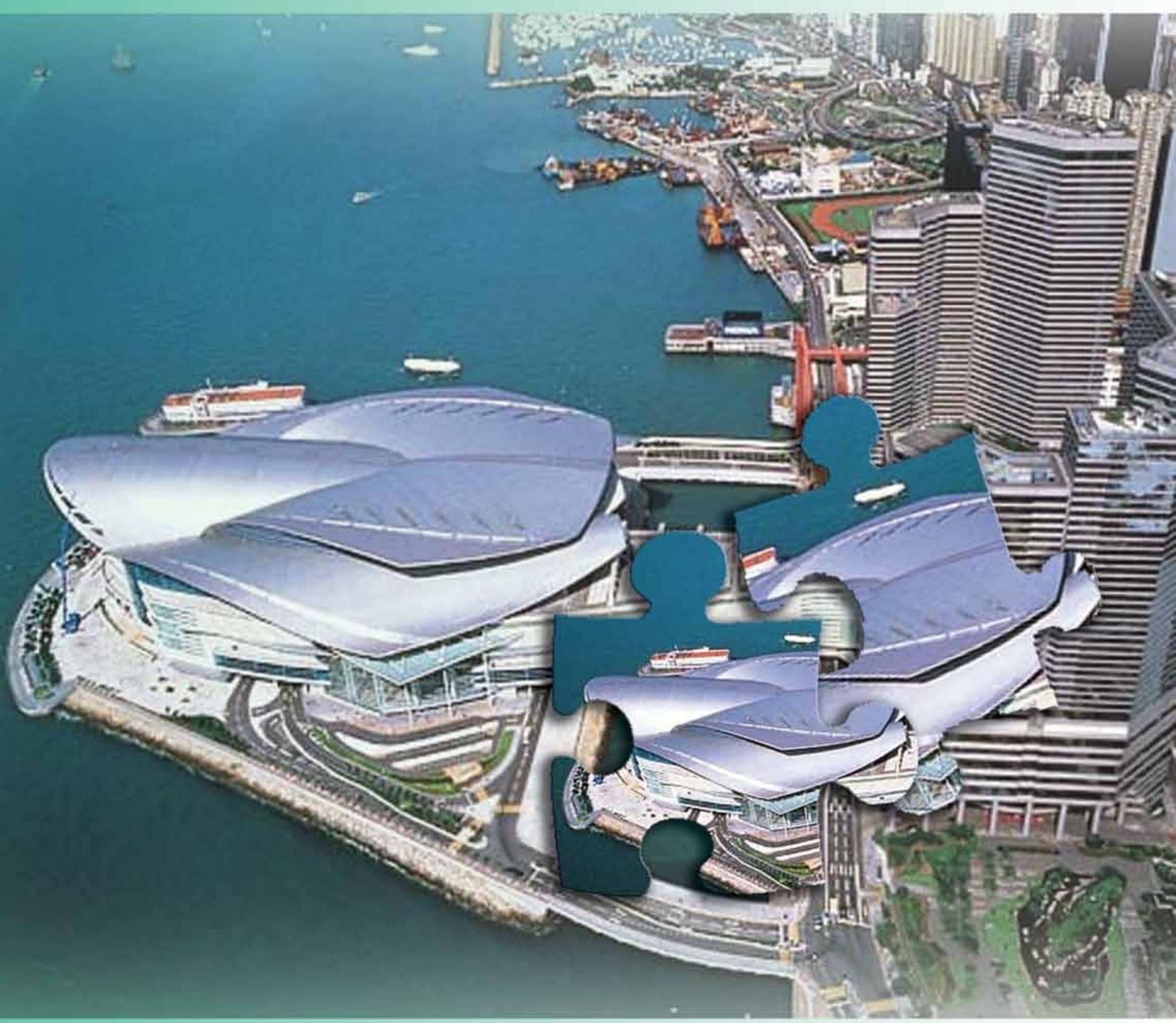

Editors-in-Chief

S.L. Chan, The Hong Kong Polytechnic University, Hong Kong

W.F. Chen, University of Hawaii at Manoa, USA

R. Zandonini, Trento University, Italy 


\section{Advanced Steel \\ Construction an international journal}

\section{EDITORS-IN-CHIEF}

\section{Asian Pacific, African} and organizing Editor

S.L. Chan

The Hong Kong Poly. Univ., Hong Kong

\section{American Editor \\ W.F. Chen \\ Univ. of Hawaii at Manoa, USA}

\section{European Editor}

R. Zandonini

Trento Univ., Italy

\section{INTERNATIONAL EDITORIAL BOARD \\ F.G. Albermani}

The Univ. of Queensland, Australia.

F.S.K. Bijlaard

Delft Univ. of Technology, The Netherlands.

R. Bjorhovde

The Bjorhovde Group, USA

M.A. Bradford

The Univ. of New South Wales, Australia.

D. Camotim

Technical Univ. of Lisbon, Portugal.

C.M. Chan

Hong Kong Univ. of Science \& Technology, Hong Kong.

S.P. Chiew

Nanyang Technological Univ., Singapore.

K.F. Chung

The Hong Kong Poly. Univ.

Kowloon, Hong Kong.

G.G. Deierlein

Standford Univ., California, USA.

L. Dezi

Univ. of Ancona, Italy.

D. Dubina

The "Politehnica" Univ. of Timosoara, Romania.

R. Greiner

Technical Univ. of Graz, Austria.
G.P. Shu

G.W.M. Ho
Ove Arup \& Partners Hong Kong Ltd., Hong Kong.

J.P. Jaspart

Univ. of Liege, Belgium.

S. Kitipornchai

City Univ. of Hong Kong, Hong Kong.

D. Lam

Univ. of Leeds, UK.

G.Q. Li

Tongji Univ., China.

J.Y.R. Liew

National Univ. of Singapore, Singapore.

X. Liu

Tsinghua Univ., China.

E.M. Lui

Syracuse Univ., USA.

Y.L. Mo

Univ. of Houston, USA.

J.P. Muzeau

CUST, Clermont Ferrand, France.

D.A. Nethercot

Imperial College of Science, Technology and Medicine, UK.

\section{D.J. Oehlers}

The Univ. of Adelaide, Australia.

K. Rasmussen

The Univ. of Sydney, Australia.

T.M. Roberts

Cardiff Univ., UK.

J.M. Rotter,

The Univ. of Edinburgh, UK.

C. Scawthorn

Scawthorn Porter Associates, USA.

P. Schaumann

Univ. of Hannover, Germany.
Southeast Univ. China.

J.G. Teng

The Hong Kong Poly. Univ.,

Hong Kong.

G.S. Tong

Zhejiang Univ., China.

K.C. Tsai

National Taiwan Univ., Taiwan.

C.M. Uang

Univ. of California, USA.

B. Uy

The Univ. of Wollongong, Australia

\section{Veljkovic}

Univ. of Lulea, Sweden.

F. Wald

Czech Technical Univ. in Prague,

Czech.

Y.C. Wang

The Univ. of Manchester, UK.

D. White

Georgia Institute of Technology, USA.

E. Yamaguchi

Kyushu Institute of Technology,

Japan.

Y.B. Yang

National Taiwan Univ., Taiwan.

B. Young

The Univ. of Hong Kong,

Hong Kong.

X.L. Zhao

Monash Univ., Australia. 


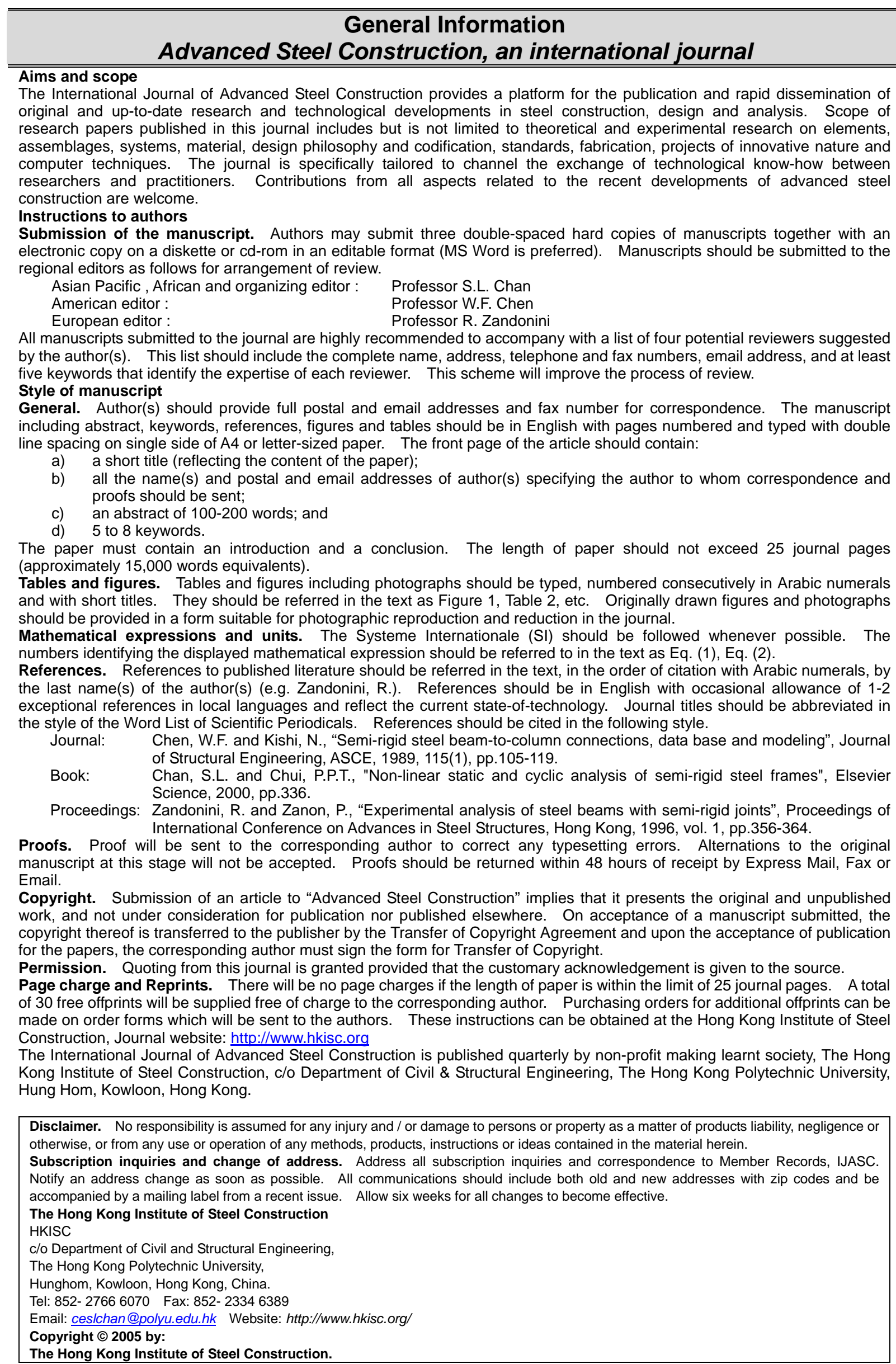




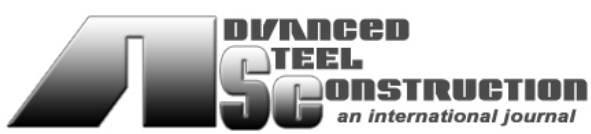

EDITORS-IN-CHIEF

Asian Pacific, African and organizing Editor

S.L. Chan

The Hong Kong Poly. Univ., Hong Kong

\section{American Editor}

W.F. Chen

Univ. of Hawaii at Manoa, USA

European Editor

R. Zandonini

Trento Univ., Italy

\section{Published by}

The Hong Kong Institute of Steel Construction

\section{Advanced Steel \\ Construction an international journal}

VOLUME 1/ NUMBER 1

JUNE 2005

Foreword for the Inaugurate Issue of the

International Journal of Advanced Steel Construction

W.F. Chen

Technical Papers

Effects of Concrete Slab on Ductility of Steel Moment 3

Connections

C.B. Joh and W.F. Chen

Compressive Performance of Cold-formed Thin-walled Steel Channel Sections in Fire

Y.C. Wang, M.Q. Feng and B. Salhab

An Equilibrium Approach for Flexural-Torsional Buckling of Elastic Steel Arches

Y.L. Pi, M.A. Bradford and Y.Y. Chen

Steel Framed Structures Subjected to the Combined Effects of Blast and Fire -Part 1: State-of-the-Art-Review

H.X. Yu and J.Y.R. Liew

Steel Framed Structures Subjected to the Combined Effects of Blast and Fire -Part 2: Case Study

H.X. Yu and J.Y.R. Liew

Design of Plane Steel Frames - Towards a Rational Approach

R. Gonçalves and D. Camotim

Flexural Behaviour of Steel Panels Composed of Bolted Modular Units

H.T. Wong, J.G. Teng, Z.C. Wang, Y. Zhao and S.L. Dong

Second-order P- $\Delta-\delta$ Analysis and Design of Angle Trusses Allowing for Imperfections and Semi-rigid Connections

S.L. Chan and S.H. Cho 


\section{Foreword for the Inaugurate Issue of the International Journal of Advanced Steel Construction}

The International Journal of Advanced Steel Construction is dedicated to the advancement of structural engineering and steel construction by innovation and creativity for the engineers in the regions of Greater China. The Journal provides a platform for the publication and rapid dissemination of original and up-to-date research and technological developments in steel construction, design and analysis worldwide.

China is a rising power in the $21^{\text {st }}$ century and has had an annual growth rate of greater than 8 percent for more than a decade. It consumes a large quantity of natural resources including cement, steel and oil, among many others. Innovation and technology transfer in a timely manner for engineers in the Greater China regions are critical for efficiency, economy and sustainability for further growth.

In structural engineering and steel construction, true innovation is more than just a new design concept or a new construction technology. The more efficient use of materials in construction frequently involves more complicated computation with more exotic theories. Simplifications are necessary for engineers to maintain a "feel" for their design. Simplification will always lead to better structures that require less materials, labor and construction time. Generally speaking, simplicity leads to a wider and faster adoption of innovation.

In my career spanning over the last 40 years, I have had first-hand experience of such a transformation in the development of simple solutions from complex but well founded theories of mechanics and materials. From my first work at Lehigh University on the development of a simple plastic theory for steel frame design, to the development of simple limit analysis techniques for geotechnical engineering applications, to my most current work on the development of practical advanced analysis methods for the 2005 AISC code for steel building design, I have witnessed and operated on one basic principle: make complex theories work in engineering practice by keeping the solutions simple and practical.

The impact of these advances on the steel construction industry is tremendous as evidenced by the release of different versions of the AISC specifications over the last 80 years: from Allowable Stress Design, to Plastic Design, to Load and Resistance Factor Design, to the most recent Performance-Based Design. Today, we are again on the cusp of releasing the next generation of the 2005 AISC specifications that will bring safety, economy and simplicity for generations to come.

To this end, I would like to share with you, the reader, my three simple cardinal rules for a good practice of structural engineering:

Cardinal Rule One: Ductility can be forgiving of one's mistakes.

Be wary when you deal with a new environment with a familiar material but with possibly a much less ductility due to size effect, temperature change, damage due to cold work or the new way of making steels. For example, structural steel is considered to be a homogeneous, isotropic, and ductile material, but none of these properties is true at a fully welded beam-to-column joint with thick flange plates.

Cardinal Rule Two: Connection detailing is everything.

Most structural failures initiated from the connections as a result of some poor detailing in joints. Structural members seldom fail in a sudden manner but joints fail frequently in brittle fracture. Extensive computation and modeling may not be helpful because in-situ material properties and residual stresses are not known at these joints. Simple design rules developed on the basis of full scale tests are more relevant and result in safer joints with lower labor and material costs.

Cardinal Rule Three: Redundancies are the best defense against unexpected failures.

Good structural engineers need to look ahead and anticipate unexpected events to guard against such progressive failures as witnessed in the World Trade Center collapse. Redundancies can also compensate for some undetected quality control problems that may occur during construction.

In summary, the true fulfillment for the authors of this Journal is to see their work find its way into engineering practice. That is to be "a place in practice". To achieve this goal, one must always keep in mind: make things simple.

\section{W. F. Chen}

Professor of Civil Engineering Dean, College of Engineering University of Hawaii at Manoa Honolulu, Hawaii, USA 
[Blank Page] 


\title{
EFFECTS OF CONCRETE SLAB ON DUCTILITY OF STEEL MOMENT CONNECTIONS
}

\author{
Changbin Joh ${ }^{1}$ and Wai-Fah Chen ${ }^{2}$ \\ ${ }^{1}$ Korea Institute of Construction Technology (KICT), 2311 Daehwa-Dong, ilsan-Gu, Goyang-Si, \\ Gyeonggi-Do, 411-712 Korea. \\ Tel: 82-31-9100-332 Fax: 82-31-9100-121 Email: cjoh@kict.re.kr \\ ${ }^{2}$ College of Engineering, University of Hawaii at Manoa 2540 Dole Street, Holmes Hall 240, \\ Honolulu, HI 96822, USA. \\ Tel: (808)956-7727 Fax: (808)956-2291 Email: chenwf@wiliki.eng.hawaii.edu
}

\begin{abstract}
The effects of slab on the ductility of steel moment connections representing typical Japanese and US details are investigated based on an interpretation of existing composite connection tests and our own numerical analyses. Different seismic behaviors between typical Japanese and US connections are also investigated. The results show that the presence of slab: increases the beam strength, imposes a constraint near the beam top flange, and, as a consequence, induces concentrated deformation near the beam bottom flange, which in turn reduces the ductility of the connection. The total deformation capacity of the connection depends not only on the beam but also on the connecting column and panel zone. The detrimental slab effects and the relative strength between beams, column, and panel zone should be considered in the seismic design of these connections.
\end{abstract}

Keywords: Seismic Design, Concrete Slab, Local Ductility, Steel Moment Connection, Rupture Index, Relative Strength

\section{INTRODUCTION}

During the Northridge in 1994 and Hyogoken-Nanbu in 1995 earthquakes, Steel Moment Connections (SMC) failed in a brittle manner. These connections were designed to have a ductile and stable failure mechanism such as the formation of a plastic hinge. Most of the brittle failure occurred at the column weld interface of the lower portion of the connection (Figure 1). These unexpected failures initiated several experimental studies on SMCs with various reinforcements and improved details. The improvements include the use of Reduced Beam Section (RBS), haunches, and cover plate (FEMA [1] and Nakashima et al., [2]) both in Japan and US. These studies focused on the tests of full-scale sub-assemblages of a column and a beam to guarantee energy dissipation through the stable formation of a plastic hinge at the beam.

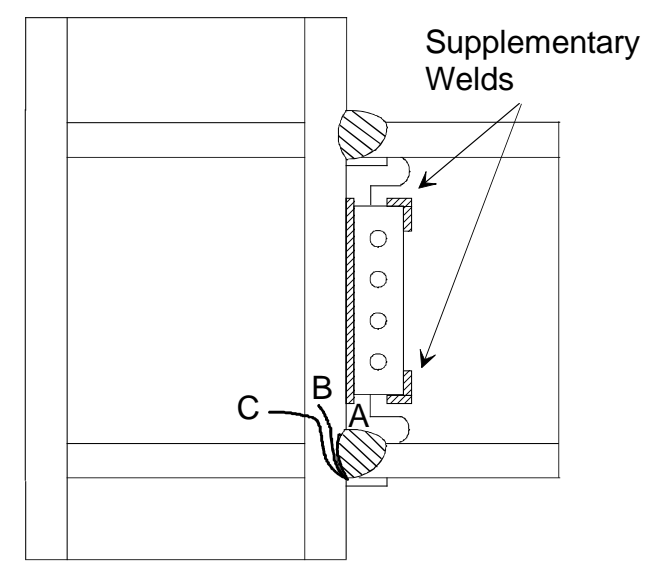

Figure 1. Typical Damages During Northridge Earthquake (Joh and Chen 1999) 
Most of these test specimens, however, did not consider the composite action of the slab. This is probably because of the assumption that the composite connection will behave like a bare steel connection after a few cycles of earthquake loading due to the cracks at the face of a column flange.

Since an actual steel building frame has floor slabs that are bonded to supporting beams from full to partial composite actions, its actual behavior under earthquake load will be different from what is expected from a bare steel building. For instance, the composite connection will attract more moment than that from the analysis based on the bare steel building. On the other hand, under the same story drift, a composite connection needs more local deformation capacity than a bare steel connection. The reason is that the composite slab adds constraint to the top of the connection, concentrates the deformation at the lower portion of the connection, and eventually reduces the global deformation capacity. In spite of some of these cracks at the face of the column flange, the composite action might be quite effective as will be shown later.

Another relatively less studied issue is the relative strength effect on the seismic behavior of the SMC. Total deformation of the SMC is the sum of the deformation from beams, columns, and panel zone. Contribution of each component is dependent on the relative strength between the connection components; the columns, the beams, and the panel zone. Due to the strong column-weak beam design concept, the ductility of a SMC largely depends on the deformation capacity of the beam. However, with a relatively less strong column, the burden of a beam can be lowered without lowering the total ductility of a SMC.

In this paper, the slab effects on the deformation capacity of a SMC are investigated using the interpretation and numerical analyses of composite connection tests. The untested connection details are also numerically analyzed based on our successful numerical modeling of the tested specimens. The relative strength effects are also investigated based on the numerical analysis. The contribution to the total deformation from each connection component is quantified and compared between typical Japanese and US connections.

\section{STEEL MOMENT CONNECTION IN USA AND JAPAN}

Seismic design codes require that structural integrity be maintained under site-specific earthquake excitations. To achieve this, steel moment connections are designed to attain the plastic moment $\left(\mathrm{M}_{\mathrm{p}}\right)$ in the beams and the columns without allowing the fracture of the connection itself. Moreover, the "strong column-weak beam" concept is often used to force the formation of plastic hinges in the beams to minimize lateral deflections and global stability. This design concept is taken for granted in two high seismic regions in the world: Japan and USA.

However, typical details of the connections between Japan and US practices are different each other, because design practice are closely related with not only the design concept but also with the material and the fabrication skills used in the region. In this section, typical connection details for Japan and USA are briefly reviewed and the composite connection tests used in this paper will then be described. 


\subsection{USA: before and after the Northridge Earthquake}

The welded flange-bolted web (WFBW) connection uses the principle and design details as shown in Figure 1. The column is continuous through the joint. Shear plates are welded to the column flange in the shop and bolted to the beam web in the field. Beam flanges are welded to column flanges using full penetration butt groove welding. An E70T-4, the self-shielded flux cored electrode with a very low toughness, was commonly used. During the Northridge earthquake, while the top flange of beams and shear tabs showed some damage, brittle failures at the column-weld interface were most common (Figure 1, Joh and Chen, [3]).

After the Northridge earthquake, SAC Joint Venture initiated several projects to investigate the connection failures experimentally and analytically (FEMA, [1]). These test results lead to two conclusions. First, the standard WFBW connection demonstrated poor performance (brittle fracture). Second, reinforced connections with reduced beam sections (RBS, Figure 2(a)) and hunches (Figure 2(b)) can improve the performance of standard moment connections. It should be noted that most of these test setups did not include the composite floor slab.

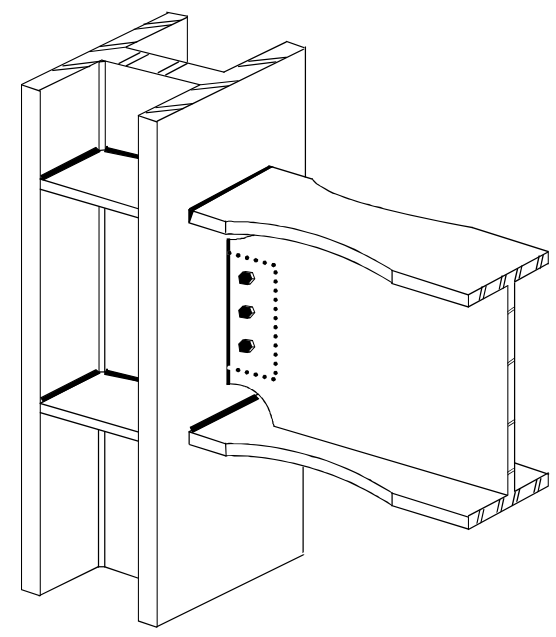

(a) Reduced Beam Section Connection

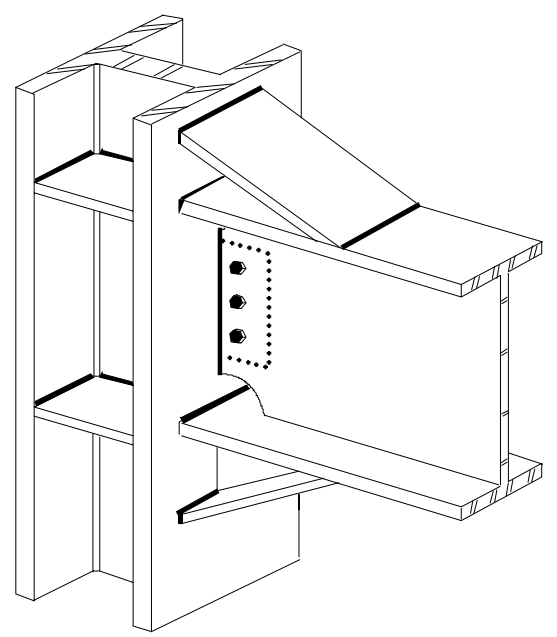

(b) Haunch Reinforced Connection

Figure 2. Improved Connection Details after Northridge Earthquake

\subsection{Japan: before and after the Hyogoken-Nanbu Earthquakes}

In Japan, modern steel moment frames are usually constructed using square tube column (often cold-formed) and wide flange beams known as a ‘through-diaphragm connection' (Nakashima et al., [2]). In this connection, a square tube is cut into three pieces, one for the panel zone, others for the lower and upper columns respectively (Figure 3). Two diaphragm plates slightly bigger than the square tube are placed between the columns and shop welded all around by full penetration groove welding. A short segment of wide flange section is then welded to the diaphragm in the shop using full penetration groove welding to guarantee high quality welding at the stress concentrated region. Then the beam web is fillet welded to the column. Later in the field, mid-span of the beam is connected by the bolted splice. This type of connection is very popular in Japan, particularly for low and mid-rise buildings. 


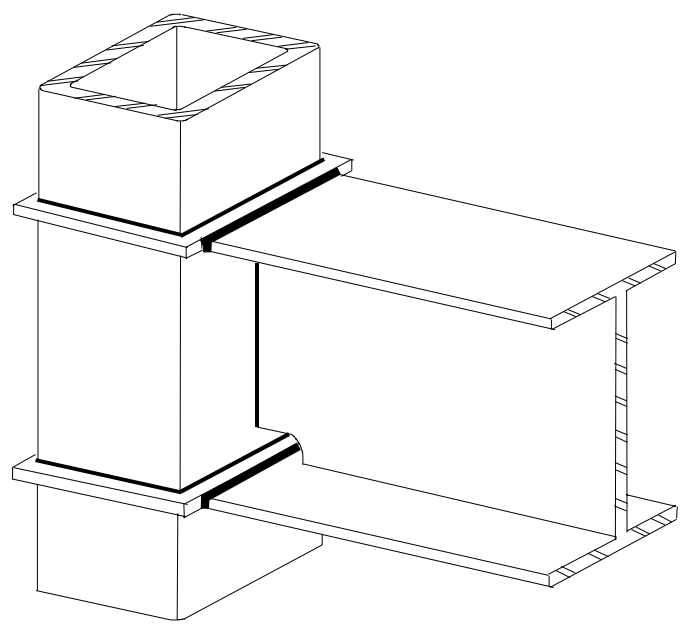

Figure 3. Typical Japanese Connection

After the Hyogoken-Nanbu earthquake, many damages were found in this connection. Most of these failures are, with some degree of plastic deformation and local buckling in the beam, brittle fracture at the weld metal or beam base metal near weld toe (Nakashima et al., [2]). Possible causes are: stress concentrated at the web access hole with low fracture toughness, concentrated welding near the beam flange due to a short diaphragm, and an un-removed backing bar.

\section{COMPOSITE CONNECTION TESTS}

\subsection{Composite Connection Test: Japanese Connections}

For the composite connection tests representing Japanese connection detailing, the tests performed at the Research Institute of Industrial Science and Technology (RIST) are used. (RIST, [4], and Joh and Chen, [5]). Of 10 specimens tested with many parameters, 3 specimens representing composite steel connections (S01 and S04) and a bare steel connection (S02) are numerically modeled to investigate the slab effects (Table 1).

Table 1. Details of Japanese Connections

\begin{tabular}{|c|c|c|c|c|}
\hline $\begin{array}{l}\text { Model } \\
\text { (1) }\end{array}$ & $\begin{array}{c}\text { Column } \\
(2)\end{array}$ & $\begin{array}{c}\text { Beam } \\
(3)\end{array}$ & $\begin{array}{c}\text { Slab } \\
(4)\end{array}$ & $\begin{array}{c}\text { Comment } \\
\text { (5) }\end{array}$ \\
\hline S01 & B-Box-450 × $450 \times 22$ & H-612 x 202 × 13x 23 & $200 \mathrm{~mm}$ & Standard Slab \\
\hline S02 & B-Box-450 x 450 x 22 & H-612 x 202 x 13 × 23 & -- & $\begin{array}{c}\text { No Slab, Bare } \\
\text { Steel }\end{array}$ \\
\hline S04 & B-Box-450 x 450x 22 & H-612 x 202 x 13 × 23 & $130 \mathrm{~mm}$ & Shallow Slab \\
\hline
\end{tabular}

The test specimen is designed to represent the lower part of a moment connection of typical 10-story building in Japan. The column height between the hinges is $3.7 \mathrm{~m}$ and the beam length from the face of the column is $3.275 \mathrm{~m}$ (Figure 4). For columns, the square box sections (B-Box-450 x $450 \times 22$ ) with the height and the width of $450 \mathrm{~mm}$ and the thickness of $22 \mathrm{~mm}$ are used. For beams, H sections (H-612 x 202 x 13 x 23) with the height of $612 \mathrm{~mm}$ and the width of $202 \mathrm{~mm}$ are used. The thickness of the web and the flange are $13 \mathrm{~mm}$ and $23 \mathrm{~mm}$ respectively. Real scale top and bottom box columns are welded each other using a $25 \mathrm{~mm}$ thick complete penetration diaphragm. Beam flanges (23 mm thick) are welded to this diaphragm instead of a column flange and beam access hole is used as shown in Figure 4. The beam web is welded to a column flange directly without using a shear tab. To see the slab effects clearly, the panel zone is designed to 
remain elastic range even under ultimate loading. To simulate the actual steel building, four side beams are designed at each column web and each side of loading zone, and fully bonded to the slab using $22 \mathrm{~mm}$ diameter stud bolts. To have complete composite action between the beam and slab, two $22 \mathrm{~mm}$ diameter studs are used at $200 \mathrm{~mm}$ spacing. All steel materials used are SM490 and their material properties are shown in Table 2.

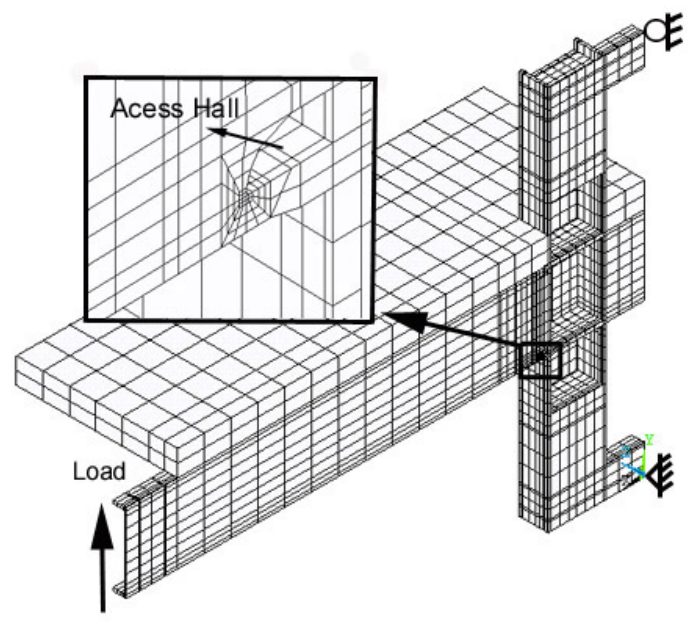

Figure 4. Numerical Model for a Japanese Connection (S01)

Table 2. Material Properties of Japanese Connections

\begin{tabular}{c|c|c|c|c}
\hline $\begin{array}{c}\text { Specimen } \\
\mathbf{( 1 )}\end{array}$ & $\begin{array}{c}\sigma_{\mathbf{y}} \mathbf{( M P a )} \\
\mathbf{( 2 )}\end{array}$ & $\begin{array}{c}\sigma_{\mathbf{u}} \mathbf{( M P a )} \\
\mathbf{( 3 )}\end{array}$ & $\begin{array}{c}\sigma_{\mathbf{y}} / \sigma_{\mathbf{u}} \\
\mathbf{( 4 )}\end{array}$ & $\begin{array}{c}\text { Elongation (\%) } \\
\mathbf{( 5 )}\end{array}$ \\
\hline Plate & 374.4 & 541.9 & 0.59 & 24.5 \\
\hline Flange & 390.4 & 536.1 & 0.65 & 25.5 \\
\hline Web & 443.9 & 551.7 & 0.81 & 24.9 \\
\hline
\end{tabular}

Concrete slab is designed to represent thick and thin slabs. Concrete strength measured at the time of the test is $25.7 \mathrm{MPa}$. For reinforcement, both $30 \mathrm{~mm}$ from the top and bottom of the slab, D13 (diameter $=13 \mathrm{~mm}$ ) bar at $200 \mathrm{~mm}$ spacing in both directions are used. The members of the specimens numerically modeled are described in Table 2. The major difference between composite specimens (S01 and S04) is the thickness of slab and other details are identical to S01.

The failure of S01 specimen occurred at the root of bottom flange access hole, which is similar to the damage occurred during the Hyogoken-Nanbu earthquake (RIST, [4], and Joh and Chen, [5]). Under cyclic loading, semi-elliptic ductile crack is propagated from the root of bottom flange access hole, where the geometry changes abruptly and crack-like defects can be found due to the cutting process of access hole. After this ductile crack reaches its critical size, the brittle fracture occurs.

Figures 5 and 6 show the test results of global behavior of S01 and S02. The displacement in the figures is the displacement measured at the loading position (here after 'Beam Tip Displacement'). Due to the composite action of the slab, S01 has greater strength than that of S02. For the ductility of the connection, however, S02, a bare steel connection, took more cyclic loading before it failed than S01 did. Therefore, S01 has smaller deformation and energy dissipation capacity than that of S02. This is because the slab increases the constraint near the top flange and deformation is concentrated at the lower flange as shown in the numerical analysis. The specimen, S04, with a 
shallower slab, has smaller ultimate strength than that of S01 but shows similar deformation behavior to S01. More test results will be discussed along with numerical analysis later.

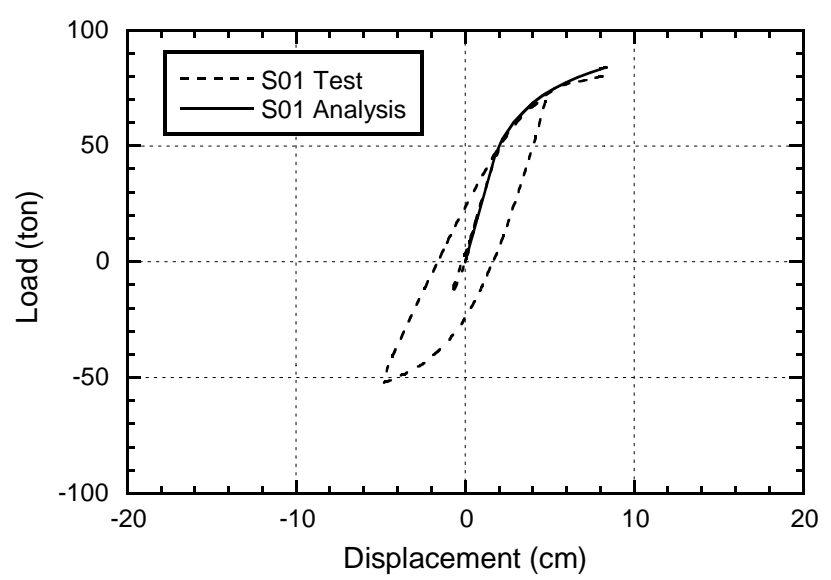

Figure 5. Global Behavior of a Japanese Connection (S01, Composite Connection)

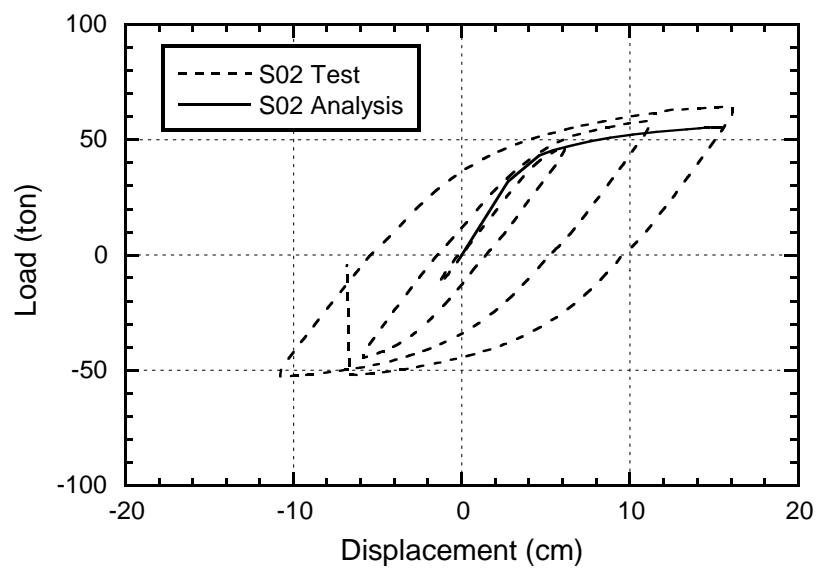

Figure 6. Global Behavior of a Japanese Connection (S02, Bare Steel Connection)

\subsection{Numerical Model}

Numerical models are used to investigate the local behavior near the beam access hole, where the fracture occurs, not for the detailed behavior of the slab. Figure 4 shows the numerical model of a composite connection (S01). Only one-half is modeled due to the symmetry. 8-node solid elements are used for a bare steel connection and concrete slab using ANSYS commercial code (ANSYS, [6]). For the local behavior near stress concentration, the meshes in the vicinity of the access hole are finer than the meshes for other region (Figure 4). Hinged boundary conditions are imposed at both ends of the column to describe the test setup. Monotonously increasing load is applied at the end of the beam. Multi-linear isotropic hardening model is used for the steel beam and the column based on the material test results (Table 2). Concrete slab is modeled as the Drucker-Prager material, because our primary concern of the analysis is not the detailed behavior of the slab such as cracking but the behavior near the beam access hole.

In the composite specimens (S01 and S04), constraint equations are used to connect the slab to the steel beam and column, which has achieved full composite action (i.e., no slip). Side beams are also simulated by the constraint equation. Reinforcing bars in the slab are not modeled for simplicity. 


\subsection{Composite Connection Test: US Connections}

The tests performed by Civjan et al. are modeled (Civjan et al., [7,8]). The original purpose of the test was to find an effective and economic repair method for existing connections. Four specimens representing composite steel connections (DB2 and HCH4) and bare steel connections (DB1 and HCH3) are numerically modeled to investigate the effects of the slab (Table 3). DB1 and DB2 are RBS connections, and $\mathrm{HCH} 3$ and $\mathrm{HCH} 4$ are reinforced with haunches. DB1 and HCH3 are identical to DB2 and $\mathrm{HCH} 4$ respectively except the presence of the slab.

Table 3. Details of US Connections

\begin{tabular}{|c|c|c|c|c|}
\hline $\begin{array}{l}\text { Model } \\
\text { (1) }\end{array}$ & $\begin{array}{c}\text { Column } \\
(2)\end{array}$ & $\begin{array}{c}\text { Beam } \\
\text { (3) }\end{array}$ & $\begin{array}{c}\text { Slab } \\
(4)\end{array}$ & $\begin{array}{c}\text { Comment } \\
(5)\end{array}$ \\
\hline DB1 & W12 x 279 & W30 x 99 & No Slab & $\begin{array}{c}\text { Bottom flange } \\
\text { RBS }\end{array}$ \\
\hline DB2 & W12 x 279 & W30 x 99 & $160 \mathrm{~mm}$ & $\begin{array}{c}\text { Bottom flange } \\
\text { RBS }\end{array}$ \\
\hline HCH3 & W12 x 279 & W30 x 99 & No Slab & Bottom haunch \\
\hline $\mathrm{HCH} 4$ & W12 x 279 & W30 x 99 & $160 \mathrm{~mm}$ & Bottom haunch \\
\hline
\end{tabular}

Figures 7 and 8 show the connection test setup schematically for DB 2 and HCH4 respectively. The column height between the hinge at the bottom and the loading is $3.66 \mathrm{~m}$ and the beam length between the hinges is $7.32 \mathrm{~m}$ (Figure 7 and 8). Actually, both ends of the beams are supported by rigid-link with load cell from the floor. In the test, specimens were loaded at the top of the column under quasi-static cyclic loading as per ATC-24 (ATC-24, 1992) guidelines. The test specimens are designed to represent retrofitted connections from typical mid-1970s pre-Northridge building. RBS retrofitting is only applied to the beam bottom flange considering the high cost and practical difficulty of applying RBS to the upper flange in the presence of slab. The haunch retrofitting is applied to weld wide flange section into the area of intersection of the lower beam flange and the column flange for the same reason. For the column, W12 x 279 (Gr. 50) and, for the beam, W30 x 99 (A36) are used for all specimens. For HCH3 and HCH4, haunches are cut from W21 x 139 (Gr. 50). Material properties are shown in Table 4.

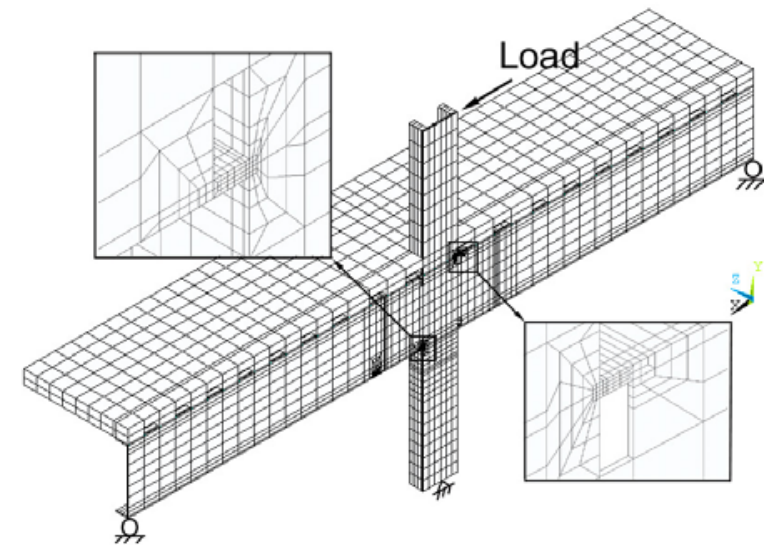

Figure 7. Numerical Model for an US Connection (DB2)

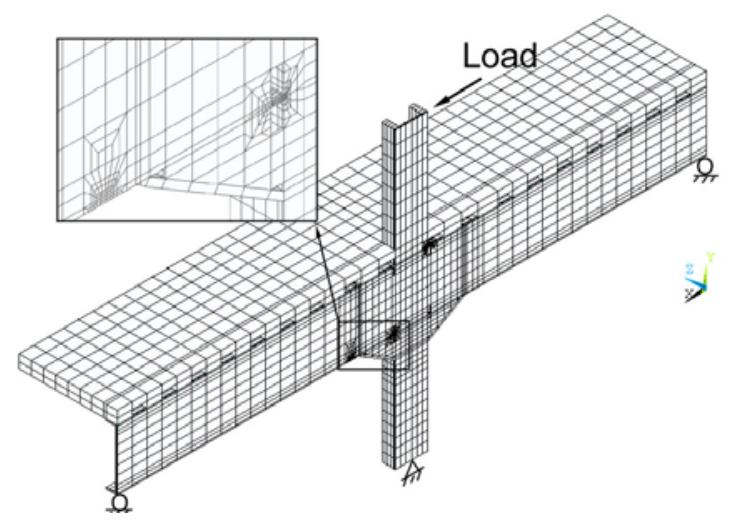

Figure 8. Numerical Model for an US Connection (HCH4) 
Table 4. Material Properties of US Connections

\begin{tabular}{c|c|c|c|c}
\hline $\begin{array}{c}\text { Specimen } \\
(\mathbf{1})\end{array}$ & $\begin{array}{c}\text { Static } \sigma_{\mathbf{y}}(\mathbf{M P a}) \\
\mathbf{( 2 )}\end{array}$ & $\begin{array}{c}\left.\text { Dyn. } \sigma_{\mathbf{y}} \mathbf{( M P a}\right) \\
\mathbf{( 3 )}\end{array}$ & $\begin{array}{c}\left.\text { Dyn. } \sigma_{\mathbf{u}} \mathbf{( M P a}\right) \\
\mathbf{( 4 )}\end{array}$ & $\begin{array}{c}\sigma_{\mathrm{y}} / \sigma_{\mathrm{u}} \\
\mathbf{( 5 )}\end{array}$ \\
\hline Beam & 329 & 345 & 452 & 0.76 \\
\hline Column $^{\mathrm{a}}$ & 379 (assumed) & -- & 521.4 (assumed) & -- \\
\hline${ }^{a}$ A572
\end{tabular}

${ }^{a}$ A572 Gr. 50 is used for columns but no specific data are not available from the reference (Civjan et al., [7,8]). For numerical modeling, typical material properties for A572 Gr. 50 are used.

For the slab, lightweight concrete was used with metal decking oriented perpendicular to the beam. To represent the partial composite action of existing buildings, location and number of studs are decided and the rate of composite action as defined by the AISC LRFD specification is approximately $18 \%$. Concrete strengths measured at the time of the test were $33.7 \mathrm{MPa}$ and 22.2 MPa for DB2 and HCH4 respectively. For reinforcement, No 3 bars were placed perpendicular to the beam preventing temperature and shrinkage cracking and for longitudinal reinforcement, 6 × 6 wire meshes were used.

The test results show that simply applying RBS to the beam bottom flange alone to the pre-Northridge connection will not improve its seismic performance, but haunch reinforcing would be an effective way to retrofit the old connections.

Figures 9, 10, 11 and 12 show the envelope curves of hysteresis curves of these tested specimens. The envelope curve is the curve connecting the peak response points of the first cycle in the second quadrant for each of deformation amplitude. The displacement in the figures is the displacement measured at the loading position (here after 'Column Tip Displacement'). Due to the composite action of the slab, DB2 has greater strength than that of DB1. However, DB2 has greater deformation and energy dissipation capacity than that of DB1, which is just opposite from what is observed in the Japanese connection test. Similar results can be observed from those of HCH3 and HCH4. DB2. The composite RBS connection achieved the plastic rotation of 0.02 , while DB1, the bare steel connection, only achieved the plastic rotation in the range of $0.006-0.009$. The haunch reinforced specimen, $\mathrm{HCH} 4$, achieved the plastic rotation in the range of $0.028-0.055$, while HCH3 achieved the plastic rotation in the range of 0.012-0.023.

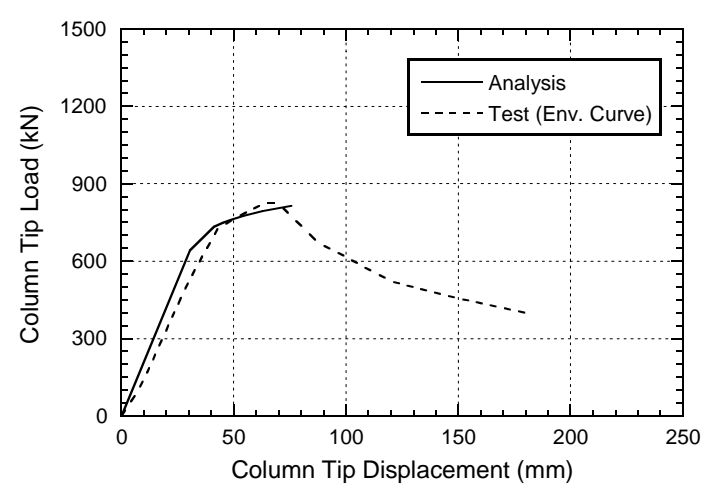

Figure 9. Global Behavior of an US Connection (DB1, Bare Steel Connection)

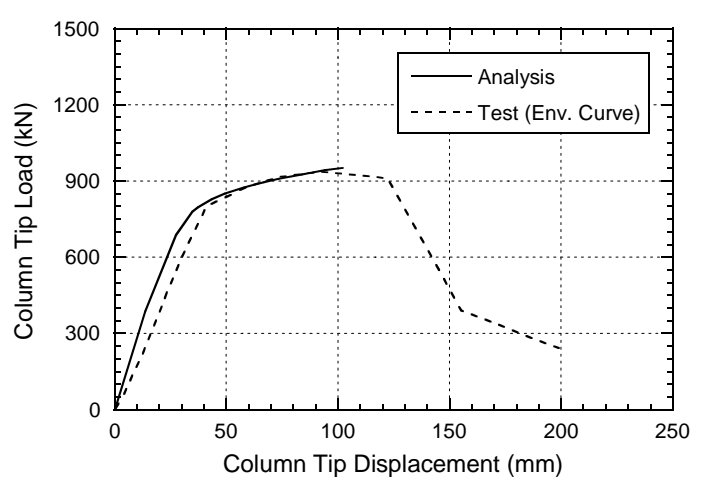

Figure 10. Global Behavior of an US Connection (DB2, Composite Connection) 


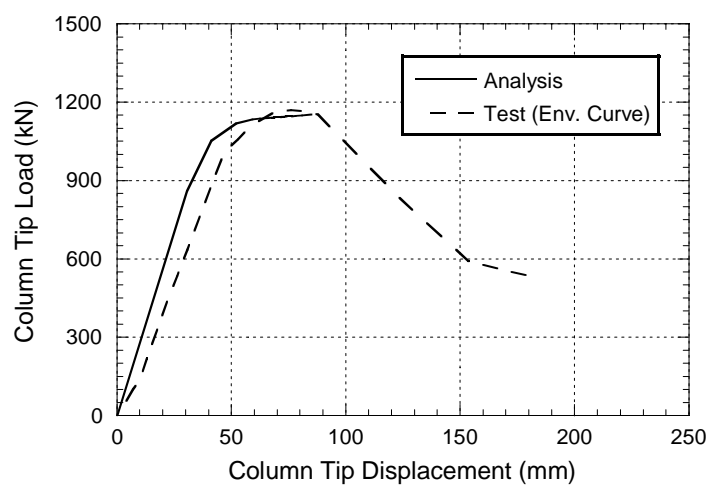

Figure 11. Global Behavior of an US Connection (HCH3, Bare Steel Connection)

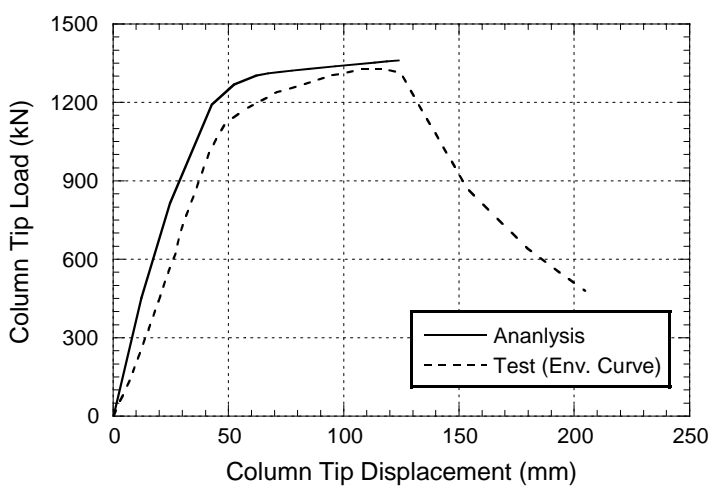

Figure 12. Global Behavior of an US Connection (HCH4, Composite Connection)

According to this result, the presence of the slab does improve the ductility of the connection, and the concentration of the beam deformation due to the confining effect of the slab does not to occur. This beneficial effect of the slab comes from the lateral support and the delaying of local buckling due toe presence of the slab. In fact, according to the references (Civjan et al., [7,8]), the bare steel connections showed some lateral instabilities during the loading stage, probably due to the poor test setup. Nevertheless, since no actual building has bare steel frame alone, this effect is taken for granted. The possible explanation why the detrimental effect of the slab was not seen for the connection with the US detailing will be discussed in the next section. Detailed information about these test results can be found in the references (Civjan et al., [7,8]).

\subsection{Numerical Model}

Figures 7 and 8 also show numerical models to investigate the local behavior near stress concentrated area. As before, only one-half is modeled due to the symmetry. 8-node solid elements are used for the bare steel connection and concrete slab using ANSYS commercial code (ANSYS, [6]). For the local behavior of the RBS specimens, the meshes near the beam flanges in tension are finer than the meshes for other region (Figures 7 and 8). In Figure 7, the RBS is modeled at the beam bottom flange, although modeling is not shown due to the viewing direction. For the haunch reinforced model, additional fine meshes are applied in front of the haunch where the local buckling occurred during the test. Hinged boundary conditions are imposed at both ends of the beam to simulate test setup. Monotonously increasing load is applied at the end of the column. Again, multi-linear isotropic hardening model is used for the steel beam and the column based on the material properties reported (Table 4).

Flute concrete slab is modeled, but metal decking is not modeled because the metal decking is considered as a secondary member. For the composite specimens (DB2 and HCH4), constraint equations are used again to connect the slab to the steel beam and column to achieve a partial composite action (i.e., slip). No reinforcing bars are modeled. 


\section{NUMERICAL RESULTS AND DISCUSSION}

\subsection{Rupture Index}

To evaluate and compare fracture potential relatively between different connection models, a rupture index (RI) is computed at the reported critical location from the tests. The definition of RI is as follows,

$$
R I=\frac{\varepsilon_{e p} / \varepsilon_{y}}{\exp \left(-1.5 \sigma_{h} / \sigma_{\text {mises }}\right)}
$$

where, $\varepsilon_{e p}$ is effective plastic strain $\left(\left(2 \varepsilon_{i j}^{p} \varepsilon_{i j}^{p} / 3\right)^{0.5}\right), \varepsilon_{y}$ is yield strain, $\sigma_{h}$ is hydrostatic stress, and $\sigma_{\text {mises }}$ is the von Mises stress. A numerator of Eq. (1) is known as PEEQ Index representing local ductility demand, and $\sigma_{h} / \sigma_{\text {mises }}$ in the denominator of Eq. (1) is known as triaxiality that causes the reduction in rupture strain of metal (El-Tawil et al., [10]). The value, RI, therefore, is the ratio between the local ductility demand and triaxiality and, in a relative sense, the greater the RI value means the greater fracture potential.

Hancock and Mackenzie [11] introduced the RI concept and showed, at least, 3 types of steel used for their test, the value RI was effective to compare fracture potentials. The RI has been used as an indicator of fracture potential by others (El-Tawil et al., [10]; Mao et al., [12]).

\subsection{Japanese Connections}

To validate the numerical procedure and model, numerical results are compared with some existing test results. Figures 5 and 6 show that numerical results are close to the test results, which validate the numerical modeling and material properties used in the analysis.

Figure 13 compares the local deformation of S01 and S02 near the column face under almost the same beam tip displacement. It should be noted that these deformed figures are exaggerated 10 times for the clear comparison. In Figure 13(a), the slab and the upper beam flange are deformed relatively small and the deformation is concentrated at the root of beam access hole where possible crack-like defect can be found. The reason of the concentration is that the deformation of the beam upper flange is constrained by the slab as shown from the comparison of the deformation near beam upper flange between Figures 13(a) and 13(b). Most of the beam deformation is contributed by the deformation of the beam lower flange.

In Figure 13(b), on the contrary, the both beam flanges are deformed in compression and tension respectively and the beam web is deformed too. The deformation is distributed over the entire beam cross section at the column face and, consequently, relatively small deformation is occurred at the root of the bottom beam access hole. It should be mentioned that these connections have a strong panel zone so that most of the column panel zone remains in the elastic range even at the ultimate state. In addition, full composite action prevents the relative displacement between the beam and the slab. Therefore, the deformation required to achieve the beam tip displacement is mainly provided by the beam deformation, especially by the beam bottom flange near access hole. The connection with weak panel zone or the partial composite slab may have a different behavior. 


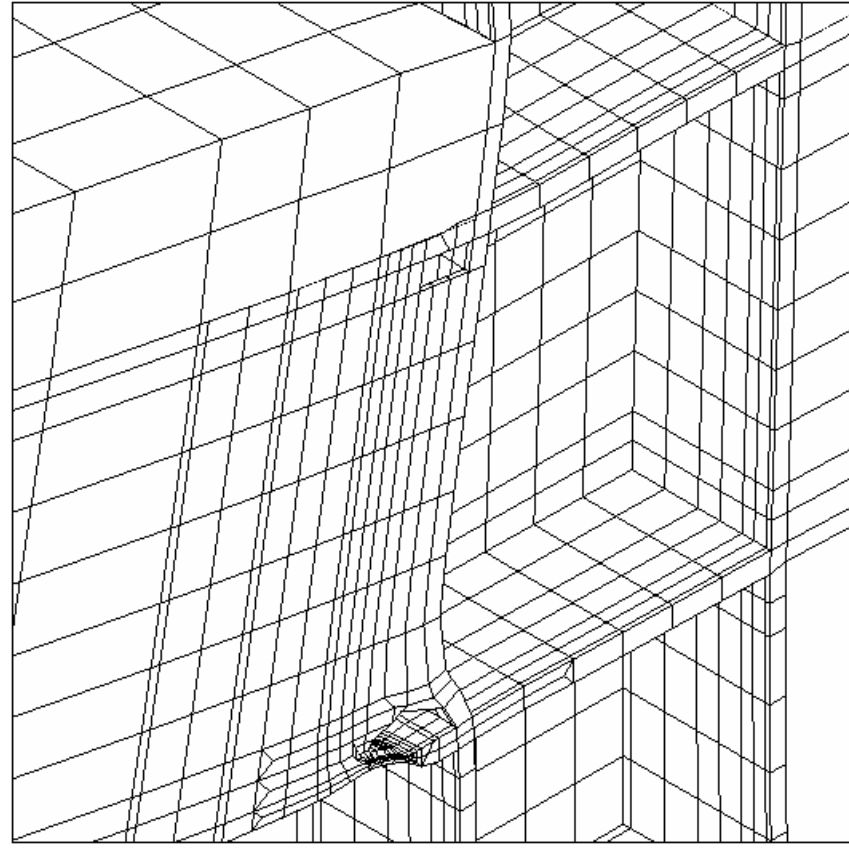

Figure 13(a). Deformed Shapes (10 times exaggerated ), S01 at Beam Tip Disp. $=7.6 \mathrm{~cm}$

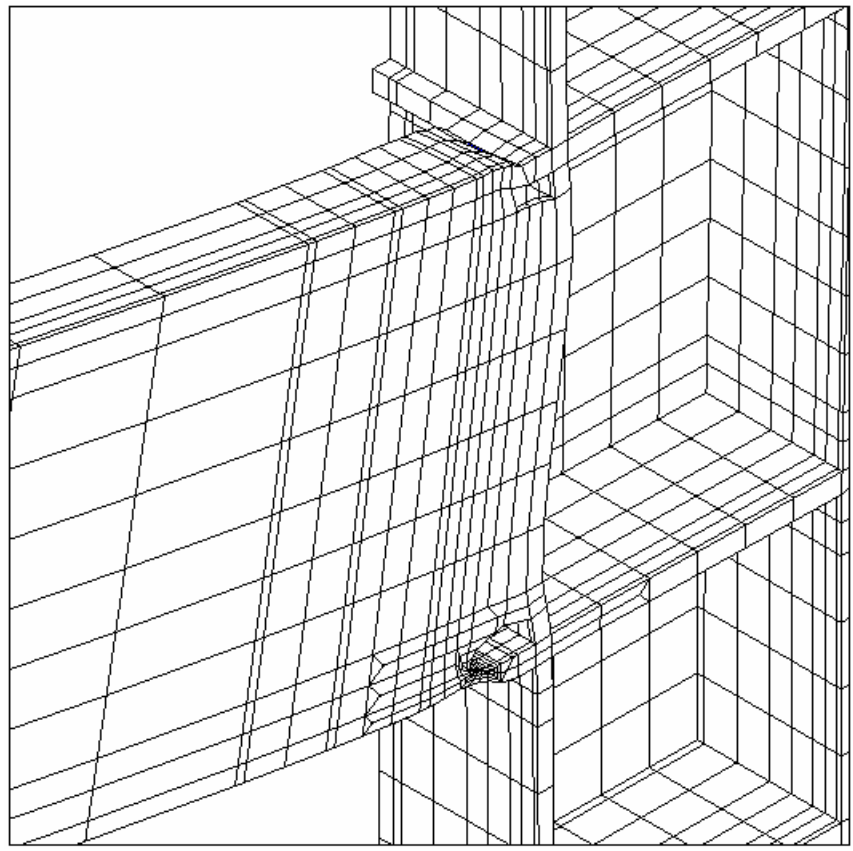

Figure 13(b). Deformed Shapes (10 times exaggerated ), S02 at Beam Tip Disp. $=7.7 \mathrm{~cm}$

Another interesting observation is the deformation of the column flange. A square tube column has two webs at each side but no web at the center where the beam web is connected. Therefore, comparing with the US connection that has only a web at the center, the deformation of the column flange is increased. This will serve as another reason for the fracture occurring near the lower beam flange.

In Figures 14(a) and 14(b), The RI values are plotted at the root of bottom flange access hole where the ductile fracture was initiated. The RI values are plotted against the beam tip displacement and load. The average RI value over the elements near the root of access hole is used.

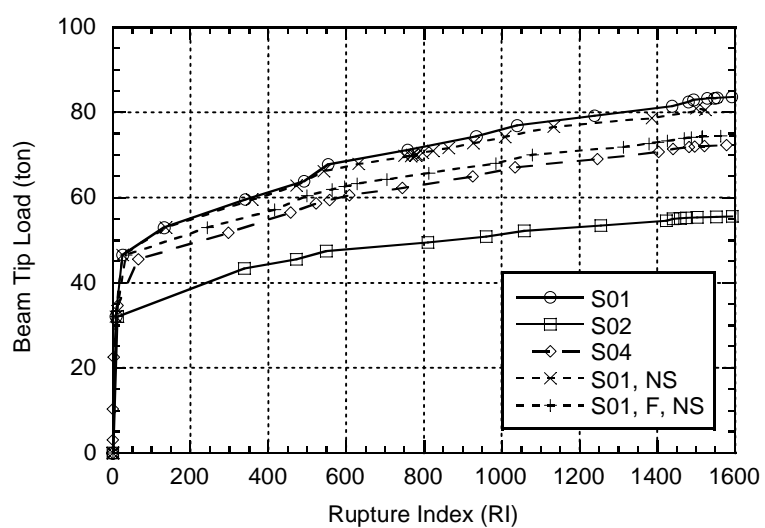

Figure 14(a). Rupture Index (RI) vs. Beam Tip Load.

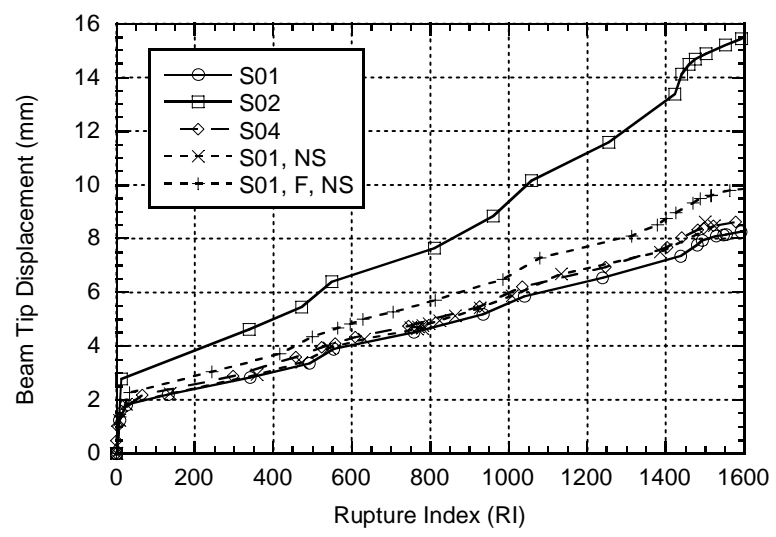

Figure 14(b). Rupture Index (RI) vs. Beam Tip Displacement

Figure 14(a) shows that, at the same load level, composite and non-composite connections have different RI values at the root of bottom beam access hole. For example, at the load level of 50 ton, the RI value for S02 has already reached 850, while, for S01 and S04, the values are only 80 and 240, respectively. This means that the composite action increases the strength of the cross section and reduces the fracture potential at the same load level as expected. 
In Figure 14(b), at the same beam tip displacement or at the same story drift, the RI value at the root of bottom beam access hole is different. Two composite connections, S01 and S04 have almost twice of RI of S02, non-composite connection, at the same beam tip displacement. For example, at the beam tip displacement of $9 \mathrm{~cm}$, the RI of S02 reaches only 850, but S01 already reaches around 1500. As shown in the deformation figures (Figure 13), this is because, for the composite connection, the deformation near beam is constrained by the slab. Therefore, the deformation required for the beam tip displacement is concentrated near beam bottom flange where the constraint is minimal. For the non-composite connection, the deformation is relatively well distributed over the entire section. This result indicates that, under the same story drift, the composite connection in a steel building has a higher probability of fracture potential than that of the non-composite connection. As mentioned early, practical steel building has floor slabs, the slab that imposes the constraint on the deformation of the connection, should be considered in the design.

Another interesting result is that S01 and S04 have similar values of RI in spite of different slab thickness. In Figure 14(a), these connections have different strengths, and this imply that, if the slab strength is in the practical range, the slab effect is almost the same regardless of slab strength or thickness.

For comparison purpose, two untested composite connections are also modeled. First one is the composite model with no side beams to investigate the effect of the side beams on the constraint (S01, NS in the Figure 14). The other is the composite connection with no side beams and the slab having flute to investigate the effect of the flute on the local buckling of the beam flange (S01, F, NS in the Figure 14). The result shows that no particular effects are found as shown in Figures 14(a) and 14(b) except slight strength difference due to the flute in the slab.

In general, PEEQ index and triaxiality index are given with the RI index as complementary indices. PEEQ index showed almost the same trend as the RI index and triaxiality reached approximately constant value after yielding.

\subsection{US Connections}

Figures 9, 10, 11 and 12 also show that numerical results are very similar to the test results except that the initial stiffness of the numerical analysis is shafted to the left of the envelope curve. This shift occurs in all models consistently. However, considering that the test results show a sudden change right after loading begins, this shift of the initial stiffness comes from the slip of the test specimens due to the setup.

As shown in the previous section, Figures 15(a) and 15(b) compare the local deformation of RBS and haunch reinforced models respectively under similar column tip displacement. Again, it should be noted that these deformation figures are exaggerated 10 times. Straight dotted line is the un-deformed edges for reference. In Figure 15(a), the deformation is distributed over the connection. The beam flange and access hole are deformed relatively small compared to Japanese connections. In addition, both deformations in the column and panel zone are quite large compared to Japanese connections. The constraint near the beam top flange does not exist. The column tip displacement, the total deformation of the connection, is not contributed by the localized deformation. In Figure 15(b), similarly, beam upper and lower flanges are deformed in compression and tension 
respectively and the beam webs, column, and panel zone are also deformed. The deformation is distributed over the beams, column, and panel zone.

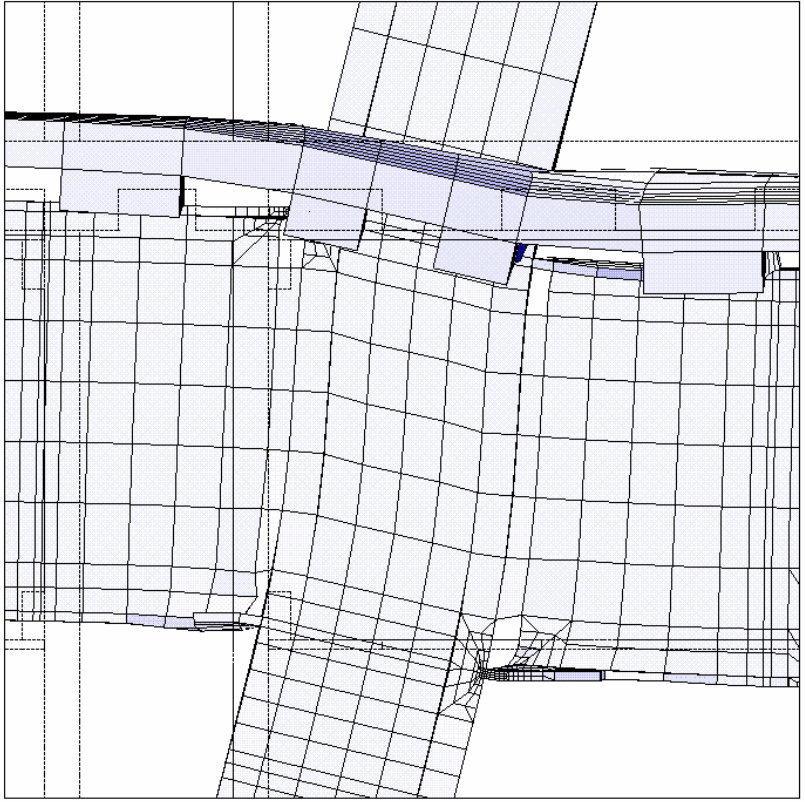

Figure 15(a). Deformed Shapes (10 times exaggerated), DB1 at Beam Tip Disp. $=8.6 \mathrm{~cm}$

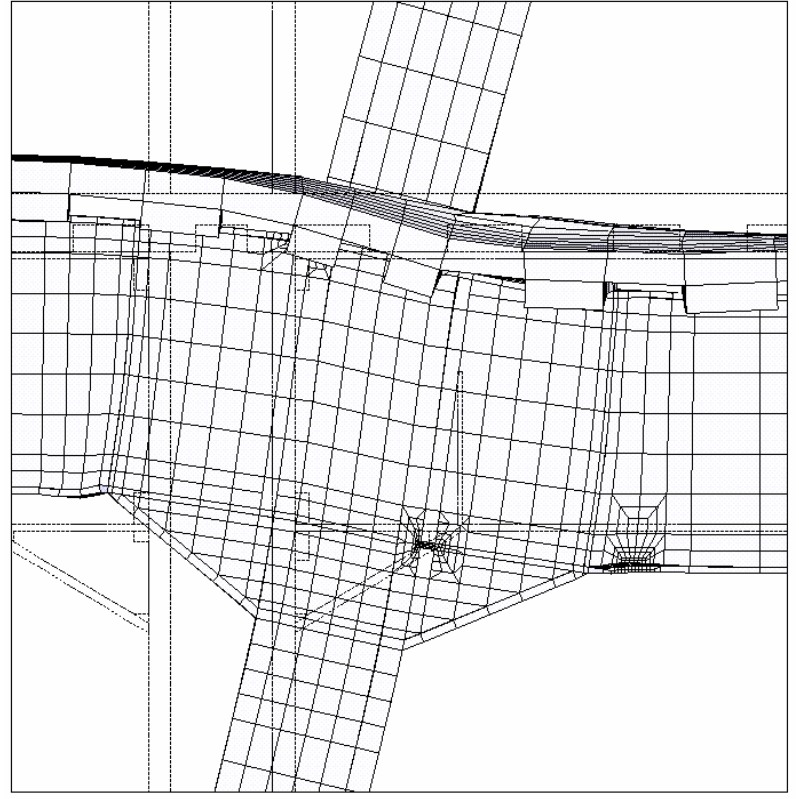

Figure 15(b). Deformed Shapes (10 times exaggerated), $\mathrm{HCH} 4$ at Beam Tip Disp. $=8.1 \mathrm{~cm}$

Different from the Japanese connections, out of plane deformation of the column flange is evenly distributed due to the column web location. This will serve as another reason for the well distributed deformation for the US connections.

Figures 16(a) and 16(b) compare the RI values of RBS and haunch reinforced models respectively. The RI value is calculated at the column-weld interface for the RBS model and near the end of haunch for the haunch reinforced specimen. The RI values are plotted against the column tip displacement. The maximum displacement in the Figures 16(a) and 16(b) came form the analysis models as shown in Figures 9-12. Again, these RI values may not be exact due to the model simplifications but the relative comparison can help to understand the slab effects.

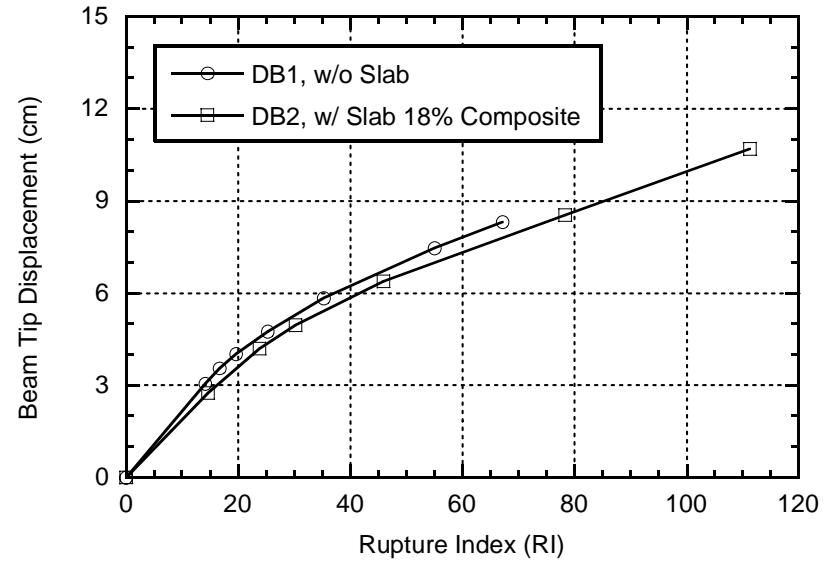

Figure 16(a). Rupture Index (RI) vs. Column Tip Displacement, DB1 and DB2

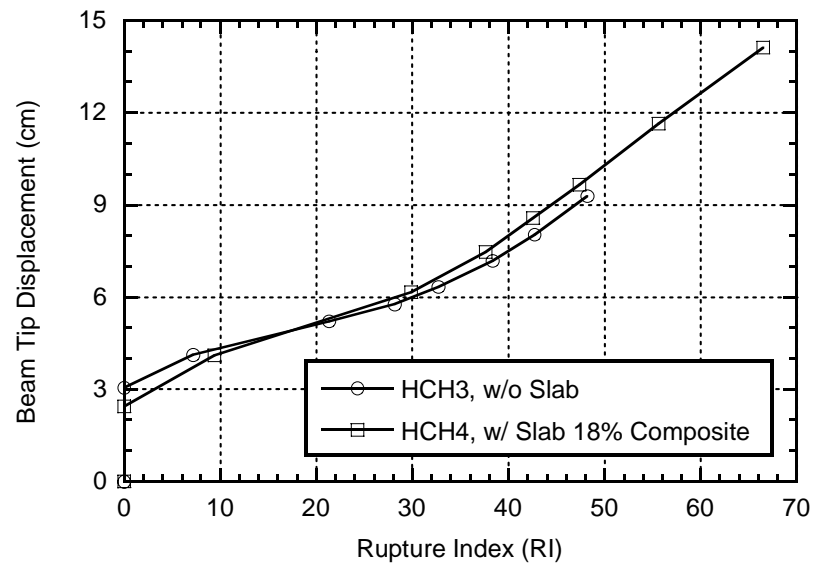

Figure 16(b). Rupture Index (RI) vs. Column Tip Displacement, $\mathrm{HCH} 3$ and $\mathrm{HCH} 4$ 
Figure 16(a) shows that, at the same displacement level, or at the same story drift, composite and non-composite connections have similar RI values at column-weld interface. In Figure 16(b), at the same beam tip displacement, the RI value near the end of haunch is different slightly, but the absolute value of RI is small. For example, at the column top displacement of $6 \mathrm{~cm}$, the specimens, HCH3 and HCH4, showed the RI values of 44 and 48, respectively. The magnitude of the RI, however, is about $3.0 \%$ of that of the Japanese connection. Note that the RI value of Japanese detailed connection is in the range of 1500. Therefore, although there is a some difference in deformation due to the presence of the slab, the slab effect is quite limited as shown in the deformation figures (Figures 15(a) and 15(b)).

\section{RELATIVE STRENGTH EFFECTS}

The deformation capacity of the test specimen is usually measured by the beam or column tip displacements. This tip displacement, however, is not just the displacement from the beam or the column as being implied by its name, but also includes other displacements from the deformation of other components of the connection. In fact, the total displacement consists of three displacements from the deformation of connection components: beams, columns, and panel zone, as shown schematically in Figure 17. Here, $\Delta_{1}, \Delta_{2}$, and $\Delta_{3}$ are the beam or column tip displacements due to the deformation of beam, columns, and panel zone, respectively. $\Delta_{1}$ and $\Delta_{2}$ come from the bending of a beam and a column, and $\Delta_{3}$ comes from the shear deformation of the panel zone. The ductility of the connection, therefore, is affected and controlled by the relative strength between the panel zone, the column, and the beam. This is called 'relative strength effect' in this paper. The required ductility or tip displacement can be achieved without concentrating the deformation on the beam by controlling the relative strength of the connection components.

Table 5 shows the relative strength of connection components of test specimens. The details of strength calculation of each component are shown in Appendix II. The relative strength is normalized with respect to the beam strength. The Japanese connections, S01 and S02, have a strong panel zone and a strong column. The panel zone and the column should remain elastic when the beam experiences the plastic deformation. The composite connection, S01, has relatively weak panel and column compared to the bare steel connection, S02, due to the full composite action. The US connections have a strong column but weak panel zone, which means a large portion of the 'tip displacement' would be contributed by the panel zone deformation. The weak panel zone is permitted by the UBC code (1988). But, according to the reference (Civjan et al., 2000), these connections representing a typical connection prior to 1988, they do not exactly meet the code requirement due to the lack of supplemental web weld.

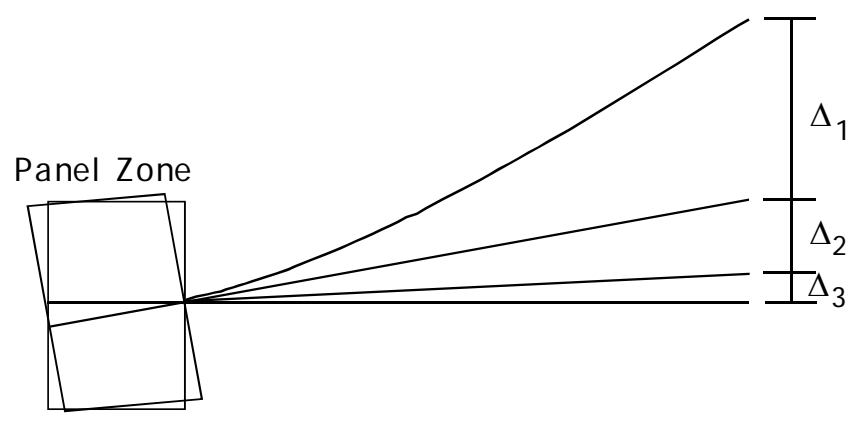

Figure 17. Definition of the Displacements from a Beam, a Column, and Panel Zone 
Table 5. Relative Strength of Connection Component

\begin{tabular}{c|c|c|c|c}
\hline $\begin{array}{c}\text { Model } \\
(\mathbf{1})\end{array}$ & $\begin{array}{c}\text { S01 } \\
\mathbf{( 2 )}\end{array}$ & $\begin{array}{c}\text { S02 } \\
\mathbf{( 3 )}\end{array}$ & $\begin{array}{c}\text { DB1 } \\
\mathbf{( 4 )}\end{array}$ & $\begin{array}{c}\text { DB2 } \\
\mathbf{( 5 )}\end{array}$ \\
\hline $\mathrm{P}_{\mathrm{b}} / \mathrm{P}_{\mathrm{b}}$ & 1 & 1 & 1 & 1 \\
\hline $\mathrm{P}_{\mathrm{c}} / \mathrm{P}_{\mathrm{b}}$ & 1.96 & 3.77 & 2.13 & 1.75 \\
\hline $\mathrm{P}_{\mathrm{z}} / \mathrm{P}_{\mathrm{b}}$ & 1.72 & 3.32 & 0.63 & 0.52 \\
\hline
\end{tabular}

Figures 18(a) and 18(b) show the relationship between beam tip load and $\Delta_{1}, \Delta_{2}, \Delta_{3}$, and total displacement of S01 and S02. First of all, $\Delta_{3}$, the displacement due to panel zone deformation is very small compared to others and remain in the elastic region. This is because Japanese connections use very thick web and a square column that have two webs as shown in Table 5 . The displacement due to column bending $\left(\Delta_{2}\right)$ is greater than the panel zone displacement. It is also small compared to the displacement by beam bending. Therefore, most of beam tip displacement is from beam deformation, especially in the inelastic region. For the bare steel connection, S02, most of the tip displacement is from the beam deformation. This result is consistent with the relative strength in Table 5 and previous observation from Figures 13(a) and 13(b).

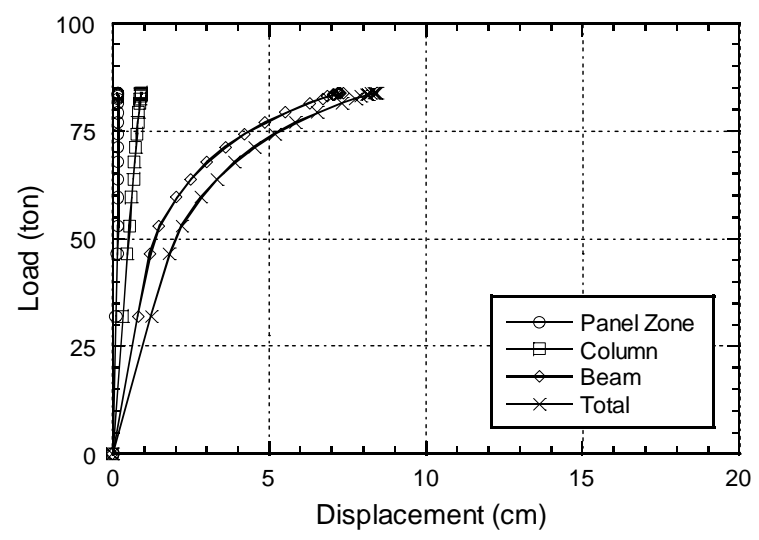

Figure 18(a). Displacement Distribution vs. Loading, S01

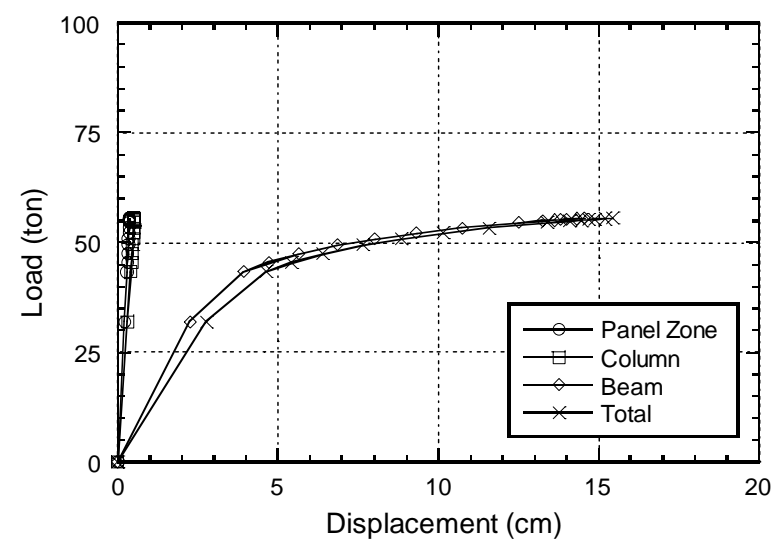

Figure 18(b). Displacement Distribution vs. Loading, S02

The other interesting result is that the displacement by the column bending, $\Delta_{2}$, of the S01, is greater than that of S02, because, as shown in Table 5, the relative strength of beam of S01 is greater than that of S02 due to the composite action. With respect to the distributed deformation, in fact, S01 has slightly better relative strength than that of S02. But the beam deformation of S01 is still very large compared to others. Furthermore, the deformation of the beam top flange is constrained by the slab, which leads to the fracture of the beam bottom flange.

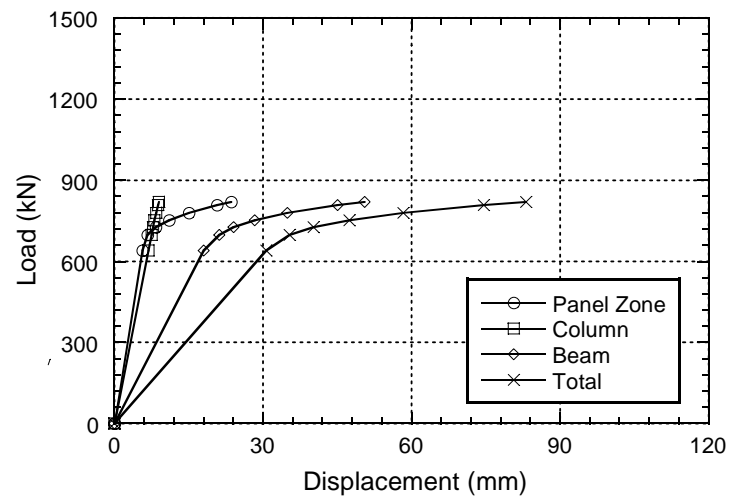

Figure 19(a). Displacement Distribution vs. Loading, DB1

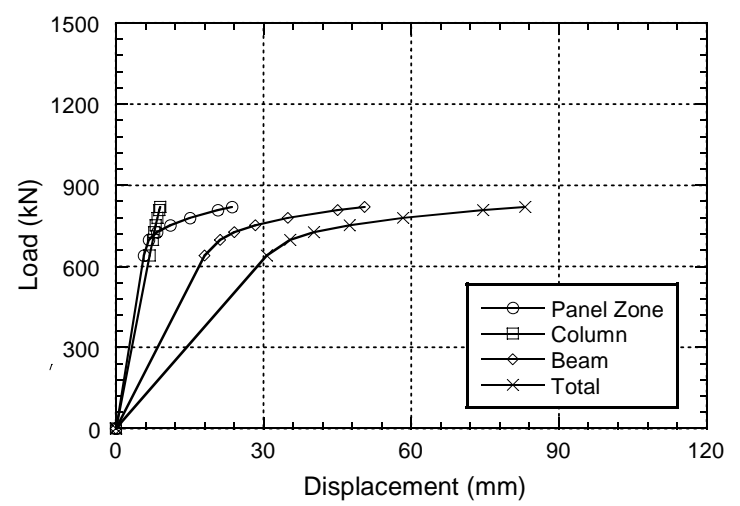

Figure 19(b). Displacement Distribution vs. Loading, DB2 


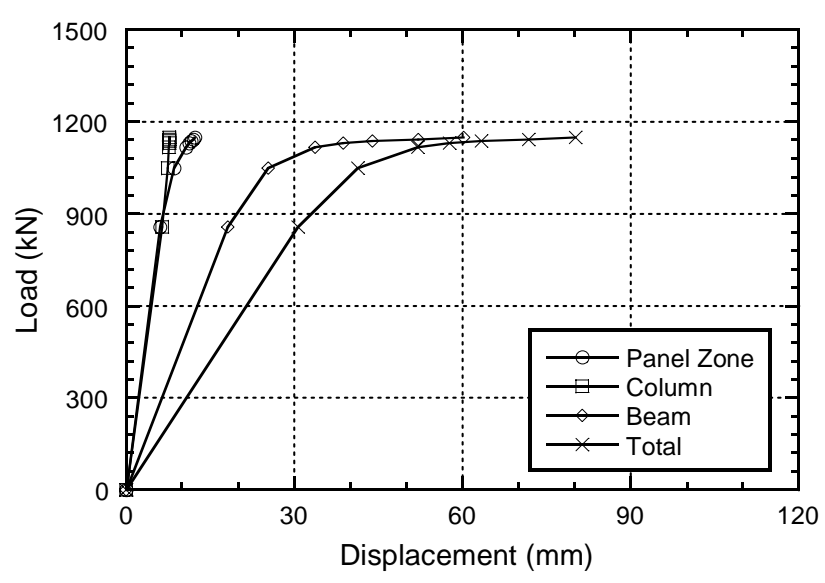

Figure 20(a). Displacement Distribution vs. Loading, HCH3

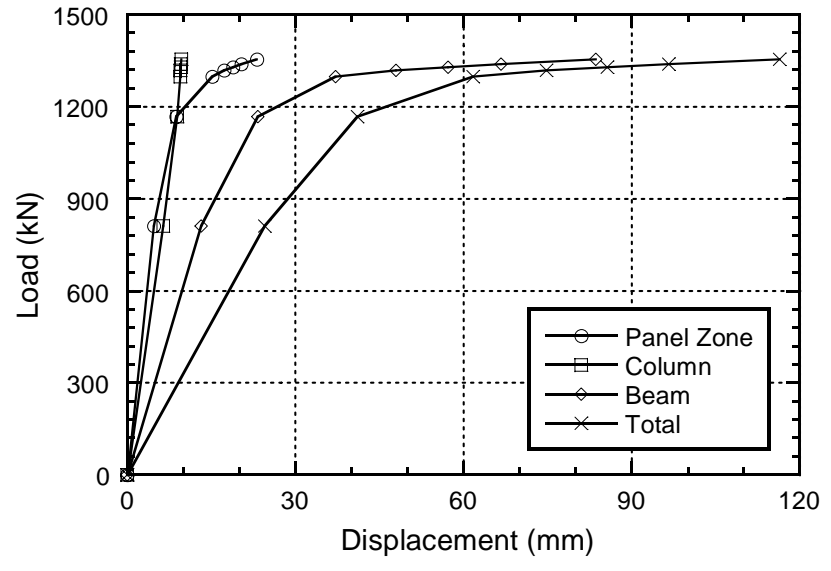

Figure 20(b). Displacement Distribution vs. Loading, HCH4

For the US connections, Figures 19(a), 19(b), 20(a), and 20(b) show the displacement distribution of RBS and haunch reinforced connections. First, the displacement distribution is quite different from those of S01 and S02. Displacement by the panel zone deformation is up to about $20 \%$ of total displacement at the lower load level and entered into the inelastic range at higher load level. This is expected from the relative strength shown in Table 5, because the strength of the panel zone is smaller than that of the beam, not to mention the column strength. Before panel zone yields, the displacement by the column deformation is almost same with the displacement by panel zone and about $40 \%$ of total displacement is contributed by the column and the panel zone. After panel zone yields, the displacement distribution is redistributed due to the changing stiffness of each component. The beam displacement is about $60 \%$, which is a small portion of the total displacement compared to the Japanese connections. The deformation of the US detailed connection is well distributed between beams, a column, and panel zone, as shown in the deformed figures.

By comparing the displacement distribution and relative strength of the Japanese and US connections, the reason why the slab effect is apparently different for different connections can be explained. In the US connections, due to a large panel zone deformation, the beam deformation to meet the desired beam tip displacement is relatively small. Accordingly, the slab effect was not observed. On the contrary, in Japanese connections, all displacements except the beam are suppressed due to the design practice, and consequently, the beam undertook all deformations to meet the beam tip displacement. For a composite connection, this beam deformation is further concentrated at the beam lower flange and access hole due to the confining effect by the slab.

\section{SUMMARY AND CONLUSIONS}

In this paper, the slab effects on the behavior of composite connections during an earthquake are investigated using numerical analyses based on some existing composite connection tests. Two different connection details are modeled. One is the typical US connection detailing using wide flange sections for both beam and column. Another is the typical Japanese connection details, which are designed to have a square column with a wide flange beam section. Both are designed with strong column-weak beam concept, but the Japanese connection detailing usually has a stronger panel zone and column than that of the US detailing. 
Numerical results indicate that the composite slab imposes the constraint on the deformation near the beam top flange. The deformation due to the beam tip displacement is concentrated at the root of beam access hole where the geometry changes abruptly and manufacturing cutting process often leaves crack-like defects. In the test, the brittle fracture at this spot occurred after semi-elliptic shape ductile crack propagated, but energy dissipation and beam tip displacement are far less compared to that of the bare steel connection.

The ultimate strength of the connection is increased with thicker slab, but the fracture potential at the beam access hole is almost the same under the same beam tip displacement. This result implies that the constraint on deformation of the beam section due to the presence of the slab is about the same regardless of slab strength or degree of composite action.

The analyses of the US connections show that the column or beam tip displacement is composed of three displacements from the deformation of the beam, the column, and the panel zone. The magnitude of each displacement depends on the relative strength between connection components. Therefore, even if the beam or column tip displacement is large, the deformation from each member can be small as shown in the US connection cases. This is why the composite connections in the US connection show better ductility than the bare steel connection. The detrimental slab effect is minimized and the beneficial effect is unaffected. It should be mentioned that the deformation in the column and panel zone might cause possible stability problem.

Since numerical analyses show the detrimental slab effects on the ductility of the connection and every practical steel building has composite floor slabs, the detrimental slab effect on possible connection fracture potential should be considered in the connection design. In fact, the slab effect can be minimized by simply adjusting the relative strength between connection components as long as the global stability is assured. 


\section{REFERENCES}

[1] Federal Emergency Management Agency (FEMA). Recommended seismic design criteria for new steel moment buildings. Rep No FEMA 350. Washington, DC; 2000.

[2] Nakashima M, Suita K, Morisako K, Maruoka Y. Test of welded beam-column subassemblies I: Global Behavior. $\mathrm{J}$ of Structural Engineering, ASCE 1998;124(11):1236-1244.

[3] Joh C, Chen WF. Fracture strength of welded flange-bolted web connections. J of Structural Engineering, ASCE 1999;125(5):565-571.

[4] Research Institute of Industrial Science and Technology (RIST). Earthquake resistance capacity evaluation of steel structural frame considering composite beam effect. Rep No 2000H002. Kyungkido, Korea; 2001.

[5] Joh C, Chen WF. Seismic Behavior of Steel Moment Connections with Composite Slab. International Journal of Steel Structures, The Korean Society of Steel Construction 2001;1(3):175-183.

[6] ANSYS 5.6 user's manual. ANSYS, Inc. Southpointe 275 Technology Drive, Canonsburg, PA; 1994.

[7] Civjan SA, Engelhardt MD, Gross JL. Retrofit of pre-Northridge moment-resisting connections. J of Structural Engineering, ASCE 2000;126(4):445-452.

[8] Civjan SA, Engelhardt, MD, Gross JL. Slab effects in SMRF retrofit connection tests. J of Structural Engineering, ASCE 2000;127(4):230-237.

[9] Applied Technology Council (ATC). ATC-24: Guidelines for seismic testing of components of steel structures. Redwood, California; 1992.

[10] El-Tawil S, Mikesell T, Vidarsson E, Kunnath SK. Strength and ductility of FR welded-bolted connections. Rep No SAC/BD-98/01. SAC Joint Venture, Sacramento, California; 1998.

[11] Hancock JW, MacKenzie AC. On the mechanisms of ductile failure in high-strength steel subjected to multi-axial stress states. J Mech Phys Solids 1976;24:147-169.

[12] Mao CR, Ricles J, Lu LW, Fisher J. Effect of local details on ductility of welded moment connections. J of Structural Engineering, ASCE 2001;127(9):1036-1044. 


\section{APPENDIX: RELATIVE STRENGTH}

The following formulas and symbols are used for the relative strength calculation:

For Exterior Connection Test Setup (El-Tawil et al., 1998)

Beam Strength: $\quad P_{b}=M_{p b} / L_{b}$

Column Strength: $\quad P_{c}=2 M_{p c} L_{c} /\left(L_{b}+d_{c} / 2\right)\left(L_{c}-d_{b}\right)$

Panel Zone Strength: $\quad P_{z}=0.55 F_{y c} d_{c} t_{w c} \frac{\left[1+3 \frac{b_{f c} t_{f c}^{2}}{d_{c} d_{b} t_{w c}}\right]}{\left[\frac{L_{b}}{0.95 d_{b}}-\frac{L_{b}+d_{c} / 2}{L_{c}}\right]}$

For Interior Connection Test Setup (load applied from the column top)

Column Strength: $\quad P_{c}=2 M_{p c} /\left(L_{c}-d_{c}\right)$

Beam Strength: $\quad P_{b}=2 M_{p b} L_{b} /\left(L_{c}\left(L_{b}-d_{c}\right)\right)$

Panel Zone Strength: $\quad P_{z}=0.55 F_{y c} d_{c} t_{w c} \frac{\left[1+3 \frac{b_{f c} t_{f c}^{2}}{d_{c} d_{b} t_{w c}}\right]}{2\left[\frac{0.5\left(L_{c}-d_{b}\right)}{0.95 d_{c}}-\frac{0.5 L_{c}}{L_{b}}\right]}$

$d=$ Beam or column depth

$t_{w}=$ Beam or column web thickness

$t_{f}=$ Beam or column flange thickness

$b_{f}=$ Beam or column flange width

$P_{b}=$ Beam or column tip load to make test setup to reach beam strength

$P_{c}=$ Beam or column tip load to make test setup to reach column strength

$P_{Z}=$ Beam or column tip load to make test setup to reach panel zone strength

$L_{b}=$ Beam Length

$L_{c}=$ Column Length

\section{Subscripts}

$b=$ beam

c = column 
[Blank Page] 


\title{
COMPRESSIVE PERFORMANCE OF COLD-FORMED THIN-WALLED STEEL CHANNNEL SECTIONS IN FIRE
}

\author{
Y.C. Wang1, M.Q. Feng and B. Salhab \\ ${ }^{1}$ School of Mechanical, Aerospace and Civil Engineering (MACE), University of Manchester, UK. \\ Email: yong.wang@umist.ac.uk
}

\begin{abstract}
This paper presents the main results of an extensive study of the compressive performance of cold-formed thin-walled steel sections under conditions of fire, recently conducted by the authors. Experimental, numerical and design calculation studies were performed. The experiments include:

- Fire tests on small panels, measuring 300 x $300 \mathrm{~mm}$, consisting of a solid or perforated cold-formed thin-walled steel channel section, one or two layers of $12.5 \mathrm{~mm}$ thick gypsum plasterboard on both sides and either with or without interior insulation, exposed to the standard BS 476 fire condition on one side;

- Compression tests on short (400 mm) channel sections at various uniform elevated temperatures up to $700^{\circ} \mathrm{C}$;

- Fire tests on six full-scale panels of $2.2 \times 2.0 \mathrm{~m}$, each consisting of three cold-formed thin-walled steel channel sections, one layer of $12.5 \mathrm{~mm}$ gypsum plasterboard on both sides and with interior insulation, exposed to the standard BS 476 fire condition on one side;

- Fire test on one full-scale panel with the same arrangement as above, but using channel sections with perforations along the length of the web of the steel section.

Numerical studies, using ABAQUS, were carried out to investigate the following aspects:

- Validation of heat transfer analysis against the small panel fire test results;

- Structural behaviour of the short test columns under uniform temperature;

- Effect of non-uniform temperature distributions in the steel cross-section of a column on its structural behaviour;

- Effect of gypsum plasterboard falling on column structural behaviour.

The different current design methods were assessed by comparing the design calculation results against finite element simulation and experiment results.

It has been concluded that the behaviour of this type of construction is complex, affected by a number of factors of some of which our current understanding is poor, for example, how to predict gypsum plasterboard falling at high temperatures. ABAQUS is a useful tool for studying detailed thermal and structural behaviour of cold-formed thin-walled steel structures in fire. This paper shows that provided steel temperatures are available, ENV 1993-1-2 provides a reasonable and conservative prediction of ultimate strength and failure time of the samples tested in this study.
\end{abstract}

Keywords: Thin-walled structures, fire tests, fire resistance, elevated temperatures, thermal behaviour, heat transfer, perforation, gypsum plasterboard

\section{INTRODUCTION}

Recent studies of steel structural performance in fire have been intensive and progresses in this area rapid, but most of these studies have focused on hot-rolled steel products which represent a majority of the market share of steel framed building structures. Nevertheless, cold-formed thin-walled steel structures are widely used as primary load bearing members, for example in steel framed housing and apartment buildings. It is important that their performance in fire is adequately dealt with.

Because cold-formed thin-walled steel products are often used in proprietary systems, determination of whether a system comprising cold-formed thin-walled steel products has adequate 
fire resistance is based on the manufacturer of the system showing a certificate to state that a representative of such a system has passed the relevant standard fire resistance test. Leaving aside the well-publicised criticisms of using the standard fire resistance test as the only means of assessing structural performance in fire, the following issues are specifically related to cold-formed thin-walled steel structures that cannot be properly resolved by simply performing the standard fire resistance test:

(1) A system using cold-formed thin-walled steel structures can have many components. It cannot be possible to fire test every combination of the many different components in the system.

(2) The dimensions (e.g. the height) of a cold-formed thin-walled steel structural system can be different from those of the standard fire test sample. It may not be safe to extrapolate the standard fire test results to larger dimensions.

(3) The standard fire resistance test is expensive and time-consuming to perform, relying on it would slow down developments of better products in a competitive market.

The alternative is to develop better fundamental understanding of the fire performance of cold-formed thin-walled steel structures, which when combined with appropriate selection of a small number of confirmatory fire tests, would enable predictive and rational design methods to be developed for more economical and reliable use of cold-formed thin-walled steel structures in fire. Since only a small number of studies of the fire performance of cold-formed thin-walled steel structures have been performed, our understanding of this topic is still poor and the objective of this paper is to provide some results of the authors recent research to fill the gap in knowledge.

The three general aspects of dealing with structural performance in fire are: quantifying behaviour of the fire (fire dynamics), calculation of temperatures in the structure (heat transfer) and assessing structural behaviour at elevated temperatures (structural engineering). Although much of the general knowledge of these three aspects, gained from studies of hot-rolled steel structural performance in fire, can be adapted to cold-formed thin-walled steel structures, significant differences exist between structural systems using hot-rolled and cold-formed thin-walled steel products.

(1) Figure 1 shows a generic panel system using cold-formed thin-walled steel sections to which this paper is relevant. Since such construction usually forms part of the fire resistant construction of a building, fire exposure is from one side. Therefore, non-uniform temperature distributions will develop in the steel structure. The non-uniform temperature distribution is not only in the thickness direction of the panel, but also along the flanges of the steel sections as they are thin and heat dissipation along their flanges is relatively high compared to that in hot-rolled steel sections that are usually much thicker. Furthermore, fire exposure to hot-rolled steel structural sections is from all sides. Hence, if a hot-rolled steel section is protected, it is reasonable to assume that the steel temperature is uniform. If it is not protected, the different components of the steel section (e.g. flanges and web) may be assumed to have uniform temperature and it is easy to calculate these temperatures by using the individual section factors of the components.

(2) Cold-formed thin-walled steel structures are prone to various types of buckling and have to rely on other components of the system (e.g. plasterboards) to provide stability. On the contrary, in systems using hot-rolled steel sections, the strength and stiffness of these 
(3) components (if they exist) are insignificant compared to those of the hot-rolled section. To simplify structural analysis, they can be neglected.

(4) The structural behaviour of cold-formed thin-walled steel sections involves interaction of different buckling modes (local, distortional and global). This is far more complex than the relatively simple global buckling mode that governs the behaviour of thicker hot-rolled steel sections. Even in global buckling mode, the different types of restraint to cold-formed thin-walled steel sections make the structure prone to flexural buckling, torsional buckling or combined flexural-torsional buckling instead of the relatively simple flexural buckling problem in hot-rolled steel sections.

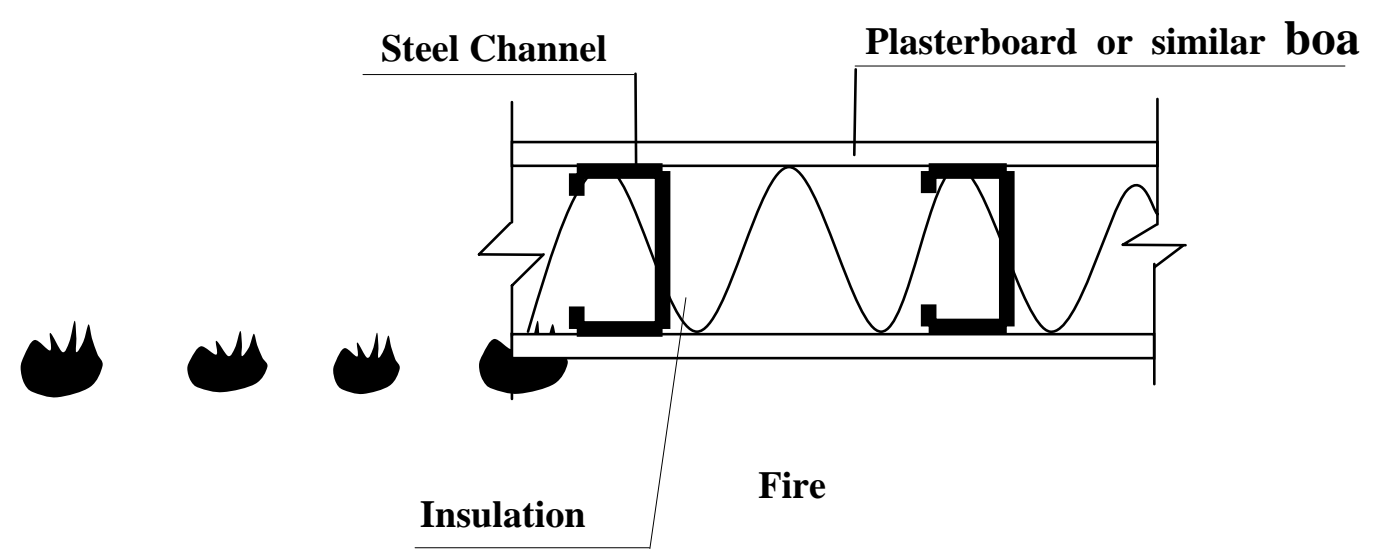

Figure 1. Cold-formed thin-walled steel in panel exposed to fire attack on one side

These fundamental differences between hot-rolled and cold-formed thin-walled steel sections make it necessary to study the fire performance of cold-formed thin-walled steel structures in a comprehensive manner so that rational performance based design guidance can be developed. Other major relevant research studies of cold-formed thin-walled steel structural performance in fire include those conducted in the National Research Council of Canada (Sultan [1], Alfawakhiri et al [2], Kodur \& Sultan [3], Sultan and Lougheed [4], Benichou \& Sultan [5]) and by Sakumoto et al [6] of Japan. Of the NRCC studies, Sultan [1] described a one-dimensional heat transfer program to predict temperatures in non-insulated unloaded steel-stud gypsum board wall assemblies exposed to fire, but the steel stud was not modelled on the basis of its small effect on heat transfer in the system. Alfawahkiri et al [2] provided a comprehensive review of relevant investigations until the late 1990s. The other NRCC papers and the Japanese research report provide the results of a large number of standard fire resistance tests on walls and floors using both wood sticks and thin-walled steel channel sections. In both sets of studies, the wall tests included both loaded and unloaded panels. From the NRCC loaded fire tests on steel stud walls, they concluded that the main factors that affect the fire resistance of steel stud walls were the type of interior insulation, stud spacing, number and type of boards and whether or resilient channel is present. They observed that the loaded walls without interior insulation had higher fire resistance than the ones with interior insulation. An explanation would be that the walls with interior insulation had higher temperature gradients through the thickness of the walls, thereby inducing higher thermal bowing deflections leading to increased P- $\delta$ effect. The NRCC observation on the non-loaded steel stud walls suggests that the interior insulation had exactly the opposite effect from that on the loaded walls. For the unloaded walls, the failure criterion was according to the temperature attained on the unexposed side of the wall. Without any interior insulation, the temperature gradient in the thickness direction of the wall was lower than with interior insulation, so that the temperature on the unexposed surface of the wall was higher, hence the fire resistance of the wall was lower according to the temperature criterion. The main additional conclusion from the 
study of Sakumoto et al [6] is that gypsum plasterboard falling could have significant effect on fire performance of the walls.

The above studies are mainly experimental ones. Whilst they would contribute to an invaluable database of experimental results (if and whenever their detailed results are made publicly available), their conclusions are general and any specific conclusion would only be applicable to the systems that they have tested. Complete understanding of the fire performance of this type of construction can only be gained through detailed experimental, numerical and analytical studies. This is the objective of the authors' research.

As previously mentioned, understanding the structural behaviour of a system in fire involves studies of fire dynamics, heat transfer and structural assessment. Fire behaviour is common to both hot-rolled and cold-formed thin-walled steel structures. Although our understanding of fire behaviour is far from complete, as far as structural performance is concerned, well accepted design guidance is available on this aspect [7]. This paper will concentrate on the thermal behaviour to obtain temperatures in the structure and structural assessment at elevated temperatures. This paper summarises the main findings of the authors' research and some more detailed information may be obtained from a number of other publications by the authors [8-14].

\section{THERMAL BEHAVIOUR}

Fire tests were performed on unloaded and loaded specimens. The unloaded tests were performed on small samples shown in Figure 2, which were $300 \times 300 \mathrm{~mm}$ in plan dimensions and consisted of one $300 \mathrm{~mm}$ long steel channel section and one or two layers of $12.5 \mathrm{~mm}$ thick Fireline gypsum plasterboard (manufactured by British Gypsum Limited) on each side. The steel section was either lipped channel (dimensions $100 \times 54 \times 15 \times 1.2 \mathrm{~mm}$ or $100 \times 56 \times 15 \times 2 \mathrm{~mm}$ ) or unlipped channel (dimensions 104 x 63 x $1.5 \mathrm{~mm}$ ) from Metsec. Both solid sections and sections with perforated web were tested. Perforated sections are commonly used in cold regions to reduce the effect of cold bridging in

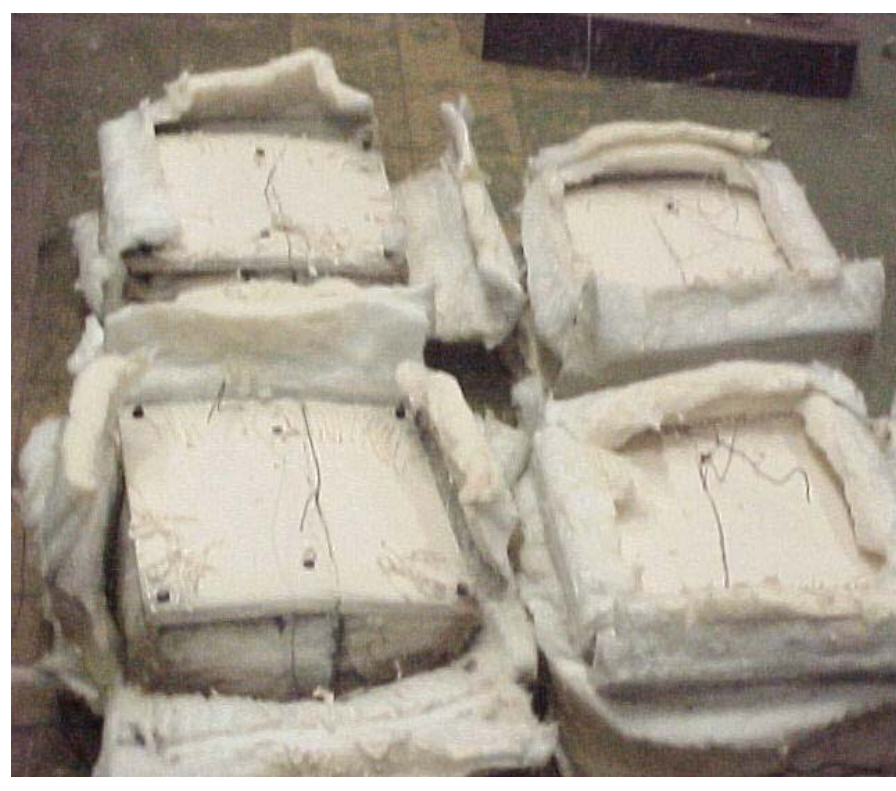

Figure 2. Small scale samples after fire test external walls. Some specimens using a solid steel section had interior insulation of the type Isowool 1000 mineral wool manufactured by British Gypsum Limited. Table 1 gives details of the test samples without perforation. For the test samples with perforation, Figure 3 shows the pattern and dimensions of perforation; the steel section was either of the above two lipped channel types; either one or two layers of gypsum plasterboard was used on each side and all samples had interior insulation Isowool 1000. Figure 4 shows the furnace used for these tests, which had four apertures of $300 \times 300 \mathrm{~mm}$ and allowed four small specimens to be tested at the same time. 


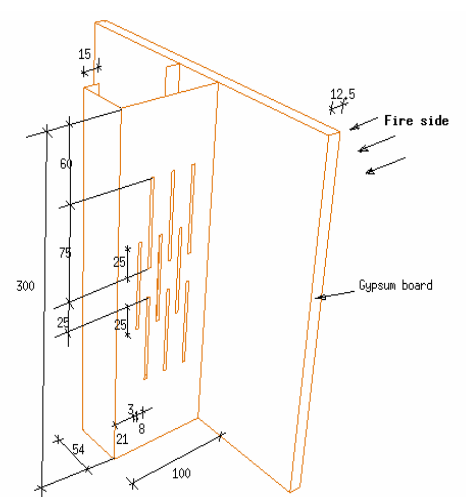

Figure 3. Pattern and dimensions of perforation

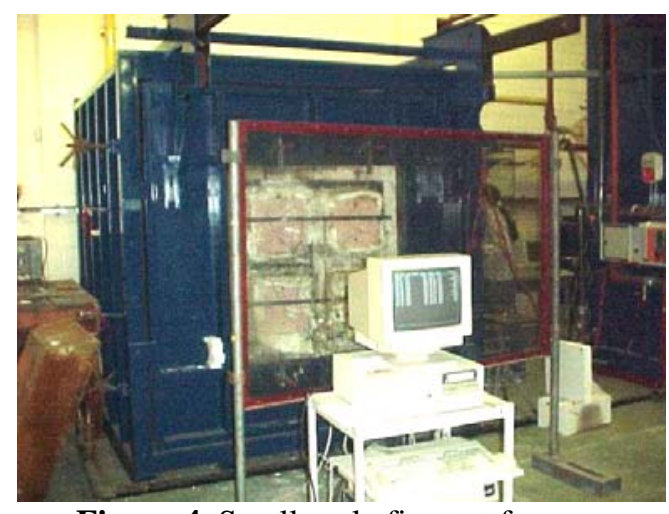

Figure 4. Small scale fire test furnace

Table 1. Small scale unloaded fire test specimens - no perforation

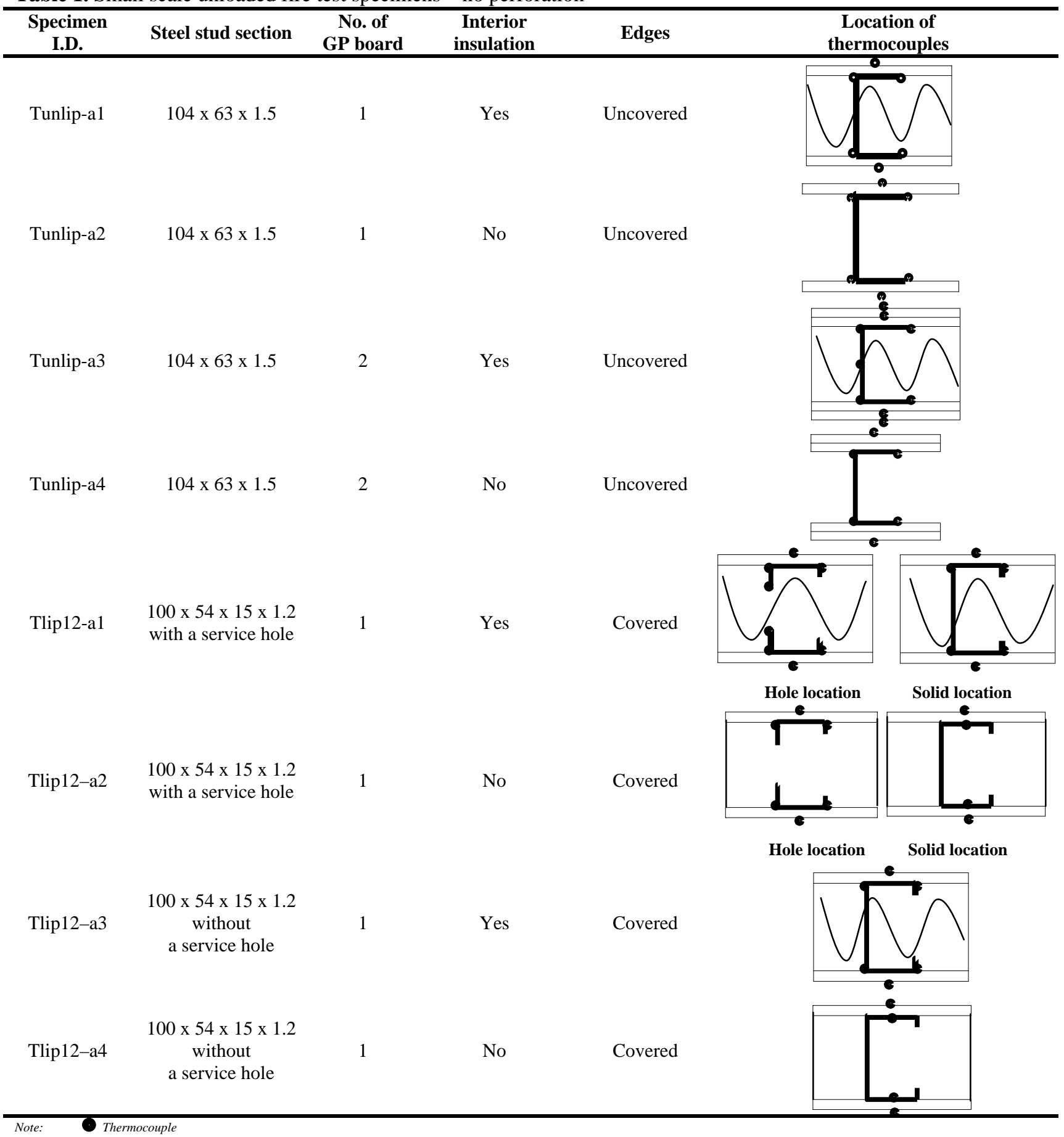


The seven loaded tests were performed on large panels of $2 \times 2.2 \times 0.125 \mathrm{~m}$ in dimensions, each consisting of three sections of either of the above two lipped channel types, spaced at $750 \mathrm{~mm}$ centres, with one layer of $12.5 \mathrm{~mm}$ thick Fireline gypsum plasterboard on each side and all having interior insulation Isowool 1000. Figure 5 shows dimensions of the loaded large scale panels and also a sketch of the fire test setup. Six tests had solid sections and one test had perforations along the web of the steel sections. The six tests using solid sections comprised three load ratios $(0.2,0.4$ and 0.7 ) for each of the two types of lipped steel channel sections. The load ratio was calculated as the applied load in the fire test to the panel load carrying capacity at ambient temperature, obtained from separate tests. The one test with perforated steel sections used lipped channel sections of dimensions $100 \times 54 \times 15 \times 1.2 \mathrm{~mm}$ and the same applied load as the panel with solid steel sections of the same dimensions at a load ratio of 0.4. Tables 2 summarises the main variables for the large (loaded) scale fire tests.

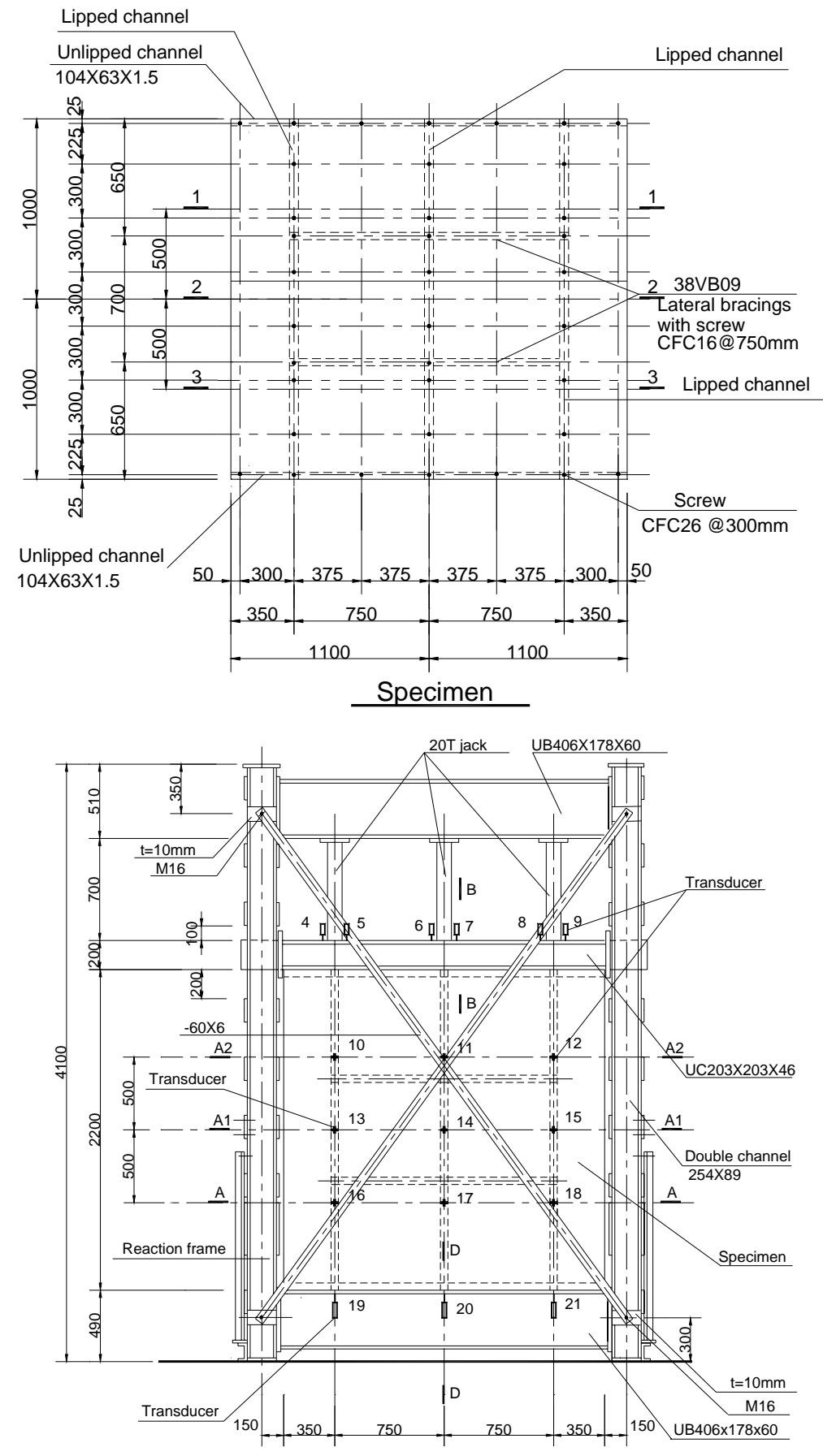

Figure 5. Large scale test: specimen dimensions and test set up 
In all tests, the fire exposure was from one side of the specimen and was according to the BS 476 [15] temperature - time relationship.

\subsection{Main observations and experimental results}

Figure 2 shows typical unloaded small scale test specimens after the fire test. A single crack was observed in the exposed gypsum plasterboard, but there was no detachment of the gypsum plasterboard. When interior insulation was used, it remained in place and did not shrink or get burnt. Figure 6 shows the measured temperatures in the various locations of a test specimen. It can be seen that the temperature distribution was highly non-uniform through the thickness of the test sample. There were also temperature gradients along both flanges of the steel section.

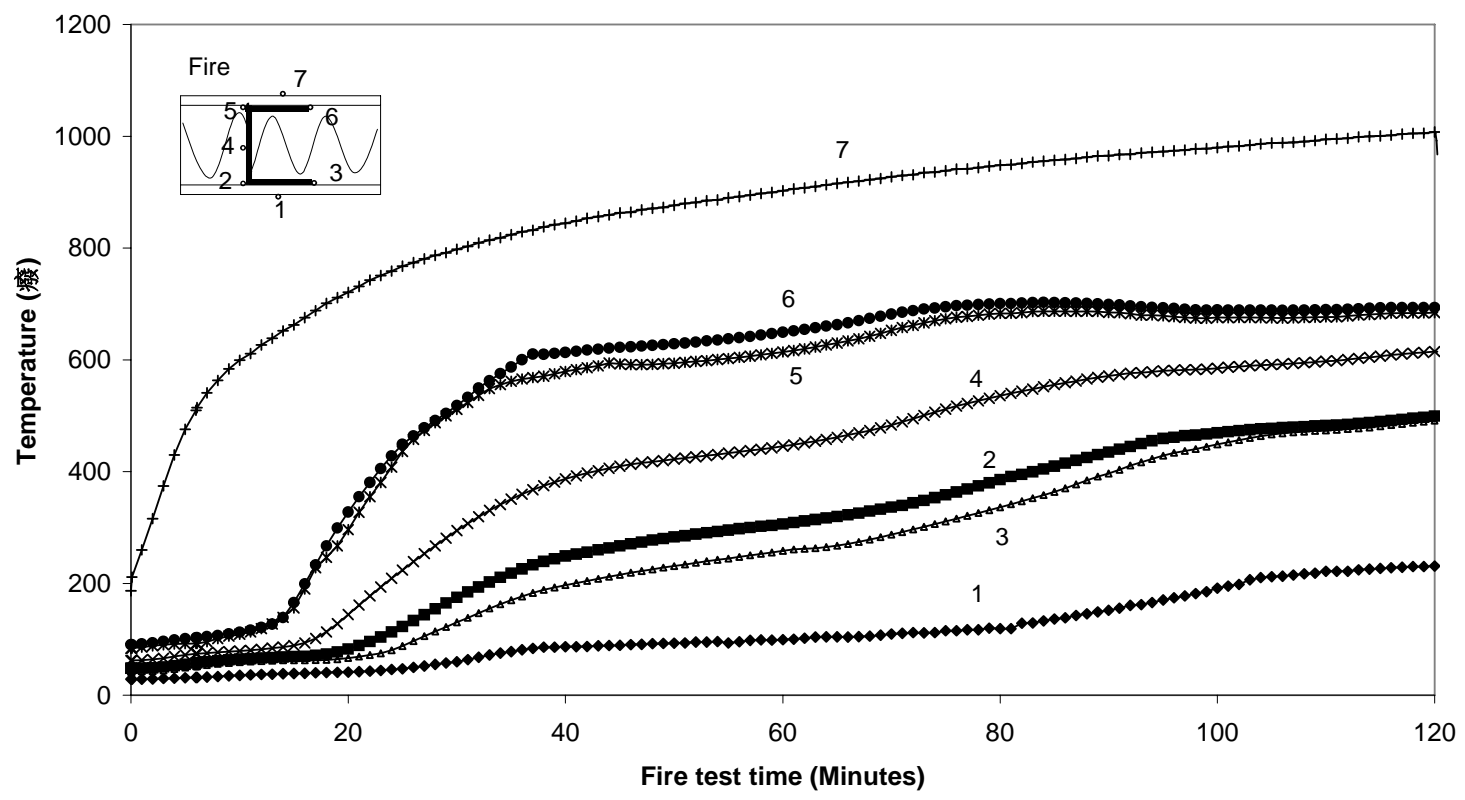

Figure 6. Time-temperature curves of unlipped channel 104 x 63 x 1.5 - single layer of gypsum board faces with mineral wool core

For the loaded large scale fire tests, behaviour of the gypsum plasterboard on the fire exposed side and the lightweight interior insulation were different. Figure 7 shows a large scale specimen after the fire test. In this case, some part of the interior insulation appeared to have shrunk whereby forming holes. This resulted in the steel section to attain near uniform temperature distribution as indicated in Figure 8 (compare temperatures recorded by thermocouples 2 and 3 with those by thermocouples 4 and 5). The test panel failed shortly afterwards. Shrinking of the interior insulation was possibly caused by direct contact with the fire flame which got into the interior insulation through the joint of the two exposed gypsum plasterboards that was not adequately sealed during the fire test. Clearly, the type of interior insulation as well as detailing of the gypsum plasterboards adopted in this study would not be adequate to provide sufficient fire protection. 

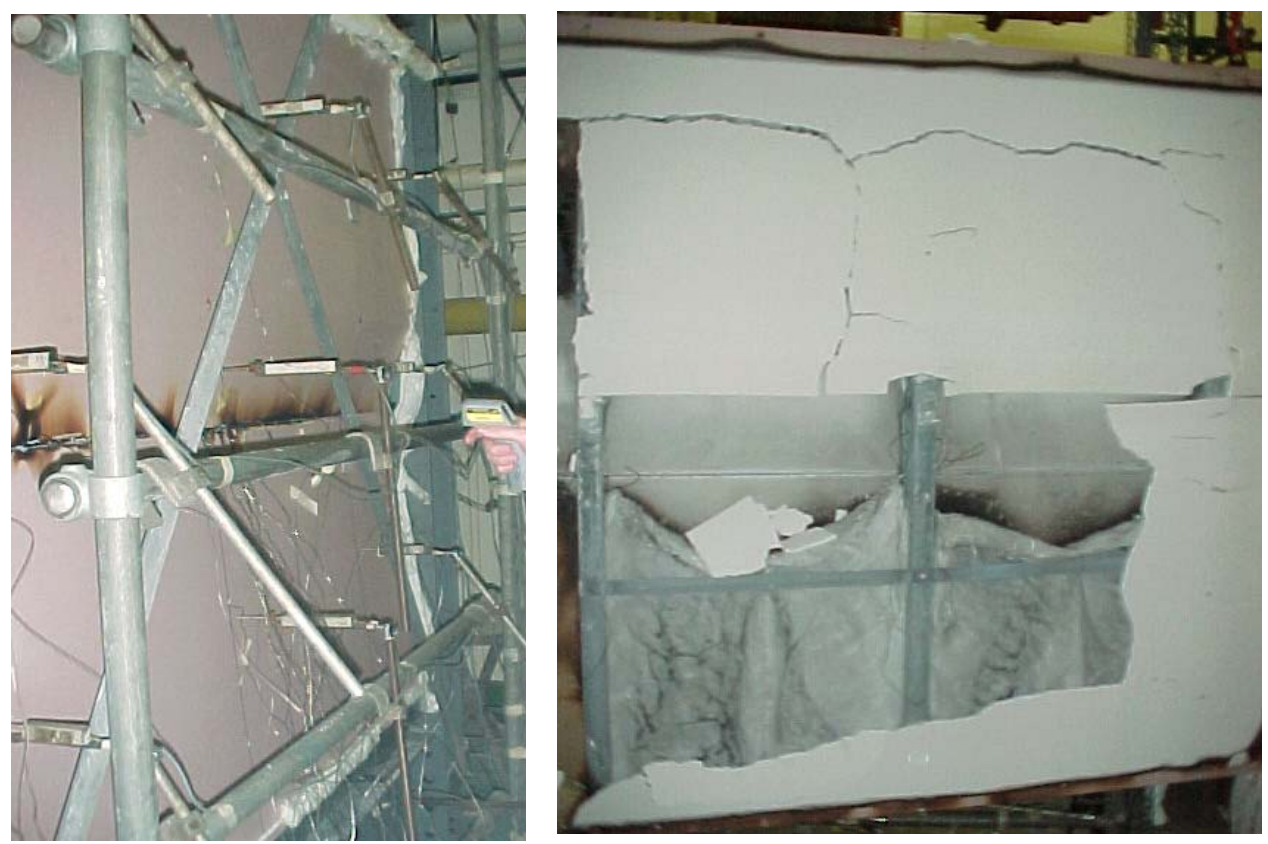

(a) Behaviour of gypsum plasterboard (before removal of plasterboard)
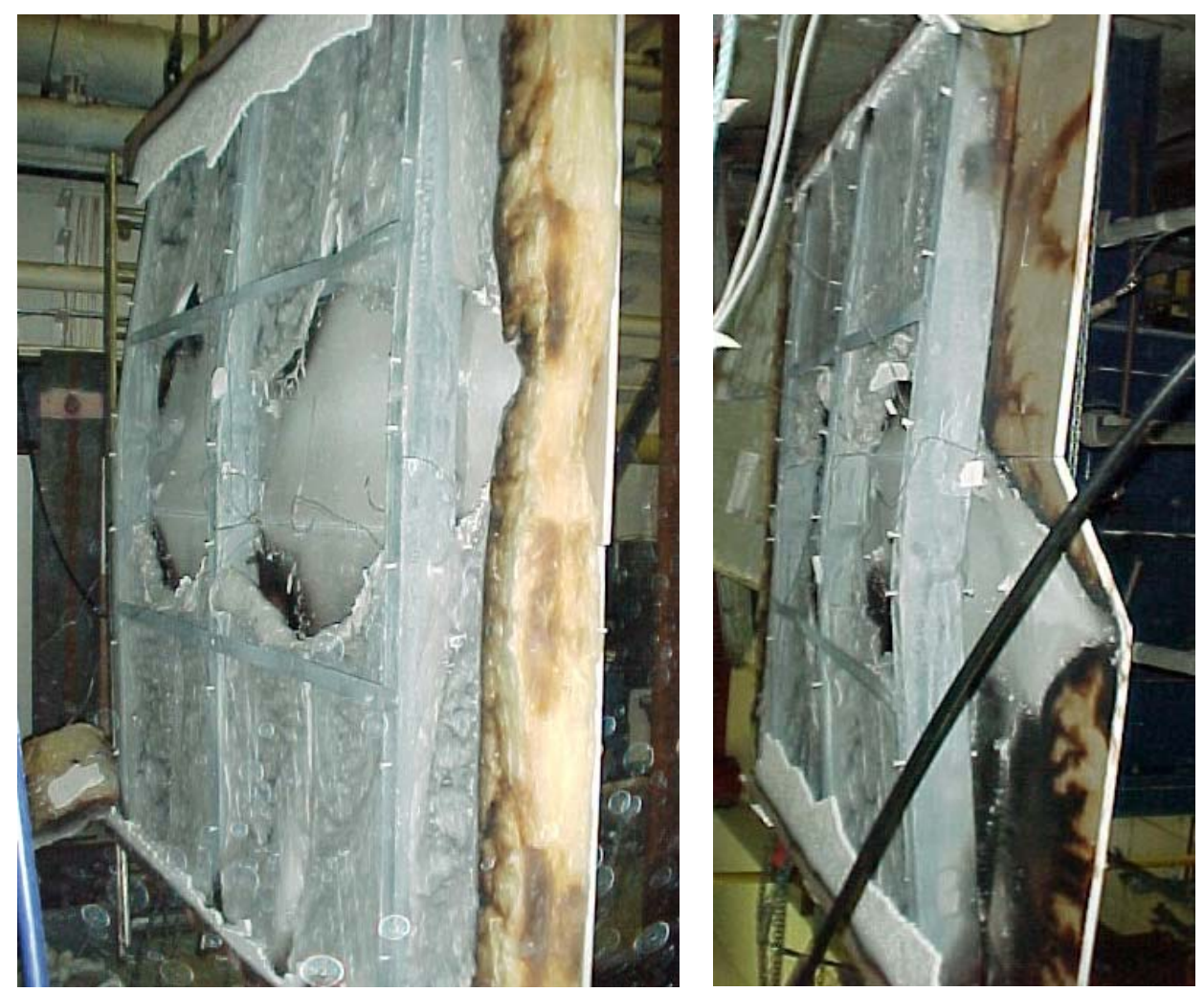

(b) Behaviour of steel studs (gypsum plasterboard removed for clarity)

Figure 7. Failure mode of panel using $100 \times 56$ x $15 \times 2$ sections under 0.2 load ratio 


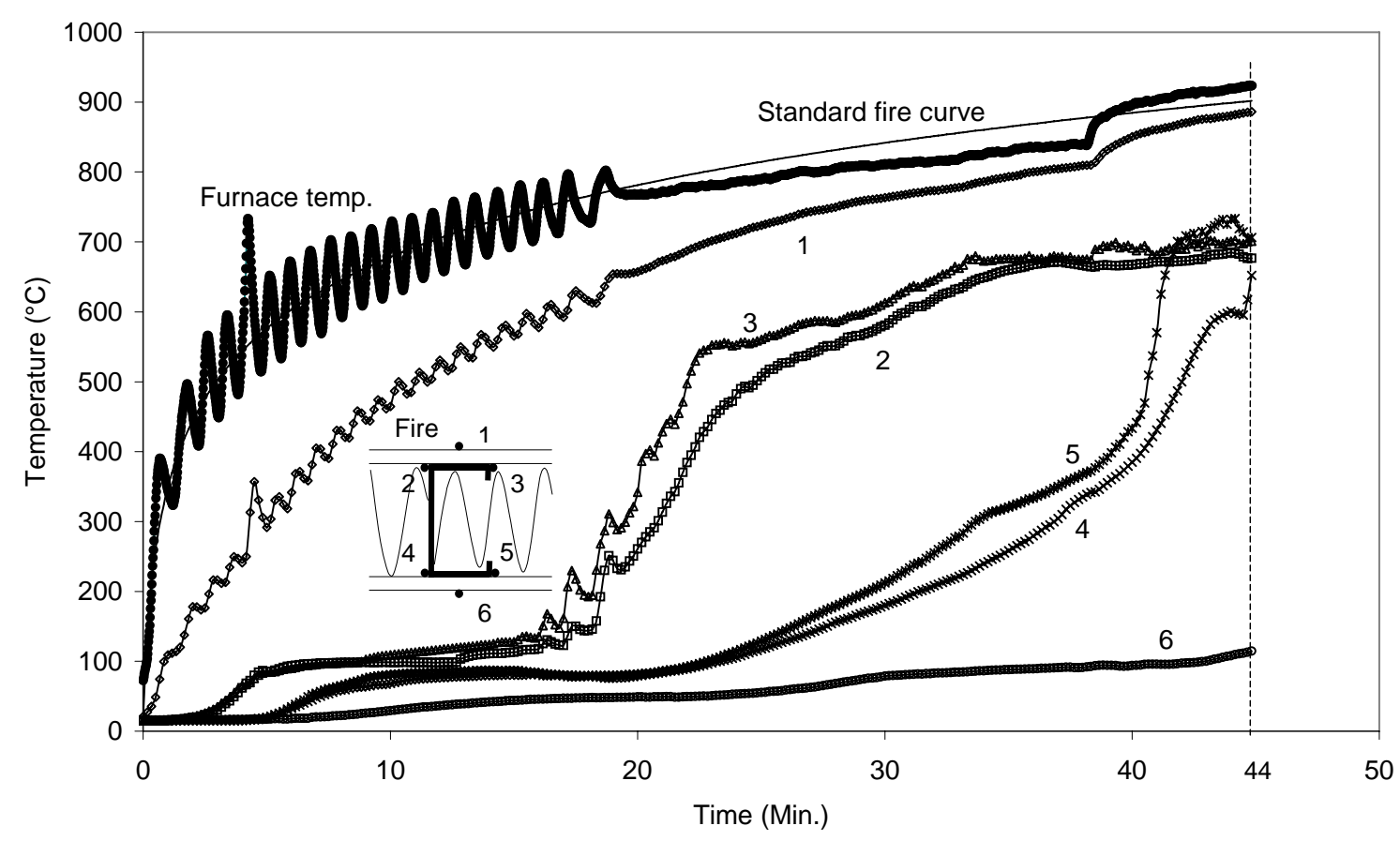

Figure 8. Time-temperature curves of large panel using 100 x 56 x 15 x 2 sections under 0.2 load ratio

In general, the performance of the gypsum plasterboard in a panel system, in particular whether and when it would fall during the fire exposure, will be an important factor. At this stage, it is not possible to draw any definitive conclusion from experimental observations of the authors study and of a number of other investigations. For loaded panels, Sakumoto et al [6] reported gypsum plasterboard falling in their tests. Figure 7 also shows that the gypsum plasterboard fell in the authors' own tests. However, Figure 8 shows that in the authors test, gypsum plasterboard falling was the effect, not the cause, of structural failure of the panel. This may be seen by comparing the recorded temperatures measured by thermocouple 1 on the exposed surface of the gypsum plasterboard and thermocouples 2 and 3 at the junction between the gypsum plasterboard and the steel section on the exposed side. The temperatures in the steel section (thermocouples 2 and 3 ) were always lower than that on the exposed surface of the gypsum plasterboard (thermocouple 1), indicating that the gypsum plasterboard had not fallen and was still offering fire protection to the steel sections. However, because it was not possible to view the exposed gypsum plasterboard during the fire test, it was not possible to definitely confirm this deduction. The fact that part of the gypsum plasterboard was missing after the fire test could have been a result of the large strains at structural failure of the steel sections, causing the already fragile gypsum plasterboard to fall, but such fall would not adversely affect the structural performance of the steel structure. The authors did not perform any large scale unloaded panel fire tests. The evidence of the fire tests of Sultan and Lougheed [4] appears to indicate that there was no gypsum plasterboard falling in their unloaded panel tests. However, the unloaded panel test results quoted in Sultan [1] indicate that gypsum plasterboard falling occurred when the exposed gypsum plasterboard temperature was about $600^{\circ} \mathrm{C}$. At present, observation of gypsum plasterboard performance in fire has been a by-product of studies of the steel section in panel system, rather than a subject in its own right. Considering the importance of this subject on the fire performance of the steel section in a panel system, studying the thermal and mechanical performance of stand-alone gypsum plasterboards will enable a better understanding and prediction of the panel system fire performance.

Figure 9 shows the recorded temperature - time relationships of one unloaded small scale test using perforated steel sections. One main point is that even the very narrow perforations were able to 
break the heat transfer paths and induce large temperature differences across the perforation (compare temperatures measured by thermocouples 4 and 5). However, because heat transfer in the perforated section was 3-dimensional in nature, the results in Figure 10 indicate that the difference between temperatures in the solid and perforated steel sections is small.

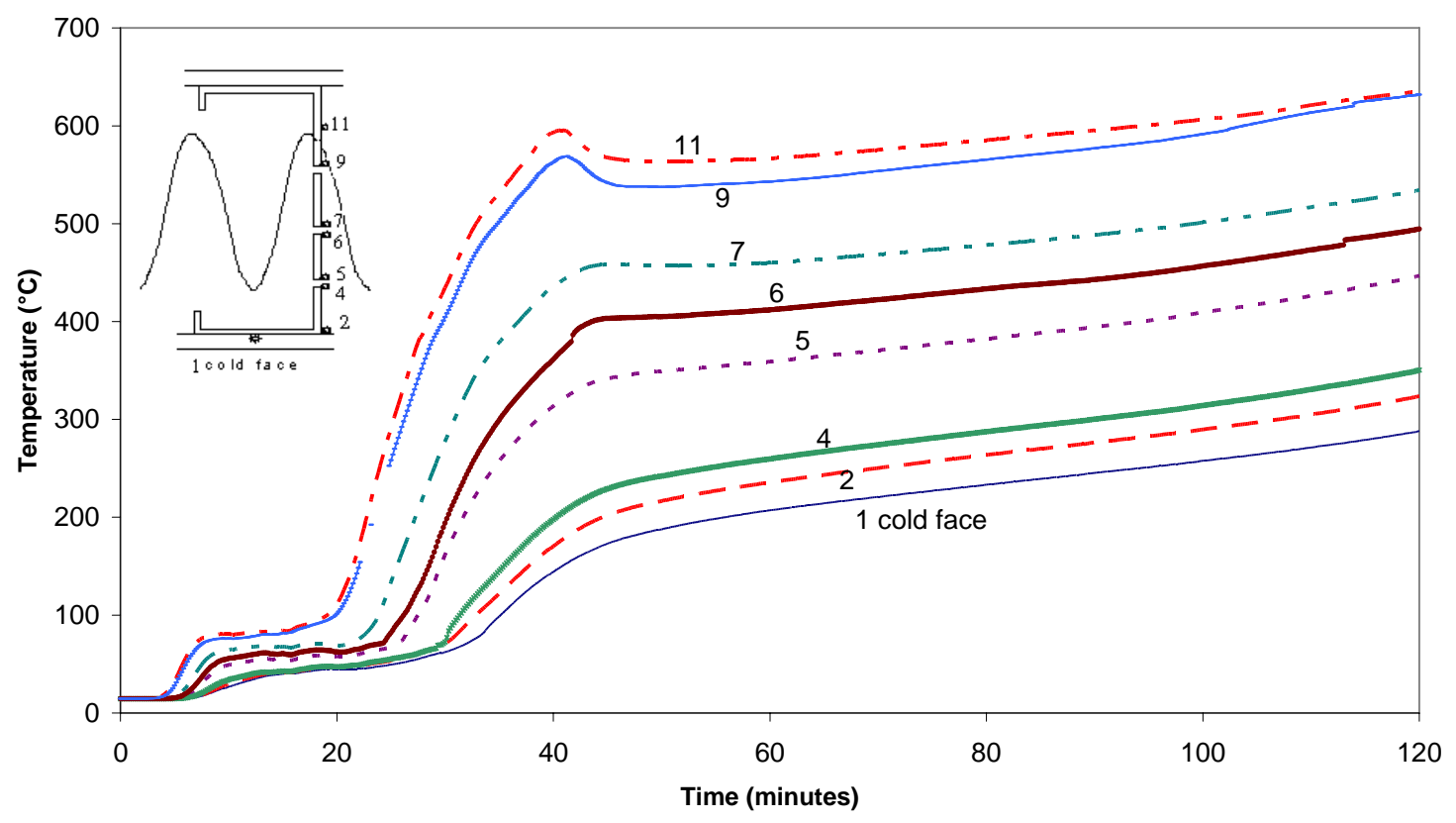

Figure 9. Time-temperature curves in $1.2 \mathrm{~mm}$ thick perforated section with one-layer gypsum plasterboard

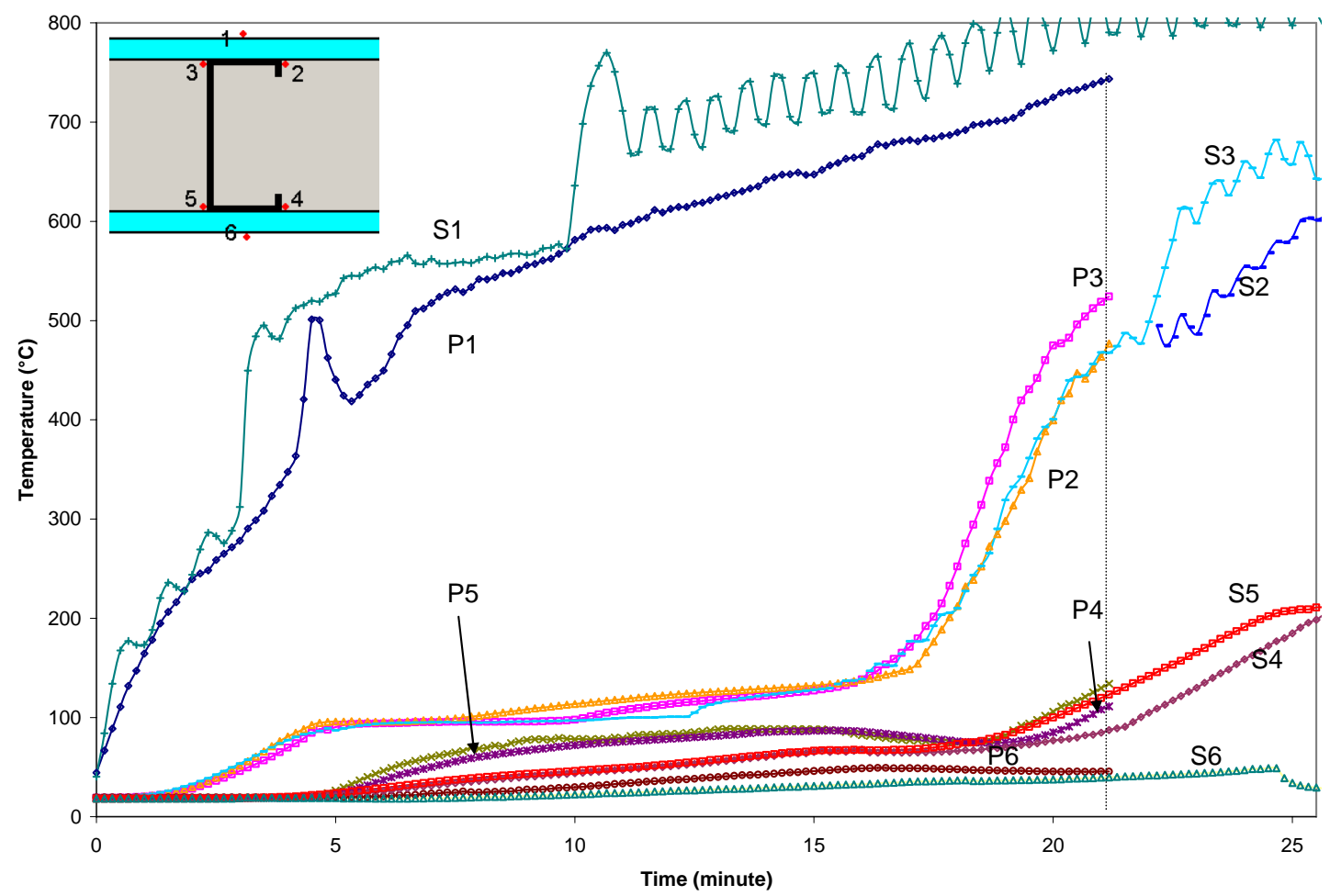

Figure 10. Comparison between temperature-time curves in perforated and solid sections, large panels, lipped channels of dimensions 100 x 54 x 15 x 1.2 mm (P for perforated section, $\mathrm{S}$ for solid section) 


\section{2}

\section{Numerical simulations}

The small-scale panel fire tests have been simulated using ABAQUS [16]. In the simulations, the gypsum plasterboard and the interior insulation were assumed to be intact during the entire fire exposure according to observation. Figure 11 shows the 2-dimensional finite element mesh used to simulate heat transfer in the small test panels using solid sections. Figure 12 shows typical comparison between the measured and simulated temperatures at various locations of one test. In the simulations, the thermal properties of steel were the same as in Eurocode 3 Part 1.2 [17]. The thermal properties of the gypsum plasterboard were based on Wang [18]. The thermal conductivity of Isowool 1000 was constant at $0.04 \mathrm{~W} /(\mathrm{mK})$, as given by the manufacturer. Figure 12 shows that correlation between the simulation and test results is reasonable. However, the simulated steel temperatures on the exposed side (thermocouples 4 and 5) are higher than the test results in the later stage of the fire test, while the simulated steel temperatures on the unexposed side (thermocouples 2 and 3) are lower than the test results. This may be attributed to the inaccurate values of thermal conductivity of Isowool 1000. At present, the only information is that from the manufacturer, however, this value is for ambient temperature only. According to Feng et al [10], the thermal conductivity of mineral wool would be higher at higher temperatures. If the actual values of thermal conductivity of mineral wool had been incorporated in numerical simulations, the temperature gradients would be reduced, improving correlation between the predicted and test results.

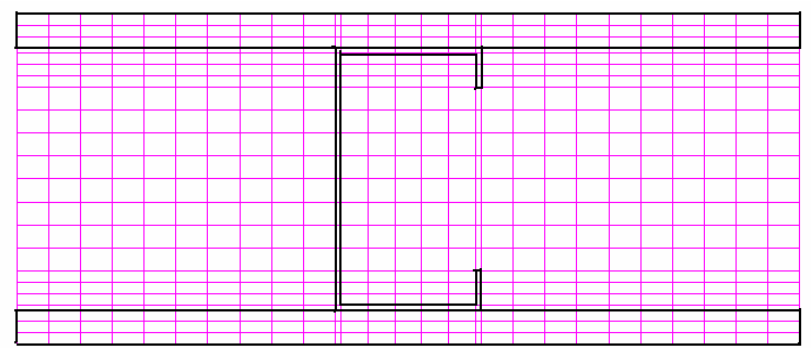

Figure 11. 2-Dimensional heat transfer finite element mesh

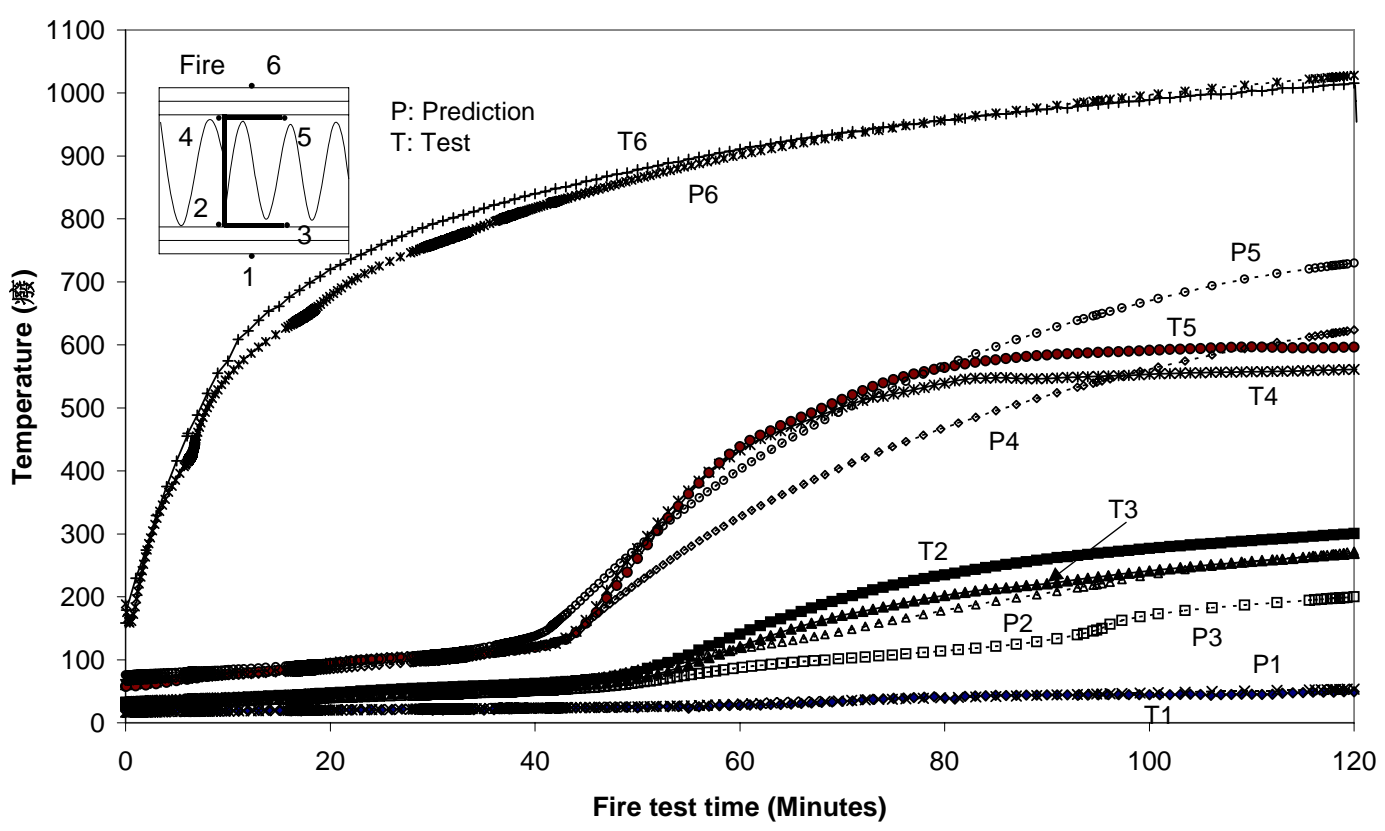

Figure 12. Comparison between test results and numerical analysis for unlipped channel 104 x 63 x 1.5 - double layers of gypsum board and mineral wool insulation 


\section{STRUCTURAL BEHAVIOUR}

Under realistic conditions of application as illustrated in Figure 1, the steel section will develop non-uniform temperature distribution in fire. During the author's research, tests and numerical studies were conducted on uniformly heated steel sections, so as to gain fundamental understanding of their performance at elevated temperatures, and on steel sections with non-uniform temperature distributions so that the realistic performance of this type of construction can be assessed.

\subsection{Uniform temperature study on short columns}

The uniform temperature study was conducted on short steel channel sections to investigate local and distortional bucking behaviour at elevated temperatures. A total of 52 tests were conducted on $400 \mathrm{~mm}$ long steel channel sections of three different types: unlipped channel section $104 \mathrm{x} 63 \mathrm{x}$ $1.5 \mathrm{~mm}$, lipped channel section 100 x 54 x 15 x $1.2 \mathrm{~mm}$ and lipped channel section $100 \times 56$ x $15 \times$ $2 \mathrm{~mm}$, some of the two lipped sections also having a service hole. These tests were conducted in an electrically heated kiln shown in Figure 13, at ambient temperature, $250^{\circ} \mathrm{C}, 400^{\circ} \mathrm{C}, 550^{\circ} \mathrm{C}$ and $700^{\circ} \mathrm{C}$, to provide information on their local and distortional buckling behaviour. In each test, the unloaded specimen was heated in an electrically heated kiln to the target temperature. Compression load was incrementally applied to the specimen until failure while maintaining the target temperature.

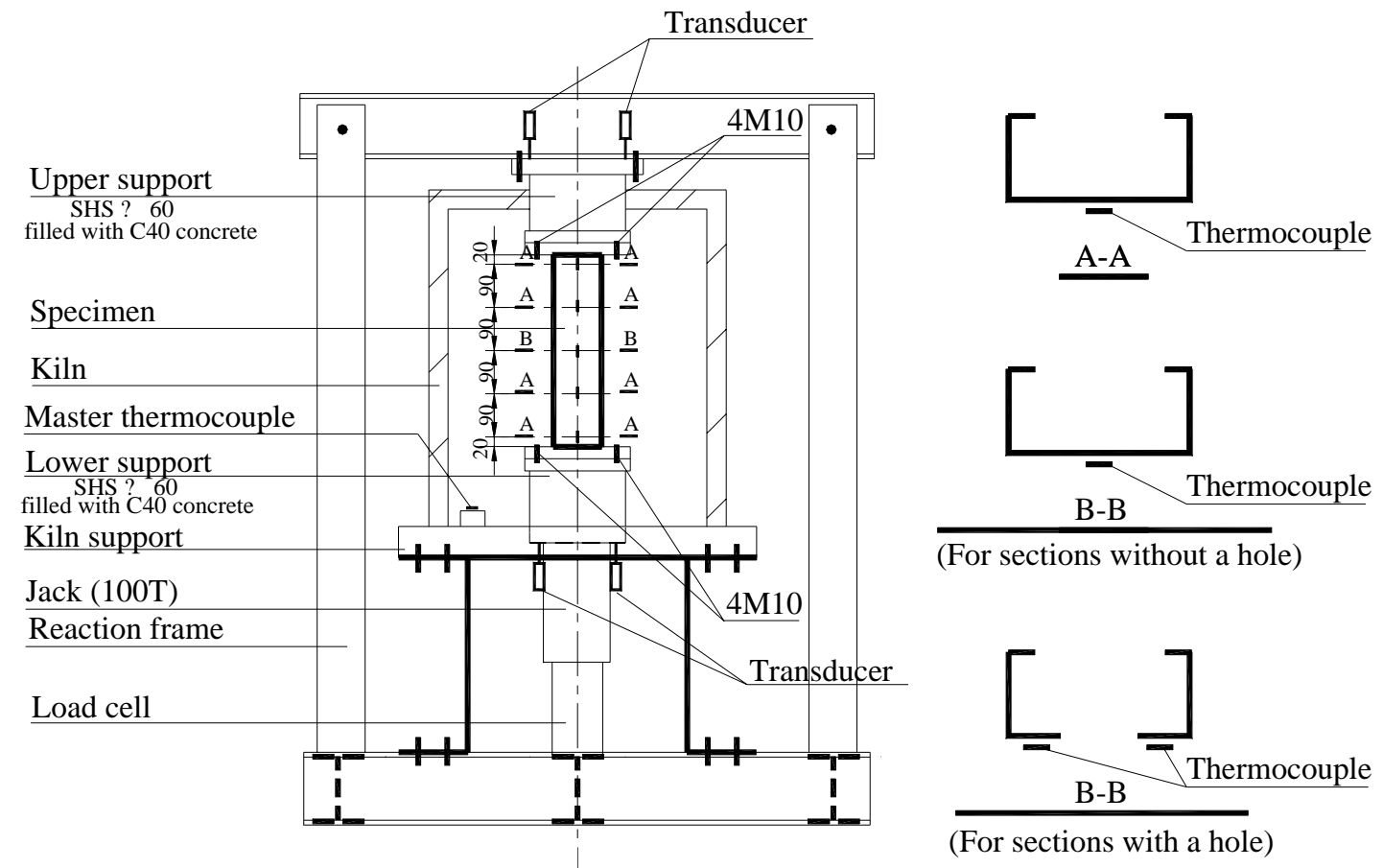

Figure 13. High temperature compression test rig

Table 2 gives the observed failure load and failure mode for each test. The experimental results clearly suggest that local buckling was associated with the unlipped and the thinner $(1.2 \mathrm{~mm})$ lipped sections and distortional buckling occurred more often in the thicker (2 mm) lipped sections. Whether local or distortional buckling would occur or not was also affected by the initial imperfection of the test specimen and the contact between the test specimen and the loading system. Thus, two nominally identical test specimens could fail in different modes. Nevertheless, as far as their failure loads are concerned, there was usually very little difference. These general conclusions 
are not affected by the level of elevated temperature. For example, Figure 14 shows the recorded load-axial deformation curves for the $2 \mathrm{~mm}$ thick lipped channel sections. Despite the difference in failure modes of some of the two nominally identical specimens, the recorded column deformation - temperature behaviour was very similar. Furthermore, Figure 15 shows that at each particular temperature, the short column strength for the different types of specimens, expressed as the ratio of the column strength at elevated temperature to that at ambient temperatures, varies within a relatively small range, suggesting that the limiting temperature approach such as that adopted in the SCI design guide for thin-walled steel structures [19], would be suitable.

Table 2. Failure modes and loads for short solid sections

\begin{tabular}{|c|c|c|c|c|}
\hline Section type & $\begin{array}{c}\text { Temp. } \\
\left({ }^{\circ} \mathrm{C}\right)\end{array}$ & $\begin{array}{c}\text { Name of } \\
\text { Specimens }\end{array}$ & Test Strength $\quad(\mathbf{k N})$ & Observed Failure mode \\
\hline $\begin{array}{c}\text { Lipped } \\
\text { channel } 100 \times \\
54 \times 15 \times 1.2 \\
\text { without hole }\end{array}$ & $\begin{array}{l}250 \\
400 \\
550 \\
700\end{array}$ & $\begin{array}{c}\text { Lip12a1 } \\
\text { Lip12a2 } \\
\text { Lip12d5 } \\
\text { Lip12b1 } \\
\text { Lip12b225** } \\
\text { Lip12b325 } \\
\text { Lip12d225 } \\
\text { Lip12C140 } \\
\text { Lip12C240 } \\
\text { Lip12C355 } \\
\text { Lip12C455 } \\
\text { Lip12D370* } \\
\text { Lip12D670* } \\
\text { Lip12e170 } \\
\end{array}$ & $\begin{array}{c}55.99 \\
53.46 \\
53.86 \\
50.97 \\
40.04 \\
53.16 \\
47.86 \\
45.75 \\
47.01 \\
23 \\
27 \\
5.52 \\
5.7 \\
8.85 \\
\end{array}$ & $\begin{array}{l}\text { Local and flexible buckling } \\
\text { Local and torsion buckling } \\
\text { Local, distortional buckling and bending } \\
\text { As above } \\
\text { Local buckling \& local crush } \\
\text { Local, distortional buckling and bending } \\
\text { As above } \\
\text { Local buckling \& bending } \\
\text { As above } \\
\text { Distortional buckling } \\
\text { Local buckling \& bending } \\
\text { Local, distortional buckling and bending } \\
\text { As above } \\
\text { As above }\end{array}$ \\
\hline $\begin{array}{c}\text { Lipped } \\
\text { channel } 100 \text { x } \\
56 \text { x } 15 \times 2 \\
\text { without hole }\end{array}$ & $\begin{array}{l}250 \\
400 \\
550\end{array}$ & $\begin{array}{l}\text { Lip2a1*** } \\
\text { Lip2a2 } \\
\text { Lip2a5 } \\
\text { Lip2b1 } \\
\text { Lip2d1 } \\
\text { Lip2b225 } \\
\text { Lip2b325 } \\
\text { Lip2C140 } \\
\text { Lip2C240 } \\
\text { Lip2C355 } \\
\text { Lip2a555 } \\
\text { Lip2e155 } \\
\text { Lip2D270* } \\
\text { Lip2D370* } \\
\text { Lip2D470 }\end{array}$ & $\begin{array}{l}110.21 \\
129.16 \\
124.66 \\
116.79 \\
108.97 \\
123.69 \\
123.23 \\
101.87 \\
101.56 \\
45.52 \\
43.33 \\
45.03 \\
12 \\
13.83 \\
15.77 \\
\end{array}$ & $\begin{array}{c}\text { Local buckling } \\
\text { Distortional buckling } \\
\text { As above } \\
\text { Local, distortional buckling } \\
\text { and bending } \\
\text { As above } \\
\text { As above } \\
\text { As above } \\
\text { As above } \\
\text { As above } \\
\text { As above } \\
\text { As above } \\
\text { As above } \\
\text { As above } \\
\text { As above } \\
\text { As above }\end{array}$ \\
\hline $\begin{array}{c}\text { Unlipped } \\
\text { channel } 104 \text { x } \\
63 \text { x } 1.5\end{array}$ & $\begin{array}{c}\text { Ambient } \\
250 \\
400 \\
550 \\
700\end{array}$ & $\begin{array}{c}\text { Unlip15a1 } \\
\text { Unlip15a2 } \\
\text { Unlipc1 } \\
\text { Unlipc225 } \\
\text { Unlipc325 } \\
\text { Unlipc440 } \\
\text { Unlipc540 } \\
\text { Unlipd155 } \\
\text { Unlipd255 } \\
\text { Unlipc670 } \\
\text { Unlipb570 }\end{array}$ & $\begin{array}{c}55 \\
58.02 \\
54.5 \\
49.58 \\
50.77 \\
45.7 \\
44.67 \\
27.07 \\
28.38 \\
9.28 \\
9.21\end{array}$ & $\begin{array}{c}\text { Local buckling } \\
\text { Local buckling } \\
\text { Local buckling and local crush } \\
\text { As above } \\
\text { As above } \\
\text { As above } \\
\text { As above } \\
\text { As above } \\
\text { As above } \\
\text { As above } \\
\text { As above }\end{array}$ \\
\hline & $\begin{array}{l}* \text { Results } \\
* * \text { Faulty } \\
* * * \text { Faulty }\end{array}$ & $\begin{array}{l}\text { able due to high } \\
\text { due to movemen }\end{array}$ & $\begin{array}{l}\text { erature effect on load ce } \\
\text { he reaction frame }\end{array}$ & \\
\hline
\end{tabular}




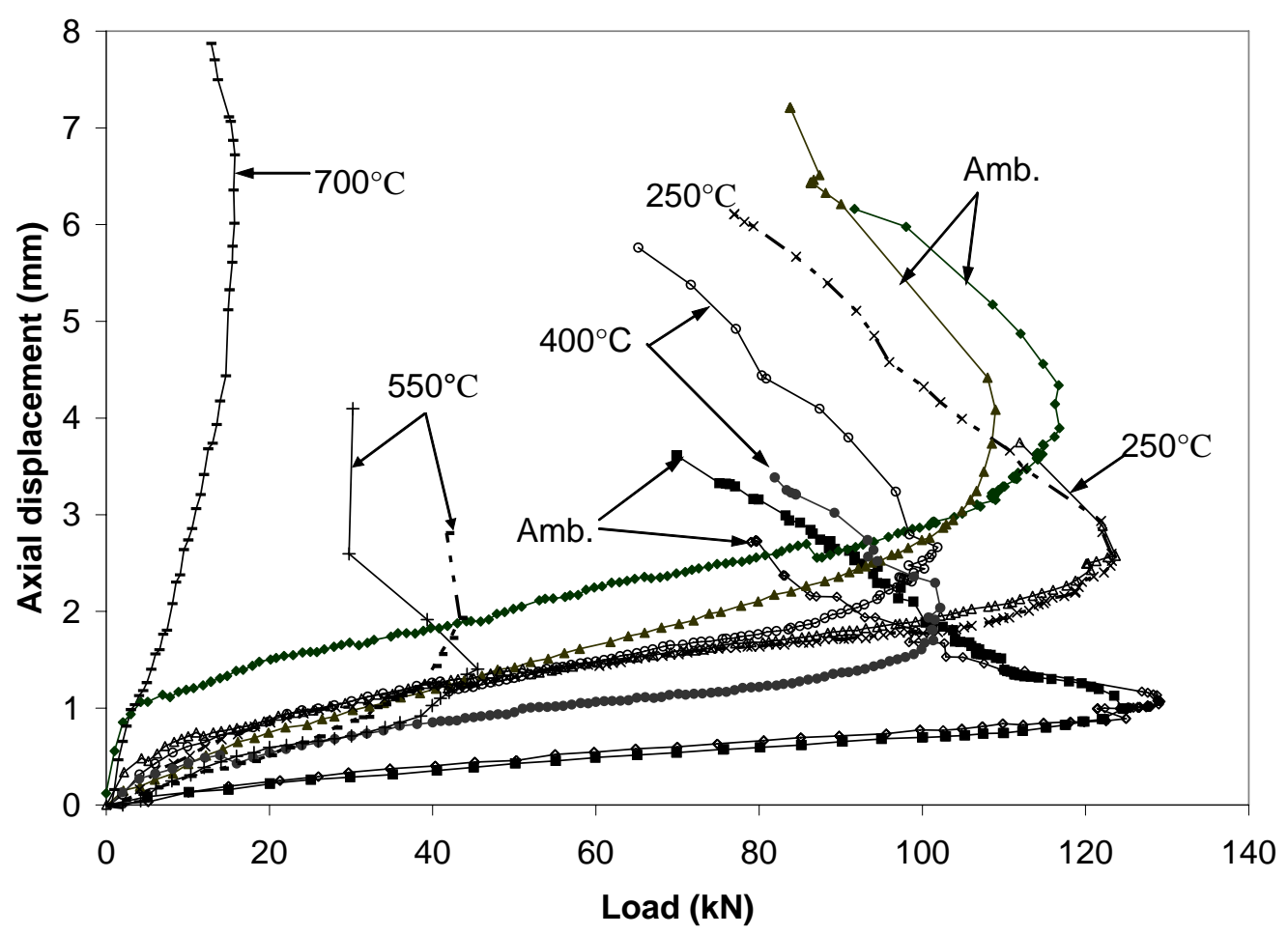

Figure 14. Load-axial deformation relationships of lipped channel 100 x 56 x 15 x 2 without a service hole under different temperatures

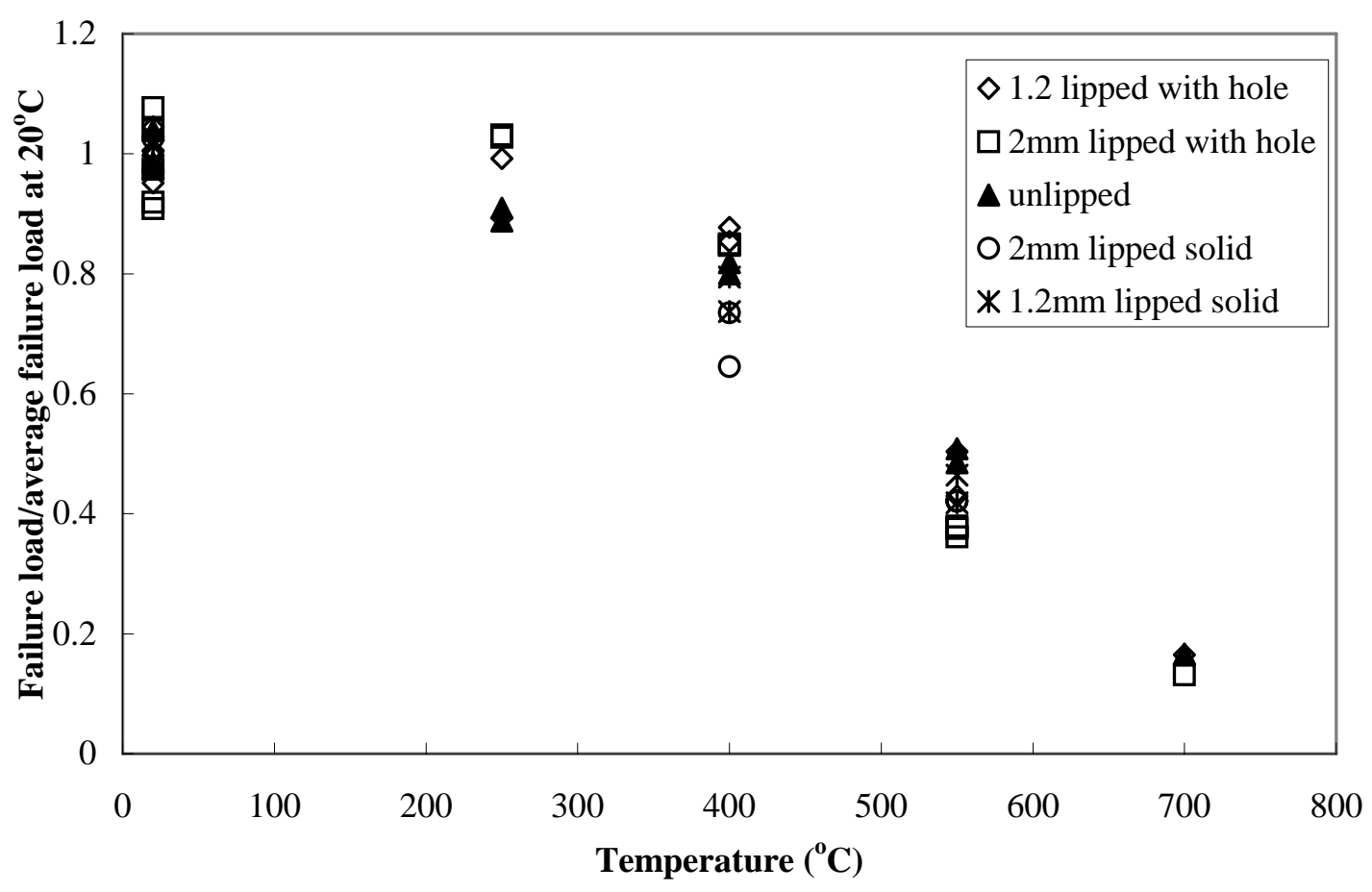

Figure 15. Reduction of column strength as a function of temperature

The uniform high temperature test results were compared against calculations using a number of design calculation methods, including Eurocode 3 Part 1.2 [17] for fire resistance and Eurocode 3 Part 1.3 [20], BS 5950 Part 5 [21] and AISI [22] for ambient temperature. To make use of the ambient temperature methods, the material properties of steel at ambient temperature were replaced by those at high temperatures. Figure 16 summarises the comparison between the test results and 
the different design calculations in which the steady state elevated temperature material properties of Outinen [23] were used. Figure 16 suggests that the BS 5950 Part 5 and AISI methods tend to give higher results than the Eurocode methods. Between the two Eurocode methods, the ambient temperature one (Eurocode 3 Part 1.3) tends to give slightly higher results than the elevated temperature one (Eurocode 3 Part 1.2). Nevertheless, the difference in the predicted results from the different design calculation methods is relatively small, all giving prediction results within about $10 \%$ from the test results. It should be pointed out that Eurocode 3 Part 1.2 recommends that the effective widths at ambient temperature be kept unchanged at elevated temperatures. This saves a great deal of calculation effort, but as shown in Figure 16, it does not seem to suffer any inaccuracy in the design calculation results.

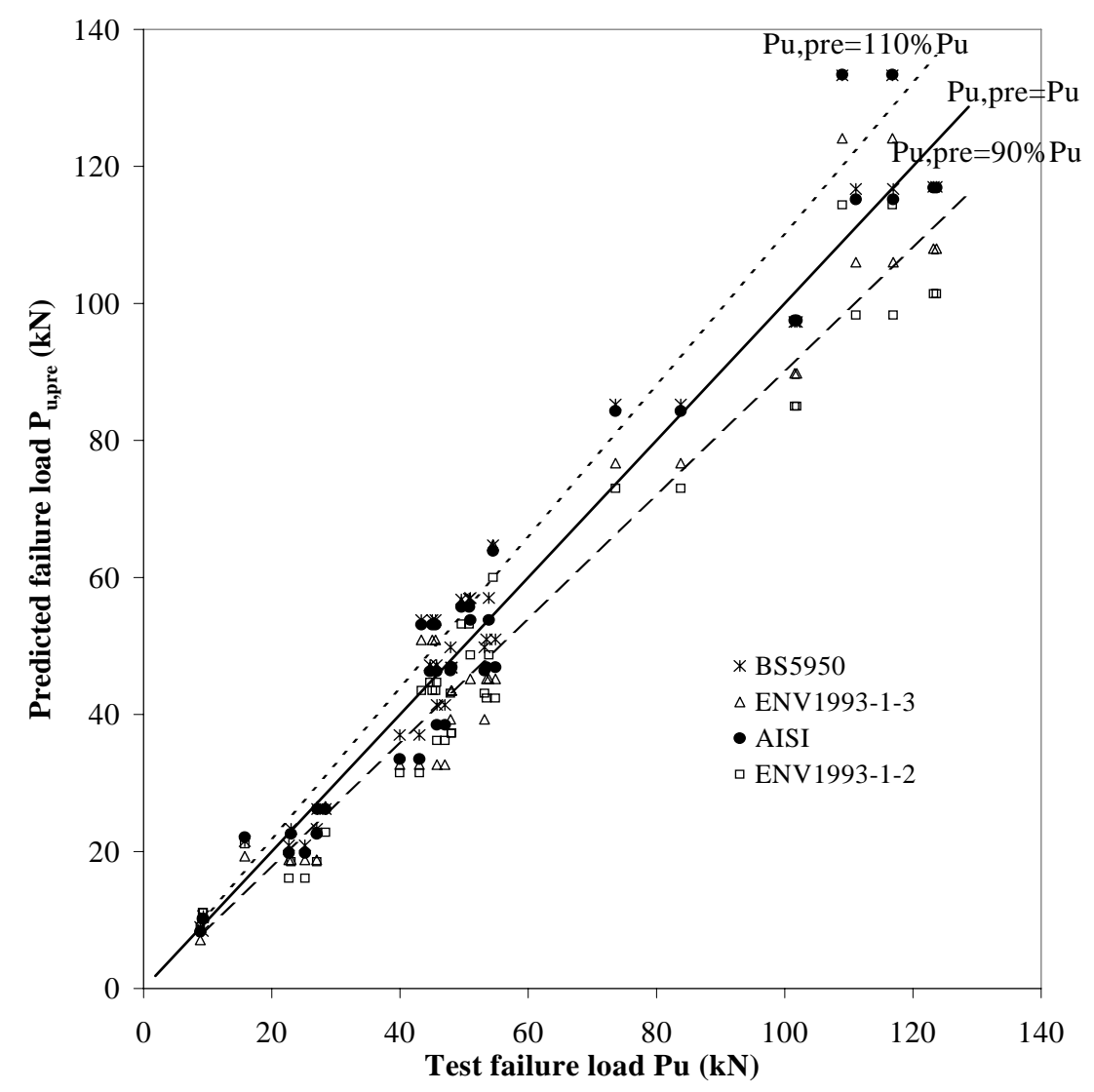

Figure 16. Comparison between test failure loads and predictions of modified BS5950 Part 5, ENV1993-1-3, ENV1993-1-2 and AISI, using Outinen properties

\subsection{Non-uniform temperature study}

It has already been mentioned in a number of places of this paper (e.g. Figure 6) that the temperature distribution in the steel cross-section is non-uniform in both directions. It would be extremely difficult to take this into account in practical design calculations. In the authors' research, ABAQUS simulations were performed to assess whether it would be possible to use simplified temperature distributions in design calculations. The following procedure was adopted:

(1) 2-dimensional ABAQUS simulation was performed to obtain temperature distribution of the steel section under fire exposure to the panel from one side;

(2) ABAQUS simulation was then performed to obtain the ultimate failure load of the steel section using the above temperature distribution; 
(3) The temperature distribution profile in step 1 was represented by two simplified temperature distribution profiles. In simplification 1, the flange temperatures were uniform and their values were the averages of the respective flange temperatures obtained in step 1 . The web temperature distribution was linear. In simplification 2, the flange and web temperature distributions were linear with the flange tip and flange/web junction temperatures taking values from the ABAQUS simulation results in step 1.

(4) ABAQUS simulations were performed to obtain the ultimate failure loads of the steel section using the two simplified temperature profiles of step 3.

The simulations were performed for lipped channel section of dimensions 100 x 54 x 15 x $1.2 \mathrm{~mm}$ for different column heights and different positions of lateral restraints to the column. Figure 17 summaries the simulation results, which indicate that the simulation results using simplification 2 are slightly better correlated than those using simplification 1 with the simulation results using the full non-uniform temperature distribution profile. However, simplification 1 would be much easier to implement in practical design calculations and there was very little loss of accuracy by using this temperature simplification.

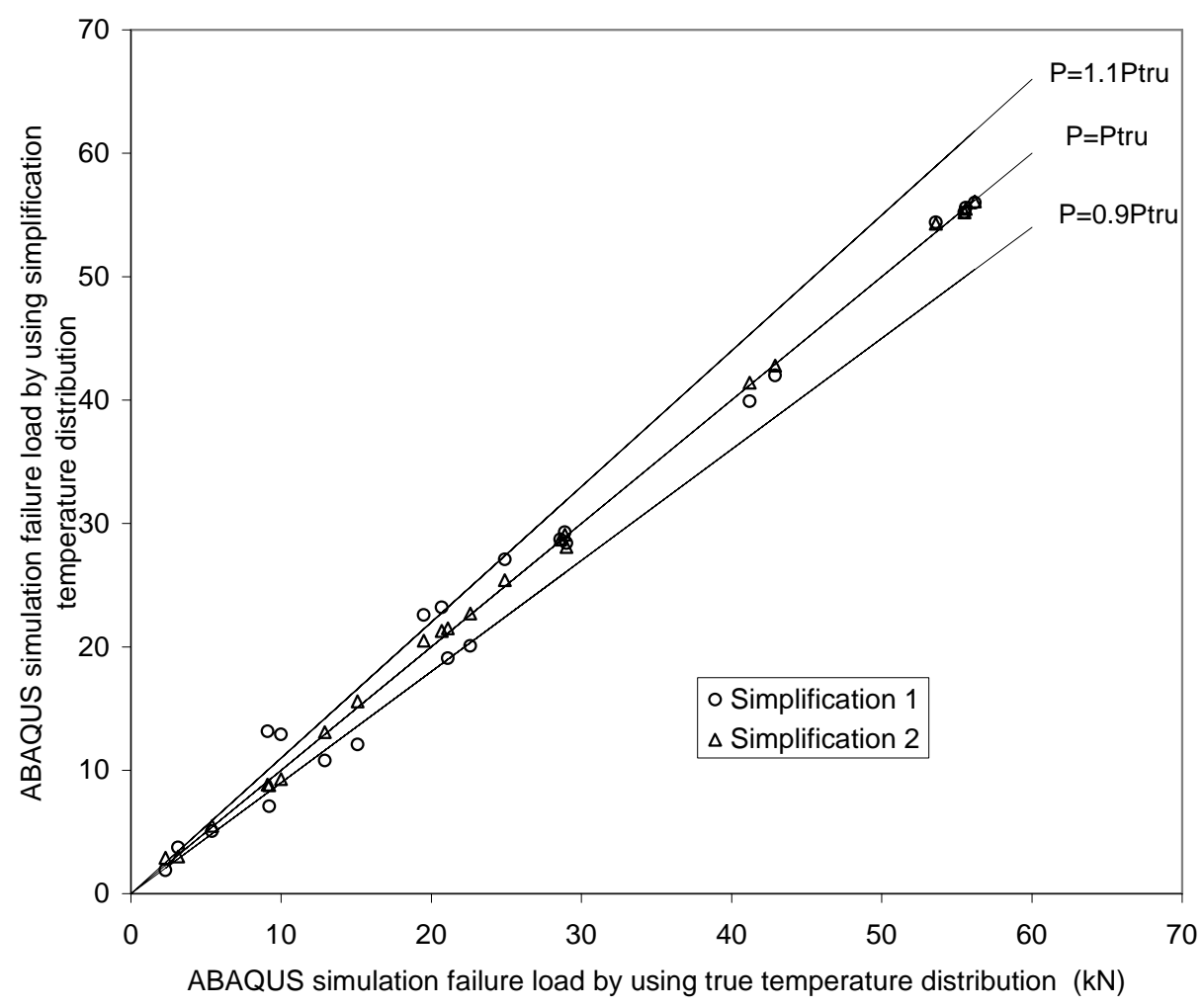

Figure 17. Comparison of ABAQUS predicted failure loads between using the "true" and simplified temperature distributions 


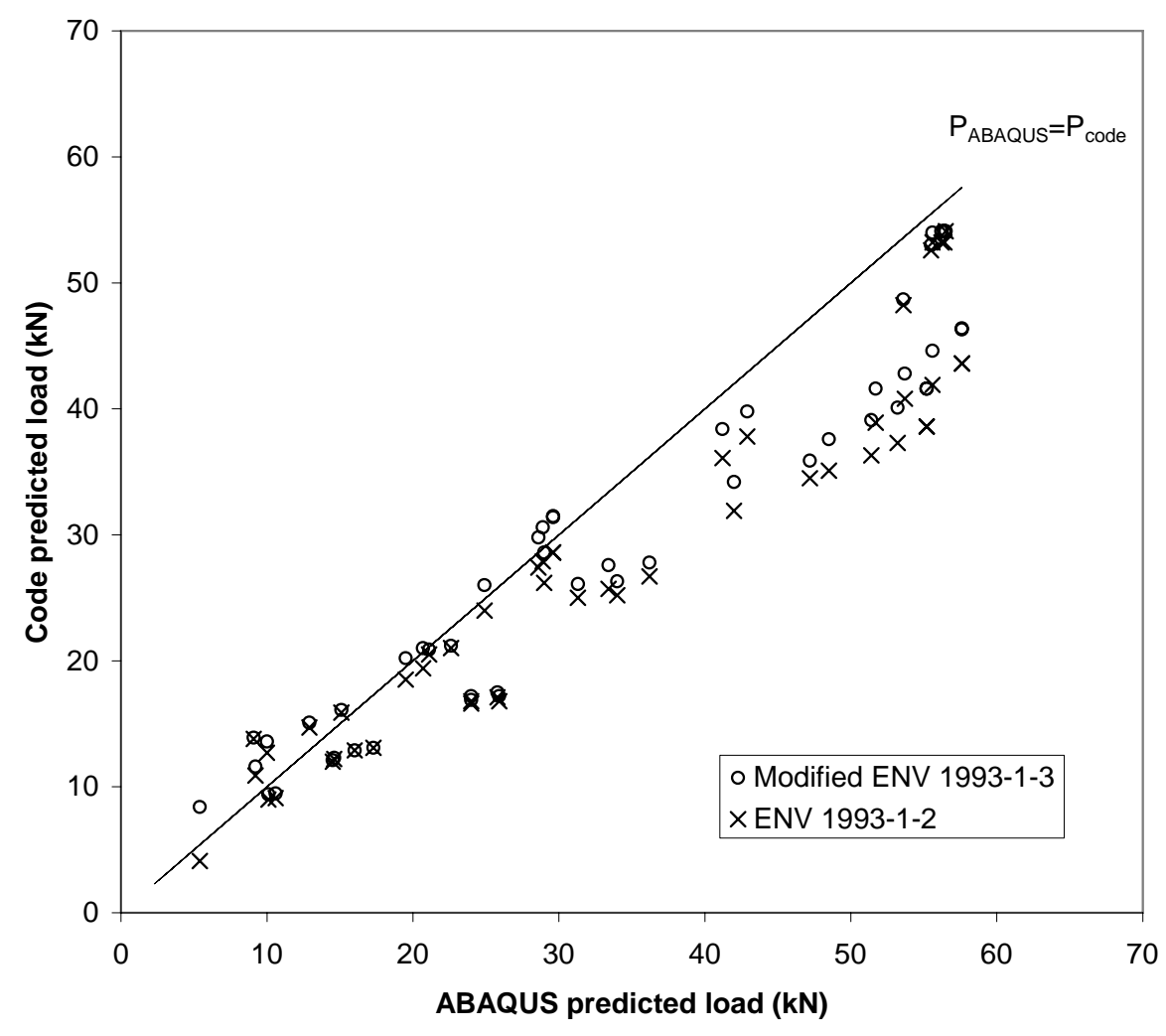

Figure 18. Comparison of failure loads between ABAQUS simulations, modified ENV1993-1-3 and ENV1993-1-2 predictions

Using temperature profile simplification 1, the simulated column strengths were also compared against design calculations using Eurocode 3 Part 1.2 [17] and Eurocode 3 Part 1.3 [20]. Because both design methods are only suitable for applications under uniform temperature distribution, it was necessary to make a number of modifications to account for the effects of non-uniform temperature distributions in the steel section. The principal effects of non-uniform temperature distribution are to induce thermal bowing deflections and to cause a shift in the neutral axis of the steel cross-section. Therefore, the modified calculation method had to deal with bending moments at the steel column supports (due to shift of neutral axis) as well as bending moments in the span (due to combined neutral axis shift and thermal bowing). Also, depending on the stress distributions at the supports and at mid-height as well as the reduced steel strengths at different elevated temperatures, it was necessary to check for stress conditions at different locations. Table 4 summaries the different possible design failure criteria that should be checked, depending on whether the design is according to first yield or partial plasticity. The authors recently published [14] an example of using Eurocode 3 Part 1.2 to calculate the failure strength of a thin-walled column with non-uniform temperature distribution. Even though the effective widths were the same as at ambient temperature, the design calculations still involved pages after pages of calculations, clearly suggesting that the current design calculation method is not suitable as a practical design tool. Nevertheless, Figure 18 shows that the modified design methods based on either Eurocode 3 Part 1.2 or Eurocode 3 Part 1.3 appear to give reasonably acceptable predictions of the numerically calculated column strengths. Figure 18 also confirms the trend shown in Figure 16 that using the elevated temperature method (Eurocode 3 Part 1.2) gives slightly lower column strength than using the ambient temperature method (Eurocode 3 Part 1.3). Since Eurocode 3 Part 1.2 recommends keeping the ambient temperature effective widths unchanged, thus saving some calculation efforts, it is a more suitable design method. 
Table 4. Design yield strength

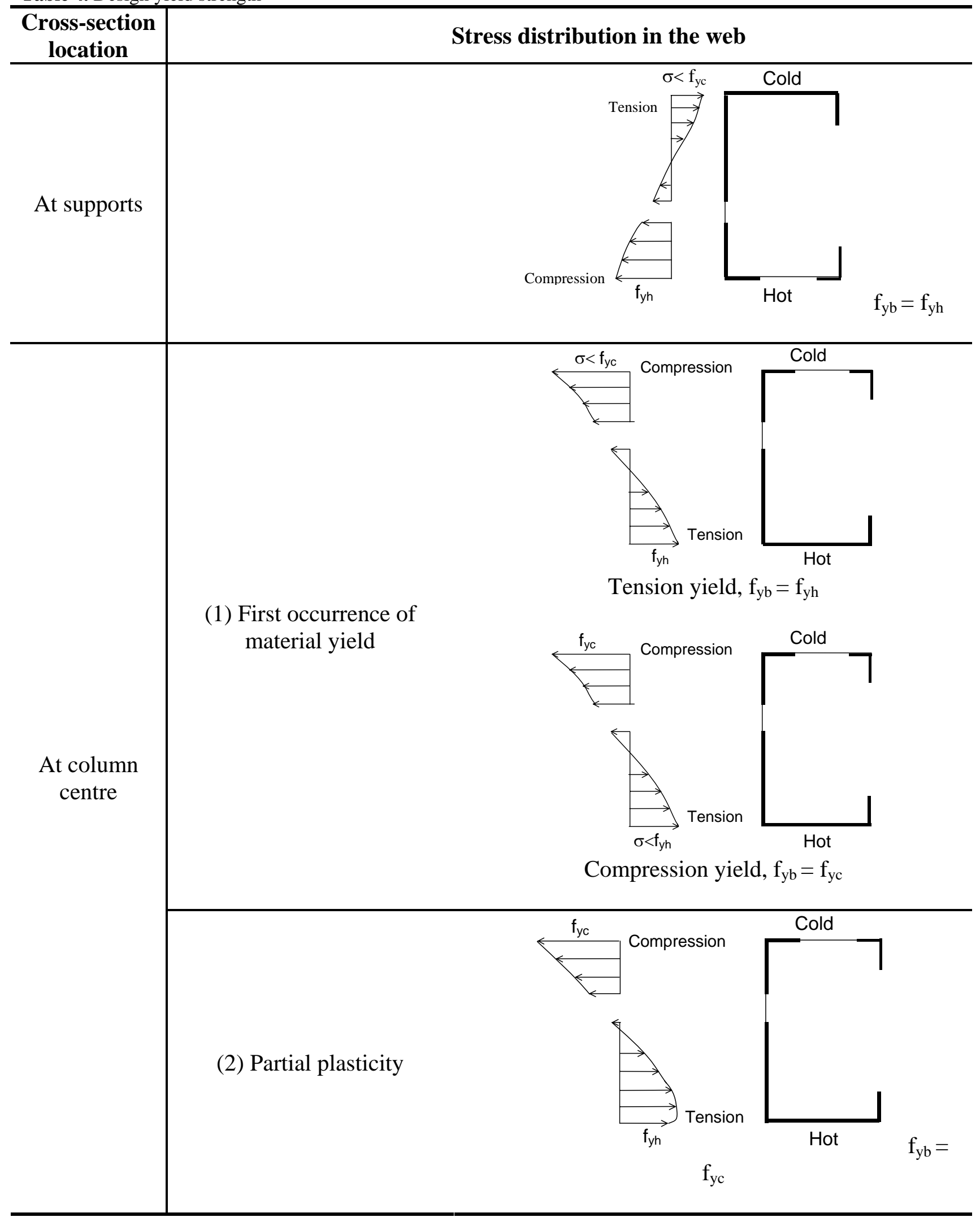

As previously mentioned, the authors conducted 6 fire tests on axially loaded large panels using cold-formed thin-walled steel sections. These panels have also been analysed using the two modified Eurocode design methods. Figure 19 provides a comparison of the recorded and calculated fire resistance times with different assumptions. In this figure, pure thermal bowing refers to the calculation of the panel thermal bowing deflection based purely on temperature 
gradient in the steel section. Magnified thermal bowing refers to using the increased thermal bowing deflection to take into account the reduction in elastic modulus of steel at elevated temperatures. Figure 19 indicates that it is not necessary to calculate the magnified thermal bowing. Design calculations were also performed to assess whether it would be necessary to accurately calculate the shifts in neutral axis in both directions, which would be time consuming. Figure 20 presents a comparison of the calculated results where different assumptions of calculating the neutral axis shifts were made. In Figure 20, $e_{x}$ and $e_{y}$ refer to the shift of neutral axis in the directions parallel to the flanges and the web respectively. Full $e_{x}$ and $e_{y}$ mean that they were both calculated by considering the different steel stiffness at different elevated temperatures. Figure 20 shows that because the steel column was mainly bending about the major axis, it would not be necessary to include the effect of neutral axis shift in the direction parallel to the flanges $\left(e_{x}=0\right)$. To calculate $\mathrm{e}_{\mathrm{y}}$, considering only the two flanges would make the calculations less complicated, but this is at the expenses of much reduced accuracy in the predicted column fire resistance times. It is necessary to include the effect of the web when calculating $\mathrm{e}_{\mathrm{y}}$.

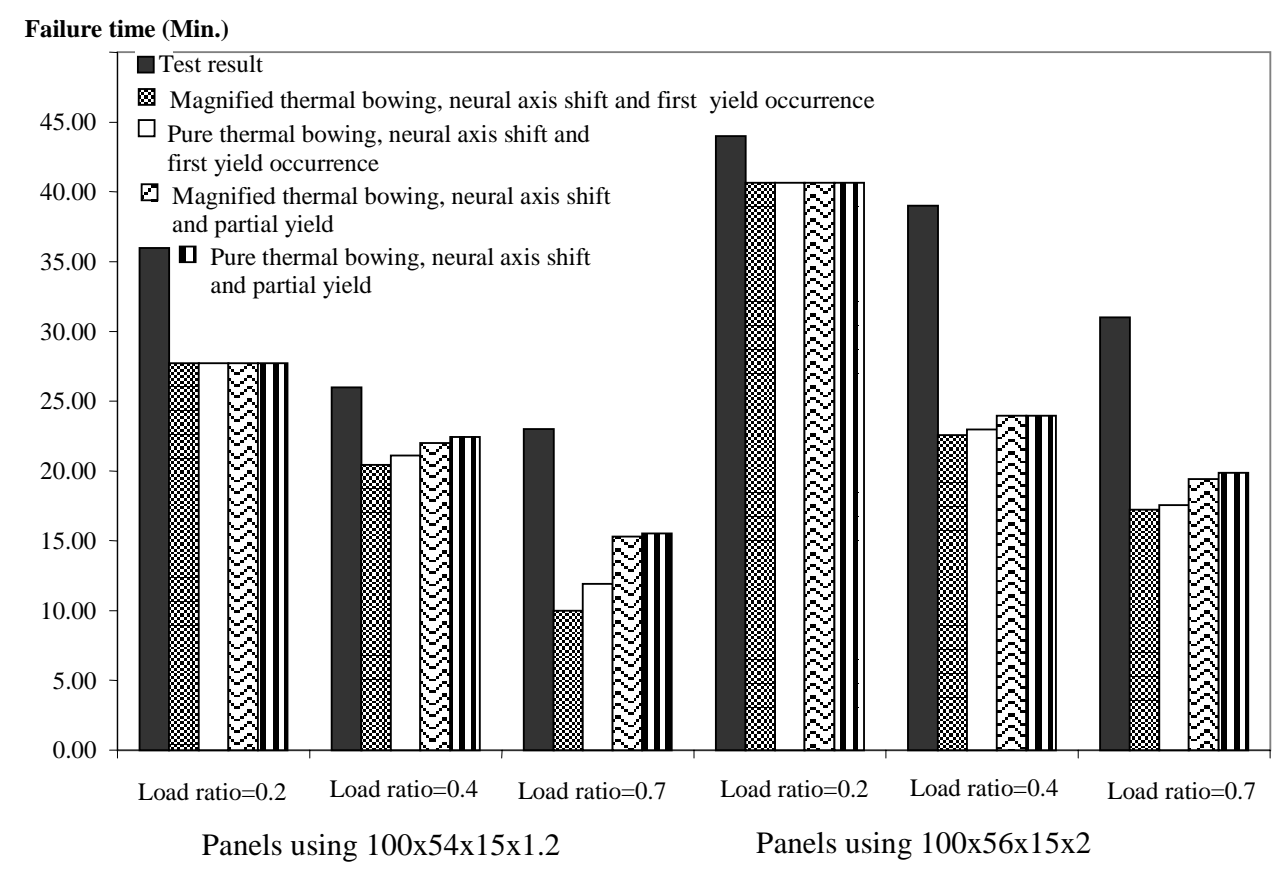

Comparison between test results and ENV 1993-1-2 predictions

Figure 19. Comparison of failure times between test results and predicted results

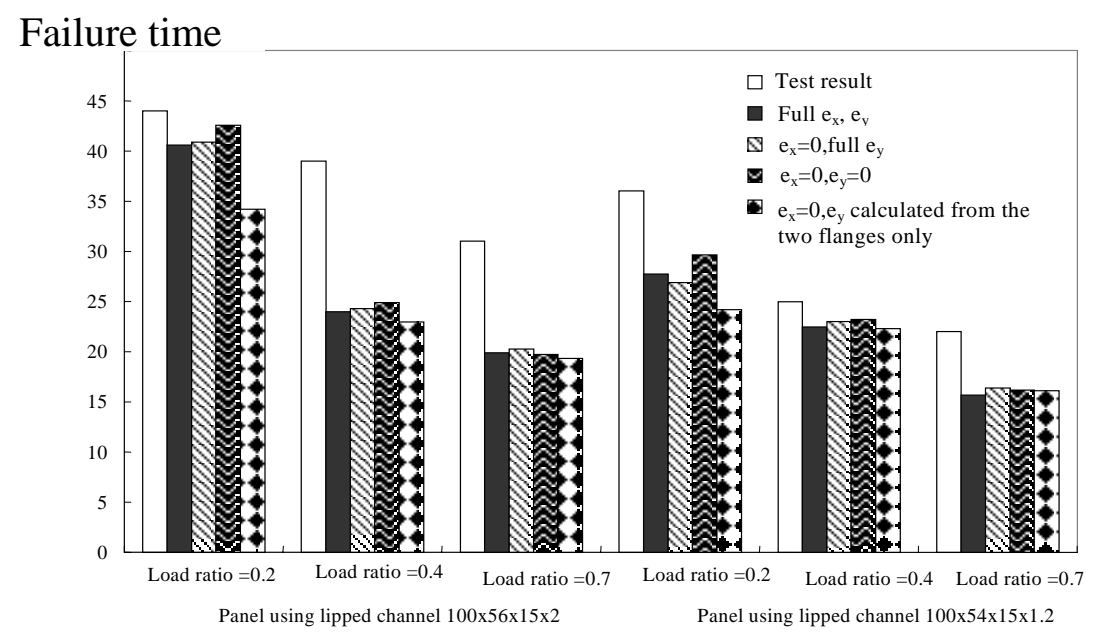

Figure 20. Comparisons of panel failure times between different methods of calculating the shifts of neutral axes 
As part of the $\mathrm{PhD}$ project of the third author, a fire test was recently conducted on a panel consisting of three lipped steel channel sections of dimensions 100 x 54 x 15 x 1.2 mm with perforated web, with one layer of gypsum plasterboard on each side and interior insulation of type Isowool 1000. As shown in Table 3, this test is directly comparable to test "panel-5" which had no perforation. Analysis is still being carried out to gain fundamental understanding of structural behaviour of this type of construction in fire. In the meantime, ABAQUS simulations have been performed to investigate the effect of gypsum plasterboard on the structural performance of the steel section, by removing the lateral and torsional restraints provided by the gypsum plasterboard on the exposed side at the locations of joint between the gypsum plasterboard and the steel section. In these simulations, the steel temperatures were the same as those measured during the fire test.

Table 3. Large scale, loaded panel fire test specimens

\begin{tabular}{ccccc}
\hline ID. & Steel sections & $\begin{array}{c}\text { Load } \\
\text { ratio }\end{array}$ & $\begin{array}{c}\text { Load in } \\
\text { individual } \\
\text { channel (kN) }\end{array}$ & $\begin{array}{c}\text { Failure time } \\
\text { (min) }\end{array}$ \\
\hline panel-1 & $100 \times 56 \times 15 \times 2$ & 0.2 & 20.6 & 44 \\
panel-2 & As above & 0.4 & 41 & 39 \\
panel-3 & As above & 0.7 & 72 & 31 \\
panel-4 & $100 \times 54 \times 15 \times 1.2$ & 0.2 & 12 & 36 \\
panel-5 & As above & 0.4 & 23 & 25 \\
panel-6 & As above & 0.7 & 41 & 22 \\
panel-P & As above (perforated) & $\approx 0.4$ & 23 & 21.5 \\
\hline
\end{tabular}

Figure 21 compares the test results against different ABAQUS simulations in which the restraints provided by the gypsum plasterboard on the fire exposed side were removed at different times. It indicates that, as expected, the earlier the removal of these restraints, the lower the panel fire resistance. However, since the same measured steel temperatures were used in all simulations, the simulated panel failure time was not particularly sensitive to the timing of removal of these restraints. It appeared that the simulation result was the closest to the test result when the restraints were removed at around 20 minutes. Shortly afterward (21 minutes), the panel failed, correlating well with the recorded panel failure time of 21.5 minutes. The recorded temperatures of this test are shown in Figure 22. At 20 minutes, the average temperature of the fire exposed gypsum plasterboard was about $600^{\circ} \mathrm{C}$, suggesting that the gypsum plasterboard would have lost its restraining effect at this temperature. If the restraints provided by the gypsum plasterboard on the fire exposed side were kept throughout the numerical simulation, the panel failure time was 23.7 minutes. It should be pointed out that at this time, the furnace had already been switched off during the actual test, however, the steel temperatures were still increasing, whereby allowing the numerical simulation to predict panel failure after the peak fire temperature. Figure 22 also reveals that the steel temperatures on the exposed side (thermocouples 2 and 3) jumped after failure of the test specimen, indicating that the exposed gypsum plasterboard had fallen. Since thermocouples 2 and 3 had recorded much lower steel temperatures than the exposed gypsum plasterboard surface temperature (recorded by thermocouple 1) before panel failure, it may be deduced that the exposed gypsum plasterboard had remained in place before panel failure, which confirms the observation deduced from Figure 8. 


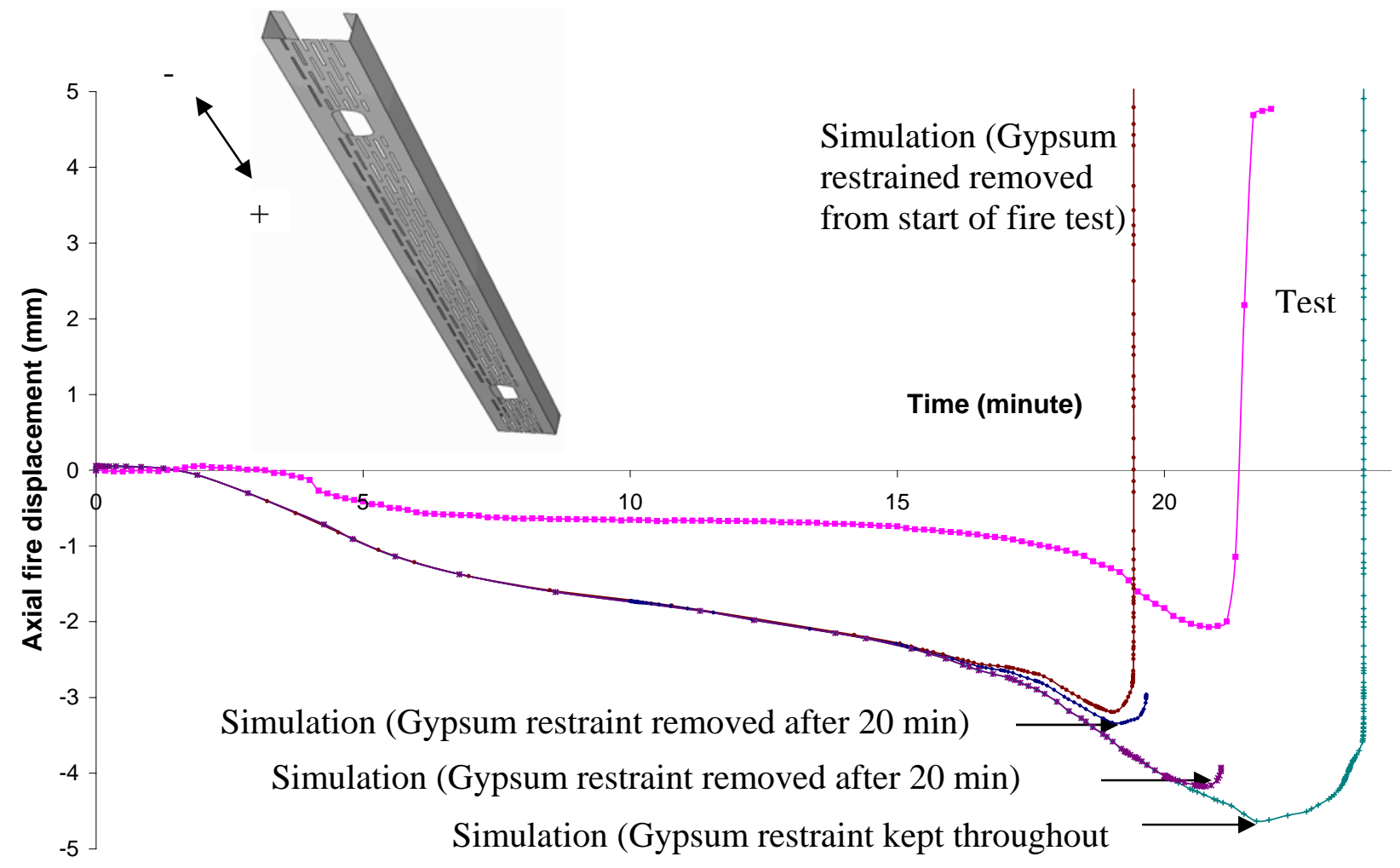

Figure 21. Comparison between test and simulation results for perforated section, gypsum plasterboard restraining effect removed at different times of simulation

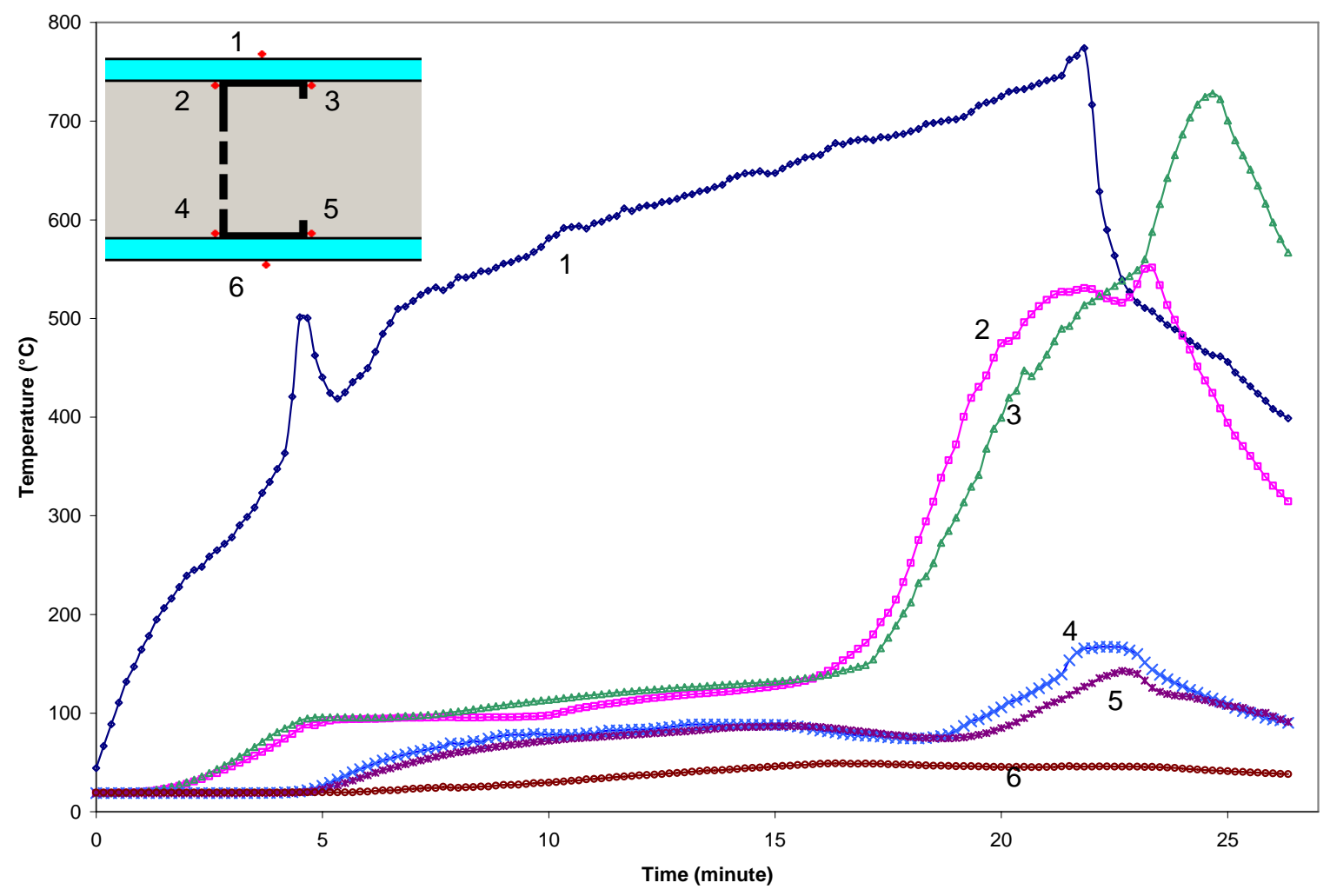

Figure 22. Temperatures in loaded, perforated steel section 


\section{CONCLUSIONS}

This paper has presented a summary of an extensive experimental, numerical and design calculation study of cold-formed thin-walled steel sections under compression in fire. The following main conclusions may be drawn:

(1) The structural behaviour of thin-walled steel sections under compression in fire is closely related to its thermal behaviour. The thermal behaviour of the steel section forming part of a panel system incorporating gypsum plasterboards and interior insulation is strongly affected by the behaviour of these two parts. Accurate simulation of temperatures attained in the steel section depends critically on accurate information of the thermal properties of these materials as well as whether the gypsum plasterboard would fall.

(2) Present knowledge is not sufficient to enable prediction of gypsum plasterboard falling under fire conditions. This does not only depend on temperatures attained in the gypsum plasterboard, but also on whether the gypsum plasterboard is loaded or not as well as its size.

(3) For design purpose, it is possible to considerably simplify the temperature distributions in thin-walled steel sections with non-uniform temperature distribution. For the steel channel section in the panel system discussed in this paper, it may be assumed that each flange of the channel section has uniform temperature and the web temperature distribution is linear. Also the existing design methods for cold-formed thin-walled steel structures may be modified to take into consideration non-uniform temperature distributions and reductions in strength and stiffness of steel at elevated temperatures.

(4) Even if gypsum plasterboard could remain intact during the entire fire exposure, it could lose its restraining effects at high temperatures. Numerical simulations and design calculations should take this into account. For the Fireline gypsum plasterboard manufactured by British Gypsum, it is reasonable to discard the gypsum plasterboard restraining effect when the average temperature in the gypsum plasterboard has reached $600^{\circ} \mathrm{C}$.

(5) By suitable modification of the ENV 1993-1-2 procedures to include the effects of non-uniform temperature distribution in the steel section, it is possible to obtain reasonable and conservative predictions of the ultimate loads and failure times of the samples tested in this study.

\section{ACKNOWLEDGEMENTS}

This paper is based on a research project supported by the UK's Engineering and Physical Science Research Council (EPSRC) under grant GR/M56319 and the PhD research project of the third author, sponsored by the Syrian Damascus University. 


\section{REFERENCES}

[1] Sultan, M.A., A model for predicting heat transfer through noninsulated unloaded steel-stud gypsum board wall assemblies exposed to fire, Fire Technology, third quarter, 1996, pp. 239-259.

[2] Alfawakhiri, F., Sultan, M.A. and MacKinnon, D.H., Fire resistance of loadbearing steel-stud walls protected with gypsum board: A review, Fire Technology, 35(4), 1999, pp. 308-335.

[3] Kodur, V.R. and Sultan, M.A., Factors governing fire resistance of loadbearing steel stud walls, NRCC-45211, National Research Council Canada, 2001.

[4] Sultan, M.A. and Lougheed, G.D., Results of fire resistance tests on full-scale gypsum board wall assemblies, Internal report No. 833, Institute of Research in Construction, National Research Council Canada, 2002.

[5] Benichou, N. and Sultan M.A., Design considerations for fire resistance of lightweight-framed assemblies, NRCC-38776, National Research Council Canada, 2003.

[6] Sakumoto, Y., Hirakawa, T., Masuda, H. and Nakamura, K., Fire resistance of walls and floors using light-gauge steel shapes, ASCE Journal of Structural Engineering, 129(11), 2003, pp. 1522-1530.

[7] CEN, Draft prENV 1991-1-2, Eurocode 1, Basis of design and actions on structures, Part 1.2: Actions on Structures - Actions on structures exposed to fire, British Standards Institution, 2000.

[8] Feng, M., Wang, Y.C. and Davies, J.M., Structural behaviour of cold-formed thin-walled short steel channel columns at elevated temperatures. Part 1: experiments. Thin-Walled Structures, 41, 2003, pp. 543-570.

[9] Feng, M., Wang, Y.C. and Davies, J.M., Structural behaviour of cold-formed thin-walled short steel channel columns at elevated temperatures. Part 2: design calculations and numerical analysis. Thin-Walled Structures, 41, 2003, pp. 571-594.

[10] Feng, M., Wang, Y.C. and Davies, J.M., Thermal performance of cold-formed thin-walled steel panel systems in fire, Fire Safety Journal, 38, 2003, pp. 365-394.

[11] Feng, M., Wang, Y.C. and Davies, J.M., An assessment of the ultimate strength of cold-formed thin-walled steel channel columns exposed to fire on one side, Fire Safety Journal, 38, 2003, pp. 679-707.

[12] Feng, M., Wang, Y.C. and Davies, J.M., A numerical imperfection sensitivity study of cold-formed thin-walled steel tubular columns at uniform elevated temperatures, Thin-Walled Structures, 44(4), 2004, pp. 533-555.

[13] Feng, M. and Wang, Y.C., An experimental study of full-scale cold-formed thin-walled steel structural panels under fire conditions, Fire Safety Journal, 40(1), 2005, pp. 43-63. 
[14] Feng, M. and Wang, Y.C., An analysis of the structural behaviour of axially loaded full-scale cold-formed thin-walled steel structural panels tested under fire conditions, Thin-Walled Structures, 43, 2005, pp. 291-332.

[15] BSI, British Standard 476, Fire Tests on Building Materials and Structures, Part 20: Method for Determination of the Fire Resistance of Elements of Construction (General Principles), British Standards Institution, 1987.

[16] ABAQUS Standard User’s Manual, Hibbit, Karlsson \& Sorensen Inc., 1998.

[17] CEN, ENV 1993-1-2, Eurocode 3; Design of steel structures, Part1.2: General rules, structural fire design, British Standards Institution, 2001.

[18] Wang H.B., Heat transfer analysis of components of construction exposed to fire, PhD thesis, University of Salford, 1995.

[19] Lawson R M., Building design using cold formed steel sections: Fire protection. The Steel Construction Institute, Publication P129, 1993.

[20] CEN, EN1993-1-3, Eurocode 3: Design of steel structures, Part 1.3: General rules, supplementary rules for cold formed thin gauge members and sheeting, British Standards Institution, 1996.

[21] BSI, British Standard: Structural use of steelwork in building, Part 5: Code of practice for design of cold formed thin gauge sections, British Standard Institution, 1998.

[22] AISI, Specification for the design of cold-formed steel structural members with commentary 1996 edition supplement No.1, Washington DC: American Iron and Steel Institute, 1999.

[23] Outinen, J., A study for the development of the design of steel structures in fire condition. Proceedings of the first international workshop on structures in fire, page 269-281, Copenhagen, 2000. 


\title{
AN EQUILIBRIUM APPROACH FOR FLEXURAL-TORSIONAL BUCKLING OF ELASTIC STEEL ARCHES
}

\author{
Y.L. $\mathrm{Pi}^{1}$, M.A. Bradford and Y.Y. Chen \\ ${ }^{1}$ The corresponding author, Senior Research Fellow, School of Civil and Environmental Engineering, \\ NSW, Sydney, NSW 2052, Australia. \\ Email: y.pi@unsw.edu.au
}

\begin{abstract}
When an arch is subjected to in-plane loading, it may suddenly deflect laterally and twist out of the plane of loading and fail in a flexural-torsional buckling mode. This paper presents a static equilibrium approach for the elastic flexural-torsional buckling of circular arches under uniform bending, or under uniform compression. Solutions for the buckling moment and buckling load are obtained in closed form, and discrepancies among existing solutions are clarified. It is found that it is reasonable to use material curvatures and twist, rather than spatial curvatures and twist, for the flexural-torsional buckling analysis of arches. First order buckling deformations provide a sufficient basis for the static equilibrium methods for the flexural-torsional buckling analysis of arches. Equilibrium of a lengthwise differential element of an arch should be considered in the analysis, and so the couplings between the lateral bending and torsional actions and resistances can be included in the differential equations of equilibrium. If the equilibrium is considered only at the cross-section, this is equivalent to treating arches as analogous with straight members, and so the coupling terms in the differential equations of equilibrium are lost.
\end{abstract}

Keywords: Arch, Bending, Buckling, Compression, Elastic, Equilibrium Approach, Flexural-Torsional

\section{INTRODUCTION}

When an arch is subjected to in-plane loading, it may suddenly deflect laterally and twist out of the plane of loading and fail in a flexural-torsional buckling mode. In general, finite element methods can be used to obtain the flexural-torsional buckling load under general conditions of in-plane loading and restraints. When a circular arch is subjected to in-plane uniform bending or to uniform compression (Figures 1(a) and 1(b)), closed form solutions for the elastic flexural-torsional buckling (Figs 1(c)(d)) can be obtained, and the buckling loads for an arch under uniform bending or uniform compression are important reference loads for the design of a steel arch [1]. The elastic flexural-torsional buckling of arches under uniform bending or under uniform compression has been studied extensively by a number of researchers [2-9] using energy or virtual work approaches. Energy and virtual approaches are suitable for systematic treatments. However, because energy and virtual approaches usually deal with strains and stress resultants, second order nonlinear strain-displacement relationships are needed [10]. Different methods are used in deriving the strain-displacement relationships [2-9] and so different second order terms for strain-displacement relationships can be obtained. As a result, the closed form solutions for flexural-torsional buckling loads derived by different researchers may differ from each other.

Static equilibrium approaches for flexural-torsional buckling analysis deal with equilibrium between external loads and internal resistances directly, and thus the second order strain-displacement relationships are not needed. In addition, since the buckled equilibrium configuration is infinitesimally close to the unbuckled equilibrium configuration, the curvatures and the buckling actions related to the first order buckling deformations are sufficient for the buckling analysis. Static equilibrium approaches have been used only by Timoshenko and Gere [2] for arches under uniform bending, and by Vlasov [11] for arches under uniform bending or under uniform compression. Timoshenko and Gere [2] considered equilibrium at the cross-section to establish the differential equations of equilibrium in the same way as for straight beams. However, in an arch, the lateral bending action and resistance are coupled with the torsional action and resistance, so that 
neither the lateral bending action and resistance nor the torsion action and resistance alone are in equilibrium. Equilibrium of a lengthwise differential element of an arch, rather than only at the cross-section, should therefore be considered, and so the method of Timoshenko and Gere [2] appears to miss the coupling terms in the differential equations of equilibrium for the buckling deformations. Vlasov [11] substituted the spatial curvatures and twist into the differential equations of equilibrium that were derived for the flexural-torsional buckling analysis of straight members. In general, however, this method is not suitable for the flexural-torsional buckling of arches, and it has been shown [4-9] that the method may lead to an incorrect flexural-torsional buckling load for arches under uniform compression.

The purpose of this paper is to use a static equilibrium approach to study the elastic flexural-torsional buckling of circular arches with doubly symmetric cross-section under uniform bending or under uniform compression, to obtain closed form solutions for the buckling moment and load, and to clarify the discrepancies that arise among existing solutions.

\section{SPATIAL AND MATERIAL CURVATURES}

The following assumptions are made in this study: (1) the Euler-Bernolli bending theory and Vlasov's torsion theory are used, so that the cross-section is assumed to remain rigid and local buckling and/or effects of distortion of the cross-section are not considered; (2) the arches are circular and of doubly symmetric uniform cross-section, so that the centroid and the shear centre of the cross-section coincide; (3) the height $D$ of the cross-section is much smaller than both the length $S$ and the radius $R$ of initial curvature of the arch, i.e. $D / S<<1$ and $D / R<<1$, which imply that the arches considered are slender; and (4) the strains are small.

A body attached curvilinear orthogonal axis system oxys is defined as follows. The axis os passes through the locus of the centroids of the cross-section of the arch and the axes $o x$ and $o y$ coincide with the principal axes of the cross-section, as shown in Figures 1-3. In the undeformed configuration, the axis $o y$ is towards to the centre of the arch. After deformation, the origin $o$ displaces $u, v, w$ in the directions of the axes $o x, o y$, and $o s$ to $o_{1}$ and the cross-sections (that are assumed to remain rigid in their plane and so do not distort) rotate through an angle $\phi$, and so the body attached curvilinear orthogonal axis system oxys moves and rotates to a new position $o_{1} x_{1} y_{1} s_{1}$ as shown in Figure 2. In general, the centroidal axis os of a circular arch has an initial curvature $\kappa_{x 0}$ about the major principal axis $o x$ (i.e. in the direction of the axis $o y$ ) as shown in Figure 1).

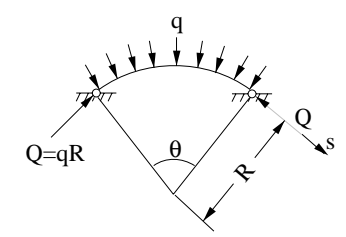

(a) Arch in uniform compression

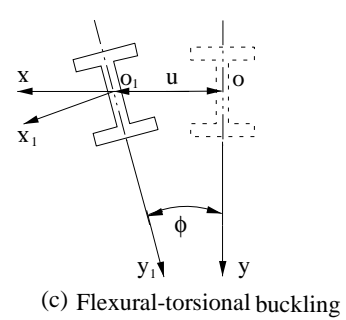

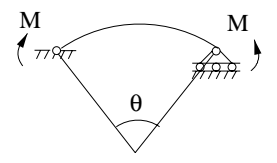

(b) Arch in uniform bending

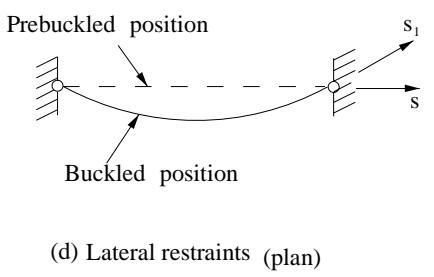

Figure 1. Flexural-torsional buckling of arches 
A basis vector $\mathbf{p}_{s}$ in the tangent direction of the axis $o$, and basis vectors $\mathbf{p}_{x}$ and $\mathbf{p}_{y}$ in the directions of the axes ox and oy (Figures 2-3) are used as the fixed reference basis. The basis vectors $\mathbf{p}_{x}, \mathbf{p}_{y}$, and $\mathbf{p}_{s}$ do not change with the deformation, but their directions change from point to point along the arch axis os. In the deformed configuration, a basis vector $\mathbf{q}_{s}$ is defined in the tangent direction of the axis $o_{1} s_{1}$, and basis vectors $\mathbf{q}_{x}$ and $\mathbf{q}_{y}$ are defined in the direction of the principal axes $o_{1} x_{1}, o_{1} y_{1}$ of the rotated cross-section at $o_{1}$ as shown in Figures 2-3. The basis vectors $\mathbf{q}_{x}, \mathbf{q}_{y}, \mathbf{q}_{s}$ are attached to the arch and move with the arch during the deformation with the vector $\mathbf{q}_{s}$ being normal to the cross-section at all times.

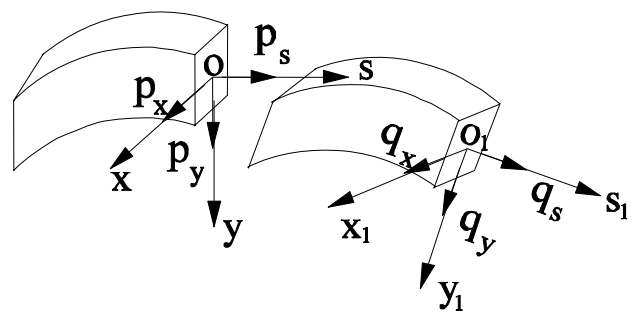

Figure 2. Basis vectors before and after buckling
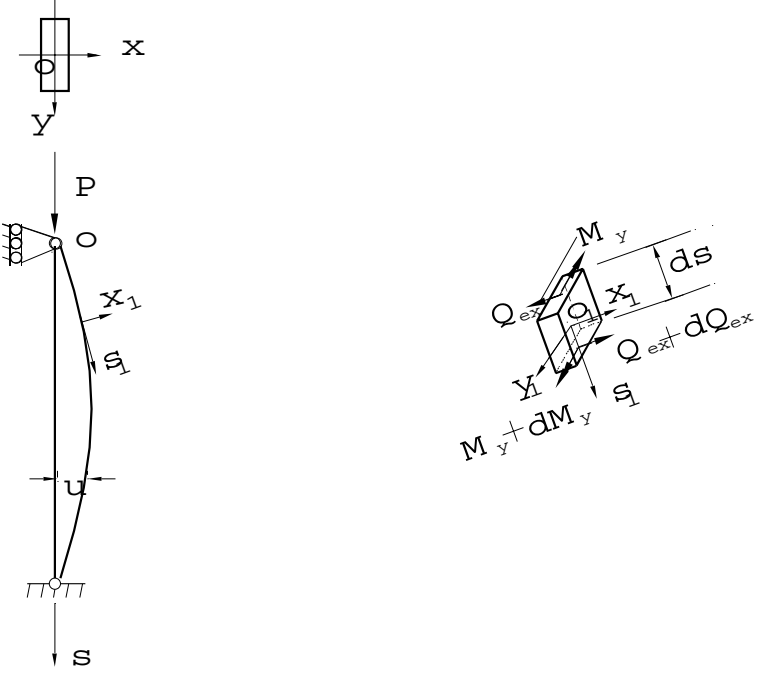

(a) Laterial buckling of column

(b) Alternative method

Figure 3. Lateral buckling of a column under uniform compression

The rotation from the basis vectors $\mathbf{p}_{x}, \mathbf{p}_{y}, \mathbf{p}_{s}$ to the basis vectors $\mathbf{q}_{x}, \mathbf{q}_{y}, \mathbf{q}_{s}$ (Figure 2) can be expressed using a rotation matrix $\mathbf{R}$ as [12-13]

$$
\mathbf{q}_{i}=\mathbf{R p}_{i} \quad(i=x, y, s)
$$

Static equilibrium methods deal with the equilibrium of external loads and internal resistances directly, and it is well known that the classical flexural-torsional buckling is characterized by the fact that, as the load passes through its critical stage, the structure passes from its unbuckled equilibrium configuration to an infinitesimally close buckled equilibrium configuration, Therefore, 
second order terms are not needed in the flexural-torsional buckling analysis for arches by static equilibrium approaches, and so a small-rotation matrix $\mathbf{R}$ is sufficient for undertaking the buckling analysis, which is given by

$$
\mathbf{R}=\left[\begin{array}{ccc}
1 & -\phi & u^{\prime} \\
\phi & 1 & \tilde{v}^{\prime} \\
-u^{\prime} & -\tilde{v}^{\prime} & 1
\end{array}\right]
$$

where $\tilde{v}^{\prime}=v^{\prime}-w \kappa_{x 0},()^{\prime}=\mathrm{d}() / \mathrm{d} s$, and the initial curvature $\kappa_{x 0}$ of the centroidal axis os of a circular is given by $\kappa_{x 0}=-1 / R$ for the arches with the upward rise as shown in Figure 1.

It can be obtained from calculus of vectors [14] that the spatial curvatures referred to the undeformed configuration and the material curvatures referred to the deformed configuration can be obtained from the rotation matrix $\mathbf{R}$ as

$$
\boldsymbol{\Omega}=\frac{\mathrm{d} \mathbf{R}}{\mathrm{d} s} \mathbf{R}^{T}+\mathbf{R} \mathbf{K}_{0} \mathbf{R}^{T} \text { and } \mathbf{K}=\mathbf{R}^{T} \frac{\mathrm{d} \mathbf{R}}{\mathrm{d} s}+\mathbf{R}^{T} \mathbf{K}_{0} \mathbf{R}
$$

where ( $)^{T}$ is the transpose of a matrix, $\mathbf{K}_{0}$ is the matrix of the initial curvatures and given by

$$
\mathbf{K}_{0}=\left[\begin{array}{ccc}
0 & 0 & 0 \\
0 & 0 & -\kappa_{x 0} \\
0 & \kappa_{x 0} & 0
\end{array}\right]
$$

while $\boldsymbol{\Omega}$ and $\mathbf{K}$ are the matrices of spatial and material curvatures and given by

$$
\boldsymbol{\Omega}=\left[\begin{array}{ccc}
0 & -\omega_{s} & \omega_{y} \\
\omega_{s} & 0 & -\omega_{x} \\
-\omega_{y} & \omega_{x} & 0
\end{array}\right] \text { and } \mathbf{K}=\left[\begin{array}{ccc}
0 & -\kappa_{s} & \kappa_{y} \\
\kappa_{s} & 0 & -\kappa_{x} \\
-\kappa_{y} & \kappa_{x} & 0
\end{array}\right]
$$

in which $\omega_{x}$ and $\omega_{y}$ are the spatial curvatures about the positive direction of the axes $o x$ and $o y$, and $\omega_{s}$ is the spatial twist about the positive direction of the os axis in the undeformed configuration; while $\kappa_{x}$ and $\kappa_{y}$ are the material curvatures about the positive direction of the axes $o_{1} x_{1}$ and $o_{1} y_{1}$, and $\kappa_{s}$ is the material twist about the positive direction of the $o_{1} s_{1}$ axis in the deformed configuration.

Substituting Eqs. (2) and (4) into Eq. (3) and ignoring second and higher order terms leads to the spatial curvatures $\omega_{x}$ and $\omega_{y}$, and the spatial twist $\omega_{s}$ as

$$
\begin{aligned}
& \omega_{x} \approx-\tilde{v}^{\prime \prime}+\kappa_{x 0}=-\tilde{v}^{\prime \prime}-\frac{1}{R} \\
& \omega_{y} \approx u^{\prime \prime}+\phi \kappa_{x 0}=u^{\prime \prime}-\frac{\phi}{R} \\
& \omega_{s} \approx \phi^{\prime}-u^{\prime} \kappa_{x 0}=\phi^{\prime}+\frac{u^{\prime}}{R}
\end{aligned}
$$

and to the material curvatures $\kappa_{x}$ and $\kappa_{y}$ and the material twist $\kappa_{s}$ as

$$
\kappa_{x} \approx-\tilde{v}^{\prime \prime}+\kappa_{x 0}=-\tilde{v}^{\prime \prime}-\frac{1}{R}
$$




$$
\begin{aligned}
& \kappa_{y} \approx u^{\prime \prime}-\phi \kappa_{x 0}=u^{\prime \prime}+\frac{\phi}{R} \\
& \kappa_{s} \approx \phi^{\prime}+u^{\prime} \kappa_{x 0}=\phi^{\prime}-\frac{u^{\prime}}{R}
\end{aligned}
$$

where ()$^{\prime \prime} \equiv \mathrm{d}^{2}() / \mathrm{d} s^{2}$.

In studies of the flexural-torsional buckling of an arch, the spatial curvatures and twist given by Eqs. (7)-(9) have been used by a number of researchers [2-3,5,11] while the material curvatures given by Eqs. (10)-(12) have been used by other researchers [4,6-9]. It is noteworthy that the equilibrium for flexural-torsional buckling of an arch should be referred to the buckled configuration. Hence, it is reasonable to use the material curvatures and twist rather than the spatial curvatures and twist for the flexural-torsional buckling analysis of arches.

\section{UNIFORM COMPRESSION}

\subsection{Buckling of Columns}

In order to compare the differences between the flexural-torsional buckling of arches and the buckling of columns under uniform compression, the buckling of a column under uniform compression is briefly summarized in the following. In the buckled configuration, the axial compressive force $P$ has the components: a lateral force $Q_{e x}$ in the direction of the axis $o_{1} x_{1}$, a lateral force $Q_{e y}$ in the direction of the axis $o_{1} y_{1}$, and an axial force $Q_{e s}$ in the direction of the axis $o_{1} \mathrm{~s}_{1}$ and they are given by

$$
\left\{\begin{array}{l}
Q_{e x} \\
Q_{e y} \\
Q_{e s}
\end{array}\right\}=\mathbf{R}^{T}\left\{\begin{array}{l}
0 \\
0 \\
P
\end{array}\right\}=\left\{\begin{array}{c}
-P u^{\prime} \\
-P v^{\prime} \\
P
\end{array}\right\}
$$

where the rotation matrix $\mathbf{R}$ is the same as that given by Eq. (2) with $\tilde{v}^{\prime}=v^{\prime}$.

The elastic lateral buckling load of a column about its minor principal axis oy can be determined by considering lateral equilibrium in the buckled configuration as shown in Figure 3. Two methods can be used to obtain the buckling load. Most researchers $[2,10,15]$ have used the method shown in Figure 3(a) and have obtained the differential equation of equilibrium for the lateral buckling as

$$
P u+E I_{y} u^{\prime \prime}=0
$$

where $E$ is Young's modulus of elasticity and $I_{y}$ is the second moment of area of the cross-section about its minor principal axis $o y$.

Alternatively, the differential equation of equilibrium for lateral buckling can be obtained by considering the lateral equilibrium of a differential element of length $\mathrm{d} s$ in the buckled configuration shown in Figure 3(b). For lateral bending equilibrium,

$$
\mathrm{d} M_{y}+Q_{e x} \mathrm{~d} s=0
$$


where the bending moment $M_{y}$ about the axis $o_{1} y_{1}$ is equal to the internal bending resistance of the cross-section $M_{i y}$ and so given by [15] $M_{y}=M_{i y}=E I_{y} u^{\prime \prime}$; and $Q_{e x}$ is the lateral component of the axial load $P$ in the buckled configuration given by Eq. (13). Hence, Eq. (15) becomes

$$
P u^{\prime}+E I_{y} u^{\prime \prime \prime}=0
$$

The solution that satisfies the kinematic boundary conditions $u_{0}=u_{S}=0$ can be assumed to be given by

$$
\frac{u}{u_{m}}=\sin \frac{n \pi s}{S}
$$

where $u_{m}$ is the maximum lateral displacement during buckling, $s$ is the coordinate in the column axis os as shown in Figure 3, $S$ is the length of the column and $n$ is the number of the buckled half waves. Substituting Eq. (17) into Eq. (14) or (16) leads to the $n$-th mode elastic flexural buckling load of a column about its minor principal axis of the cross-section $[2,15]$ given by

$$
P_{y n}=\frac{(n \pi)^{2} E I_{y}}{S^{2}}
$$

The axial compressive force $Q_{e s}$ in the direction of the axis $o_{1} s_{1}$ may produce an external torque about the axis $o_{1} s_{1}$ and so the column may buckle in a torsional mode. Consider the differential element of length $\mathrm{d} s$ and differential strip $\mathrm{d} A \mathrm{~d} s$ as shown in Figure 4, where $\mathrm{d} A$ is the cross-sectional area of the differential strip. The relative twist angle between both ends can be represented by $\mathrm{d} \phi$ (Figure 4(b)). The force acting on the differential area $\mathrm{d} A$ due to the axial compressive force $Q_{e s}$ is equal to $\mathrm{d} q_{e s}=\left(Q_{e s} / A\right) \mathrm{d} A$, where $A$ is the area of the cross-section. The distance of the differential area $\mathrm{d} A$ from the shear centre of the cross-section is given by $\rho=\sqrt{x^{2}+y^{2}}$ (Figure 4(a)) and the relative displacement of both ends of the differential strip due to the relative twist angle $\mathrm{d} \phi$ is equal to $\rho \mathrm{d} \phi$. Hence, the force $\mathrm{d} q_{e s}$ has a component $\mathrm{d} q=\mathrm{d} q_{e s}(\rho \mathrm{d} \phi / \mathrm{d} s)$ (Figure 4(b)) which exerts a torque $\mathrm{d} m_{e s}$ about the shear centre given by $\mathrm{d} m_{e s}=\mathrm{d} q \times \rho=\mathrm{d} q_{e s} \rho^{2}(\mathrm{~d} \phi / \mathrm{d} s)$, and so the total external torque $M_{e s}$ produced by the axial compressive force $Q_{e s}$ is

$$
M_{e s}=\int_{A} d m_{e s}=\int_{A} d q_{e s} \rho^{2} \frac{d \phi}{d s}=\int_{A} \frac{Q_{e s}}{A} \rho^{2} \frac{d \phi}{d s} d A=r_{0}^{2} P \phi^{\prime}
$$

where $r_{0}$ is the radius of gyration of the cross-section and given by

$$
r_{0}=\sqrt{\frac{\int_{A} \rho^{2} \mathrm{~d} A}{\mathrm{~A}}}=\sqrt{\frac{\int_{A}\left(x^{2}+\mathrm{y}^{2}\right) \mathrm{d} A}{\mathrm{~A}}}=\sqrt{\frac{I_{x}+I_{y}}{\mathrm{~A}}}
$$

and in which $I_{x}$ is the second moment of area of the cross-section about its major principal axis $o x$.

The internal torsional resistance is given by [15]

$$
M_{i s}=-G J \phi^{\prime}+E I_{w} \phi^{\prime \prime \prime}
$$


where $G$ is the elastic shear modulus, and $J$ and $I_{w}$ re the torsion and warping constants of the cross-section. The axial force $Q_{e s}=P$ is given by Eq. (13). During torsional buckling, the resultant of the external and internal torques vanishes and so

$$
M_{e s}+M_{i s}=r_{0}^{2} P \phi^{\prime}-G J \phi^{\prime}+E I_{w} \phi^{\prime \prime \prime}=0
$$

which is the differential equation of equilibrium for the torsional buckling of a column under uniform compression [2,15].

The solution that satisfies the kinematic boundary conditions $\phi_{0}=\phi_{S}=0$ can be assumed to be given by

$$
\frac{\phi}{\phi_{m}}=\sin \frac{n \pi s}{S}
$$

where $\phi_{m}$ is the maximum twist angle of the cross-section during buckling. Substituting Eq. (23) into Eq. (22) leads to the $n$-th mode elastic torsional buckling load of a column about its shear centre axis [2,15]given by

$$
P_{s n}=\frac{1}{r_{0}^{2}}\left(G J+\frac{(n \pi)^{2} E I_{w}}{S^{2}}\right)
$$

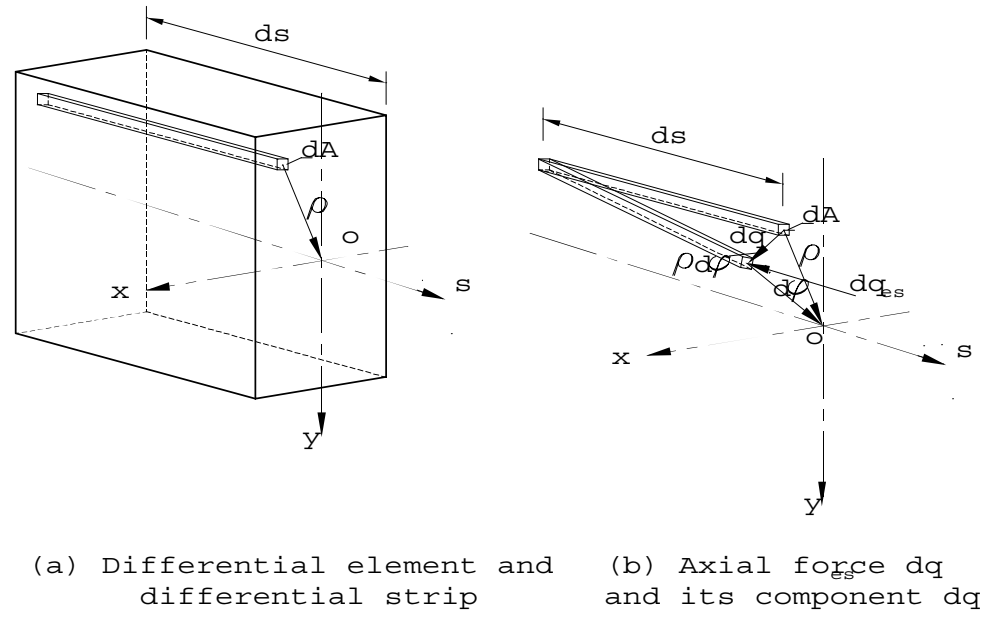

Figure 4. Torsional buckling of a column under uniform compression

\subsection{Flexural-Torsional Buckling of Arches}

When a pin-ended arch with a in-plane radial load $q$ acting at the centroid of the cross-section, uniformly distributed around the arch axis, the arch is subjected primarily to a uniform compressive force $Q=q R$ as shown in Figure 1(a). In this study, it is assumed that the directions of the radial loads do not change and remain parallel to their initial directions during deformation. Under this action, the arch may buckle out of the plane of loading and fail in a flexural-torsional mode. Similarly to the case of a column, in the buckled configuration of an arch, the axial compressive force $Q$ in the direction of the axis os has an axial compressive component $Q_{e s}=Q$ in the direction of the axis $o_{1} s_{1}$, and a lateral component $Q_{e x}=-Q u^{\prime}$ in the direction of the axis $o_{1} x_{1}$. The force $Q_{e s}$ 
also produces an external torsional moment action $M_{e s}$ about the axis $o_{1} s_{1}$ of the arch and is given by $[7,9]$

$$
M_{e s}=r_{0}^{2} Q_{e s} \kappa_{s}=r_{0}^{2} Q\left(\phi^{\prime}-\frac{u^{\prime}}{R}\right)
$$

while the total internal torsional resistance $M_{i s}$ can be obtained by combining the uniform and warping torsional resistances as $[9,11]$

$$
M_{i s}=-G J\left(\phi^{\prime}-\frac{u^{\prime}}{R}\right)+E I_{w}\left(\phi^{\prime \prime \prime}-\frac{u^{\prime \prime \prime}}{R}\right)
$$

In a column, the torsional action is in equilibrium with the torsional resistance as shown in the previous section. However, in an arch, the torsional action couples with the lateral bending action while the torsional resistance also couples with the lateral bending resistance. The resultant torsional moment at the cross-section is then given by

$$
M_{s}=M_{e s}+M_{i s}=r_{0}^{2} Q\left(\phi^{\prime}-\frac{u^{\prime}}{R}\right)-G J\left(\phi^{\prime}-\frac{u^{\prime}}{R}\right)+E I_{w}\left(\phi^{\prime \prime \prime}-\frac{u^{\prime \prime \prime}}{R}\right)
$$

which does not vanish.

The resultant lateral bending moment at the cross-section is equal to the lateral bending resistance $M_{i y}$ of the cross-section about the axis $o_{1} y_{1}$ and given by

$$
M_{y}=M_{i y}=-E I_{y} \kappa_{y}=-E I_{y}\left(u^{\prime \prime}+\frac{\phi}{R}\right) .
$$

For lateral moment equilibrium, it can be deduced from Figure 5 that

$$
\left(M_{y}+\mathrm{d} M_{y}\right)-M_{y}+2 M_{s} \sin \frac{\mathrm{d} \theta}{2}+Q_{e x} \mathrm{~d} s=\mathrm{d} M_{y}+\frac{M_{s}}{R} \mathrm{~d} s+Q_{e x} \mathrm{~d} s=0
$$

which leads to the differential equation of equilibrium for the lateral deformations as

$$
\frac{\mathrm{d} M_{y}}{\mathrm{~d} s}+\frac{M_{s}}{s} \frac{1}{R}+Q_{e x}=0
$$

For the torsional moment equilibrium, it can be shown from Figure 5 that

$$
\left(M_{s}+\mathrm{d} M_{s}\right)-M_{s}-2 M_{y} \sin \frac{\mathrm{d} \theta}{2}=\mathrm{d} M_{s}-M_{y} \frac{\mathrm{ds}}{R}=0
$$

which leads to the differential equation of equilibrium for the torsional deformations

$$
\frac{\mathrm{d} M_{s}}{\mathrm{~d} s}-\frac{M_{y}}{R}=0
$$




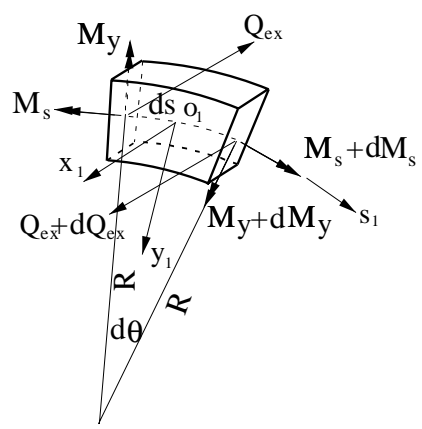

Figure 5. Buckling equilibrium of an arch element under uniform compression

It can be seen that the alternative method for the lateral buckling analysis for columns discussed in the previous section can be used for the flexural-torsional buckling analysis for arches. However, if the first method for the lateral buckling analysis of columns is employed for the flexural-torsional buckling of arches, the lateral bending action $M_{e y}=-Q u$ at the cross-section that is produced by the axial compressive force $Q$ will directly be used for the lateral bending equilibrium. Because of the coupling between the lateral bending and torsional actions, the lateral bending action $M_{e y}$ has a spurious component that will falsely contribute to the torsional action. Hence, to avoid the spurious torsional action, the alternative method is preferred and the lateral component $Q_{e x}$ of the axial compressive force $Q$ is used directly for the lateral bending equilibrium analysis of arches under uniform compression.

\subsection{Solutions for Flexural-Torsional Buckling}

Substituting $Q_{e x}=-Q u^{\prime}$ and the expressions for $M_{s}$ and $M_{y}$ given by Eqs (27)-(28) into Eqs (30) and (32) leads to the differential equations of equilibrium given by

$$
\left[E I_{y}\left(u^{\prime \prime}+\frac{\phi}{R}\right)\right]^{\prime}+G J\left(\phi^{\prime}-\frac{u^{\prime}}{R}\right) \frac{1}{R}-\left[E I_{w}\left(\phi^{\prime \prime}-\frac{u^{\prime \prime}}{R}\right) \frac{1}{R}\right]^{\prime}+Q\left[u^{\prime}-r_{0}^{2}\left(\phi^{\prime}-\frac{u^{\prime}}{R}\right) \frac{1}{R}\right]=0
$$

for the lateral deformations, and

$$
E I_{y}\left(u^{\prime \prime}+\frac{\phi}{R}\right) \frac{1}{R}-\left[G J\left(\phi^{\prime}-\frac{u^{\prime}}{R}\right)\right]^{\prime}+\left[E I_{w}\left(\phi^{\prime \prime}-\frac{u^{\prime \prime}}{R}\right)\right]^{\prime \prime}+\left[r_{0}^{2} Q\left(\phi^{\prime}-\frac{u^{\prime}}{R}\right)\right]^{\prime}=0
$$

for the torsional deformations.

The $n$-th mode buckled shapes of a pin-ended arch (Figure 1(c)) can be assumed to be given by

$$
\frac{u}{u_{m}}=\frac{\phi}{\phi_{m}}=\sin \frac{n \pi S}{S}
$$


which satisfy the boundary conditions at both ends of the arch $u_{0}=u_{S}=\phi_{0}=\phi_{S}=0$. Substituting Eq. (35) into Eqs (33) and (34) leads to the homogeneous equations

$$
\left[\begin{array}{ll}
k_{11} & k_{12} \\
k_{21} & k_{22}
\end{array}\right]\left\{\begin{array}{l}
u_{m} \\
\phi_{m}
\end{array}\right\}=\left\{\begin{array}{l}
0 \\
0
\end{array}\right\}
$$

where the coefficients $k_{11}, k_{12}, k_{21}$, and $k_{22}$ are given by

$$
\begin{aligned}
& k_{11}=\left[1+a_{n}^{2} b_{n}^{2}-\left(1+a_{n}^{2} b_{n}^{2} \frac{P_{y n}}{P_{s n}}\right) \frac{Q}{P_{y n}}\right] P_{y n} \\
& k_{12}=k_{21}=-\left(\frac{a_{n}}{b_{n}}+a_{n} b_{n}-a_{n} b_{n} \frac{P_{y n}}{P_{s n}} \frac{Q}{P_{y n}}\right) M_{y s n} \\
& k_{22}=\left(1+\frac{a_{n}^{2}}{b_{n}^{2}}-\frac{P_{y n}}{P_{s n}} \frac{Q}{P_{y n}}\right) r_{0}^{2} P_{s n}
\end{aligned}
$$

and in which the parameters $a_{n}$ and $b_{n}$ are defined by

$$
a_{n}=\frac{S}{n \pi R} \text { and } b_{n}=\frac{n \pi M_{y s n}}{P_{s n} S}
$$

and $M_{y s n}$ is the $n$-th mode elastic flexural-torsional buckling moment of the corresponding simply supported beam of length $S$ under uniform bending [2,15] given by

$$
M_{y s n}=\sqrt{r_{0}^{2} P_{y n} P_{s n}} .
$$

Eq. (36) has non-trivial solutions for $u_{m}$ and $\phi_{m}$ when the determinant of its coefficient matrix vanishes, i.e.

$$
k_{11} k_{22}-k_{12} k_{21}=0 \text {, }
$$

which leads to the equation for the elastic flexural-torsional buckling load of a pin-ended arch under uniform compression as

$$
\left(\frac{Q}{P_{y n}}\right)^{2}-\left[\left(1+\frac{a_{n}^{2}}{b_{n}^{2}}\right) \frac{P_{s n}}{P_{y n}}+\left(1-a_{n}^{2}\right)^{2} \frac{Q}{P_{y n}}\right]+\left(1-a_{n}^{2}\right)^{2} \frac{P_{s n}}{P_{y n}}=0
$$

which is the same as that of Pi and Bradford [9] using an energy method.

\subsection{Flexural Buckling or Torsional Buckling of Arches}

It can be seen from Eqs (33), (34) and (43) that if a pin-ended arch under uniform compression buckles out-of-plane, it will buckle in a flexural-torsional mode. This is different from a column under uniform compression which may buckle only in a flexural mode or in a torsional mode. 
However, if the torsional deformations of a pin-ended arch under uniform compression are fully prevented $\left(\phi=\phi^{\prime}=\phi^{\prime \prime}=\phi^{\prime \prime \prime}=0\right)$, the arch may buckle in a flexural mode and the differential equation of equilibrium for flexural buckling of the arch can be obtained from Eq. (33) by substituting $\phi=\phi^{\prime}=\phi^{\prime \prime}=\phi^{\prime \prime \prime}=0$ as

$$
\left(E I_{y} u^{\prime \prime}\right)^{\prime}-G J \frac{u^{\prime}}{R^{2}}+E I_{w} \frac{u^{\prime \prime \prime}}{R^{2}}+Q\left(u^{\prime}+r_{0}^{2} \frac{u^{\prime}}{R^{2}}\right)=0
$$

when $R \rightarrow \infty$, Eq. (44) becomes

$$
\left(E I_{y} u^{\prime \prime}\right)^{\prime}+Q u^{\prime}=0
$$

which is equivalent to Eq. (14) or (16) for the flexural buckling of a column under uniform compression.

By substituting the $n$-th mode buckling shapes given by Eq. (17) into Eqs (44), the flexural buckling load of an arch under uniform compression can be obtained as

$$
Q_{y n}=\frac{R^{2}}{R^{2}+r_{0}^{2}}\left(P_{y n}+\frac{r_{0}^{2}}{R^{2}} P_{s n}\right)
$$

which is higher than the $n$-th mode flexural buckling load $P_{y n}$ of a column under uniform compression [2,15] given by Eq. (18). When $R \rightarrow \infty$, Eq. (46) becomes the flexural buckling load of a column of length $S$

$$
Q_{y n}=P_{s n} .
$$

If the lateral deformations of a pin-ended arch under uniform compression are fully prevented ( $u=u^{\prime}=u^{\prime \prime}=u^{\prime \prime \prime}=0$ ), the arch may buckle in a torsional mode and the differential equation of equilibrium for torsional buckling of the arch can be obtained from Eq. (34) by substituting $u=u^{\prime}=u^{\prime \prime}=u^{\prime \prime \prime}=0$ as

$$
E I_{y} \frac{\phi}{R^{2}}-\left[G J \phi^{\prime}\right]^{\prime}+\left[E I_{w} \phi^{\prime \prime}\right]^{\prime \prime}+\left[r_{0}^{2} Q \phi^{\prime}\right]^{\prime}=0
$$

When $R \rightarrow \infty$, Eq. (48) becomes

$$
-\left[G J \phi^{\prime}\right]^{\prime}+\left[E I_{w} \phi^{\prime \prime}\right]^{\prime \prime}+\left[r_{0}^{2} Q \phi^{\prime}\right]^{\prime}=0
$$

which is equivalent to Eq. (22) for the torsional buckling of a column under uniform compression.

By substituting the $n$-th buckling shapes given by Eq. (23) into Eq. (48), the torsional buckling load of an arch under uniform compression can be obtained as

$$
Q_{s n}=\frac{E I_{y} a_{n}^{2}}{r_{0}^{2}}+P_{s n}
$$


which is higher than the $n$-th mode torsional buckling load of a column under uniform compression [2,15] given by Eq. (24). When $R \rightarrow \infty, a_{n} \rightarrow 0$ and Eq. (50) becomes the torsional buckling load of a column of length $S$

$$
Q_{s n}=P_{s n}
$$

\subsection{Comparisons}

When the radius of gyration of the cross-section $r_{0}$ is very small such as for a narrow rectangular section, the effects of the external torsional moment $M_{e s}$ given by Eq. (25) produced by the axial compressive force become very small compared with those of the external lateral force $Q_{e x}$ given by Eq. (13). In this case, the effects of the torsional moment $M_{e s}$, i.e. the terms in the differential equations of equilibrium (33) and (34) containing the factor $r_{0}^{2}$ can be ignored, and so the flexural-torsional buckling load reduces to

$$
\frac{Q}{P_{y n}}=\frac{\left(1-a_{n}^{2}\right)^{2}}{1+a_{n}^{2} / b_{n}^{2}}
$$

which is the same as that obtained by Timoshenko and Gere [2] for arches with a narrow rectangular section, and by Papangelis and Trahair [4], when energy methods were used.

A number of researchers [3-9] have used energy or virtual work methods to obtain closed form solutions for the flexural-torsional buckling load of arches under uniform compression. Solutions for the first mode flexural-torsional buckling load of arches under uniform compression given by Eq. (43) are compared with the solutions by other researchers [3-9,11] in Figure 6 for arches with an Australian steel cross-section 250UB37 [16] $\left(A=4750 \mathrm{~mm}^{2}, I_{x}=55.7 \times 10^{6} \mathrm{~mm}^{4}, I_{y}=5.66 \times\right.$ $\left.10^{6} \mathrm{~mm}^{4}, \quad J=158 \times 10^{3} \mathrm{~mm}^{4}, I_{w}=85.2 \times 10^{9} \mathrm{~mm}^{6}, E=200,000 \mathrm{MPa}, v=0.3\right)$ and with a length $S$ $=2000 \mathrm{~mm}$. It can be seen that there are some differences between the results. In particular, the result of Yoo [3] has a substantial discrepancy with the other results [4-9]. Although generally the energy or virtual work methods used by most researchers [4-9] were correct, the second order terms in the nonlinear strains differed from each other. In addition, the treatments for the external torsional moment were also somewhat different from each other. These may be the sources of small discrepancies among the solutions of [4-9]. Yoo [3] substituted curvature expressions for an arch directly into the strain energy and potential energy expressions that were derived for straight members, and this is probably the source of the large differences between Yoo's result and that of others. It is worth pointing out that Vlasov [11] in his study assumed that uniform compression in arches was produced by hydrostatic loads, although his result has been benchmarked by a number of researchers [3-9] as being the case for the radial loads discussed in this study. Vlasov [11] substituted the curvature $\kappa_{y}$ and twist $\kappa_{s}$ into the differential equations of equilibrium that were derived for straight members, and obtained the differential equations of equilibrium as

$$
E I_{y} \kappa_{y}^{\prime \prime}+G J \kappa_{s}^{\prime} \frac{1}{R}-E I_{w} \kappa_{s}^{\prime \prime \prime} \frac{1}{R}+Q \kappa_{y}=0
$$

for the lateral deformations, and

$$
E I_{y} \kappa_{y} \frac{1}{R}-G J \kappa_{s}^{\prime}+E I_{w} \kappa_{s}^{\prime \prime \prime}+r_{0}^{2} Q \kappa_{s}^{\prime}=0
$$


for the torsional deformations. It can be seen from Eqs. (53) and (54) that the coupling between the internallateral bending resistance and the internal torsional resistance was considered. However, the coupling term contributed by the external torsional moment $M_{e s}$ to the lateral bending deformations was missed in Eq. (53). In addition, direct substitution of curvature $\kappa_{y}$ leads to a lateral force term $Q \kappa_{y}$ in Eq. (53). By substituting $\kappa_{y}$ given by Eq. (11), $Q \kappa_{y}=Q\left(u^{\prime \prime}+\phi / R\right)$, which contains a lateral force $Q \phi / R$. In the present study and in most other studies [2-9], it is assumed that the directions of the radial uniformly distributed loads do not change but always remain parallel to the initial directions during buckling and so the lateral force $Q \phi / R$ does not exist for this load case. However, the directions of hydrostatic loads change during buckling. Hence, the lateral force $Q \phi / R$ does exist and may be understood as the contribution of the horizontal component of hydrostatic loads to the lateral resistance. It is therefore argued that the lateral force $Q \phi / R$ is the major source of the large differences of the result of Vlasov [11] from those of the other researchers [4-9].

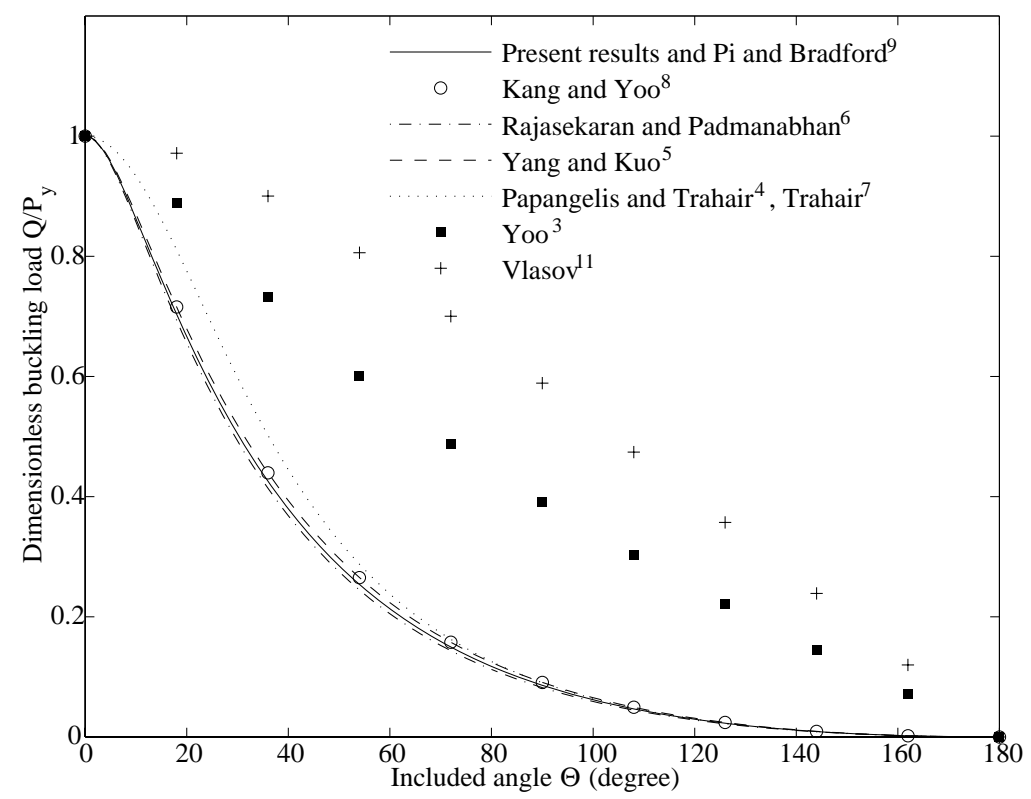

Figure 6. Comparisons of results for flexural-torsional buckling under uniform compression

It can also be seen from Figure 6 that the flexural-torsional buckling load of a pin-ended arch under uniform compression is lower than both the flexural buckling load and the torsional buckling load of a corresponding column.

\section{UNIFORM BENDING}

\subsection{Method of Timoshenko and Gere}

When an arch simply supported in-plane and pin-ended laterally is subjected to in-plane equal and opposite bending moments $M$ at both ends as shown in Figure 1(b), the arch is under uniform bending. Under this action, the arch may also buckle out of the plane of loading and fail in a flexural-torsional mode. Because the ends of the arch are free to move together and apart in the plane of loading for this special case, the arch can also be considered as a beam curved in elevation. In the buckled configuration, the in-plane uniform bending moment $M$ has the components: an in-plane bending moment $M_{e x}$ about the axis $o_{1} x_{1}$, a lateral bending moment $M_{e y}$ about the axis $o_{1} y_{1}$, and a torsional moment $M_{e s}$ about the axis $o_{1} s_{1}$ and given by 


$$
\left\{\begin{array}{l}
M_{e x} \\
M_{e y} \\
M_{e s}
\end{array}\right\}=\mathbf{R}^{T}\left\{\begin{array}{c}
M \\
0 \\
0
\end{array}\right\}=\left\{\begin{array}{c}
M \\
-M \phi \\
M u^{\prime}
\end{array}\right\}
$$

Timoshenko and Gere [2] studied the flexural-torsional buckling of a circular arch with a narrow rectangular cross-section under uniform bending. The warping moment resistance of a narrow rectangular cross-section is very small and so was ignored in their study. Timoshenko and Gere [2] considered equilibrium in the buckled configuration as shown in Figure 7. If the warping moment resistance is considered, the solution of Timoshenko and Gere [2] can be generalized in the following. For lateral equilibrium, the sum of the external bending action $M_{e y}$ and the internal bending resistance $M_{i y}$ vanishes, i.e.

$$
M_{e y}+M_{i y}=0
$$

Substituting $M_{e y}$ given by Eq. (55) and $M_{i y}$ given by Eq. (28) into Eq. (56) leads to the differential equation of equilibrium for lateral deformations given by

$$
M \phi+E I_{y}\left(u^{\prime \prime}+\frac{\phi}{R}\right)=0 .
$$

For torsional equilibrium, the sum of the external torsional action $M_{e s}$ and the internal torsional resistance $M_{i s}$ as vanishes, i.e.

$$
M_{e s}+M_{i s}=0 .
$$

Substituting $M_{e s}$ given by Eq. (55) and $M_{i s}$ given by Eq. (26) into Eq. (58) leads to the differential equation of equilibrium for torsional deformations as

$$
M u^{\prime}-G J\left(\phi^{\prime}-\frac{u^{\prime}}{R}\right)+\left[E I_{w}\left(\phi^{\prime \prime}-\frac{u^{\prime \prime}}{R}\right)\right]^{\prime}=0
$$

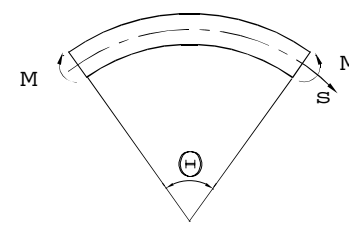

(a) Arch

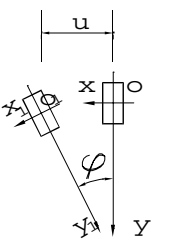

(b) Flexural-torsional buckling

Figure 7. Timoshenko's equilibrium method 


\subsection{Flexural-Torsional Buckling of Arches}

It can be seen that Timoshenko and Gere [2] treated the flexural-torsional buckling of an arch under uniform bending in the same way as for the flexural-torsional buckling of a beam under uniform bending. However, because of the curved shape, the lateral bending action necessarily couples with the torsion action and the lateral bending resistance necessarily couples with the torsion resistance, and the coupling terms were missed in the differential equations of equilibrium (57) and (59).

In the present study, the lateral and torsional equilibrium of a differential element of length $\mathrm{d} s$ in the buckled configuration is considered as shown in Figure 8. The resultant lateral bending moment $M_{y}$ at the cross-section is equal to the sum of the lateral bending action $M_{e y}$ given by Eq. (55) and internal bending resistance $M_{i y}$ given by Eq. (28), and given by

$$
M_{y}=M_{e y}+M_{i y}=-M \phi-E I_{y}\left(u^{\prime \prime}+\frac{\phi}{R}\right)
$$

which does not vanish.

The resultant torsional moment $M_{s}$ at the cross-section is given by combining the external torsional moment $M_{e s}$ given by Eq. (55) and internal torsional resistance $M_{i s}$ given by Eq. (26) as

$$
M_{s}=M_{e s}+M_{i s}=M u^{\prime}-G J\left(\phi^{\prime}-\frac{u^{\prime}}{R}\right)+E I_{w}\left(\phi^{\prime \prime \prime}-\frac{u^{\prime \prime \prime}}{R}\right)
$$

which also does not vanish.

For the lateral moment equilibrium, it can be shown from Figure 8 that

$$
\left(M_{y}+\mathrm{d} M_{y}\right)-M_{y}+2 M_{s} \sin \frac{\mathrm{d} \theta}{2}=\mathrm{d} M_{y}+M_{s} \frac{\mathrm{ds}}{R}=0
$$

from which the differential equation of equilibrium for lateral deformations becomes

$$
\frac{\mathrm{d} M_{y}}{\mathrm{~d} s}+\frac{M_{s}}{R}=0
$$

For the torsional moment equilibrium, it can be shown from Figure 8 that

$$
\left(M_{s}+\mathrm{d} M_{s}\right)-M_{s}-2 M_{y} \sin \frac{\mathrm{d} \theta}{2}=\mathrm{d} M_{s}-M_{y} \frac{\mathrm{ds}}{R}=0
$$

from which the differential equation of equilibrium for torsional deformations becomes

$$
\frac{\mathrm{d} M_{s}}{\mathrm{~d} s}-\frac{M_{y}}{R}=0
$$




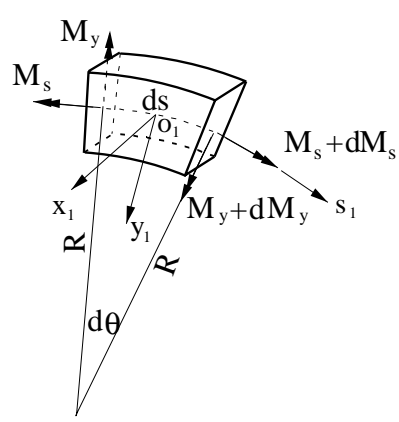

Figure 8. Buckling equilibrium of an arch element under uniform bending

\subsection{Solution for Flexural-Torsional Buckling Moment}

By substituting Eqs (60) and (61) into Eqs (63) and (65), the differential equations of equilibrium (63) and (65) become

$$
\left[E I_{y}\left(u^{\prime \prime}+\frac{\phi}{R}\right)\right]^{\prime}+G J\left(\phi^{\prime}-\frac{u^{\prime}}{R}\right) \frac{1}{R}-\left[E I_{w}\left(\phi^{\prime \prime}-\frac{u^{\prime \prime}}{R}\right)\right]^{\prime} \frac{1}{R}+(M \phi)^{\prime}-\frac{M u^{\prime}}{R}=0
$$

for the lateral deformations, and

$$
E I_{y}\left(u^{\prime \prime}+\frac{\phi}{R}\right) \frac{1}{R}-\left[G J\left(\phi^{\prime}-\frac{u^{\prime}}{R}\right)\right]^{\prime}+\left[E I_{w}\left(\phi^{\prime \prime}-\frac{u^{\prime \prime}}{R}\right)\right]^{\prime \prime}+M u^{\prime \prime}+\frac{M \phi}{R}=0
$$

for the torsional deformations. The $n$-th buckled shapes of the arch are also assumed to be given by Eq. (35). Substituting Eq. (35) into Eqs (66) and (67) yields the homogeneous equations (36). In this case, the coefficients $k_{11}, k_{12}, k_{21}$, and $k_{22}$ are given by

$$
\begin{aligned}
k_{11} & =\left(1+a_{n}^{2} b_{n}^{2}+a_{n} b_{n} \frac{M}{M_{y s n}}\right) P_{y n}, \\
k_{12}=k_{21} & =-\left(\frac{a_{n}}{b_{n}}+a_{n} b_{n}+\frac{M}{M_{y s n}}\right) M_{y s n}, \\
k_{22} & =\left(1+\frac{a_{n}^{2}}{b_{n}^{2}}+\frac{a_{n}}{b_{n}} \frac{M}{M_{y s n}}\right) r_{0}^{2} P_{s n} .
\end{aligned}
$$

In the same way as for arches under uniform compression, Eq. (36) has non-trivial solutions for $u_{m}$ and $\phi_{m}$ when the determinant of its coefficient matrix vanishes, i.e.

$$
k_{11} k_{22}-k_{12} k_{21}=0 \text {, }
$$


which leads to the equation for the elastic flexural-torsional buckling moment of an arch under uniform bending as

$$
\left(\frac{M}{M_{y s n}}\right)^{2}+\left(a_{n} b_{n}+\frac{a_{n}}{b_{n}}\right) \frac{M}{M_{y s n}}-\left(1-a_{n}^{2}\right)=0
$$

which is consistent with those of Vlasov [1] and of Rajasekaran and Padmanabhan [6].

\subsection{Comparisons}

The solution for the first mode elastic flexural-torsional buckling moment of in-plane simply supported and laterally pin-ended circular arches under uniform bending given by Eq. (71) is compared with the solutions obtained by other researchers [3-9,11] in Figure 9 for arches with an Australian steel cross-section 250UB37 [16] and a length $S=2000 \mathrm{~mm}$. The solutions of Papangelis and Trahair [4], Yang and Kuo [5], Trahair [7], Kang and Yoo [8] and Pi and Bradford [9] have small discrepancies from each other. The solution of Yoo [3] is significantly different from the other solutions[4-9]. Again, most of solutions [4-9] were correctly based on energy or virtual work methods, but different second order nonlinear strains lead to small discrepancies amongst them. Yoo [3] again used an analogy of arches with straight members, and so his solution resulted had large discrepancies with other solutions 4-9].

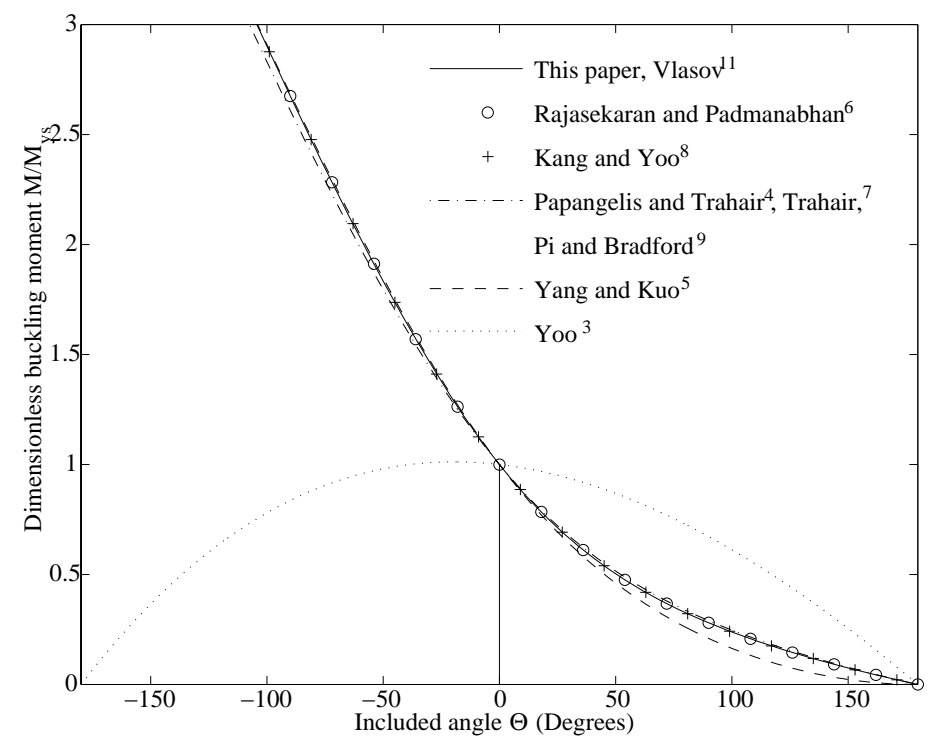

Figure 9. Comparisons of results for flexural-torsional buckling under uniform bending

Vlasov [11] substituted the curvature $\kappa_{y}$ and twist $\kappa_{s}$ into differential equations of equilibrium that were derived for the flexural-torsional buckling analysis of straight members, and considered the coupling between the internal lateral bending resistance and the internal torsional resistance. Because of the symmetric nature of the external lateral bending moment and resistance, and the torsional moment and resistance under uniform bending, Vlasov's method for the flexural-torsional buckling of arches under uniform bending is analogous to the present analysis. When the warping resistance is ignored, the solution of Eq. (71) reduces to that of Timoshenko and Gere [2]. However, as noted, since Timoshenko and Gere [2] considered equilibrium in the same way as for straight beams only at the cross-section, some coupling terms were lost in the differential equations of equilibrium. 
It can also be seen from Figure 9 that the flexural-torsional buckling moment of an arch under positive uniform bending as shown in Figure 1(b) is lower than that of a corresponding beam, while the flexural-torsional buckling moment of an arch under negative uniform bending (the end moments are opposite to those of Figure 1(b)) is higher than that of a corresponding beam.

\section{CONCLUSIONS}

This paper has used a rational static equilibrium approach to investigate the elastic flexural-torsional buckling of circular arches under uniform compression or under uniform bending. Solutions for the buckling moment and the buckling load have been obtained in closed form, and discrepancies among the existing solutions have been clarified.

It has been found that it is reasonable to use material curvatures and twist, rather than spatial curvatures and twist, for the flexural-torsional buckling analysis of arches. First order buckling deformations are sufficient for static equilibrium methods in the flexural-torsional buckling analysis of arches. When a rational static equilibrium approach is used for the flexural-torsional buckling analysis, equilibrium of a differential element should be considered and so couplings between the lateral bending action and resistance and the torsional action and resistance can be included in the differential equations of equilibrium. If the equilibrium is considered only at the cross-section, the coupling terms in the differential equations of equilibrium will be lost. A static equilibrium approach of substituting the lateral curvature and twist into the differential equations of equilibrium for the flexural-torsional buckling analysis of straight members is an analogy of arches with straight members, which should not be used for the flexural-torsional buckling analysis for arches since it may lead to incorrect results.

The flexural-torsional buckling load of a pin-ended arch under uniform compression is lower than both the flexural buckling load and the torsional buckling load of a corresponding column. A pin-ended arch under uniform compression may buckle in a flexural mode if torsional deformations are fully prevented, or may buckle in a torsional mode if lateral deformations are fully prevented. They are higher than their counterparts of a corresponding column. The flexural-torsional buckling moment of an arch under positive uniform bending is lower than that of a corresponding beam, while the flexural-torsional buckling moment of an arch under negative uniform bending is higher than that of a corresponding beam.

\section{ACKNOWLEDGEMENT}

This work has been supported by a Federation Fellowship, and a Discovery Project awarded to the second author, and a Discovery Project awarded to the first author, by the Australian Research Council.

\section{REFERENCES}

[1] Pi YL, Trahair NS, Out-of-plane inelastic buckling and strength of steel arches. Journal of Structural Engineering, ASCE 1998;124(2):174-183. 
[2] Timoshenko SP, Gere JM. Theory of elastic stability, 2nd Edition New York, USA: McGraw-Hill, 1961.

[3] Yoo CH. Flexural-torsional stability of curved beams. Journal of the Engineering Mechanics Division, ASCE 1982;108(EM6):1351-1369.

[4] Papangelis JP, Trahair NS. Flexural-torsional buckling of arches. Journal of Structural Engineering, ASCE 1987;113(4):889-906.

[5] Yang YB, Kuo SR. Effects of curvature on stability of curved beams. Journal of Structural Engineering, ASCE 1987;113(6):821-841.

[6] Rajasekaran S, Padmanabhan S. Equations of curved beams. Journal of Engineering Mechanics, ASCE 1989;115(5):1094-1111.

[7] Trahair NS. Flexural-torsional buckling of structures, London, UK: E \& FN Spon, 1993.

[8] Kang YJ, Yoo CH. Thin-walled curved beams. II: Analytical solutions for buckling of arches. Journal of Engineering Mechanics, ASCE 1994;120(10):2102-2125.

[9] Pi YL, Bradford MA. Elastic flexural-torsional buckling of continuously restrained arches. International Journal of Solids and Structures 2002;128(6):719-727.

[10] Pi YL, Bradford MA. Effects of approximations in analysis of beams of open thin-walled cross-section: 1. Flexural-torsional stability. International Journal for Numerical Methods in Engineering 2001; 51(7):757-772.

[11] Vlasov VZ. Thin-walled elastic beams, 2nd Edition. Jerusalem, Israel: Israel Program for Scientific Translation, 1961.

[12] Pi YL, Trahair NS. Nonlinear inelastic analysis of steel beam-columns. I: Theory. Journal of Structural Engineering, ASCE 1994;120(7):2041-2061.

[13] Pi YL, Bradford MA, Uy B. Nonlinear analysis of members curved in space with warping and Wagner effects. International Journal of Solids and Structures 2005; 42(11-12): 3147-3169.

[14] Gibbs J. Vector analysis. New York, USA: Dover, 1961.

[15] Trahair NS, Bradford MA, Nethercot DA. The behaviour and design of steel structures to BS5950, Third Edition - British, London, UK: E \& FN Spon, 2001.

[16] BHP. Hot rolled and structural steel products, 2000 Edition, Melbourne, Australia: BHP Co. Pty Ltd, 2000.

[17] Pi YL, Papangelis JP, Trahair NS. Prebuckling deformations and flexural-torsional buckling of arches. Journal of Structural Engineering, ASCE 1995;121(9):1313-1322. 
[Blank Page] 


\title{
STEEL FRAMED STRUCTURES SUBJECTED TO THE COMBINED
}

\section{EFFECTS OF BLAST AND FIRE - PART 1: STATE-OF-THE-ART REVIEW}

\author{
H.X. Yu and J.Y. Richard Liew* \\ *Department of Civil Engineering, National University of Singapore, \\ BLK E1A, 1 Engineering Drive 2, Singapore 117576. \\ Email: cveljy@nus.edu.sg
}

\begin{abstract}
Design of public infrastructure against terrorism has become a rising concern with the objective of reducing the level of damage to property and the loss of life. Some of the terrorism acts take the form of blast followed by fire causing catastrophic failure of the structure. This paper studies the response of steel framed structures subjected to the combined effects of blast and fire. A state-of-the-art summary on issues related to separate assessment of blast and fire resistance of multistory building frames is provided. This is followed by a systematic investigation on the combined effects of blast and fire using a proposed two-step dynamic analysis procedure. In Part 2 of a companion paper, a typical multi-storey building will be analyzed to study its behavior under a medium-scale explosion which triggers a post-blast fire in the affected compartment. This particular structure is found to be vulnerable as it possesses little fire resistance due to the high level of deformation caused by the blast load. The aim of this two-part paper is to advance the use of simulation tools for collapse analysis of three dimensional steel structures subject to attack by fire and explosion so that the complex interaction effects of blast and fire can be understood and quantified.
\end{abstract}

Keywords: blast, fire, Structural analysis, steel frame

\section{INTRODUCTION}

The main objective of designing infrastructure against terrorist acts is to reduce the level of damage to properties and loss of human life. This requires that the structure to be able to withstand local failure without disproportionate collapse. Research on assessing and enhancing civil engineering structure's blast resistance has just begun. Guidelines and design manuals developed for military protective structures (TM5-1300, [1]) or for safety in ammunition industry (USDE, [2]) were available and found to be useful for designing civilian structures subjected to extreme loading. A series of reports was published by the Steel Construction Institute (SCI, [3]) concerning every aspect of steel offshore platforms subjected to gas explosion in which the mechanical properties of materials at high strain-rate and dynamic response of structures under impulsive loading, etc., are explained. GSA [4] provides some useful progressive collapse preventive guides for designing public buildings with special emphasis on robustness and resistance against blast loading.

The recently issued US guidelines (FEMA [5-8]) about protection of infrastructure against terrorist attacks concentrates on active protective measures such as setting of the barricades, increasing stand-off distance and providing appropriate building configuration, etc. For assessing the resistance of structural members due to blast loading, a Single Degree of Freedom (SDOF) method was firstly proposed by Biggs [9] and is later widely accepted by various design codes. With the development of computer technologies, more advanced methods have been used in research and practice. It can be expected that in the future, an advanced assessment system which involves the comparison of the blast effect to the structural resistance can be considered for the safety design of structures against blast loads. 
A rational approach to fire safety assessment is to relate functional requirements, such as prevention of spreading heat and smoke, safe evacuation and rescue etc., to fire resistance considering both local and global stability of structures. In a performance-based design, the designer needs to first understand the level of performance expected, then to design to these levels and finally to predict the performance that will be achieved to ensure the reliability and robustness of the design. Nowadays, not only common constructions can be efficiently designed to meet the basic fire safety demands, but also special construction such as airport departure halls, which is unable to be designed using the conventional prescriptive based fire design code can be designed and be endowed with appropriate level of protection against fire according to the clients' requirements.

If combustible materials exist in the rooms, fire might be ignited after explosion. The interactive effect between blast and fire has been a concern in designing some of the offshore platforms and design issues are discussed by SCI (1992). However, the fire resistance of structures after the action of blast has been investigated by only a few researchers (Song et al., [11]; Izzuddin et al., [12]; Liew and Chen $[13,14])$. Song et al. [15] developed a program with appropriate solvers for blast and fire effects. Liew and Chen studied the resistance of some members or simple frames subjected to fire followed by blast. The major shortcoming of their work is that both the blast and fire loads are applied as nominal values and proper modeling of blast or fire loads considering their natural behaviour is not considered. Their results as an indicative value for the resistance of structural members subjected to the combined effect of blast and fire is meaningful, but gives no guidance to the real behaviour of the structure.

This paper studies the response of steel framed structures subjected to the combined effect of blast and fire. A state-of-the-art summary on issues related to separate assessment of blast and fire resistance of multistory building frames is provided. This is followed by a systematic investigation on the combined effects of blast and fire using a proposed two-step dynamic analysis procedure. Blast could damage the fire protection of the building and this would reduce the fire resistance of a building. Dynamic solution techniques to perform a sequential blast-fire analysis are discussed. In Part 2 of the companion paper, a typical multi-storey building will be analyzed for its response when subjected to a medium-scale explosion followed by fire. It will be demonstrated that structures may have strong resistance to explosions or fire alone, but possesses very little resistance to the combined action of blast and fire.

\section{2.}

ANALYSIS OF STRUCTURES SUBJECTED TO BLAST LOADING

Blast load was initially considered when designing important military facilities or shelters to resist the attack of conventional or nuclear weapons. According to the investigation of DOD [16], conventional structures are designed to withstand total loads equivalent to $0.2 \mathrm{psi}\left(1.4 \mathrm{kN} / \mathrm{m}^{2}\right)$. However, the blast overpressure imposed to the structure is from $0.9 \mathrm{psi}\left(6.2 \mathrm{kN} / \mathrm{m}^{2}\right)$ to $12 \mathrm{psi}$ $\left(82.6 \mathrm{kN} / \mathrm{m}^{2}\right)$ depending on the distance and existence of barrier. A large amount of explosive attacks happen to buildings around the world every year. Designing civilian structures to be fully blast resistant is not an economically viable option. However, experience from these accidents show that huge amount of human life loss happens because of the disproportional collapse of the building. Provided that the excessive collapse of the building can be prevented, the extent of damage due to blast load could be controlled within an acceptable range. For example, the blast occurred in the basement of the WTC towers in 1993 destroyed several columns while the whole building was unaffected due to the high redundancy. The building was quickly repaired and resumed its normal 
function. Therefore it is possible for engineers to mitigate the effect of extreme load into a marginal level with a little increase of cost provided that appropriate structural performance analysis is performed.

\section{$2.1 \quad$ Blast Phenomenon}

Unconfined explosions outside of the building can be divided into two categories: air burst and surface burst. The characteristic blast wave profile from a free air burst is shown in Figure 1. The violent release of energy from a detonation gives a sudden pressure increase in the medium. The air pressure is increased instantaneously from the ambient pressure to a peak incident pressure $\mathrm{P}_{\text {so }}$ and then gradually diminishes to ambient pressure as the shock front travels through this specific position. The duration of the pressure is termed $t_{0}$. The shock front travels radially from the burst point with a diminishing velocity. And as the shock front expands the peak incident pressure $\mathrm{P}_{\mathrm{so}}$ decreases and the duration of the pressure $t_{0}$ increases. The positive overpressure is followed by a period of negative overpressure until sustained normal ambient pressure returns. The incident blast pressure at a specific position as shown in Figure 1 can be depicted by the following parameters: the incident pressure $P_{s o}$, the incident impulse $I_{s}$, the arrival time $t_{a}$, the duration $t_{0}$, and negative phase parameters $-P_{\text {so }},-I_{s},-t_{0}$ in case the negative phase is concerned. These parameters are related to the charge weight $\mathrm{W}$ and the distance of the interested position $\mathrm{R}$ by empirical curves.

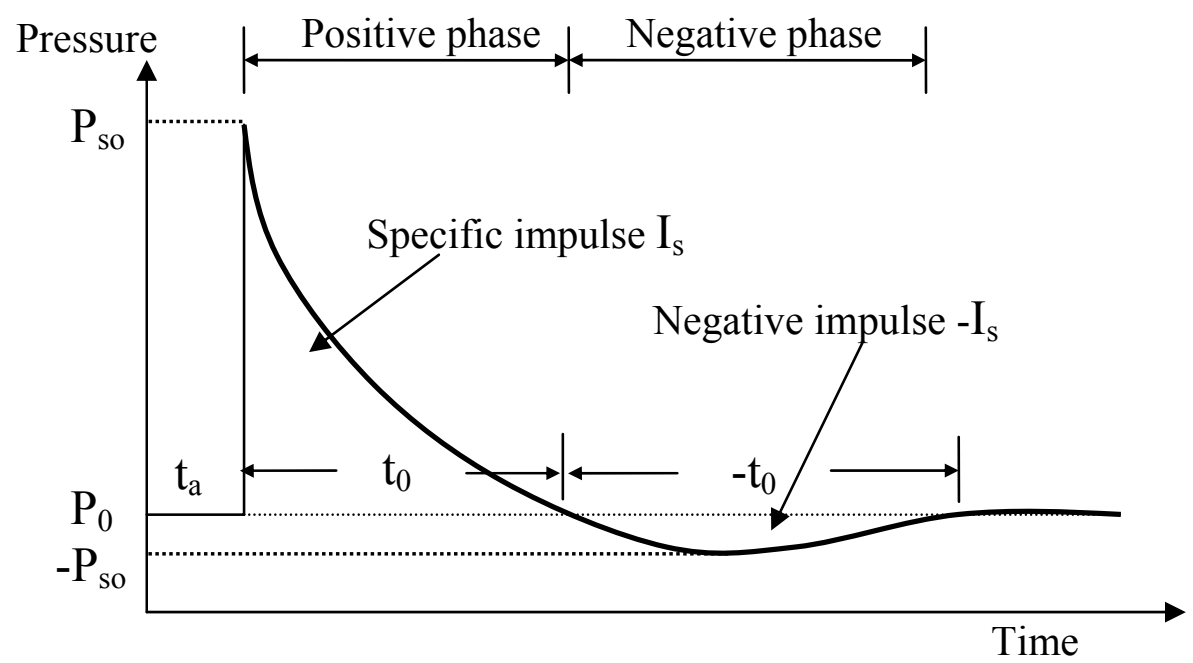

Figure 1. The variation of the overpressure at a specific position in free-air burst

After the initial blast wave or shock front has passed, a blast-induced wind, which consists of air, gases, and combustion products, causes dynamic pressures to be generated. The magnitude of the dynamic pressure $Q_{s}$ is a function of the gas particle velocity and the shock front velocity. Empirically, the dynamic pressure $\mathrm{Q}_{\mathrm{s}}$ is simply expressed as a function of the incident overpressure. Except for nuclear weapons, general explosives will be denoted near the ground surface. The initial wave of the explosion is reflected by the ground surface. The reflected wave merges with the incident wave at the point of detonation to form a single wave. Variation of the overpressure can be also depicted by Figure 1, but the blast pressure from the surface burst will be larger than that of the free air burst for the same charge weight due to the reflection effect of the ground surface. This effect can be approximately considered by enlarging the detonation weight by $1.5-2$ times. When the shock wave impinges on a rigid surface oriented at an angle to the direction of the propagation of the wave, a reflected pressure is instantly developed on the surface and the pressure is raised to a 
value that exceeds the incident pressure. The pressure-time history for a reflected wave is normally assumed to be in the same shape as incident pressure in Figure 1, but with much higher magnitudes. The reflected pressure $P_{r}$ and the reflected impulse $I_{r}$ can be determined from the incident overpressure and the inclined angle $\alpha$ of the wave propagation. Calculation charts to evaluate all parameters described above can be found in TM5-1300 [1].

\subsection{Classical Method for Determining Blast Loading on Structures}

The classical method for determining the external blast load on buildings is derived from the concept of Mach Reflection, in which far-distance, large-scale air explosion as well as small size building prototype is assumed. In the Mach Reflection model, an air burst is assumed. The initial shock wave, when propagating away from the explosion, impinges on the ground surface prior to arrival at the structure. As the shock wave continues to propagate outward along the ground surface, a front known as the Mach front is formed by the interaction of the initial wave and the reflected wave. Along the height of the Mach front, there is little variation of the pressure (See Figure 2). For design purposes, it is simply treated as a plane wave over the full height of the front. As the Mach front propagates away from the center of the detonation, its height increases, which is referred as the path of the triple point. If the height of the triple point exceeds the height of the structure, the structure is considered to be subjected to uniform pressure. The variation of this uniform pressure with time on the side facing the detonation is shown by the time-pressure curves shown in Figure 2 . At the moment the incident shock front strikes the front wall, the pressure immediately rises from zero to the reflected pressure $P_{r}$. At time $t_{c}$, the reflected wave reaches the edge of the front surface and the pressure value released to the algebraic sum of the incident pressure $P_{\text {so }}$ and the drag pressure $\mathrm{Q}_{\mathrm{s}}$ (see the solid curve in Figure 2). The clearing time $t_{\mathrm{c}}$ depends on the dimensions of the building and the travel speed of the reflected blast wave. However, the total impulse covered by the solid curve $I_{c}$ should not exceed the reflected impulse $I_{r}$, or the reflected pressure (see the dashed curve in Figure 2) should be used as the uniform blast pressure on the building surface.

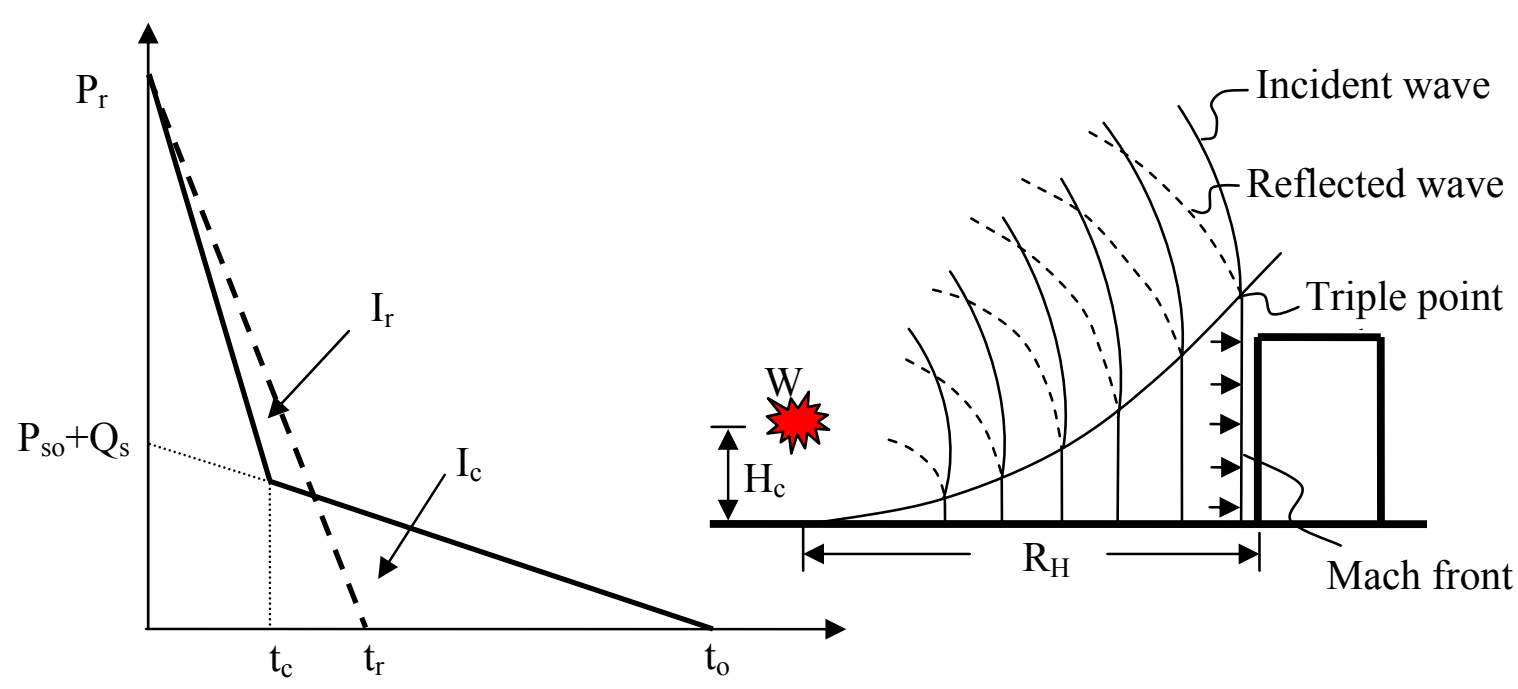

Figure 2. The Mach reflection and the variation of Mach pressure on building surface

\subsection{Proposed Method to Determine Blast Load for Large Buildings}

Commercial or federal buildings that are characterized to be high-rise or huge in dimension are identified to be of higher risk and a potential target for terrorist attack. The bombs, which are 
normally carried in cars or trucks, are detonated close to the ground and small in size compared to the building. The blast wave impinges the ground immediately after detonation and the reflected blast wave immerges with the incident wave and propagates together hemi-spherically. The blast load at a particular point on the building surface should be calculated as the reflected blast pressure at that point. TM5-1300 [1] proposes that blast pressure due to surface burst is treated as uniformly distributed over the front surface. The blast pressure at each point is a function of the distance R, inclined angle $\alpha$, and charge weight $\mathrm{W}$ as shown in Figure. 3. It can also be written as

$$
P_{r}=\Gamma\left(\frac{D}{W^{1 / 3}}, \frac{H}{D}\right)
$$

where $\frac{D}{W^{1 / 3}}$ is the scaled horizontal distance with the dimension in $\mathrm{lb}$ and $\mathrm{ft}$. Variation of the peak reflected pressure along the height of a building at various scaled horizontal distances is shown in Figure 4. $\frac{\mathrm{D}}{\mathrm{W}^{1 / 3}}=0.60$ is equivalent to a blast of $2000 \mathrm{~kg}$ TNT at $3.0 \mathrm{~m}$ away while $\frac{D}{W^{1 / 3}}=4.31$ is equivalent to a blast of $200 \mathrm{~kg}$ TNT at $10.0 \mathrm{~m}$ away. The smaller is the scaled distance, the larger is the variation of the blast pressure over the building surface. For the range of the scaled distance shown in Figure 4, it can be seen that the distribution of the peak reflected blast pressure could only be treated as approximately uniform when $H / D$ is less than 0.2 . Most blast attacks occurred to civilian buildings would have H/D exceeded this criterion. For example, a truck containing $2177 \mathrm{~kg}$ ANFO ( 3 tons TNT equivalent) was detonated at $3.05 \mathrm{~m}$ away from the front surface of the Murrah Building in the Oklahoma City in April, 1995 (Hinman and Hammond, [17]). The total height of the building is about 36 meter, with $H / D=11.8$.

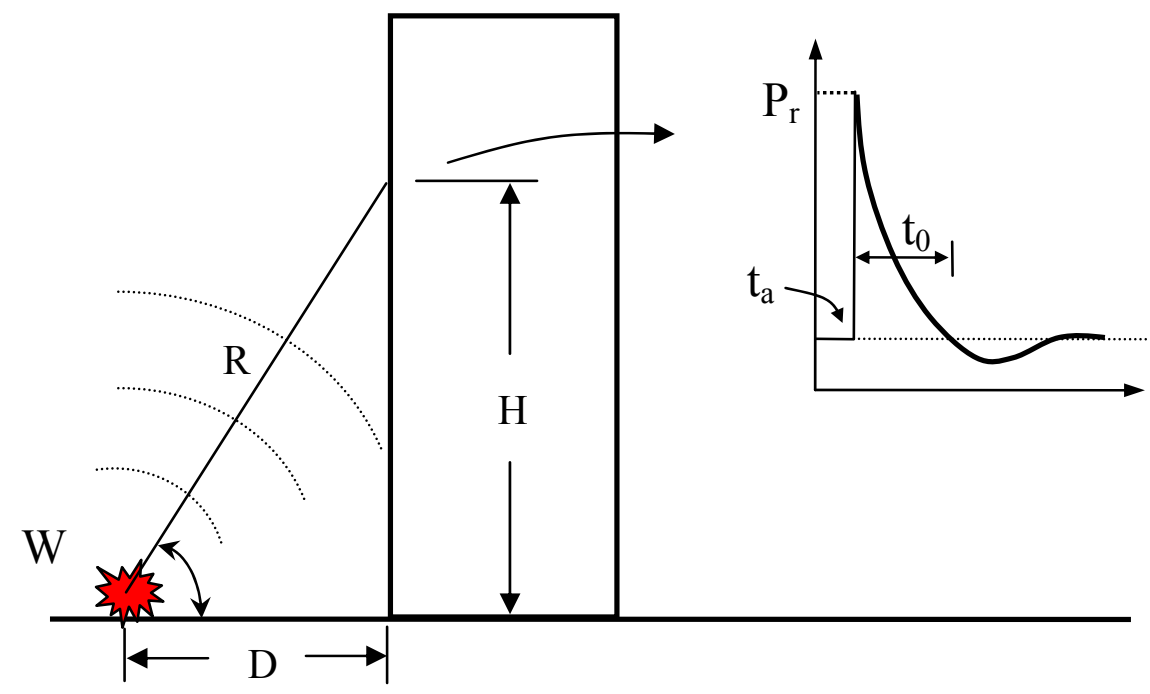

Figure 3. Calculation of the blast pressure on the building surface

Another effect that needs to be addressed is the clearance of the blast pressure due to the finite size of the building surface. It has been introduced in section 2.2 that when the blast pressure reaches the building surface, the incident pressure is reflected and accumulated along the surface. The reflected wave travels along the building surface and will be relieved when it reaches the edge of the building. If the building dimension is small, the time taken to relieve the blast pressure will be smaller than the duration of the reflected pressure duration (see Figure 2) and the actual load acting on the building surface in terms of the total impulse is smaller than the reflected impulse. Not only the edges of the building help to relieve the blast load, the presence of large openings on modern buildings such as windows or glass panels, will help to vent the blast pressure. These elements will 


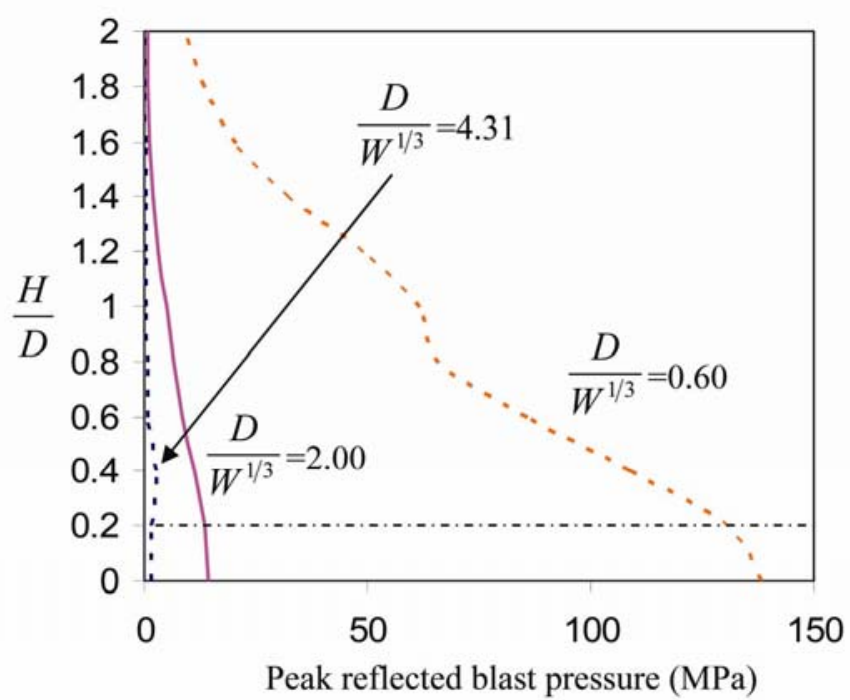

Figure 4. Variation of the peak reflected blast pressure along the building height at various scaled distances

fail almost immediately upon the arrival of the blast wave. The basic equation for calculating the clearing time is

$$
\mathrm{t}_{\mathrm{c}}=\frac{4 \mathrm{~S}}{(1+\mathrm{R}) \mathrm{C}_{\mathrm{r}}}
$$

For a rectangular panel with openings around four sides, $S$ is the clearing distance, which is the smaller of $L / 2$ or $H / 2 ; R$ is the ratio of $S / G$ where $G$ is the larger of $L / 2$ or $H / 2$ and $C_{r}$ is the sound velocity in reflected region.

To compare the clearing time and the reflected pressure duration, a case study is performed as shown in Figure 5. A plate wall strip of $2 \mathrm{~m}$ wide is assumed to have windows both above and below it. Blast pressure can be only relieved vertically by the upper or lower windows. The clearing distance is then equal to $1 \mathrm{~m}$ and $R$ approaches zero as $L$ is assumed to be infinity. It can be seen that for this plate, the clearing effect could only become noticeable after the scaled distance exceeded 11.2 or when $200 \mathrm{~kg}$ of TNT is detonated at $26 \mathrm{~m}$ away or $1000 \mathrm{~kg}$ TNT at

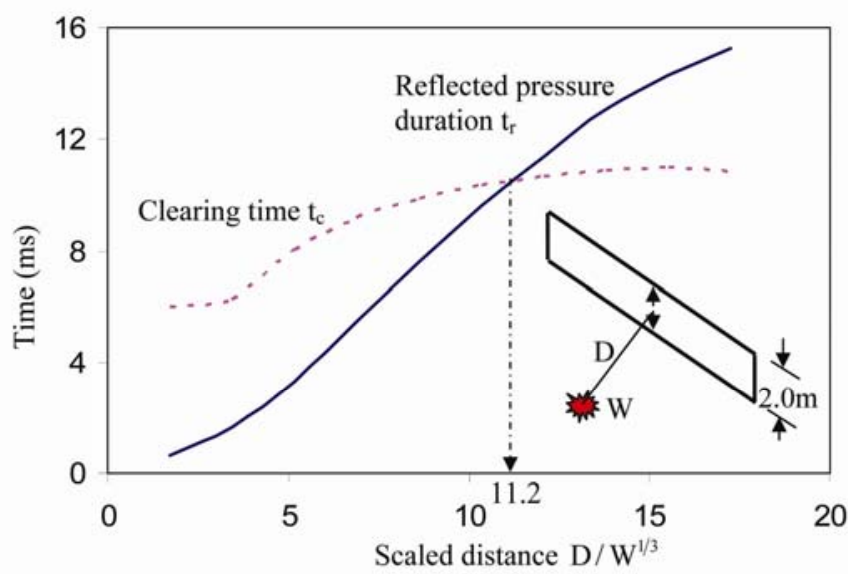

Figure 5. Comparison of the clearing time and reflected pressure duration beyond $45 \mathrm{~m}$. For any scaled distance less than that, the effect of openings on the calculation of the external structural loading could be simply ignored.

\subsection{Analysis of Structures subjected to Blast}

Blast analysis can be performed on individual members or the overall frames. The analysis methods can be varied from single-degree of freedom (SDOF)/multi-degree of freedom (MDOF) dynamic models to more complex finite element method (FEM) based on beam element model and to a highly sophisticated FEM model based on shell element model. 
The SDOF method is applied to single member, which involves simplification of a continuous structural member into a dynamic system with concentrated equivalent mass and stiffness (Biggs, [9]). The responses of multi-storey frames can be represented by MDOF systems where the floors are represented by concentrated masses. Solutions to the SDOF/MDOF systems can be found by referring to the design charts or using classical dynamic solution methods. FEM (Finite Element Method) based on beam element model considers the interaction effects between individual members and the overall framework. For example, buckling or yielding of one or more members may lead to redistribution of forces and gradually weaken the structure to resist further loads. Material and geometrical nonlinearity can be included directly in the finite element formulation.

One major short coming of the beam element model is that individual member capacity is calculated based on plastic hinge mechanism. However, under rapid blast loading, the member is subjected to high shear rather than flexural deformation. Under rapid loading, the member may have failed in shear. There is also a possibility of local buckling of steel sections under blast loading. High strain rates will enhance the yield strength of materials while the Young's modulus remains almost unchanged (Liew and Chen, [15]). When the strain-rate is varied from 1.0 to $10^{3} \mathrm{sec}^{-1}$, the yield strength is increased by a factor of 1.44 to 1.79 according to the strain rate model proposed by Soroushian and Choi [18]. That means that the criterion for section slenderness is downgraded by around $20 \%$ as the section slenderness criteria are functions of $\varepsilon=\sqrt{235 / f_{y}}$ according to EC3: Part 1.1 (CEN, 1992). The local buckling and high strain rate problems can be solved by using FEM based on shell model together with appropriate constitutive models accounting for the strain-rate effect. If more refined solid element is used, it is possible to simulate spalling and cracking of concrete or brittle failure of materials. However, refined model also means a large amount of labour in building the model and the need of intensive computation resources. Considering the inherent uncertainties in the blast loading, it should be avoided except for research purposes.

A case study is performed to compare the analysis results from the SDOF method, FEM using beam element and FEM using shell element. A steel column with section size UC356 $\times 368 \times 129$ and total length of $4.0 \mathrm{~m}$ is assumed to be subjected to uniform lateral pressure due to blast effect. Material Grade S355 $\left(\mathrm{f}_{\mathrm{y}}=355 \mathrm{~N} / \mathrm{mm}^{2}\right)$ is used which gives the section classification for this member to be non-slender for both flanges and web. Two types of boundary conditions are considered: pin-roller ends and fixed ends. The SDOF analysis is performed according to the NORSOK (NORSOK, 2004) design code for steel members under accidental loading. The equivalent system is defined as

$$
\bar{m} \ddot{y}+\bar{k} y=\bar{f}(t)
$$

where $\quad \bar{m}=\int_{l} m \varphi(x)^{2} d x, m$ is the mass per unit length

$$
\begin{aligned}
& \bar{f}(t)=\int_{l} q(t) \varphi(x) d x, \mathrm{q}(\mathrm{t}) \text { is the distribution of the load along the member } \\
& \bar{k}=\left\{\begin{array}{cc}
\int_{l} E I \varphi_{, x x}(x)^{2} d x & \text { In the elastic range } \\
0 & \text { In the plastic range } \\
\int_{l} N_{p} \varphi_{, x}(x)^{2} d x & \text { In the hardening range }
\end{array}\right.
\end{aligned}
$$


$\varphi(x)$ is the shape function. It is chosen to be $\varphi(x)=\sin \frac{\pi x}{1}$ for the column with pin-roller ends and $\varphi(x)=\frac{1}{2}\left(1-\cos \frac{2 \pi x}{1}\right)$ for the column with fixed ends. There is no hardening range for the pin-roller column because it is not restrained from inward movement. For the fixed end column, $N_{p}$ is the axial tension capacity of the section. The finite element analysis is performed using ABAQUS program with both beam and shell elements. The blast pressure is applied to one of the flange plate and forcing the member to bend about its major axis. Displacement about the weak axis is restrained. Geometrical initial imperfection is applied by appropriate scaling of the member's buckling shape.

Figure 6 and Figure 7 show the lateral displacement of the columns with pin-roller ends and fix-fix ends. Triangular blast loading with zero rise time is used, whose magnitudes are shown in the figures. Based on plastic-hinge theory, the stiffness of the column with pin-roller ends can be represented by a linear elastic-idealistically plastic curve. With appropriate choice of the shape function, the SDOF method gives almost exactly the same result as the FEM results using beam elements. FEM using shell elements give much larger displacement because local buckling reduces the effective stiffness of the section as shown in insert figure of Figure 6. The column with fixed ends has undergone three stages of deformation: (1) linear elastic regime, (2) inelastic transition regime where yielding occurs at the beam ends and (3) plastic regime where a plastic mechanism is formed. When an elastic fully plastic model is used (i.e., only a linear elastic regime and plastic regime is used), the stiffness tends to be over predicted. Figure 7 clearly shows that the initial stiffness predicted by the SDOF method is higher than the other two. However, the SDOF method predicts a largest maximum deflection. This is because of the error in the estimation of the stiffness in the hardening phase. For the FEM shell element model, the flanges deform toward the web upon the impingement of the blast pressure as shown in the insert figure of Figure 7. As the blast pressure is applied perpendicular to the external flange surface, the blast pressure is dissipated with the deformation of the flange. Therefore, the deflection from the shell model is smaller than the SDOF method and the FEM with beam element model.

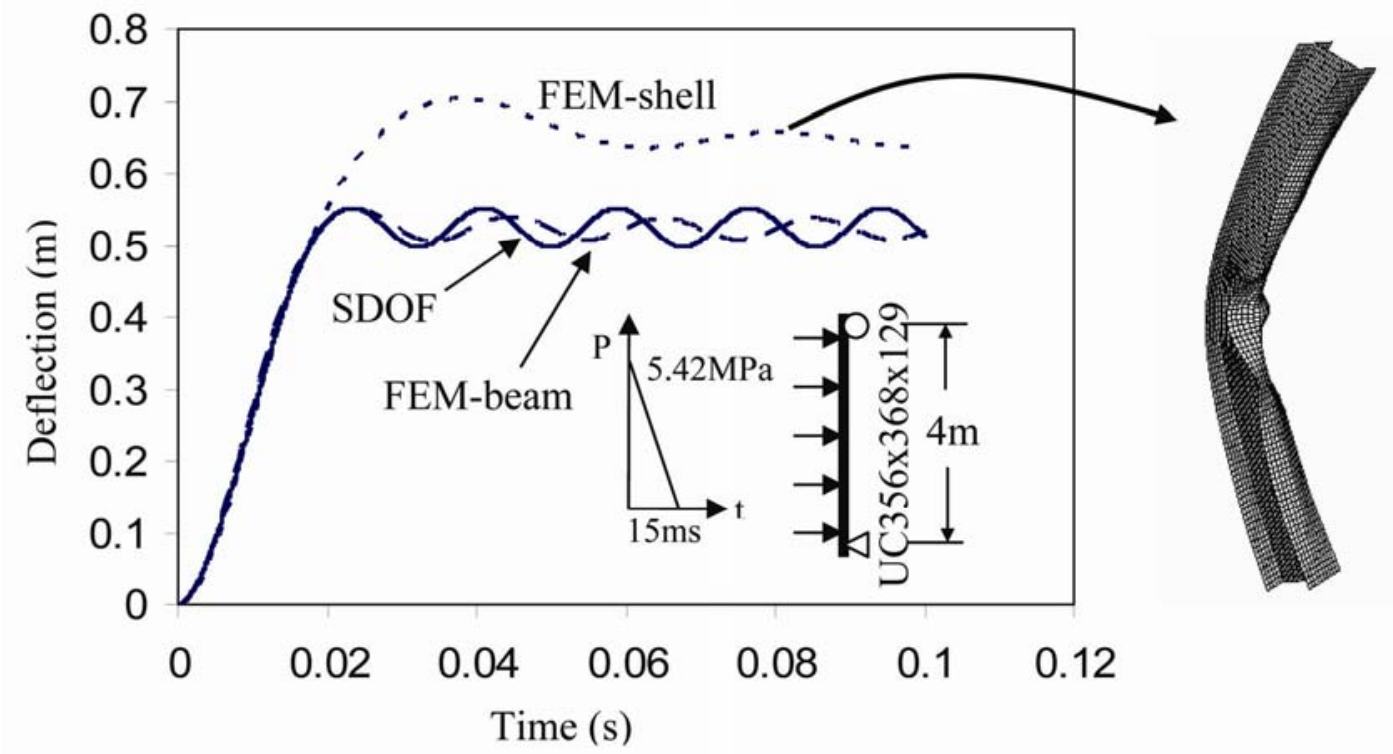

Figure 6. Comparison of the column mid-height defection with time predicted by SDOF, FEM-beam model and FEM-shell model- column with pin-roller ends 


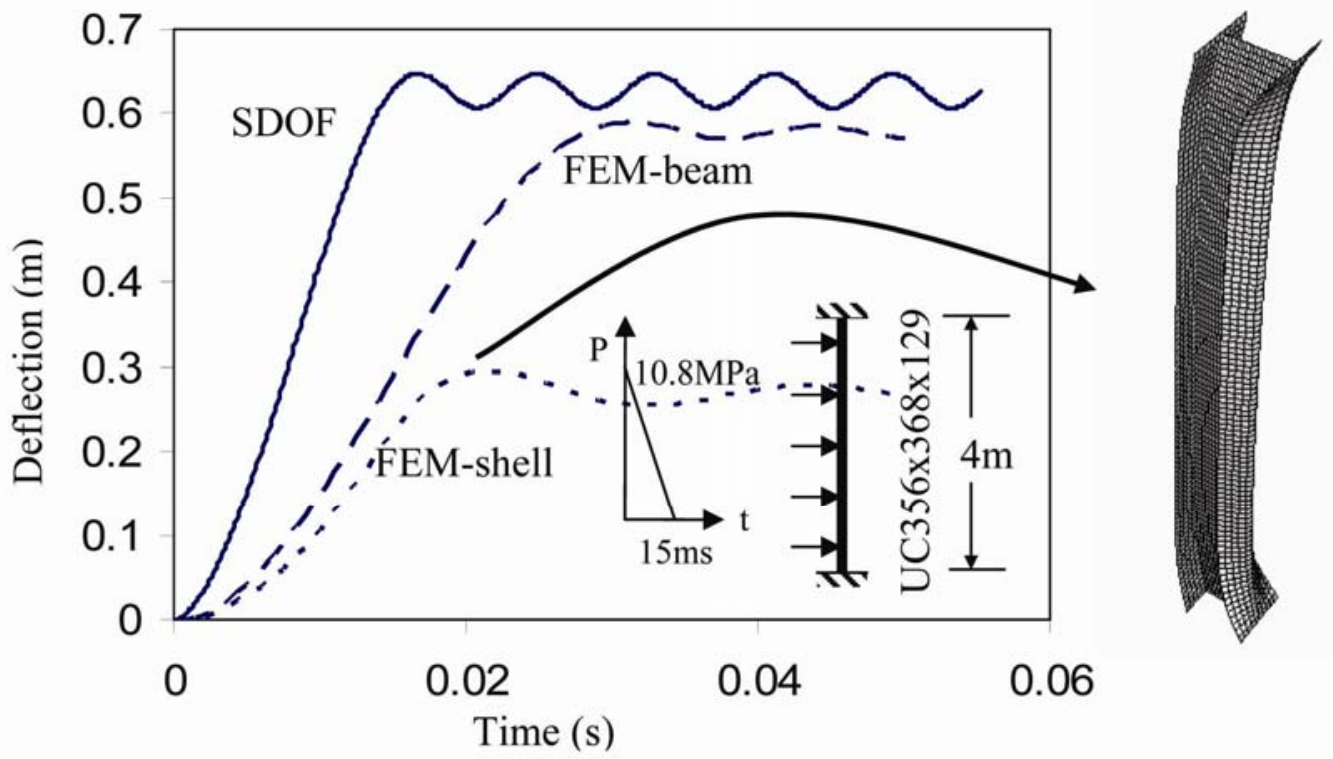

Figure 7. Comparison of the column mid-height deflection with time predicted by SDOF, FEM-beam model and FEM-shell model- column with fix-fix ends.

This example demonstrates the complexity of modeling the response of structure subjected to blast loading. The behaviour of structure depends on the difference between the blast duration and the structural natural period. The SDOF method predicts similar response behavior as the FEM-beam model provided that local deformation can be prevented and appropriate representation for the effective stiffness can be made in the SDOF method.

\section{FIRE MODELING}

Fire modeling is a mathematical simulation of the fire conditions in a compartment and is capable of providing information based on the parameters which have been designed. The fire development in a room normally involves three phases: pre-flashover, post-flashover and fire decay (see Figure 8). In the pre-flashover phase, fuels begin to burn and the gas temperature varies from one point to another in the compartment. In the post-flashover phase, the fire develops fully, and the gas temperature increases rapidly to a peak value and becomes practically uniform throughout the compartment. The fire has the greatest influence on structural design because of high temperature and radiant heat fluxes produced in this phase. In the fire decay phase, the available fuel begins to decrease and the gas temperature falls. There is considerable benefit when the effects of natural fires in buildings, where the amounts of the combustible contents are small and the buildings are of large volume, is considered than using the standard ISO fire.

For many years, fire engineering research has shown that the overall structure performs better than isolated members in a fire situation. Numerous studies have been carried out to determine the temperature reached in real (natural) fires, to quantify the factors that govern fire severity and to investigate the parameters that cause structures to fail in fire. The studies show that the severity of natural fires in building compartments is governed by the amount of combustible material (the fire load), the area of the doors and windows (the ventilation), and the thermal characteristics of the wall, floor and ceiling materials. In addition, fire-fighting measures are also important for the determination of fire exposure. 
Eurocode 1: Part 1-2 [20,21] recommends equations for parametric fires, allowing a temperature-time curve to be produced for any combination of fuel load, opening factor, height of opening and thermal characteristic of the boundary materials (Liew and Ma, [19]). Provided that the burning parameters can be determined accurately, the parametric fire model is able to provide a good estimation of the gas temperature in a fire compartment.

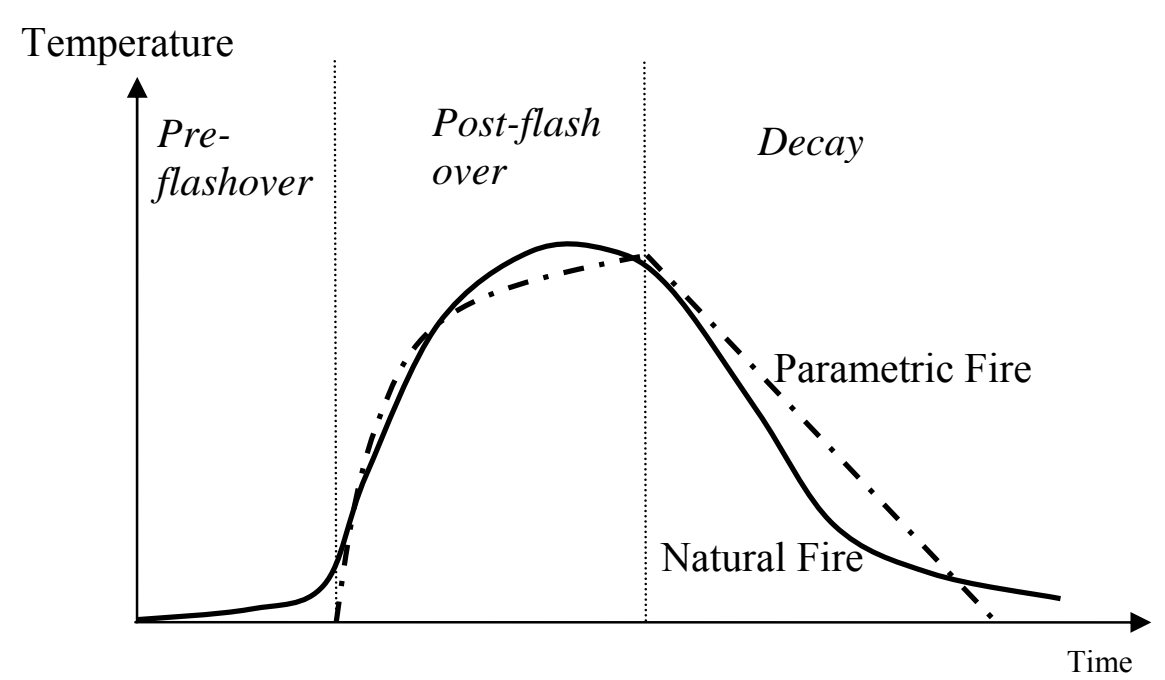

Figure 8. Comparison of the natural fire curve with a parametric fire

For a better understanding of the combustion procedure and room temperature distribution, computer programs based on CFD (Computational Fluid Dynamics) theory should be used. They work by dividing the region of interest into a large number of cells or control volumes (the mesh or grid). In each of these cells, the partial differential equations describing the fluid flow are rewritten as algebraic equations that relate the pressure, velocity, temperature, to the values in the neighboring cells. These equations are then solved numerically yielding a complete picture of the flow down to the resolution of the grid. The significant advantages of field model is ability to predict the spread of fire and smoke in compartments as well as modeling turbulence generation and dissipation, soot formation and combustion chemical reactions. Today, with the ever-increasing computing capabilities, field models have received increasing attention and spurred a lot of research and code development.

\subsection{Analysis of Structures Subjected to Fire}

The process of heat transfer between a fire and a structure can be described by the balance between the net incident thermal radiation and convective heat flux and the rate of heat conducted in the material. The rate of heating of any structural member is dependent at any time on the temperatures of both the fire atmosphere and the member. Calculation of member temperature requires solution in the time domain via a fairly complex differential equation.

Any analysis method that is used to predict structural response in fire must be able to take into account the change of material properties and thermal expansion of materials with increase of temperature. Simplified formulas for computing resistance of single members such as beams and columns can be found in EC3 Part 1.2 (CEN, [21]). Liew and his associates (Liew and Tang, [22]; Liew et al., [23], Liew et al., [24]) proposed the use of the plastic hinge based method to model skeleton steel structures subjected to fire. The proposed beam model can capture member stability accurately with the use of only one element per member. The beam element displacement fields are 
derived from the exact solution of the fourth order differential equation for a beam-column subjected to end forces (Liew et al., [22]). Material non-linearity is modeled by yield hinges at element mid-span and element ends. A more refined analysis is to use fiber elements to model the steel member in which the member cross section is divided into a number of fibers and the section forces/moments are calculated by integration of the forces at each fiber. The spread of plasticity is captured by monitoring the stress-strain relationship at each fiber. By using this model, the Euler-Bernoulli beam assumptions apply, i.e. plane sections remain plane. For a more accurate representation of detailed localized effects such as shear, warping, local deformation etc., of plate components in the member, shell element modeling is required. In case of direct analysis of the overall building response subjected to localized fires, a mixed use of different element types is required in which the fire affected members may be modeled using the shell elements and those not affected by fire may be modeled using beam elements. Some examples of the use of mixed element modeling technique can be found from Liew and Chen [14,15] and Liew et al. [25].

\subsection{Protection of Buildings for Fire Safety}

Fire protection to buildings can be divided into two categories: active protection and passive protection. The purpose of active protection is to decrease the possibilities of fire occurrence and fire spread. It takes the form of horizontal and vertical compartmentation, installation of fire detection system, installation of fire suppression system and availability of firefighters, etc. Passive protection is aimed to retard the load bearing members from being heated to excessive temperatures in a fire situation It generally means enclosing the structural members by thermal insulation materials such as mineral fiber or gypsum board.

The active protection measures may be taken into account in the risk and hazard factors that affect the fire development. For example, it is defined in EC1 Part 1.2 (CEN, [21]) that the design fire load should be calculated as

$$
\mathrm{q}_{\mathrm{f}, \mathrm{d}}=\mathrm{q}_{\mathrm{f}, \mathrm{k}} \mathrm{m} \delta_{\mathrm{q} 1} \cdot \delta_{\mathrm{q} 1} \cdot \delta_{\mathrm{n}}
$$

where $q_{f, k}$ is the characteristic fire load, $\mathrm{m}$ is the combustion factor, $\delta_{q 1}$ and $\delta_{q 2}$ are factors of the compartment size and $\delta_{n}$ are factors taking into account the active fire fighting measures.

Passive fire protection decreases the member temperature and is considered in the heat-transfer analysis in which the temperatures of the steel members are calculated according to the surrounding fire temperature. Simplified methods are provided by EC3 Part 1.2 (CEN, [20]) to calculate the temperature development in steel members with or without fire protection. For more complex heat transfer problems, finite element models should be built and full thermal analysis should be performed.

\section{INTEGRATED BLAST AND FIRE ANALYSIS}

Blast or impact is quite possibly to be followed by fire either because the detonation releases heat energy or because the blast wave damages the electricity system and causes fire. The hazard of fire to a blast or impact damaged structure is most obviously demonstrated in the collapse of WTC on Sep 11, 2001. This building was originally designed to withstand the impact of a fully-fueled Boeing 707 aircraft anywhere along the tower height. In actual case, the towers were impacted by a larger aircraft and they remained standing after the impact which damaged a large number of 
columns. However, it is the intense heating due to the burning of jet fuel that destroyed the vertical load bearing system and caused progressive collapse of the towers.

The crushing of an airplane to the Pentagon building on Sep 11, 2001 provided a case for more detailed study on the effect of fire to damaged buildings (Mlakar, et al., [26]). Along the outer surface of the building are concrete reinforced columns at about $3 \mathrm{~m}$ spacing. Impact damage on the first floor is likely to removed columns from line 10 to line 14 and the exterior columns on column lines 9, 15, 16 and 17 are severely damaged. The structure remained at the deformed shape for about 20 minutes before collapse. Investigation of the structural member's resistance to impact and fire shows that the impact damage which removed protective materials and compromised strength initially was the likely cause of the structural collapse in the following fire. The fire after impact is a typical ventilation-controlled fire whose maximum temperature is estimated to be around $800^{\circ} \mathrm{C}$. Thermal analysis shows that for the undamaged columns, the reinforcement needs 155 min to reach $500^{\circ} \mathrm{C}$ when exposed to standard fire ASTM E-119, while reinforcement in damaged columns reach $500^{\circ} \mathrm{C}$ in $50 \mathrm{~min}$ when subjected to the same burning because impact caused spalling of the enclosing concrete. For steel-framed structures, the impact will work similarly by destroying the fire protection layers that is generally required to enclosing the steel members.

It may be concluded from the above discussions that a stand-alone blast resistant design or fire safety design would not be adequate to meet the safety performance of such buildings with higher identified risk. A fully integrated blast and fire analysis is required.

\subsection{Effect of Blasts on Fire Safety System}

For a building structure subjected to a blast followed by a fire, damage to the fire safety system will impose a significant effect on the performance of the building subjected to a fire. They include:

(1) Damage to active fire fighting system. Active fire fighting system consists of fire detector, water supplier, and water dispenser, etc, if without proper protection, will be susceptible to damage during blast. Failure of any parts could affect the fire resistance of the building system.

(2) Damage to passive fire protection system: The performance of passive fire protection materials is derived from tests in which the materials are not subjected to any loads. Under blast load, some of these materials may not be properly adhered to the surface of the member. Under large displacement and yielding, the passive fire protection may fail by spalling, cracking, or de-bonding failure between material and substrate. For fire board products, opening of joints between panels may also affect their fire performance.

(3) Damage to fire compartments: Blast may damage the compartment walls and cause fire to spread within the building. Fire partition walls are usually designed for thermal insulation and integrity to avoid the passage of smoke and flame. As non-structural members, they have little resistance against lateral load due to blast wave or impact penetration from blast fragments.

(4) In view of global terrorism, some manufacturers have started to investigate the resistance of passive fire protections to withstand explosive fragment impacts (Pollak, 2005). 
Depending on the difference between the structure's natural period and the duration of the blast load, the structure may display three types of responses when subjected to dynamic loads. When the duration of the load is very small compared to the natural period of the structure, the structure's response is in the impulse regime. In this regime, the peak pressure is less important because the structure cannot reach the extent of deformation before the load is finished. The impulse delivers tremendous energy to the structure causing damages to the structure. When the duration of the blast load is much longer than the natural period of the structure, the loading is termed quasi-static. The quasi-static response tends to the response of an equivalent static force and a static analysis can be used to predict the response behavior of the structure. When the load duration is similar to the natural period of the structure, both peak force and the impulse will be important to determining the structural response. This is normally called dynamic regime. Dynamic analysis must be performed for structure subjected to this type of blast loading.

Methods for solving dynamic and impulsive equilibrium equations are broadly characterized as implicit or explicit. Explicit schemes obtain values for dynamic quantities at time $\mathrm{t}+\Delta \mathrm{t}$ based entirely on available values at time t. The central difference operator, which is the most commonly used explicit operator for stress analysis, is only conditionally stable. The benefit of explicit solver is that the governing equilibrium equation can be solved directly without the need to transpose the stiffness matrix. Convergence is ensured by definition. The main drawback is that it requires very small time steps to maintain stability, normally in $10^{-6} \mathrm{~s}$ to $10^{-5} \mathrm{~s}$ for dynamic analysis of structural members. Implicit schemes remove the constraint of using small time step by solving for the dynamic quantities at time $\mathrm{t}+\Delta \mathrm{t}$ based not only on values at $\mathrm{t}$, but also on these same quantities at $\mathrm{t}+\Delta \mathrm{t}$. Because they are implicit, nonlinear equations must be solved and the nonlinear stiffness matrix needs to be transpose. For linear elastic problem, it is unconditionally stable and one time step can be used. However, for highly nonlinear problems, smaller time steps should be used to meet convergence requirements. It is generally accepted that both solvers can be used for problems falling into dynamic regime while implicit solver is more appropriate for quasi-static problems while explicit solver is most commonly used for problems involving impulsive loads.

Integrated analysis of structures subjected to blast and fire imposes a greater challenge to numerical solution technique because 1) Blast load is rapid and intense; the corresponding analysis method is characterized by the inertia effect and strain-rate effect. The material model should include strain-rate effect and preferably material failure criterion as material fracture or connection failure is often expected. 2) Fire is a relatively milder and prolonged process. While thermal creep effect is normally implicitly considered in the constitutive model, nonlinear static analysis would be applicable. The constitutive model must be able to consider degradation in the Young's modulus and effective yielding stress at elevated temperatures as well as thermal expansions.

The first attempt to perform an integrated blast and fire analysis is by Song et al. [11] and Izzuddin et al. [12]. An integrated analysis environment is developed, in which, the blast loading is solved by explicit dynamic analysis techniques and the fire loading is solved by implicit dynamic analysis. Liew and Chen [15] investigated the interaction of blast and fire load on the performance of single members and two-dimensional steel frames using ABAQUS implicit dynamic solver. Recently, Liew and Chen [14] extend the work to three dimensional steel frames in which local and lateral torsional buckling of beams was modeled and progressive collapse of building occurred when critical columns in the building buckled under the fire attack. In all these works, realistic blast and 
fire loadings are not considered. Instead, a simple blast loading model with variable peak pressure value is used to apply a uniformly distributed load to the member surface. A monotonic increase of the temperature with assumed temperature gradient is used for the fire analysis. The study only restricted to simple steel frames. These examples are meant to demonstrate the solution techniques, the numerical results do not usually represent the real structural behaviour.

\subsection{Effect of Blast on Fire Resistance of Steel Members}

An integrated analysis considering explosion followed by a fire is a very time consuming process because the analysis must be carried out in the time domain. For practical design, it would be useful to develop design charts to relate the effect of blast and fire to the resistance of individual member. Previous studies by Liew and Chen [14] produced the interaction curve for a column with UC254 $\times 254 \times 89$ section size and length varying from 3, 4.5 to 6 meters. Triangular shaped dynamic loading is used with fixed rising and decay duration. The only parameter studied is the peak load. The interaction curve is expressed in terms of the normalized peak loading $\mathrm{P} / \mathrm{P}_{\max }$ versus normalized fire resistance $T / T_{\max }$ where $P_{\max }$ and $T_{\max }$ are the separate blast and fire resistances of the member. The analysis results show that there is no decrease of fire resistance when the blast pressure is increased up to $0.7 \mathrm{P}_{\max }$. When the blast loading is in the range of $0.9 \mathrm{P}_{\max }$ to $1.0 \mathrm{P}_{\max }$, the fire resistance dropped rapidly from around $0.8 \mathrm{~T}_{\max }$ to zero.

The difficulty of generating this type of design chart is the definition of the blast resistance $\mathrm{P}_{\max }$. Unlike members subjected to static load, the dynamic resistance is not determined from the yield stress, but depends on the amount of energy the member can absorb. Besides, the response of a member subjected to blast is not only a function of the peak loading, but also the loading history. In the impulse regime, the impulse value determines the response while in the dynamic regime, both the peak load and the load duration determines the response of the member. When the blast loading is changed or another member is used, new design chart must be generated.

A more universally used criterion to assess the level of member damage in blast loading is the plastic utilization factor which, for a SDOF system, is defined as the ratio of the maximum deflection to the elastic deflection, or

$$
\mu=\frac{y_{\max }}{y_{e l}}
$$

This parameter is independent of the blast loading and it can be conveniently calculated using the classical SDOF method.

Figure 9 shows the interaction relationship of a column subjected to blast followed by fire. The column size is UC203 $\times 203 \times 60$ and the total length is $4.0 \mathrm{~m}$. The column is initially loaded with axial load equal to $0.3 \mathrm{Af}_{\mathrm{y}}$. Three types of lateral blast loading are applied as shown in the figure. $\mathrm{t} / \mathrm{T}=0.11$ means the loading falls into the impulse loading regime and the maximum response depends on the impulse, instead of the peak loading. $\mathrm{t} / \mathrm{T}=0.45$ and $\mathrm{t} / \mathrm{T}=1.0$ fall into the dynamic loading regime where both the peak loading and the load duration are important. Figure 9 shows the interaction curves of fire resistance reduction factor $\left(\mathrm{T} / \mathrm{T}_{\max }\right)$ against the plastic utilization factor for various values of $\mathrm{t} / \mathrm{T}$ ratios. The results suggested that an unified interaction curve, which is independent from $\mathrm{t} / \mathrm{T}$ ratio, can be used for designing steel members subjected to blast and fire. It is further proposed that when the plastic utilization factor is increased from 1 to 8 , the fire resistance reduction ratio decreases linearly from 1.0 to 0.7 . After that, with further increase of the plastic utilization factor, the fire resistance reduction factor drops rapidly to zero. 


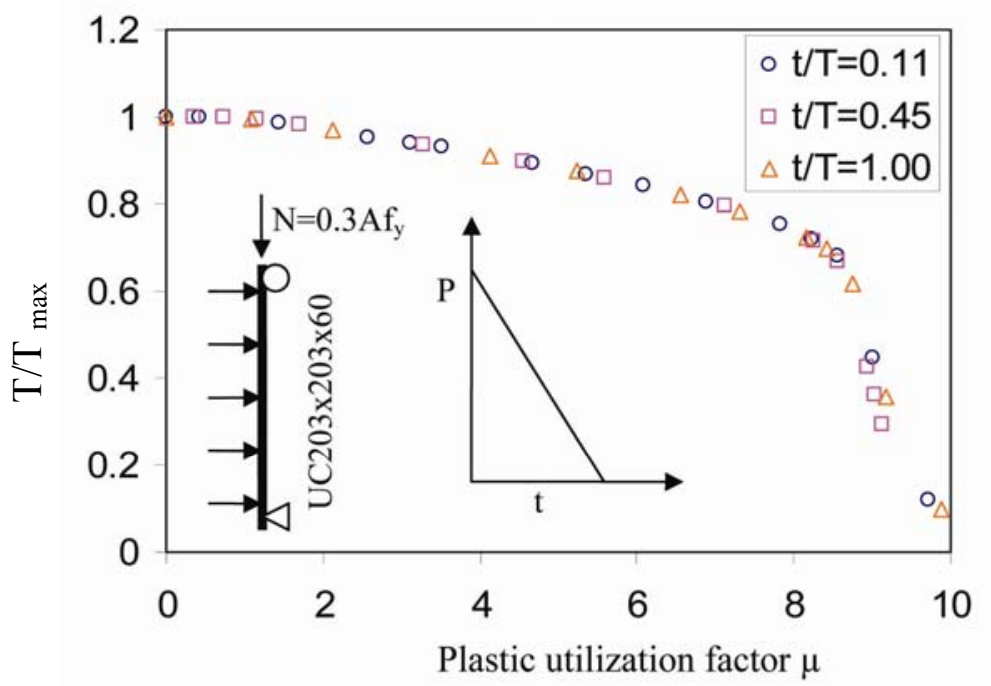

Figure 9. Interaction diagram for steel members subjected to combined blast and fire

\section{CONCLUSION}

This paper provides a state-of-the-art review on critical issues related to design and modeling of steel structures subjected to blast and fire. The conventional method for designing small-sized protective structures to resist the blast loading is introduced and a modified method for estimating the effect from small-sized bombs on public buildings is discussed. When dynamic analysis is performed to obtain the structural response in blast, caution needs to be taken about the potential assumptions especially when the simplified method is used. A comparison of three analysis methods shows the importance of local deformation caused by blast load and the need of more refined finite modeling technique.

Fire safety design for new buildings involves suppression of the fire and enclosing the load bearing members by heat retardant materials. These protective measures might be fully or partially damaged by the blast loads. The consequence of damage to fire protection measures is highlighted. Performing an integrated assessment of the structural resistance to blast and fire requires the structure to be analyzed in blast loading and then damaged structure to be analyzed for fire resistance. Techniques for performing a sequential blast-fire analysis are discussed. Analysis on column's response subjected to blast and fire suggests that the fire resistance of steel members will not be seriously damaged until the total displacement due to blast load is 8 times the elastic displacement. Based on the parametric study, an interaction diagram can be generated for any steel members in the form of plastic utilization factor due to blast load versus the fire resistance reduction factor for the purpose of design implementation. 


\section{REFERENCES}

[1] TM5-1300. Structures to Resist the Effects of Accidental Explosions. US Army Manual, November, 1990.

[2] USDE. A Manual for the Prediction of Blast and Fragment Loading on Structures. Report DOE/TIC-11268. United States Department of Energy, Amarillo, TEXAS, USA; 1980.

[3] SCI. Blast and fire engineering projects for topside structures, Ascot, Berkshire. Steel Construction Institute; 1991.

[4] General Services Administration (GSA). GSA Progressive Collapse Analysis and Design Guidelines for New Federal Office Buildings and Major Expansion Projects. Prepared by Applied Research Associates for GSA, Washington, DC, USA, 2003.

[5] FEMA 426. Reference Manual to Mitigate Potential Terrorist Attacks against Buildings. US Department of Homeland Security, December, 2003.

[6] FEMA 427. Primer for Design of Commercial Building to Mitigate Terrorist Attack. US Department of Homeland Security, December, 2003.

[7] FEMA 427. Primer for Design of Commercial Building to Mitigate Terrorist Attack. US Department of Homeland Security, December, 2003.

[8] FEMA 428. Primer to Design Safe School Projects in Case of Terrorist Attack. US Department of Homeland Security, December, 2003.

[9] Biggs JM. Introduction to Structural Dynamics. New York: McGraw Hill, 1964.

[10] SCI. Interim Guidance Notes for the Design and Protection of Topside Structures against Explosion and Fire. Steel Construction Institute, SCI-P-112; 1992

[11] Song L, Izzuddin BA, Elnashai AS, Dowling PJ. An integrated adaptive environment for fire and explosion analysis of steel frames- Part I: analytical models. Journal of Constructional Steel Research 2000;53:63-85.

[12] Izzuddin BA, Song L, Elnashai AS, Dowling PJ. An integrated adaptive environment for fire and explosion analysis of steel frames- Part II: verification and application. Journal of Constructional Steel Research, 2000;53:87-111.

[13] Liew JYR. Fire and Structural Engineering- A Multi-dimensional Integration. Advances in Structural Engineering, Multi-Science Publisher UK 2004;7(4):111-133.

[14] Liew JYR, Chen H. Direct analysis for performance-based design of steel and composite structures. Progress in Structural Engineering and Materials 2004;6(4):213-228. 
[15] Liew JYR, Chen H. Explosion and Fire Analysis of Steel Frames using Fiber Element Approach. Journal of Structural Engineering, ASCE 2004;130(7):991-1000.

[16] DOD. DOD Ammunition and Explosives Safety Standards. Department of Defense, USA, July, 1999.

[17] Hinman EE, Hammond DJ. Lessons from the Oklahoma City Bombing. Defensive Design Techniques. ASCE Press, 1997.

[18] Soroushian P, Choi KB. Steel Mechanical properties at Different Strain Rates. Journal of Structural Engineering 1987;113(4):663-671.

[19] Liew JYR, Ma KY. Advanced analysis of steel framework exposed to compartmental fire. J of Fire and Materials. USA: Wiley, 2004;28(2-4):253-267.

[20] European Committee for Standardization (CEN). DD ENV 1993-1-2, Eurocode 3: design of steel structures, Part 1.2, General rules- structural fire design. British Standards Institution, UK; 2001.

[21] European Committee for Standardization (CEN). Draft prEn 1991-1-2, Eurocode 1: Basis of Design and Actions on Structures, Part 1.2: Actions on Structures- Actions on Structures exposed to Fire. British Standards Institution, London; 2001.

[22] Liew JYR, Tang LK. Advanced plastic-hinge analysis for the design of tubular space frames. Engineering Structures 2000;22(7):769-783.

[23] Liew JYR, Tang LK, Holmas T, Choo YS. Advanced analysis for the assessment of steel frames in fire. Journal of Constructional Steel Research 1998;47(1-2):19-45.

[24] Liew JYR, Chen H, Shanmugam NE. Nonlinear analysis of steel frames with composite beams Journal of Constructional Steel Research, ASCE 2001;127(2):361-370.

[25] Liew JYR, Yu HX, Kleiveland RN. Direct Analysis of Steel and Composite Structures Considering the Effects of Fire. Proceedings of the Fourth International Conference on Advances in Steel Structures, Shanghai, China, 13-15, June, 2005.

[26] Mlakar PF. The Pentagon Building Performance Report. American Society of Civil Engineers. 
[Blank Page] 


\title{
STEEL FRAMED STRUCTURES SUBJECTED TO THE COMBINED EFFECTS OF BLAST AND FIRE- PART 2: CASE STUDY
}

\author{
H.X. Yu and J.Y. Richard Liew* \\ * Department of Civil Engineering, National University of Singapore, \\ BLK E1A, 1 Engineering Drive 2, Singapore 11757. \\ Email: cveljy@nus.edu.sg
}

\begin{abstract}
Design of public infrastructure against terrorist attack has become a rising concern to reduce the level of damage to properties and the loss of life. Some of the terrorist acts take the form of blast followed by fire causing catastrophic failure of the structure. This two-part paper aims to study the response of steel framed structures subjected to the combined effect of blast and fire. In Part 1 of the companion paper, an overview is made on the methods for determining the blast load and finite element techniques for dynamic and impulsive analysis. In this paper, a typical five-storey steel framed building with concrete slab system and external masonry cladding, subjecting to mid-scale bomb and then followed by fire, is analyzed using a dynamic analysis software, LS-DYNA. A sequential procedure for a dynamic blast-fire analysis is proposed. The effect of blast on active and passive fire protection systems is assessed. The local and lateral-torsional buckling failure modes associated with members subjected to the combined effect of blast and fire are identified in contrast with the failure modes predicted based on fire analysis alone. Collapse analysis showed that blast load could affect on the performance of passive and active fire protection system, and the blast damaged structure possesses very little resistance to fire.
\end{abstract}

Keywords: blast, collapse, fire, dynamic analysis, steel frame, strain rate effect, temperature

\section{STRUCTURAL LAYOUT}

A 3 x 4-bay and 5-story steel building with member sizes and building layout plan as shown in Figure 1 has been constructed. The storey height is $4.0 \mathrm{~m}$. Grade S275 steel is used for all steel members, and grade C30 normal weight concrete is used for the slab of $120 \mathrm{~mm}$ thick. The floor load at the accidental limit state is $6.25 \mathrm{kN} / \mathrm{m}^{2}$. The external walls are assumed to be masonry wall of $150 \mathrm{~mm}$ thickness. Rigid and full strength beam-column connections are assumed and the frame is fully continuous to [provide a progressive collapse resistant design. One member size B1 is used for all beams in the $\mathrm{x}$ direction and one beam size $\mathrm{B} 2$ is chosen for all beams in the $\mathrm{y}$ direction. For the first four stories, one column size $\mathrm{C} 1$ is used for all the internal columns, and one column size $\mathrm{C} 2$ is used for all the edge and corner columns. For the top floor, a smaller column size is used, but the beam sizes remained the same. The members' sizes are tabulated in Figure 1. All the beams are assumed to be in full composite action with the concrete slabs. 

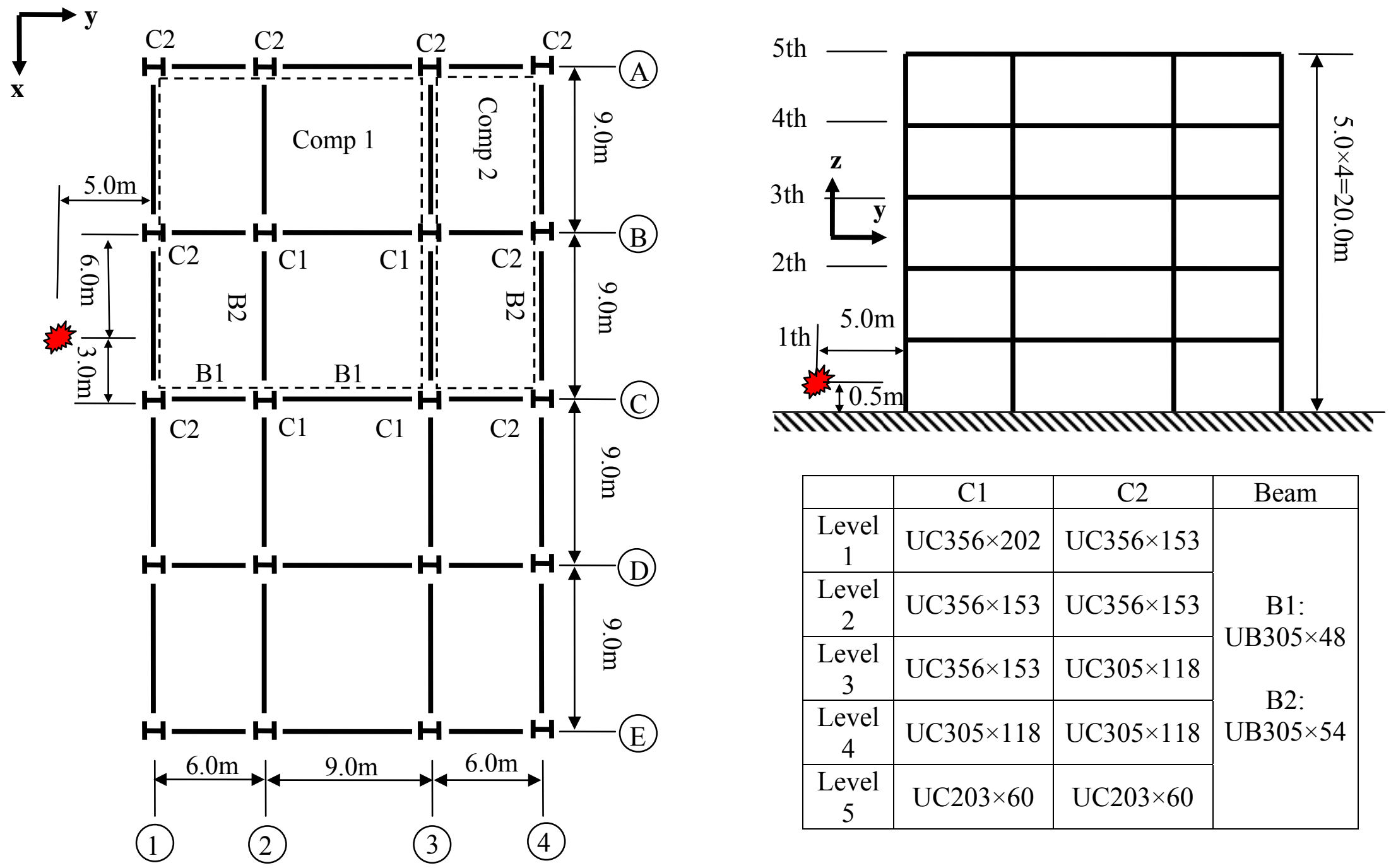

\begin{tabular}{|c|c|c|c|}
\hline & $\mathrm{C} 1$ & $\mathrm{C} 2$ & Beam \\
\hline $\begin{array}{c}\text { Level } \\
1\end{array}$ & $\mathrm{UC} 356 \times 202$ & $\mathrm{UC} 356 \times 153$ & \\
\cline { 1 - 3 } $\begin{array}{c}\text { Level } \\
2\end{array}$ & $\mathrm{UC} 356 \times 153$ & $\mathrm{UC} 356 \times 153$ & $\mathrm{~B} 1:$ \\
\cline { 1 - 2 } $\begin{array}{c}\text { Level } \\
3\end{array}$ & $\mathrm{UC} 356 \times 153$ & $\mathrm{UC} 305 \times 118$ & $\mathrm{UB} 305 \times 48$ \\
\cline { 1 - 3 } $\begin{array}{c}\text { Level } \\
4\end{array}$ & $\mathrm{UC} 305 \times 118$ & $\mathrm{UC} 305 \times 118$ & $\mathrm{UB} 305 \times 54$ \\
\cline { 1 - 2 } $\begin{array}{c}\text { Level } \\
5\end{array}$ & $\mathrm{UC} 203 \times 60$ & $\mathrm{UC} 203 \times 60$ & \\
\hline
\end{tabular}

Figure 1. The layout and member sizes of the frame 


\section{FIRE SAFETY DESIGN}

The steel frame considered here is a common office building with regular layouts. Fire safety design of structures generally follows 3 main steps: 1) determine the temperature development in a fire compartment by assuming a proper fire scenario, 2) calculate the temperature development in the structural members using heat transfer analysis, and 3) determine the fire resistance of the structural members and ensure that the resistance is greater than the effects due to the applied loads evaluated in the fire limit state. Alternatively, a limiting temperature approach may also be used to ensure that it is greater than the maximum temperature attained in the fire.

In the present study, the temperature developed in a fire compartment is calculated based on Eurocode parametric fire [1]. The limiting temperatures of all members are calculated according to the simplified design method in BS5950: Part 8 [2]. The most important factors in determine the room temperature in a fire compartment is the thermal property of the enclosure surfaces, dimensions of the room, fire load and ventilation factor. The fire can be fuel controlled or ventilation controlled. Fuel controlled fire is characterized by rapid burning and rapid decay. Ventilation controlled fire is slower process in which accumulation and dissipation of heat takes a longer time. Liew and Ma [3] have discussed the effects of each factor.

Two possible fire compartments/scenarios are assumed (indicated by the dashed lines) in view of the symmetry of the floor plan as shown in Figure 1. The fire compartments are designated by Comp 1, Comp 2. Assumptions for calculating the parametric fires are listed below:

a. This is a typical office building with characteristic floor load $q_{f, k}=511 \mathrm{MJ} / \mathrm{m}^{2}$

b. Referring to equation (1) of Part I of the companion paper, the effect of active fire fighting measure is $\delta_{n}=\sum_{i=1}^{n} \delta_{n i}=0.6$.

c. At each level, there are continuous window openings on the front and back walls with a height of $2 \mathrm{~m}$ (see Figure 2).

d. All the compartment walls are assumed to be masonry with the thermal absorptivity $b=\sqrt{\rho C \lambda}=1239$.

e. When passive fire protection is specified, sprayed mineral fiber is adopted.

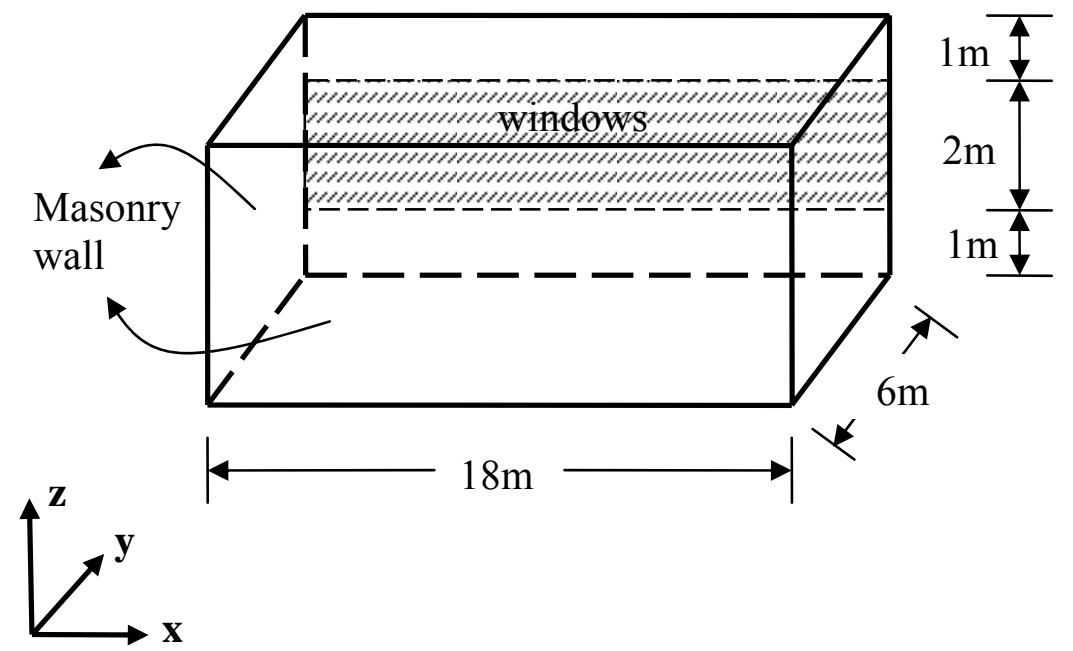

Figure 2(a) Fire Compartment 2 


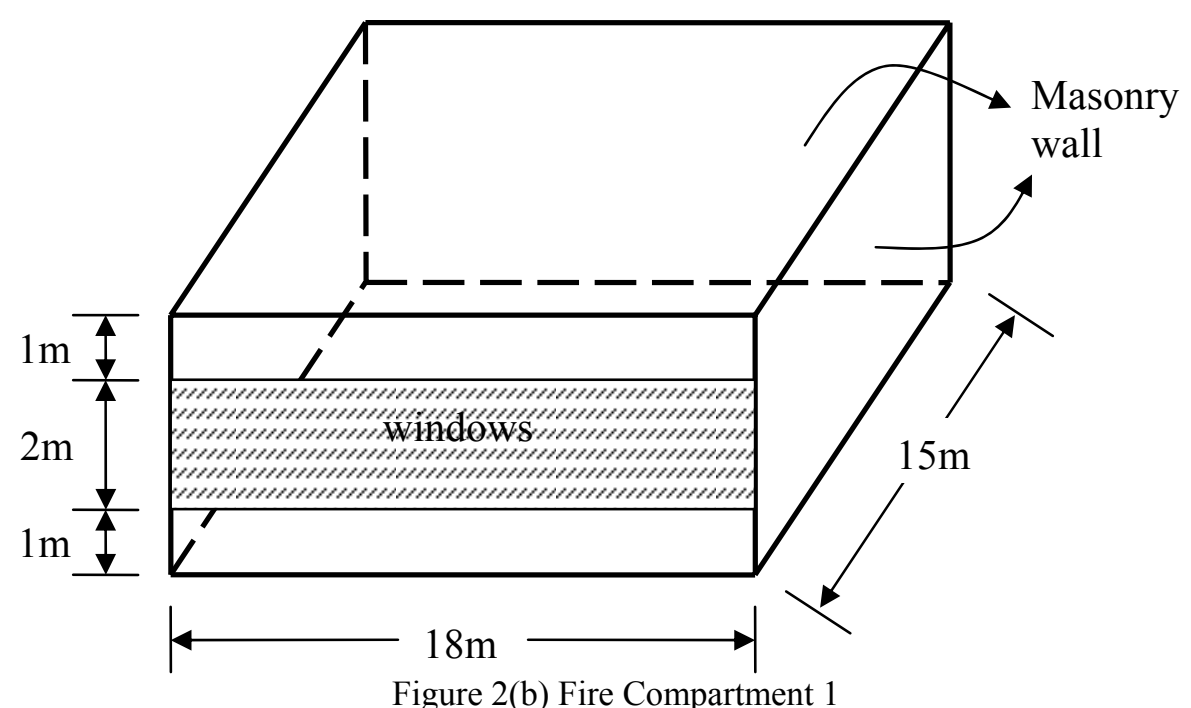

Figure 2. Dimensions and window openings for the fire compartments

The fire load density, $\mathrm{q}_{\mathrm{t}, \mathrm{d}}$, and ventilation factor, $\mathrm{O}$, are $123.6 \mathrm{MJ} / \mathrm{m}^{2}$ and 0.063 for Comp 1 and $97.4 \mathrm{MJ} / \mathrm{m}^{2}$ and 0.063 for Comp 2, respectively. The design temperature-time curves for Comp 1 and Comp 2 are determined in accordance with EC1:Part1.2 [1] as shown in Figure 3. The fire in Comp 1 is more severe than Comp 2 in terms of the peak temperature and rate of heating. Therefore, the structural members sharing the same the boundary of Comp 1 and Comp 2 are designed according to the fire temperature in Comp 1.

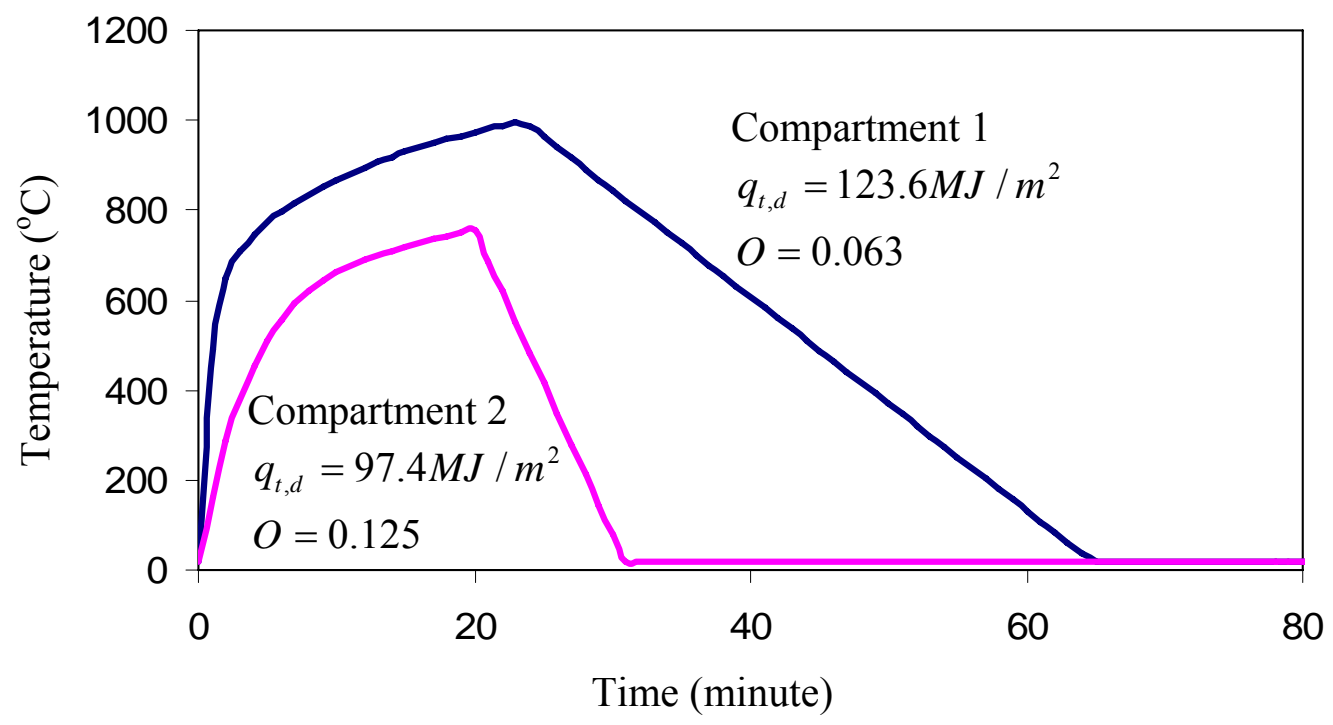

Figure. 3. Design fire for compartments 1 and 2.

Calculation of fire protections for structural members is in accordance with the procedure given in BS 5950: Part 8 [2] and the results are shown in Table 1. $\mu$ is the load ratio of the member defined as the ratio of the effect of load at fire limit state to its capacity. The limiting temperature $\mathrm{T}_{\lim }$ is calculated from the utilization factor. $T_{\text {up }}$ and $T_{p}$ are the maximum temperature in the steel member without and with fire protection. Passive fire protection is required when $T_{u p}>T_{\lim } \cdot t_{\mathrm{c}}$ is the thickness of passive fire protection. To meet the safety requirement, it requires that $T_{p}<T_{\lim }$. 
The results from fire safety design are summarized as follows:

(1) All beams are fire protected by $20 \mathrm{~mm}$ thick fibre mineral spray.

(2) Columns on Grid Line 4 can be left unprotected, the interior columns at the fifth floor need $15 \mathrm{~mm}$ fire protection because of the higher load ratio as shown in Table 2. All the other columns need only $10 \mathrm{~mm}$ fire protection.

Table 2. Calculation of the passive fire protection for all steel members

\begin{tabular}{|c|c|c|c|c|c|}
\hline Section & Level 1 & Level 2 & Level 3 & Level 4 & Level 5 \\
\hline B1 & $\mu=0.673$ & $\mathrm{~T}_{\mathrm{lim}}=598^{\circ} \mathrm{C}$; & $\mathrm{T}_{\text {up }}=1009^{\circ} \mathrm{C} ;$ & $\mathrm{t}_{\mathrm{c}}=20 \mathrm{~mm} ;$ & $\mathrm{T}_{\mathrm{p}}=524^{\circ} \mathrm{C}$ \\
\hline $\mathrm{B} 2$ & $\mu=0.709$ & $\mathrm{~T}_{\text {lim }}=550^{\circ} \mathrm{C}$ & $\mathrm{T}_{\text {up }}=1009^{\circ} \mathrm{C}$ & $\mathrm{t}_{\mathrm{c}}=20 \mathrm{~mm}$ & $\mathrm{~T}_{\mathrm{p}}=524^{\circ} \mathrm{C}$ \\
\hline C1 (Comp 1) & $\begin{array}{l}\mu=0.206 \\
\mathrm{~T}_{\text {lim }}=707^{\circ} \mathrm{C} \\
\mathrm{T}_{\text {up }}=988^{\circ} \mathrm{C} \\
\mathrm{t}_{\mathrm{c}}=10 \mathrm{~mm} \\
\mathrm{~T}_{\mathrm{p}}=576^{\circ} \mathrm{C}\end{array}$ & $\begin{array}{l}\mu=0.165 \\
\mathrm{~T}_{\text {lim }}=741^{\circ} \mathrm{C} \\
\mathrm{T}_{\text {up }}=988^{\circ} \mathrm{C} \\
\mathrm{t}_{\mathrm{c}}=10 \mathrm{~mm} \\
\mathrm{~T}_{\mathrm{p}}=576^{\circ} \mathrm{C}\end{array}$ & $\begin{array}{l}\mu=0.164 \\
\mathrm{~T}_{\text {lim }}=741^{\circ} \mathrm{C} \\
\mathrm{T}_{\text {up }}=1000^{\circ} \mathrm{C} \\
\mathrm{t}_{\mathrm{c}}=10 \mathrm{~mm} \\
\mathrm{~T}_{\mathrm{p}}=631^{\circ} \mathrm{C}\end{array}$ & $\begin{array}{l}\mu=0.111 \\
\mathrm{~T}_{\text {lim }}=790^{\circ} \mathrm{C} \\
\mathrm{T}_{\mathrm{up}}=1000^{\circ} \mathrm{C} \\
\mathrm{t}_{\mathrm{c}}=10 \mathrm{~mm} \\
\mathrm{~T}_{\mathrm{p}}=631^{\circ} \mathrm{C}\end{array}$ & $\begin{array}{l}\mu=0.120 \\
\mathrm{~T}_{\text {lim }}=782^{\circ} \mathrm{C} \\
\mathrm{T}_{\text {up }}=1005^{\circ} \mathrm{C} \\
\mathrm{t}_{\mathrm{c}}=10 \mathrm{~mm} \\
\mathrm{~T}_{\mathrm{p}}=675^{\circ} \mathrm{C}\end{array}$ \\
\hline C1 (Comp 2) & $\begin{array}{l}\mu=0.206 \\
\mathrm{~T}_{\text {lim }}=707^{\circ} \mathrm{C} \\
\mathrm{T}_{\text {up }}=663^{\circ} \mathrm{C} \\
\mathrm{t}_{\mathrm{c}}=\text { none }\end{array}$ & $\begin{array}{l}\mu=0.165 \\
\mathrm{~T}_{\text {lim }}=741^{\circ} \mathrm{C} \\
\mathrm{T}_{\text {up }}=663{ }^{\circ} \mathrm{C} \\
\mathrm{t}_{\mathrm{c}}=\text { none }\end{array}$ & $\begin{array}{l}\mu=0.164 \\
\mathrm{~T}_{\text {lim }}=741^{\circ} \mathrm{C} \\
\mathrm{T}_{\text {up }}=688^{\circ} \mathrm{C} \\
\mathrm{t}_{\mathrm{c}}=\text { none }\end{array}$ & $\begin{array}{l}\mu=0.111 \\
\mathrm{~T}_{\text {lim }}=790^{\circ} \mathrm{C} \\
\mathrm{T}_{\text {up }}=688^{\circ} \mathrm{C} \\
\mathrm{t}_{\mathrm{c}}=\text { none }\end{array}$ & $\begin{array}{l}\mu=0.120 \\
\mathrm{~T}_{\text {lim }}=782^{\circ} \mathrm{C} \\
\mathrm{T}_{\text {up }}=706^{\circ} \mathrm{C} \\
\mathrm{t}_{\mathrm{c}}=\text { none }\end{array}$ \\
\hline C2 (Comp 1) & $\begin{array}{l}\mu=0.306 \\
\mathrm{~T}_{\text {lim }}=659^{\circ} \mathrm{C} \\
\mathrm{T}_{\text {up }}=982^{\circ} \mathrm{C} \\
\mathrm{t}_{\mathrm{c}}=10 \mathrm{~mm} \\
\mathrm{~T}_{\mathrm{p}}=561^{\circ} \mathrm{C}\end{array}$ & $\begin{array}{l}\mu=0.324 \\
\mathrm{~T}_{\text {lim }}=642^{\circ} \mathrm{C} \\
\mathrm{T}_{\text {up }}=1000^{\circ} \mathrm{C} \\
\mathrm{t}_{\mathrm{c}}=10 \mathrm{~mm} \\
\mathrm{~T}_{\mathrm{p}}=631^{\circ} \mathrm{C}\end{array}$ & $\begin{array}{l}\mu=0.243 \\
\mathrm{~T}_{\text {lim }}=686^{\circ} \mathrm{C} \\
\mathrm{T}_{\text {up }}=1000^{\circ} \mathrm{C} \\
\mathrm{t}_{\mathrm{c}}=10 \mathrm{~mm} \\
\mathrm{~T}_{\mathrm{p}}=631^{\circ} \mathrm{C}\end{array}$ & $\begin{array}{l}\mu=0.214 \\
\mathrm{~T}_{\text {lim }}=702^{\circ} \mathrm{C} \\
\mathrm{T}_{\text {up }}=1003^{\circ} \mathrm{C} \\
\mathrm{t}_{\mathrm{c}}=10 \mathrm{~mm} \\
\mathrm{~T}_{\mathrm{p}}=654^{\circ} \mathrm{C}\end{array}$ & $\begin{array}{l}\mu=0.224 \\
\mathrm{~T}_{\text {lim }}=697^{\circ} \mathrm{C} \\
\mathrm{T}_{\text {up }}=1009^{\circ} \mathrm{C} \\
\mathrm{t}_{\mathrm{c}}=15 \mathrm{~mm} \\
\mathrm{~T}_{\mathrm{p}}=610^{\circ} \mathrm{C}\end{array}$ \\
\hline
\end{tabular}

\section{FINITE ELEMENT MODELLING}

\subsection{Modeling Technique}

The building frame consists of three main structural components: steel beams and columns, floor slab and external cladding. The steel beams and columns are major load-bearing members and they must be designed to provide adequate resistance to ensure overall stability and strength. The presence of floor slab is important to ensure adequate diaphragm action to ensure that the whole framework acts together in resisting the localized lateral forces generated by the blast load. External cladding is modeled so that to calculate the distribution of blast loading on the building and its deformation pattern is used to judge the damage caused by the blast. Both the slabs and walls are modeled by shell elements. For the steel members, the importance of refined modeling using shell elements has been discussed in the companion paper. Therefore, it was decided that the FEM model for the whole building should be constructed using shell elements. The connection details are ignored. Beams and columns are fully coupled at the common nodes and the connection failure is not considered. Concrete slab is fully connected to the upper flange of beams on the boundary and is continuous over the whole floor area. The external cladding in a particular storey is assumed to be attached to the columns and the beam below and is not attached to the upper beam. 
The benefits and drawbacks of implicit dynamic solver and explicit dynamic solver have been discussed in the companion paper. Generally, explicit solver is suitable for blast response analysis and implicit solver is appropriate for fire response analysis. In this example, explicit solver is used for both blast and fire analysis for the following reasons:

(1) A large amount of shell elements are involved in the FE modeling of this problem. When using implicit solver, the transpose of the stiffness matrix and solution of the equilibrium equation imposes huge requirement for computing resources.

(2) The response of the structure in fire is highly nonlinear, which makes the convergence of implicit solver very difficult. When the step size is very small, the implicit solver no longer possesses superiorities over the explicit solver.

In the explicit solver, the acceleration at any time can be directly calculated from the equilibrium equation

$$
\{\ddot{x}\}=[M]^{-1}\left(\left\{P^{n}\right\}-\left\{F^{n}\right\}\right)
$$

where $\{\ddot{x}\}$ is the acceleration vector, $[M]$ the mass matrix, $\left\{P^{n}\right\}$ is the body force and external force vector, $\left\{F^{n}\right\}$ is the internal force vector, and $\mathrm{n}$ is the numerical time step. The explicit update of the velocities and coordinates is given by

$$
\begin{aligned}
& \left\{\dot{\mathrm{X}}^{(\mathrm{n}+0.5) \square \mathrm{t}}\right\}=\left\{\dot{\mathrm{X}}^{(\mathrm{n}-0.5) \Delta \mathrm{t}}\right\}+\left\{\ddot{\mathrm{X}}^{\mathrm{n}}\right\} \Delta \mathrm{t} \\
& \left\{\mathrm{X}^{(\mathrm{n}+1) \Delta \mathrm{t}}\right\}=\left\{\mathrm{X}^{\mathrm{n}}\right\}+\left\{\dot{\mathrm{X}}^{(\mathrm{n}+0.5) \Delta t}\right\} \Delta \mathrm{t}
\end{aligned}
$$

As no iteration or convergence check is required, the computation time needed for each time step is almost constant and the total computation time to finish one analysis depends on the total analysis time and the size of time step, $\Delta t$. For this model to be analyzed on a computer with $3.0 \mathrm{G} \mathrm{CPU}$ processor and $1 \mathrm{G}$ memory, the time to complete each second of analysis time is about 1500 minutes. If the fire burning duration is to be analyzed in real time scale, it needs 750 hours to complete the analysis of a 30 minutes fire. Therefore, it is necessary to scale the burning duration so the computational time can be shorten without affecting the final result.

To study on the effect of time scaling, a steel beam with fixed ends loaded by lateral static loading and heated to $1000^{\circ} \mathrm{C}$ is considered. It can be seen from Figure 4 that the response of the beam in fire is not very sensitive to the rate of heating. Small difference in displacement results is observed when the rate of heating varies from $150^{\circ} \mathrm{C} / \mathrm{s}$ to $1000^{\circ} \mathrm{C} / \mathrm{s}$ for temperature less than $800^{\circ} \mathrm{C}$. Some variation in beam displacement is observed at the ends of the analysis (i.e., temperature $>800^{\circ} \mathrm{C}$ ) when steel has softened significantly and the cross section deformed rather significantly at high temperature. A static analysis is also performed by using ABAQUS and the deflection curve is shown in Figure 4. The static analysis terminates at $750^{\circ} \mathrm{C}$ due to convergence problem. However, for temperatures below $750^{\circ} \mathrm{C}$, results given predicted by the static analysis is very close to that by the explicit dynamic analysis. This study concluded that for fire analyses at high temperature $(>$ $800^{\circ} \mathrm{C}$ ) which usually involves significant cross section deformation (local buckling or distortional buckling), the rate of heating may be scaled up to $250^{\circ} \mathrm{C} / \mathrm{s}$. At low temperature $\left(<800^{\circ} \mathrm{C}\right)$, the rate of heating may be increased to $1000^{\circ} \mathrm{C} / \mathrm{s}$. In the analysis of the five storey building frame, the 30 
minutes duration of the parameter fire is scaled to 6 seconds. This is equivalent to an average heating rate of less than $200^{\circ} \mathrm{C} / \mathrm{s}$.

Temperature $\left({ }^{\circ} \mathrm{C}\right)$

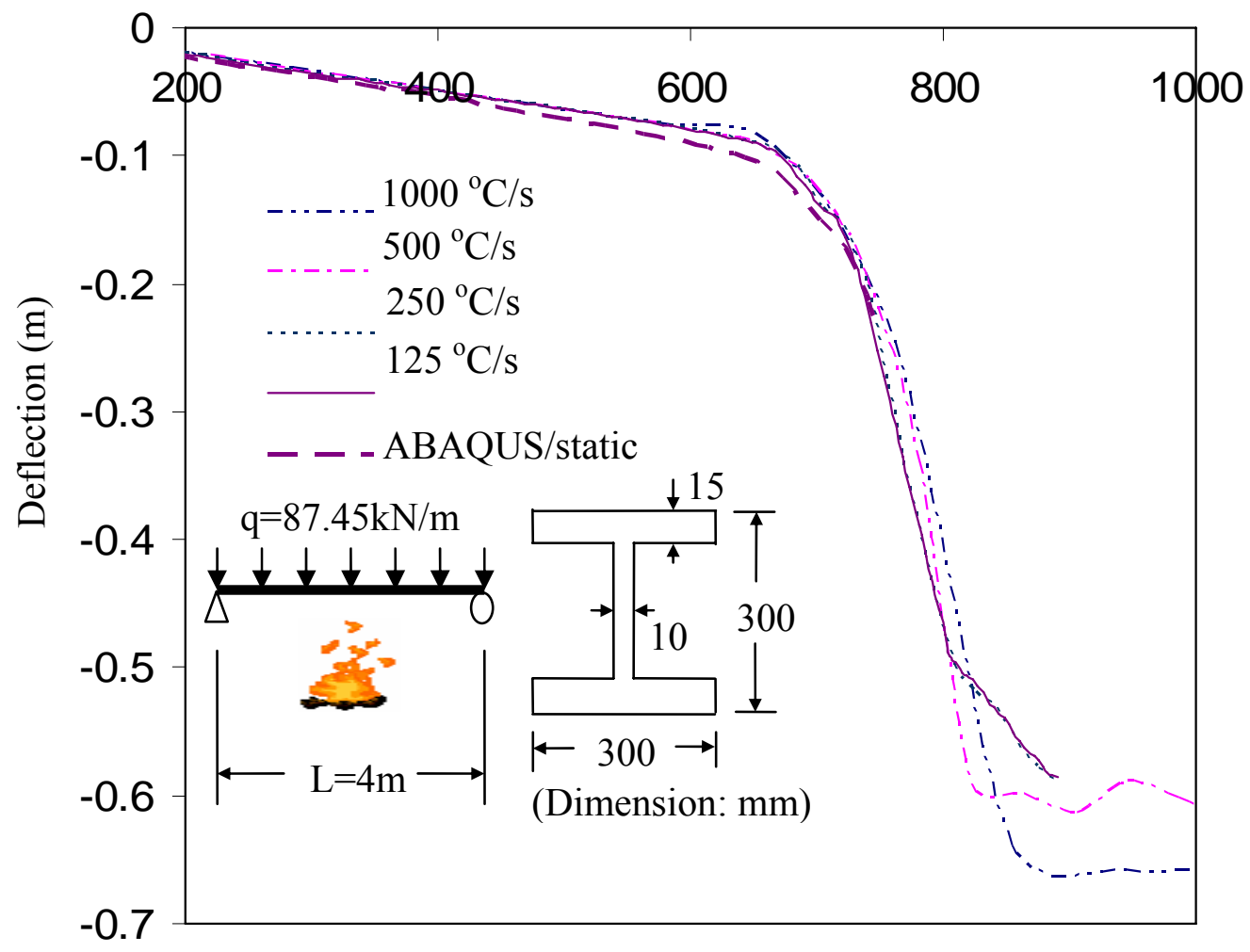

Figure 4. Effect of rate of heating on the deflection of steel beam

\subsection{Material Property}

For blast and fire analysis, the constitutive model should be able to capture 1) material hardening due to strain-rate effect, 2) material softening due to thermal effect and 3) material failure.

Steel is a high-strength, isotropic material with very good ductility. It can sustain extreme deformations before any sign of material failure. However, steel lose its strength when it is heated beyond to $400^{\circ} \mathrm{C}$. Degradation of the strength at elevated temperature is the major reason that leads to structural collapse in fire. Therefore thermal effect must be included and the elastic-plastic-thermal material model is chosen for structural steel. In the present study, the stress-strain curves for steel at elevated temperature is in accordance with EC3: Part 1.2 [4] as shown in Figure 5. 


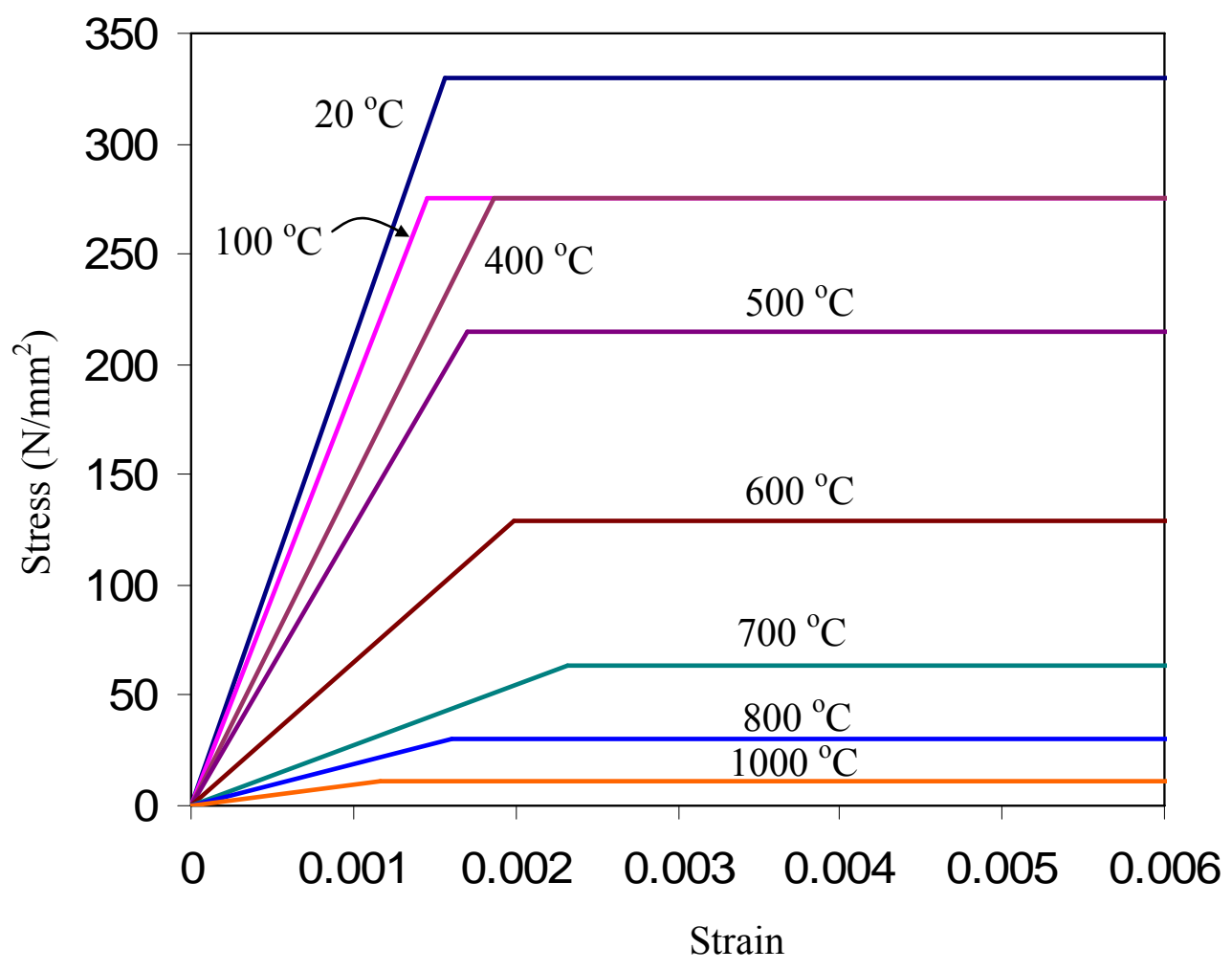

Figure 5. Constitutive model used for structural steel (CEN, 2001a)

To model the strain rate effect, the work by Soroushian and Choi [5] shows that the yield strength of steel can be enhanced by $20 \%$ to $50 \%$ at when the strain rate increases from $10^{-3} \mathrm{sec}^{-1}$ to $1 \mathrm{sec}^{-1}$. For simplified calculation, TM5-1300 (1990) recommends that the design strength of steel can be increased by $20 \%$ to consider the strain-rate effect under blast loading. For the ease of modeling, TM5-1300 [6] recommendation is adopted in the present analysis for modeling the strain rate effect on steel strength.

Concrete is a heat retardant material which has a relatively low conductivity as compared to steel. Heat transfer analysis shows that the maximum average temperature of the concrete slab is only slightly above $200^{\circ} \mathrm{C}$ in the fire compartments. The degradation of concrete strength and stiffness with temperature is therefore neglected and the nominal design strength of $24 \mathrm{~N} / \mathrm{mm}^{2}$ is used for C30 concrete. The effect of strain-rate is simply dealt with by amplifying the static yield strength with a factor

$$
\lambda=1+\left(\frac{\dot{\varepsilon}}{C}\right)^{\frac{1}{P}}
$$

where $\dot{\varepsilon}$ is the strain rate and $\mathrm{C}$ and $\mathrm{P}$ are two constant parameters depending on the types of material used. TM5-1300 [6] recommends the values of $\mathrm{C}=30$ and $\mathrm{P}=3.5$ for $\mathrm{C} 30$ concrete, and the strength enhancement factor $\lambda$ versus the strain rate is shown in Figure 6.

The masonry wall is removed in the fire analysis and the thermal effect is non-relevant for this material. The most critical feature for modeling the cladding is to propose a failure criterion that can simulate the cracking and destruction of the masonry wall. However, this phenomenon is too complicated for detailed consideration here and a simplified criterion based on the failure strain is defined. According to the work by Makovicha et al. [7], masonry wall panel may be considered as 
collapsed when the angle of the change of gradient of the bending line near the mid-span area exceeds the limiting value of $1^{\circ} \sim 2^{\circ}$. The failure of masonry wall is governed by either the maximum displacement or the maximum tensile strength being reached. For a masonry panel of dimension $2250 \times 2755 \mathrm{~mm}$ and thickness $65 \mathrm{~mm}$, the maximum displacement at failure was $50 \mathrm{~mm}$. This is equivalent to a tensile stress of $2.3 \mathrm{MPa}$ with an effective wall stiffness of $268 \mathrm{MPa}$. Dividing the stress by the effective stiffness gives a failure strain of 0.0084 . This failure strain value will be used as a criterion to define the failure of the masonry cladding in the present study.

So far no work has been conducted on the effect of strain rate on the strength of masonry. According to the work by Grote et al.[8], mortar is extremely sensitive to strain rate applied in the range of $10^{-3} \mathrm{sec}^{-1}$ to $1170 \mathrm{sec}^{-1}$. It is expected that the design strength of masonry wall will also be significantly enhanced in high strain rate due to blast loading. In the present study, the material model for concrete is used for masonry to approximate the strain-rate effect.

\section{4. $\quad$ BLAST ANALYSIS}

\subsection{Calculation of the Blast Pressure}

Assume a mid-size car explosive is detonated at $5 \mathrm{~m}$ from the outer surface of the building. From the terrorist bomb summary data provided by Bangash [9], the TNT equivalent weight of the explosive is assumed to be $1000 \mathrm{~kg}$. The blast pressure acting on a particular point on the external cladding is calculated as the reflected blast wave pressure at that position. The maximum pressure is at the point with shortest distance to the charge position. The blast pressure for a point at $5 \mathrm{~m}$ away from the detonation position may be calculated as follows:

(1) The distance of this point to the detonation is

$$
R=5 \mathrm{~m}=16.404 \mathrm{ft}
$$

The scaled distance is

$$
Z=\frac{R}{W^{1 / 3}}=\frac{16.404}{2203^{1 / 3}}=1.26 f t \cdot l b^{-\frac{1}{3}}
$$

where $\mathrm{W}$ is the TNT equivalent weight of the explosive in $\mathrm{lb}$.

(2) According to the scaled distance $\mathrm{Z}$, the incident overpressure $\mathrm{P}_{\mathrm{s}}$ (psi) and scaled arrival time of the wave $\frac{t_{a}}{W^{1 / 3}}$ can be obtained from TM5-1300 [6] as $\mathrm{P}_{\mathrm{so}}=707.5 \mathrm{psi}$ and $\frac{t_{a}}{W^{1 / 3}}=0.110 \mathrm{~ms} \cdot \mathrm{lb}^{-\frac{1}{3}}$. The arrival time is $1.43 \mathrm{~ms}$.

(3) The reflected over-pressure is simply a scale of the incident over-pressure by the amplification factor $\mathrm{C}_{\mathrm{r}}$. At this point, the incident wave is perpendicular to the wall, therefore, $\alpha=90^{\circ}$. The reflected wave amplification factor can be calculated as $\mathrm{C}_{\mathrm{r}}=8.13$, that is, $\mathrm{P}_{\mathrm{so}}=5752$ psi. The reflected impulse is obtained from $\frac{I_{r}}{W^{1 / 3}}=195.55 \mathrm{psi} \cdot \mathrm{ms} \cdot \mathrm{lb}{ }^{-\frac{1}{3}}$, or $I_{r}=2544.5 \mathrm{psi} \cdot \mathrm{ms}$ 
(4) The shape of the reflected pressure can be approximated by triangular with zero rise time and the duration of the blast pressure is

$$
t_{0}=\frac{2 \times 2544.5}{5752}=0.885 \mathrm{~ms}
$$

Figure 7 shows the variation of the blast pressure on the front wall surface with a change of the distance $\mathrm{R}$ from the detonation source. With increase of distance, the peak pressure is decreased rapidly and the duration of the blast pressure is increased moderately.

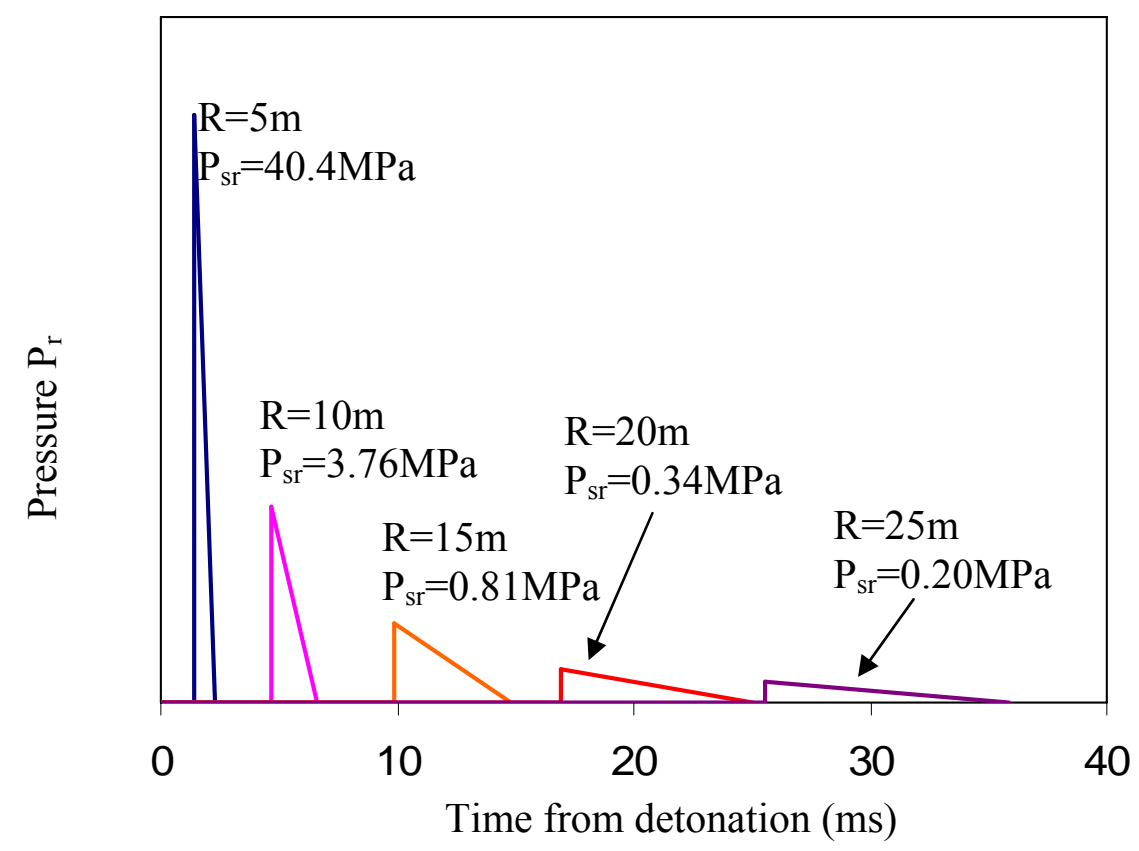

Figure 7. Variation of the blast pressure with distance to the charge position

\subsection{Structural Behaviour in Blast Load}

Comparing Figure 1 indicating the location of explosion with Figure 7 shows that the blast wave covers the whole structure in $50 \mathrm{~ms}$. It takes a little more time for the structure to respond. The damaged shape of the structure in $0.5 \mathrm{~s}$ is shown in Figure 8 for the front view and Figure 9 from the side view. Three wall panels W1, W2 and $\mathrm{W} 3$ are knocked out from the frame and fly toward the inside of the building. The wall panel that is nearest to the explosion is endowed

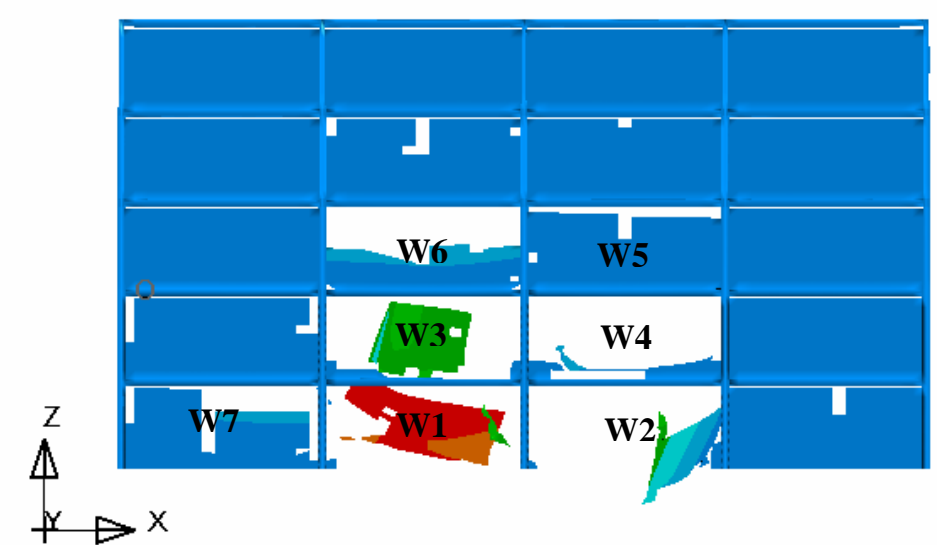

Figure 8. Front view of the structure after explosion with so much energy that it will fly to the back of the building with high speed provided that there is no obstruction. The other two panels can only reach grid line 3. Up to 1 s after explosion, four other panels W4, W5, W6 and W7 collapsed. But no initial speed is attained to cause any flying fragments. 
Effect of direct blast pressure acting on the concrete slab or direct impact from the damaged wall panels on the concrete slab are not considered in this analysis. The floor slab system is only subjected to lateral force from the blast pressure on the walls. The analysis results show no signs of failure on the slab system. The strong in-plane rigidity of the slab system ensures that the building deforms together in the lateral direction at each level. The lateral

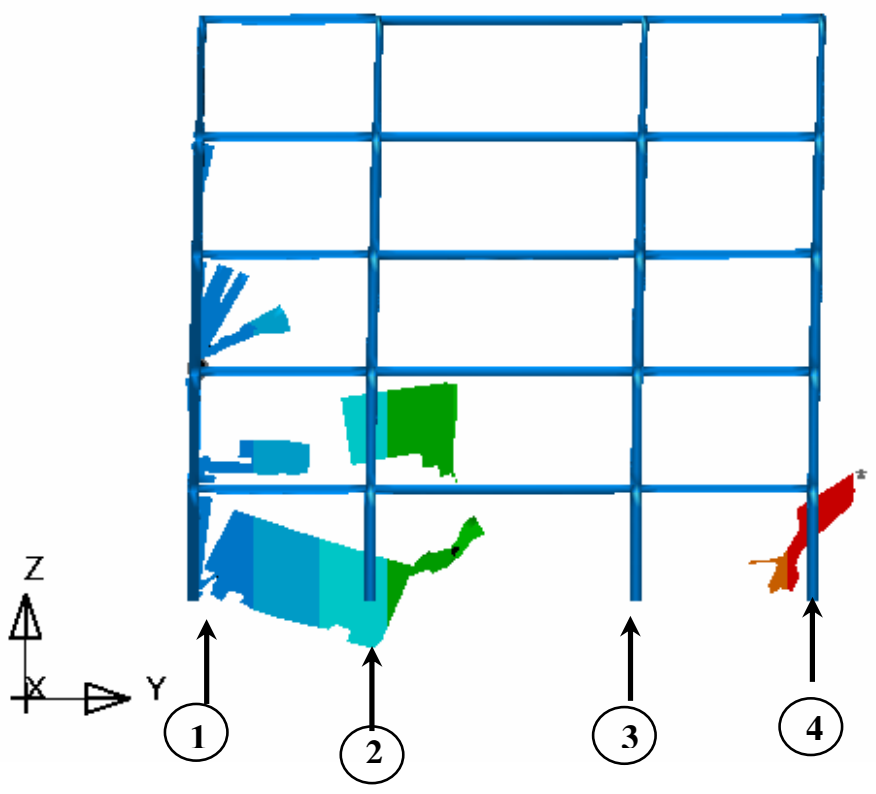

Figure 9. Side view of the structure after explosion displacements at each floor level are shown in Figure 10. The maximum inter-storey drift is about $0.12 \mathrm{~m}$ at the top level. At maximum deflection (corresponding to time $=0.6 \mathrm{~s}$ ), extensive yielding occurred at the upper and lower ends of the steel columns at each level.

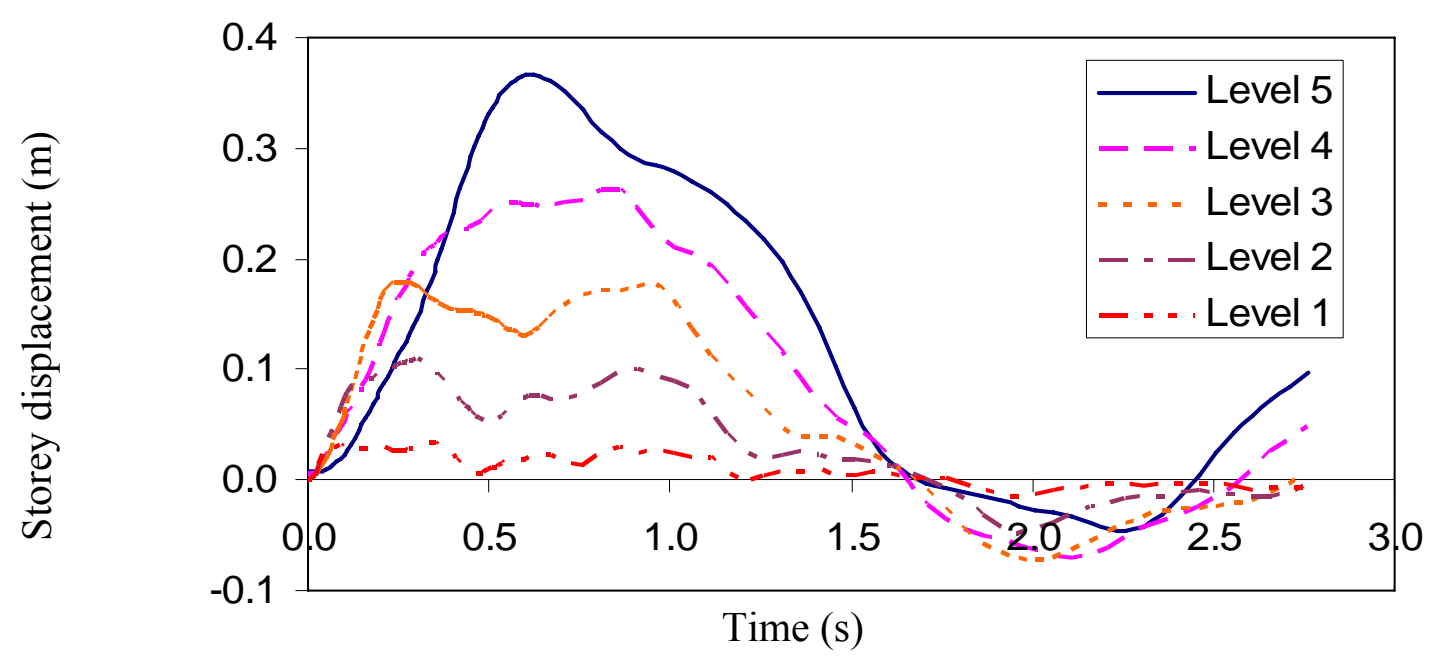

Figure 10. Lateral displacement of the frame at each floor level due to the blast load

Damages to the steel members are mostly concentrated to the columns at level 1 and 2 along grid line B1 and $\mathrm{C} 1$ as shown in Figure 11. These columns exhibit typical shear deformation mode near the upper and lower ends. The first wall panel failed within $10 \mathrm{~ms}$. The second and third one failed within $30 \mathrm{~ms}$. After the failure of these walls, the blast pressure acting the steel members is released immediately. Therefore, these columns are loaded with a very short duration. The maximum deflection of the steel columns is $60 \mathrm{~mm}$ for $\mathrm{C} 1$ at level 2. The deformed columns remain standing and supporting the vertical loads. The steel beams are restrained by the floor system at their upper flanges and very little damage is observed. The steel beams nearer to the blast positions have 
obvious distortion at the lower flanges. The beam nearest to the blast position at level 2 is blown upward and deflected by about $60 \mathrm{~mm}$ at the mid-span.

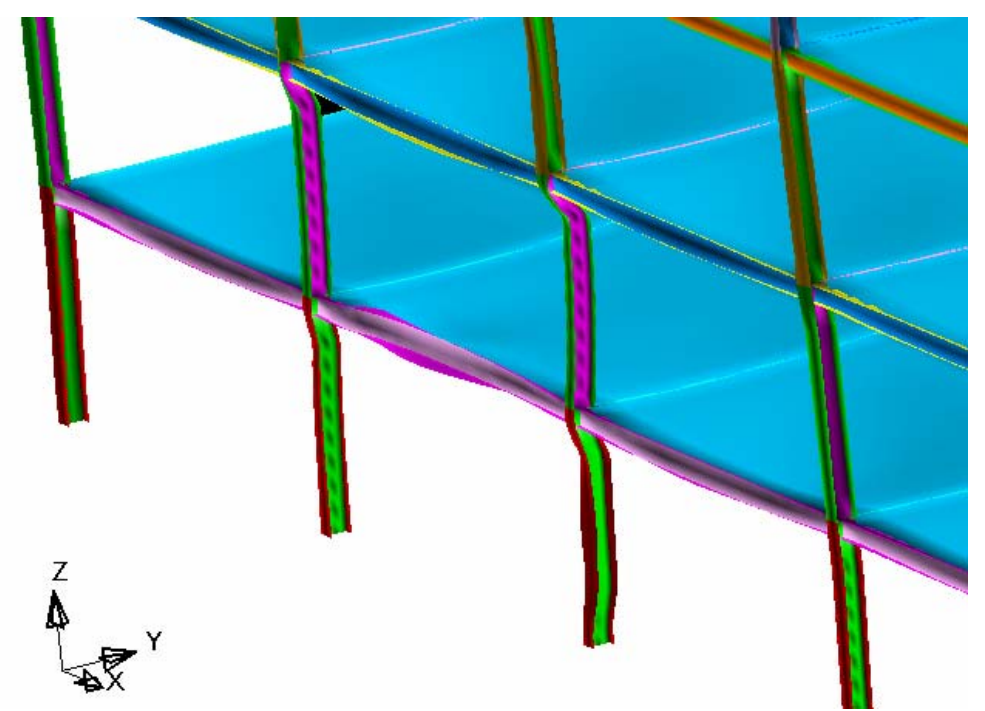

Figure 11. Shear deformation at the column ends and distortional deformation of the steel beams at 1.6 seconds after blast detonation

In general, damages caused by the blast load are limited to the cladding systems. Steel beams and floor slab system are subjected to minor local damages. Damage to several columns does not impose any threat to the overall stability of the building and there is no obvious downward movement of the floor system.

\section{SUBSEQUENTIAL FIRE ANALYSIS}

In this section, the devastating effect from the blast loading will be discussed and the fire resistance of the damaged building will be assessed.

\subsection{Effect of Blast on Fire Protection System}

Damage on active and passive fire protection system caused by blast load or fragmentation impact is very difficult to assess quantitatively because little information is available from the literature. For a reliable assessment, the manufactures of such systems should be consulted or tests should be carried to evaluate their performance in blast. In the present study, the following assumptions are made:

(1) At the ground floor level, the compartment wall separating Comp1 and Comp 2 will be impacted by the flying masonry bricks. It is required by EC1: Part 1.2 [1] that fire walls should resist a minimum horizontal impact load with a design energy of $3000 \mathrm{Nm}$. From the blast analysis results, the speed of the wall panel fragment reaching the compartment wall is about $45 \mathrm{~m} / \mathrm{s}$. The impact energy is equivalent to $437.4 \mathrm{kN} / \mathrm{m}$, which is far exceeding the designed resistance. Therefore, it may be assumed that the fire wall fails due to the impact. Therefore Comp 1 and Comp 2 can be combined to form a single fire compartment with a bigger burning space. At level 2 and level 3, the flying wall did not reach the compartment wall and the integrity of the wall is not breached. 
(2) The active fire fighting facilities such as fire alarm system, water sprinkler system, etc. are conservatively assumed not to be functional after blast.

(3) Due to the failure of the external cladding, fire is assumed to be ignited at the ground floor and it spreads to the upper floor levels. Considering the damaged shape of the claddings shown in Figure 7, fire is assumed to spread from level 1 to level 2 and then to level 3 . The higher floor level is assumed to be ignited when the temperature of the lower floor level reaches $700^{\circ} \mathrm{C}$.

(4) The damage to the passive fire protections covering the steel members are assessed based on the flying distance of the wall fragments. All the front columns that are directly exposed to blast pressure are assumed to have their fire protection completely removed. Considering the flying distance of the fragments, members that are within the reach of the flying fragments are assumed to lose half of their fire protections. Those members that are out of reach of the fragmentations are assumed to remain intact. According to this principle, the state of the steel members from level 1 to level 3 for the left part of the building are shown in Figure 12.

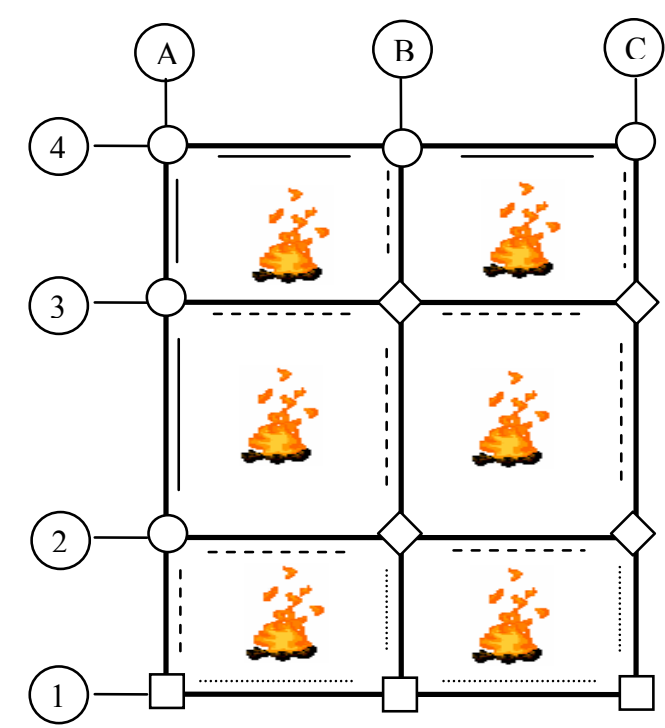

Level 1

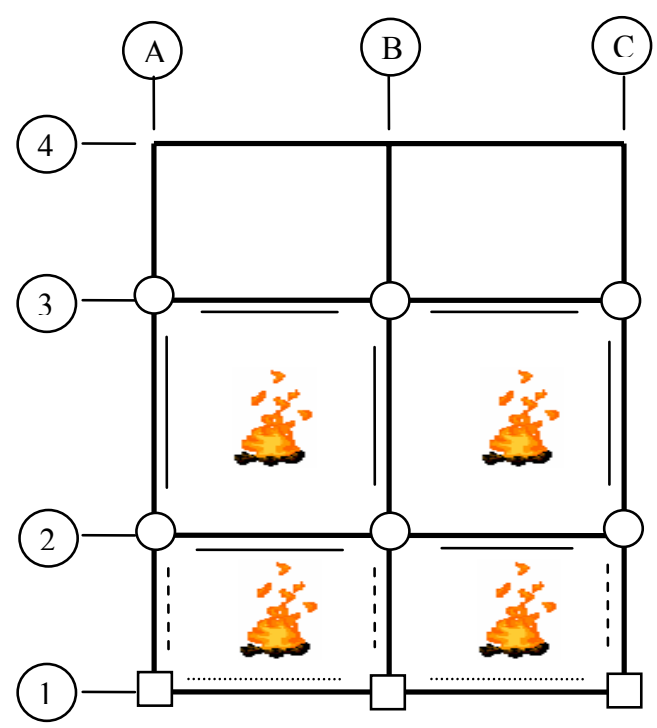

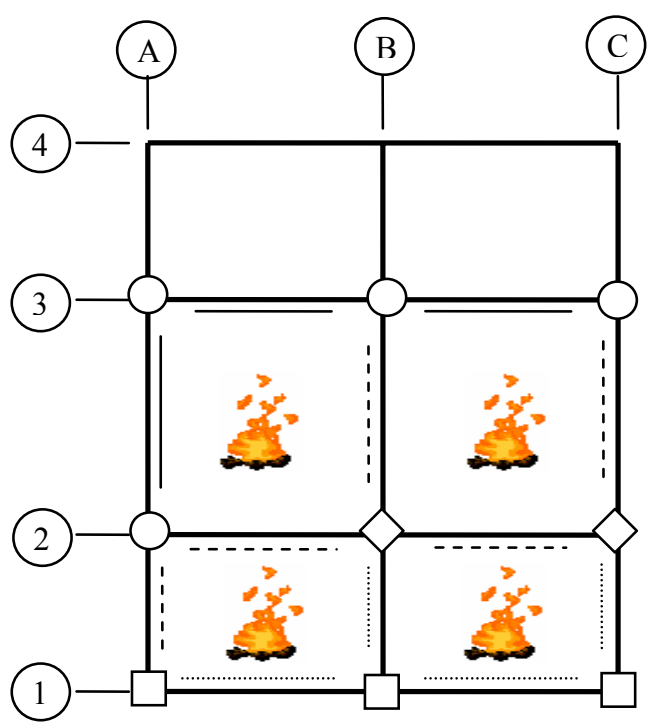

$\underline{\text { Level } 2}$

Symbols:

Column fire protection damaged

$\diamond$ Column fire protection partially damaged

Column fire protection undamaged

Beam fire protection damaged

Beam fire protection partially damaged

Beam fire protection undamaged

Level 3

Figure 12. Blast damage to passive fire protection 
The design fire model will be different from the design fire for the originally undamaged building due to the change of the parameters such as the fire load, fire compartment geometry, ventilation, etc. In the present study, the following changes are made in calculating the design fire in the fire compartment:

(1) when calculating the fire load, the effect of active fire fighting measure is set to $\delta_{n}=1.0$ instead of 0.6 so that the design fire load is enlarged by 1.67 times;

(2) At the ground floor, Comp 1 and Comp 2 merged into one big compartment with floor area equal to $378 \mathrm{~m}^{2}$;

(3) The opening area to the fire compartment is increased due to the collapse of the external walls.

After considering all the above factors, a new design fire curve for the ground floor and the upper floor levels are recalculated as shown in Figure 13. The fire curves are very close to each other. This is because the parametric fire curves for both compartments are fuel controlled and the there is little difference in the fire load for different floor levels. By assuming that fire will spread from the lower level to the upper level when the temperature of the lower level reaches $700^{\circ} \mathrm{C}$, it takes only 3 minutes for the fire at the ground floor to spread to the second level. The spread of fire is simulated by the different timing of fire curves shown in Figure 14. Comparison of the original fire curves in Figure 3 and the new fire curve in Figure 13 seems to indicate that fire in the damaged structure will become less severe despite the increase of the fire load. This is because when the opening area is increased, the fire becomes fuel controlled, the room fire is rapidly burnt out and heat is dissipated through the opening.

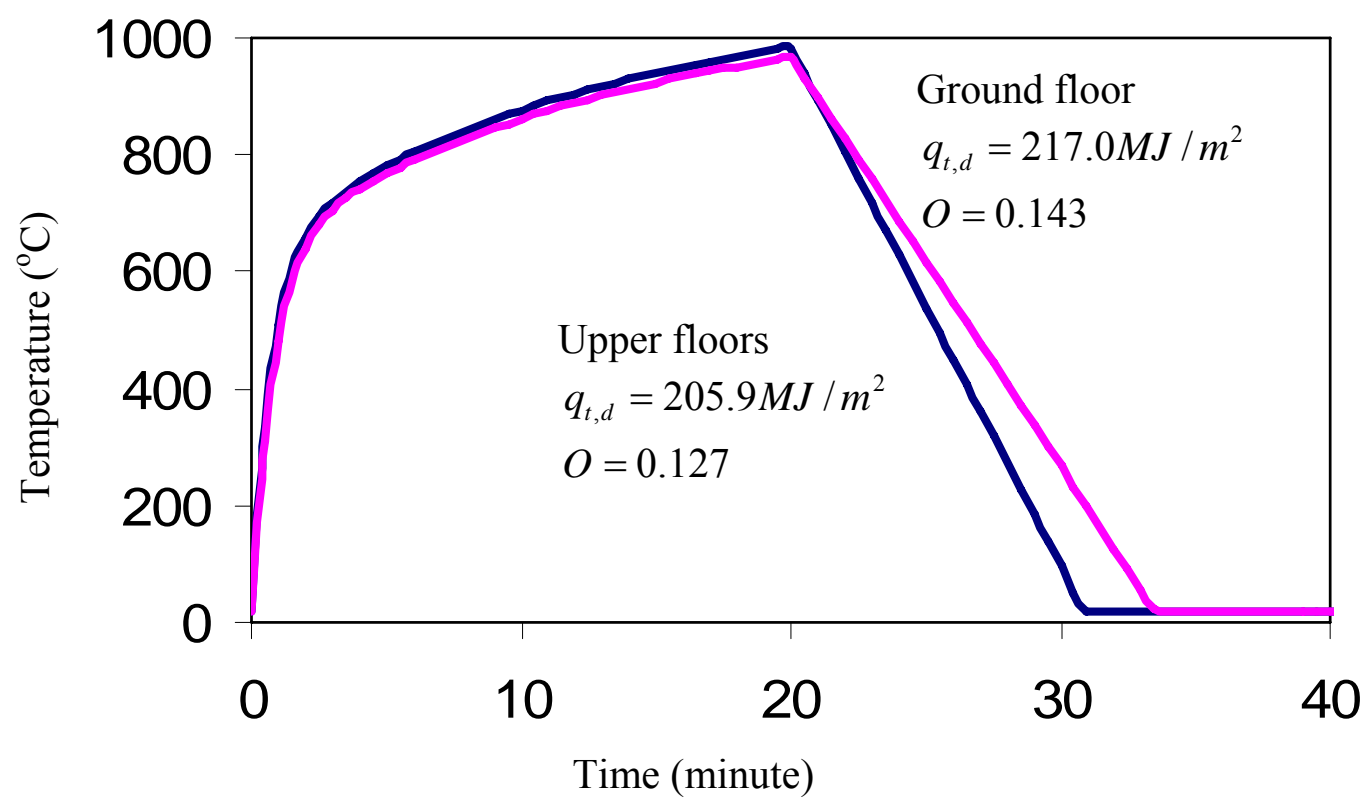

Figure 13. Design fire models for the building after blast 


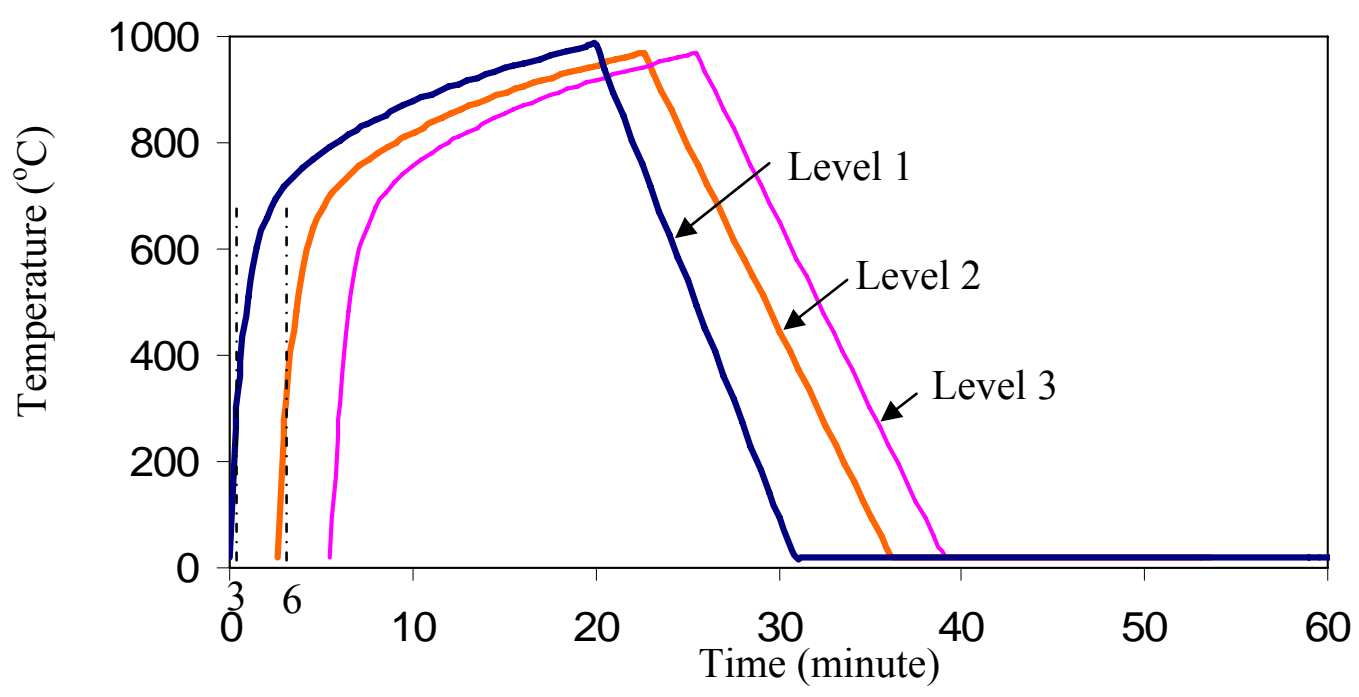

Figure 14. Spreading of fire from level 1 to level 3

\subsection{Response of the Damaged Structure in Fire}

According to the state of passive fire protection shown in Figure 12 and the design fire curves shown in Figure 13, the temperatures of the steel members in fire can be calculated from the incremental method recommended by EC3: Part 1.2 [4]. The approximate temperature development for beams and columns with fire protection undamaged, half damaged, and totally damaged are shown in Figure 15 and Figure 16. The temperature of steel members without any fire protection could be heated up to $1000^{\circ} \mathrm{C}$ in 20 minutes. Refer to Table 2 where the limiting temperatures of all the members are below $800^{\circ} \mathrm{C}$, it is expected that those members with their fire protection totally damaged after the blast will fail in fire.

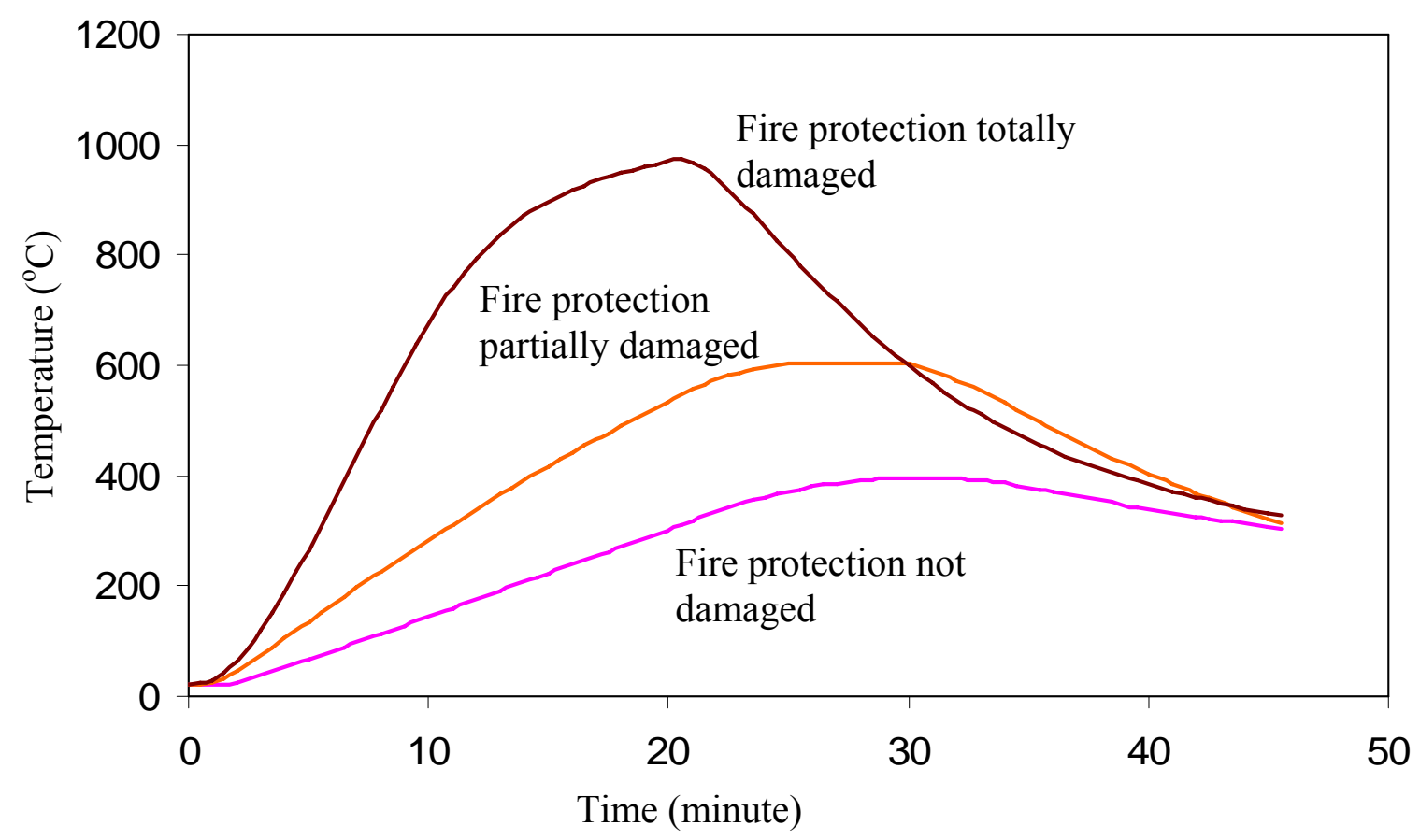

Figure 15. Temperature-time curves for steel beams in fire 


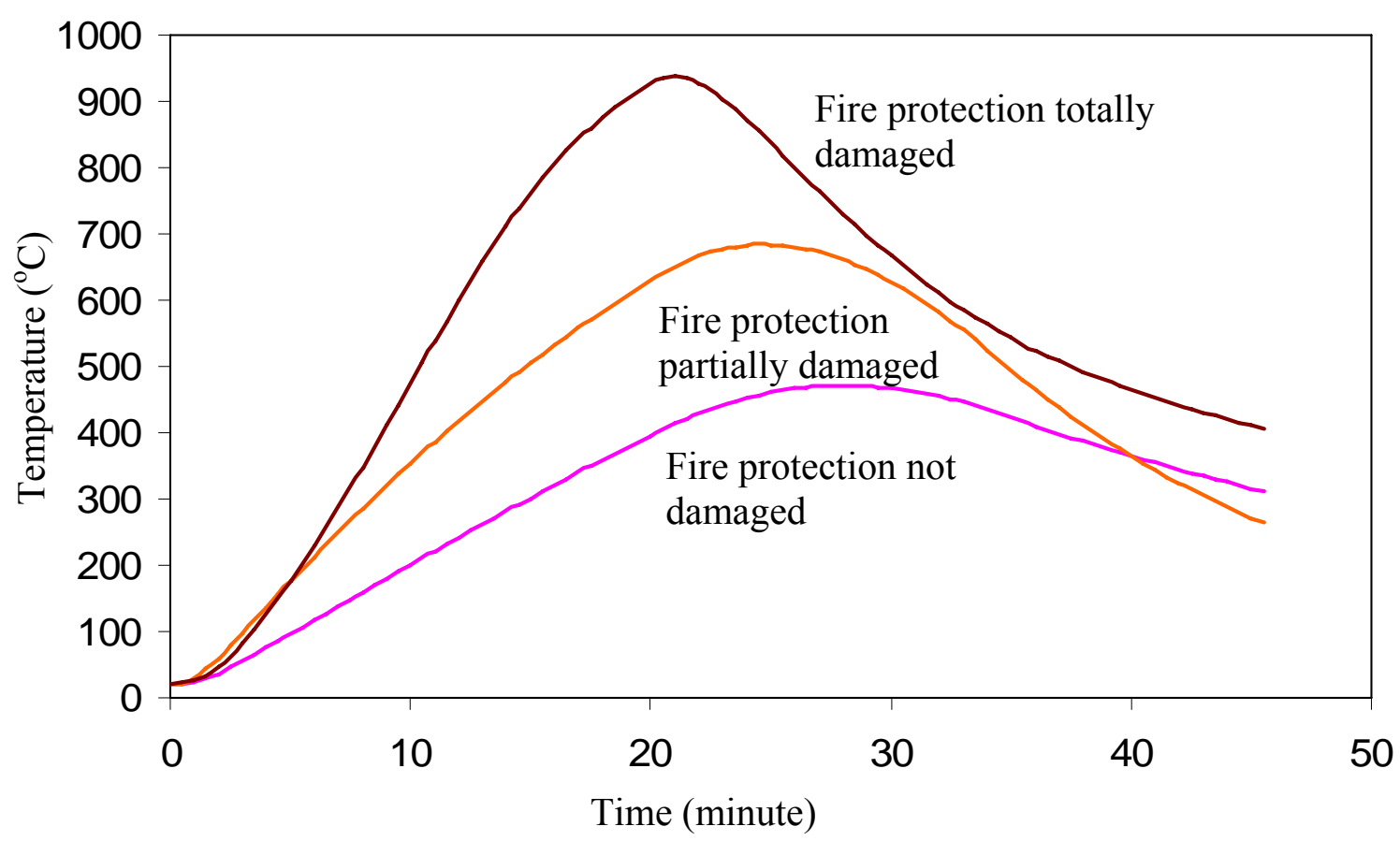

Figure 16. Temperature-time curves for steel columns in fire

The response of the structure in fire can be divided into several stages and the typical deformed shape of the building at each stage is displayed in Figures 17-19. The first stage is for heating time at 14 minutes, in which the deformed shape of the building is characterized by the large deflection of the beam and the slabs. With the increase of temperature, both the stiffness and the yield

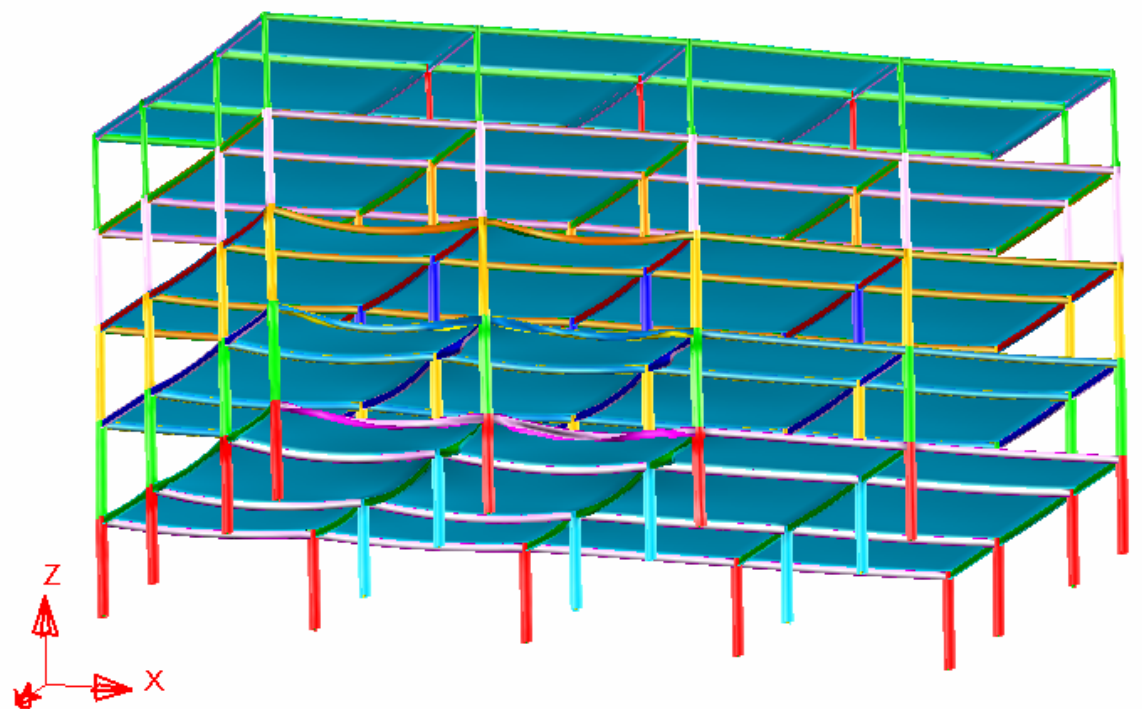
strength of the steel beams decrease and their deflections are increased. Although the degradation of concrete strength is not considered, the total deflection of the slab increased significantly due to the deflection of the supporting beams at the edges. Extensive local and torsional buckling of the steel beam section is observed in the fire compartments when the thermal expansions of the steel members are restrained both by the slab and the columns causing further deflection due to the secondary P- $\delta$ effect. 


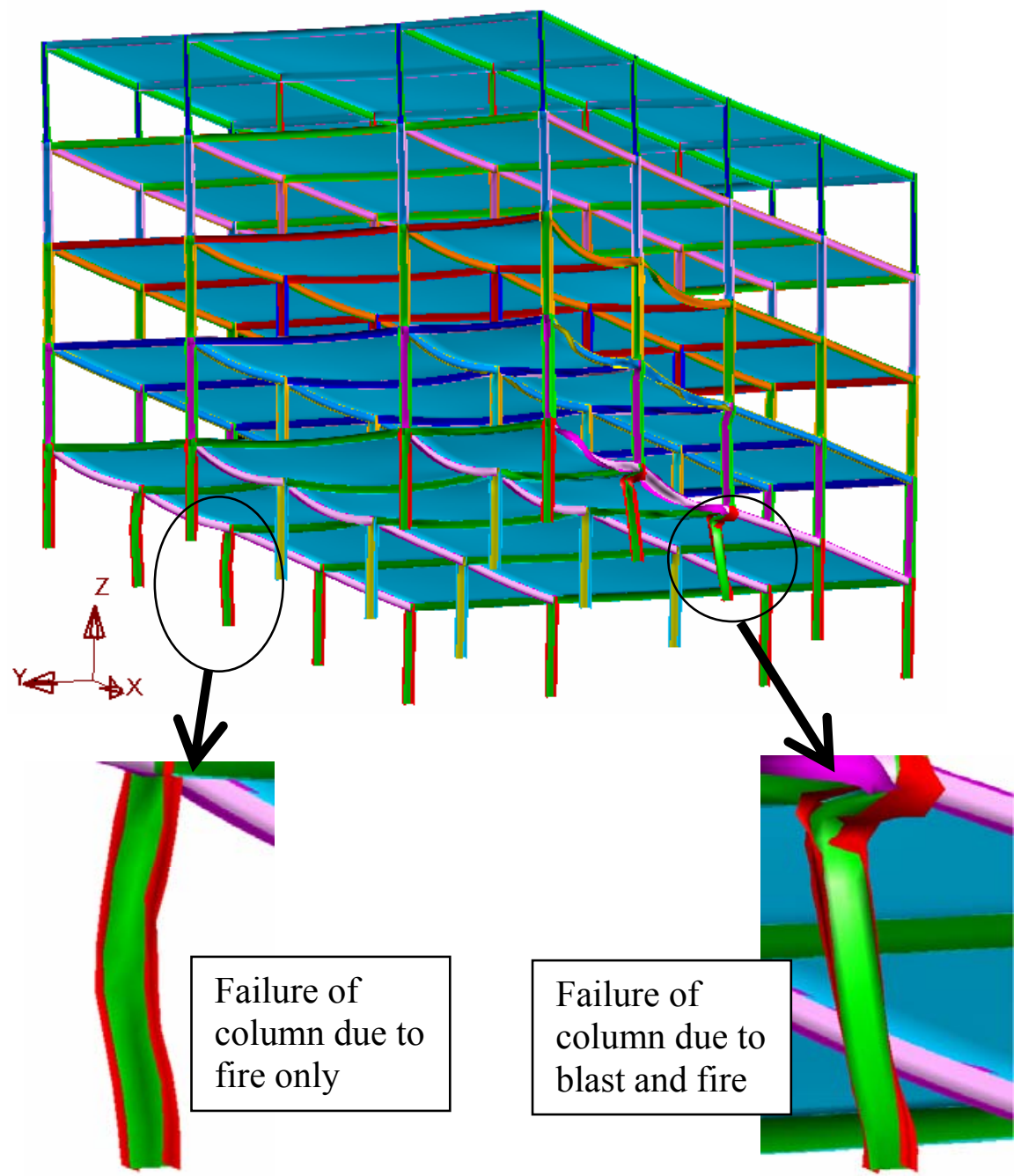

Figure 18. Buckling of the columns $(t=15$ minutes $)$

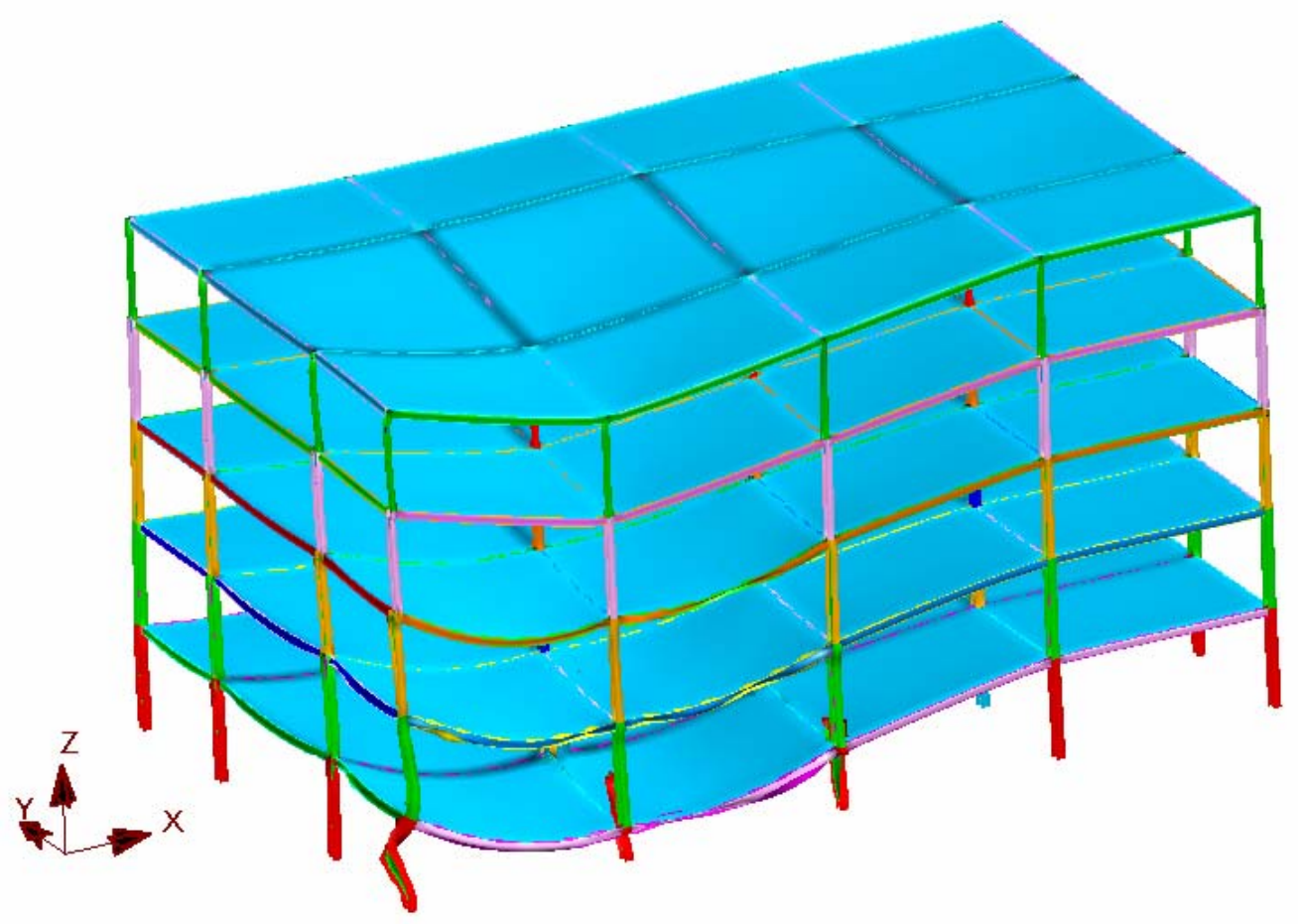

Figure 19. Collapsed shape of the frame $(t=18$ minutes $)$ 
After 14 minutes of burning, the columns in the fire compartment begin to show signs of buckling and initiated the second stage. At the ground floor, it was observed that Column A4 (column at the intersection of grid $\mathrm{A}$ and 4, etc.), B4 and C4 are unprotected columns by design, and the fire protection of $\mathrm{A} 1, \mathrm{~B} 1$ and $\mathrm{C} 1$ are totally damaged during the blast. These 6 columns are subjected to the same fire temperature, but columns $\mathrm{A} 1, \mathrm{~B} 1$ and $\mathrm{C} 1$ are initially deformed by the blast load. Therefore, when they are subjected to fire, column $\mathrm{B} 1$ and $\mathrm{C} 1$ show obvious buckling at 14.5 minutes, the failure position is at the top of the column as shown in Figure 17. Columns B4 and C4 did not fail until 15.5 minutes. The buckling mode is lateral deflection at the middle of the column. Comparing the behaviour of these two groups of columns, it may be concluded that the damage from the blast decreased the fire resisting time of the columns by about one minute or the fire resisting temperature by $47^{\circ} \mathrm{C}$.

Using the blast-fire interaction diagram proposed in the Part 1 of the companion paper can also predict similar results. The blast analysis gives the maximum deflection of the column to be about $60 \mathrm{~mm}$. The equivalent elastic deformation for this column is $25 \mathrm{~mm}$, which gives the plastic utilization factor to be 2.4. From the interaction diagram, a plastic utilization factor of 2.4 gives $T / T_{\max }=0.95$. The $T_{\max }$ for column $\mathrm{B} 1$ and $\mathrm{C} 1$ is given in Table 2 to be $707^{\circ} \mathrm{C}$. After damage from the blast effect, the limiting temperature is decreased to $672^{\circ} \mathrm{C}$. Blast will reduce the fire resisting temperature of the column by $35^{\circ} \mathrm{C}$.

After the failure of columns B1, C1, B4 and C4, the edge of the frame has undergone excessive vertical deflection, but the structure did not collapse because the vertical load on the buckled columns are transferred to the adjacent columns. Although the fire protection is partially damaged, the maximum temperature of the interior columns B2 and $\mathrm{C} 2$ are only $620^{\circ} \mathrm{C}$, less than the limiting temperature of $659^{\circ} \mathrm{C}$ shown in Table 2. From member design point of view, they should be safe in the fire. However, additional load transferred from the buckled columns caused the interior column to fail at about 18 minutes. The same happened to the corner column A1. With the loss of several columns, level 1 floor collapsed and initiated progressive collapse of other floors. The collapse mode is shown in Figure 18. The collapse time is 18.5 minutes after the ground floor is ignited.

In summary, this building, which is originally designed to be safe in fire only turned out to be unsafe in a fire after the incident of blast. By analyzing the behaviour of each structural component, the floor system provides good integrity and resistance to fire although it shows excessive deflections. Collapse of the structure is due to the failure of columns. This creates a chain reaction, which means failure of one column could bring failure to the adjacent and finally the lost of several columns in a storey will eventually bring down the upper floors in a very short time. The fire after the blast is not sever compared with the design fire without considering the blast effect. Therefore, the main reason for collapse is due to the loss of passive fire protections for some critical columns. When the ground floor columns failed, the upper floors will collapse progressively irrespective of their current state. In this case, fire spread from ground floor to upper floor does not impose more threat to the building or accelerate the collapse and therefore modeling of vertical fire spread needs not be considered in future for similar building of this category. 


\section{CONCLUSIONS AND RECOMMENDATIONS}

This paper analyzed the behaviour of a multi-storey steel-concrete composite building subjected to close-distance, medium-scale blast load and then followed by the fire attack. Finite element techniques and the constitutive models for strain rate and elevated temperature effects are discussed. Assessments are made on the effectiveness of active and passive fire protections according to the damaged state of the building after blast. The following conclusions can be drawn regarding the behaviour of the unbraced moment frames subjected to blast and fire:

(1) For steel framed buildings subjected to a small-scale, close-distance blast, some permanent deformation can be expected for members positioned very near to the blast location. The overall framework, if properly designed, can withstand the blast without collapsing. The floor system is basically undamaged providing continuity to all the columns in the storey level. However, the external cladding directly exposed to the blast wave may facture causing some flying fragments.

(2) The blast causes damage to both the active fire fighting system and passive fire protection system. For this case studied, damage to passive fire protection leads to the extremely high temperature on some critical members and this is the main reason attributed to the final collapse of the building.

(3) The damaged building possesses very little fire resistance and it collapsed after 18 minutes of burning. Initial damage from the blast changes the failure mode of columns and decreases the load carrying capacity of the columns. This effect can be approximately considered using the blast-fire interaction diagram.

The example studied in this paper shows the importance of considering the effect of fire after blast. It is concluded from the study results that to avoid the structural collapse in fire following blast, there are two key issues: one is to enhance the resistance of passive fire protection enclosures to impacts and the other one is limit the permanent deformation to steel members due to blast loading to avoid excessive loss of member resistance. 


\section{REFERENCES}

[1] European Committee for Standardization (CEN). Draft prEn 1991-1-2, Eurocode 1: Basis of Design and Actions on Structures, Part 1.2: Actions on Structures- Actions on Structures exposed to Fire. British Standards Institution, London; 2001.

[2] BSI. BS5950 Structural Use of Steelwork in Building: Part 1.Code of Practice for DesignRolled and Welded Sections. British Standards Institution, London, UK; 2003.

[3] Liew JYR, Ma KY. Advanced Analysis of Steel Framework Exposed to Accidental Fire. Second International Workshop. Structures in Fire, Christchruch, 2002:303-318.

[4] European Committee for Standardization (CEN). DD ENV 1993-1-2, Eurocode 3: design of steel structures, Part 1.2, General rules- structural fire design. British Standards Institution, UK; 2001.

[5] Soroushian P, Choi KB. Steel Mechanical properties at Different Strain Rates. Journal of Structural Engineering 1987;113(4):663-671.

[6] TM5-1300. Structures to Resist the Effects of Accidental Explosions. US Army Manual, November, 1990.

[7] Makovicha D, Makovicka Jr D. Failure of masonry under explosion effect. Structures under Shock and Impact VIII. Southampton, Boston: WIT Press, 2004:475-484.

[8] Grote DL, Park SW, Zhou M. Dynamic behavior of concrete at high strain rates and pressures: I. experimental characterization. International Journal of Impact Engineering 2001;25: 869-886.

[9] Bangash MYH. Prototype Building Structures: Analysis and Design. London: Thomas Telford, 1999. 


\title{
DESIGN OF PLANE STEEL FRAMES - TOWARDS A RATIONAL APPROACH
}

\author{
Rodrigo Gonçalves ${ }^{1}$ and Dinar Camotim ${ }^{2}$ \\ ${ }^{1}$ ESTB, Polytechnic Institute of Setúbal, R. Stinville 14, 2830-114 Barreiro, Portugal \\ ${ }^{2}$ Civil Engineering Department, ICIST/IST, Technical University of Lisbon, \\ Av. Rovisco Pais, 1049-001 Lisbon, Portugal. \\ Email: dcamotim@civil.ist.utl.pt
}

\begin{abstract}
Some concepts and results dealing with the design and safety checking of members integrated in plane steel frames are presented and discussed. Initially, attention is paid to the identification and clarification of a number of ambiguities related to the application of the buckling length concept to frame members. Then, the safety checking of columns integrated in frames is addressed and it is shown that, if their buckling lengths are "correctly determined", only one particular column, designated as "critical column", needs to be checked - a finding which leads to the proposal of a "frame optimisation procedure". Next, the safety checking of beam-columns integrated in frames is dealt with: the application of the interaction formulae appearing in the upcoming EN version of Eurocode 3 is addressed and particular attention is paid to the appropriate choice of the buckling length and "equivalent moment factor" values, both in terms of safety and accuracy. In addition, one proposes an alternative approach to use the beam-column interaction formulae, which is based on the results of genuine second-order elastic analyses. In order to illustrate the application and assess the validity and advantages of the concepts and procedures presented throughout the paper, one presents numerical results concerning simple (two-bar) structural systems and these results are compared with "exact" frame ultimate (collapse) load values, yielded by second-order plastic zone analyses that incorporate member initial imperfections. On the basis of the above comparative study, it is possible to draw several conclusions and, in particular, it is shown that the proposed approaches consistently yield accurate and conservative frame strength estimates.
\end{abstract}

Key words: Steel frames, columns, beam-columns, buckling length, equivalent moment factors, non-dimensional slenderness, frame slenderness, Eurocode 3.

\section{INTRODUCTION}

Ideally, the design or safety checking of steel frames should be carried out on the basis of rigorous geometrically non-linear elastic-plastic structural analyses, which incorporate member and frame imperfections and provide "exact" frame load-carrying capacities. However, in spite of the fast growing popularity of the so-called "advanced methods of structural analysis"[1,2] - some of them are already allowed by various existing steel design codes (e.g., the current and upcoming versions of Eurocode 3 or simply EC3 $[3,4])$-, their use remains prohibitive for routine applications. This stems mostly from the fact that (i) the computational effort required is still quite high and (ii) the vast majority of designers lack the appropriate theoretical background. Thus, the most "traditional" approach, based on first-order internal forces and moments and individual member checks through beam-column interaction formulae, continues to be widely adopted by practitioners. Nevertheless, since the interaction formulae must incorporate all relevant second-order and plasticity effects, an intense research activity is still going on concerning the improvement of such formulae, which aims at making them as accurate, rational, general and easy-to-use as possible.

As far as the design of frame compressed members is concerned, it is common practice to employ "column buckling curves", an approach that requires the adoption of appropriately chosen elastic buckling lengths $\left(\mathrm{L}_{\mathrm{cr}}\right)$, in order to adequately simulate the behaviour of the member within the frame under consideration. Therefore, since the "classical" elastic buckling length concept still plays a very 
relevant role in the frame design and/or safety checking procedure, it is very important to define it properly and also to provide the means to evaluate its correct value.

In the particular case of EC3, the beam-column interaction formulae appearing in both the available (European Pre-Norm - ENV [3]) and upcoming (European Norm - prEN [4] ${ }^{1}$ ) versions were developed, calibrated and validated (experimentally and/or numerically) almost exclusively in the context of isolated and simply supported members (e.g., the so-called "European buckling curves" [5,6]). Investigations aimed at assessing the efficiency (accuracy and safety) of the application of these formulae to members integrated in frames, are still scarce. This stems mostly from the fact that codes invariably assume (implicitly) that the frame behaviour can be adequately simulated through the choice of appropriate (i) buckling lengths and (ii) equivalent moment factors $\left(\mathrm{C}_{\mathrm{m}}\right)$. However, it seems fair to say that the specific issues related to the actual choice of such buckling lengths and equivalent moment factors can seldom be found in the literature.

This paper addresses issues related to the application of the EC3 buckling formulae to compressed members (columns and beam-columns) integrated in plane frames. The chief objective of this work is to present and discuss results that will (i) contribute to a better understanding of the formulae fundamentals and (ii) pave the way to the establishment of guidelines to use them more efficiently. It is worth noting that only the member in-plane behaviour associated with major axis bending is dealt with and, moreover, that particular emphasis is given to the importance, in terms of both safety and accuracy, of appropriately choosing the values of $\mathrm{L}_{\mathrm{cr}}$ and $\mathrm{C}_{\mathrm{m}}$.

Initially, one tackles the safety checking of columns (uniformly compressed members) integrated in frames. After a brief review of the EC3 buckling provisions, attention is paid to the identification and clarification of a number of ambiguities that are commonly associated with the application of the buckling length concept to frame members. Then, one shows that, provided that the buckling lengths are "correctly determined", only the safety of one particular column - designated henceforth as "critical column" - needs to be checked. This finding provides valuable insight concerning the frame overall behaviour and, in particular, makes it possible (and fairly easy) (i) to identify and/or strengthen the frame "weaker" members and also (ii) to develop a frame optimisation procedure.

Next, the design and safety checking of beam-columns (members subjected to compression and bending) integrated in frames is dealt with, namely by discussing the so-called Method 1 and Method 2 beam-column interaction formulae appearing in EC3-prEN [4]. Besides addressing issues concerning the choice of the appropriate $\mathrm{L}_{\mathrm{cr}}$ and $\mathrm{C}_{\mathrm{m}}$ values, one also proposes an alternative approach to the use of the above formulae, which involves the use of internal force and moment values that are obtained from genuine second-order elastic analyses of "ideal" (initially "perfect") frames - this approach does not require the incorporation of initial imperfections in the frame analysis.

Finally, it is still worth mentioning that the concepts and procedures presented throughout this paper are illustrated by means of their application to simple (two-bar) structural systems. Moreover, in order to assess the validity of these concepts and procedures, one compares the member strength estimates yielded by them with "exact" results, i.e., results obtained from second-order elastic-plastic (plastic zone) finite element analyses, which (i) incorporate standard initial geometrical imperfections and

\footnotetext{
${ }^{1}$ At this moment, there is only a "preliminary" (but practically "final") version of the upcoming EC3 document.
} 
residual stresses and (ii) are performed using the commercial code ABAQUS [7]. The results of this (obviously limited) comparative study are very promising, in the sense that they provide clear evidence that the proposed approaches and methodologies consistently yield accurate and conservative strength estimates. On the basis of the above findings, it is possible to draw several important conclusions and to anticipate the formulation of rather general guidelines for the rational design and safety checking of plane steel frames - to be subsequently validated, of course.

2. DESIGN AND SAFETY CHECKING OF COLUMNS INTEGRATED IN FRAMES Buckling Resistance According to Eurocode 3

According to EC3, the safety of columns with class 1,2 or 3 cross-sections is ensured by the condition

$$
\mathrm{n}_{\mathrm{b}, \mathrm{Rd}}=\frac{\mathrm{N}_{\mathrm{Ed}}}{\mathrm{N}_{\mathrm{b}, \mathrm{Rd}}}=\frac{\mathrm{N}_{\mathrm{Ed}}}{\chi \mathrm{N}_{\mathrm{pl}} / \gamma_{\mathrm{Ml}}} \leq 1
$$

where $\mathrm{N}_{\mathrm{Ed}}$ is the acting compressive force design value, $\mathrm{N}_{\mathrm{b}, \mathrm{Rd}}$ is the flexural buckling resistance, $\mathrm{N}_{\mathrm{pl}}=\mathrm{Af}_{\mathrm{y}}$ is the plastic axial force (A is the cross-section area and $\mathrm{f}_{\mathrm{y}}$ is the characteristic yield stress), $\gamma_{\mathrm{M} 1}$ is the partial resistance factor for member instability and $\chi$ is the reduction factor for flexural buckling, which takes into account the influence of the geometrical and material non-linear effects and member imperfections. The value of $\chi$ is obtained from the appropriate buckling curve, which is defined by the expressions

$$
\chi=\frac{\Psi}{2 \bar{\lambda}^{2}} \quad \psi=\min \left(2 \bar{\lambda}^{2} ; 1+\alpha(\bar{\lambda}-0.2)+\bar{\lambda}^{2}-\sqrt{\left.\left(1+\alpha(\bar{\lambda}-0.2)+\bar{\lambda}^{2}\right)^{2}-4 \bar{\lambda}^{2}\right)}\right.
$$

where $\alpha$ is an imperfection factor, the value of which characterises each buckling curve, and

$$
\bar{\lambda}=\sqrt{\mathrm{N}_{\mathrm{pl}} / \mathrm{N}_{\mathrm{cr}}}
$$

is the column normalised, (non-dimensional) slenderness $-\mathrm{N}_{\mathrm{cr}}=\pi^{2} \mathrm{EI} / \mathrm{L}_{\mathrm{cr}}{ }^{2}$ is the elastic critical axial force, $\mathrm{L}_{\mathrm{cr}}$ is the column critical buckling length, $\mathrm{I}$ is the cross section second moment of area about the relevant axis and E is Young's modulus.

It is important to draw the reader's attention to the fact that the key step in the safety checking procedure defined by Eq. (1) is the evaluation of the critical buckling length $\mathrm{L}_{\mathrm{cr}}$ (or, equivalently, of $\mathrm{N}_{\mathrm{cr}}$ ). In fact, once $\mathrm{L}_{\mathrm{cr}}$ is known, the calculation of all the other parameters involved is extremely easy and quite straightforward. However, it will be shown in the next section that the application of the buckling length concept to members integrated in frames can lead to some rather curious and unexpected results - in fact, this concept is only well established and perfectly unambiguous for isolated uniform members $[8,9]$.

\subsection{Buckling Length of Columns Integrated in Frames}

Although the buckling length concept has been extensively covered in the structural stability literature (e.g., [8,9]), its application to members integrated in frames is by no means obvious - it still raises novel issues and poses interpretation problems $[10,11]$. In fact, it is fair to say that the 
difficulties associated with the proper use of the buckling length concept in frame members have led to a current trend that advocates either (i) its elimination from the design rules (e.g., [12-16]) and/or (ii) its replacement by global frame parameters and "frame stability curves" [17,18].

The (critical) buckling length $\mathrm{L}_{\text {cr }}$ of a uniformly compressed bar with constant cross-section is commonly defined as:

(i) The length of a fictitious isolated and simply supported, but otherwise identical, column that buckles for the same axial force value $\mathrm{N}_{\mathrm{cr}}=\pi^{2} \mathrm{EI} / \mathrm{L}_{\mathrm{cr}}^{2}$.

(ii) The distance between two consecutive inflection points (i.e., points of zero moment) of the corresponding buckling mode $\bar{w}$, which is given by [19]

$$
\overline{\mathrm{w}}(\mathrm{x})=\mathrm{A}_{1} \sin \left(\frac{\pi \mathrm{x}}{\mathrm{L}_{\mathrm{cr}}}\right)+\mathrm{A}_{2} \cos \left(\frac{\pi \mathrm{x}}{\mathrm{L}_{\mathrm{cr}}}\right)+\mathrm{A}_{3} \mathrm{x}+\mathrm{A}_{4}
$$

where $\mathrm{x}$ is a coordinate along the member axis and $\mathrm{A}_{1}-\mathrm{A}_{4}$ are constants depending on the column boundary conditions. By differentiating Eq. (4) twice with respect to $\mathrm{x}$, one obtains a sinusoidal function with a period equal to $2 \mathrm{~L}_{\mathrm{cr}}$, thus proving that the distance between two consecutive inflection points is half the period, i.e., exactly $\mathrm{L}_{\mathrm{cr}}$.

Since the above definitions apply for columns integrated in frames, a rigorous evaluation of their buckling lengths requires the performance of a linear stability analysis of the whole frame [20], which (i) must account for the axial forces acting on all the columns and (ii) provides the frame critical load parameter value $\Lambda_{\text {cr. }}$. Then, the critical axial force for each column is given by

$$
\mathrm{N}_{\mathrm{cr}, \mathrm{i}}=\Lambda_{\mathrm{cr}} \overline{\mathrm{N}}_{\mathrm{i}}
$$

where $\overline{\mathrm{N}}_{\mathrm{i}}$ is the corresponding reference axial force (i.e., associated with $\Lambda=1$ ), and leads to the determination of its buckling length, which is obtained from the expression

$$
\mathrm{L}_{\mathrm{cr}, \mathrm{i}}=\sqrt{\frac{\pi^{2} \mathrm{E}_{\mathrm{i}} \mathrm{I}_{\mathrm{i}}}{\mathrm{N}_{\mathrm{cr}, \mathrm{i}}}}=\sqrt{\frac{\pi^{2} \mathrm{E}_{\mathrm{i}} \mathrm{I}_{\mathrm{i}}}{\Lambda_{\mathrm{cr}} \overline{\mathrm{N}}_{\mathrm{i}}}}
$$

On the basis of Eq. (6) it is possible to establish the relation between the $\mathrm{L}_{\text {cr }}$ values of two columns belonging to the same frame (for a particular load combination), which reads

$$
\frac{L_{c r, i}}{L_{c r, j}}=\sqrt{\frac{E_{i} I_{i}}{E_{j} I_{j}} \frac{\bar{N}_{j}}{\bar{N}_{i}}}
$$

and shows that the buckling lengths of all the frame columns are related to each other through their (i) flexural stiffness values EI and (ii) reference axial forces $\bar{N}$. This particular feature reveals that frame members with large EI and/or small $\overline{\mathrm{N}}$ values tend to exhibit rather high $\mathrm{L}_{\mathrm{cr}}$ values. For illustrative purposes, consider the inverted L-frame depicted in Figure 1(a), subjected to two compressive loads $\mathrm{P}_{1}$ and $\mathrm{P}_{2}$. Figures $1(\mathrm{~b})$ and $1(\mathrm{c})$ display the $\mathrm{K}$-factors $\left(\mathrm{K}_{\mathrm{i}}=\mathrm{L}_{\mathrm{cr}, \mathrm{i}} / \mathrm{L}_{\mathrm{i}}\right)$ associated with each compressed member, obtained from exact linear stability analyses, for several load and bending stiffness combinations. One notices that, as predicted by Eqs. (6) and (7), decreases in $\mathrm{P}_{2}$ and (EI) lead to higher $\mathrm{K}_{2}$ and $\mathrm{K}_{1}$ values, respectively. 
This example clearly illustrates that the application of the buckling length concept to members integrated in frames may lead to unexpected results. Note also that, although the frame is braced (and, thus, classified as "non-sway"), the column K-factor can be (much) higher than 1 . However, it must be stressed that these results stem from the fact that one is somewhat "mixing" the buckling behaviours of frames and isolated columns. For instance, Figure 1(c) shows that an (EI) $)_{1}$ increase leads to a growth in both $\mathrm{N}_{\mathrm{cr}, 1}$ (obviously, because the flexural restraint is higher for column 2 and one has $\left.\mathrm{P}_{1}=\mathrm{P}_{2}\right)$ and $\mathrm{K}_{1}-$ the $(\mathrm{EI})_{1}$ increase is much more relevant that the $\mathrm{N}_{\mathrm{cr}, 1}$ one.

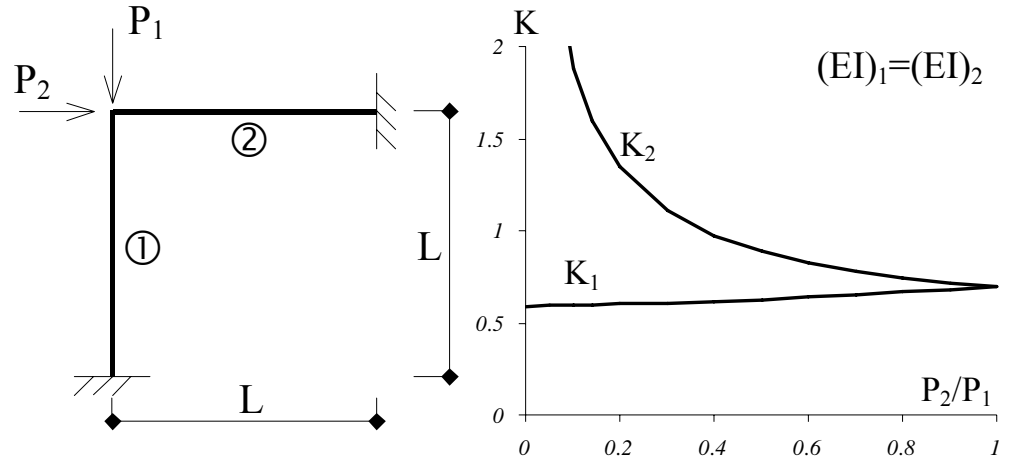

(a)

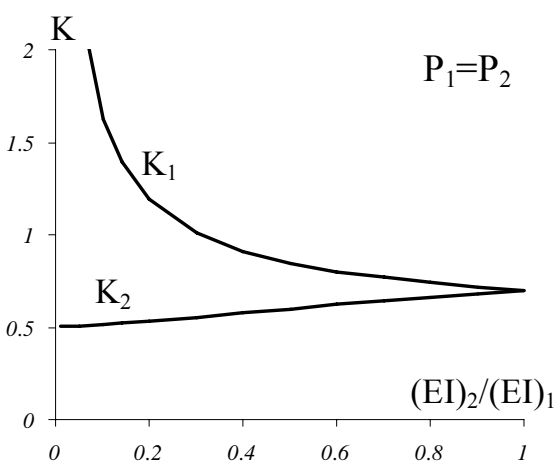

(c)

Figure 1. Inverted L-frame (a) geometry/loading and K-factors for (b) $(E I)_{1}=(E I)_{2}$ and (c) $P_{1}=P_{2}$

These examples clearly illustrate that the application of the buckling length concept to frame members may lead to unexpected results. Notice that, although the frame is obviously classified as "non-sway", the K-factors can be much higher than 1. However, it should be highlighted that these results stem from the fact that one is trying to determine "the length of a fictitious isolated and simply supported (but otherwise identical) column that buckles at the axial force level defined by the frame instability" - for instance, if $\mathrm{P}_{1}=\mathrm{P}_{2}$ and $(\mathrm{EI})_{2}$ is kept constant, it is obvious that $\mathrm{N}_{\mathrm{cr}, 1}$ increases with $(\mathrm{EI})_{1}$, although one also observes a $\mathrm{K}_{1}$ increase (see Figure 1(c)).

Moreover, from Eqs. (3) and (5), one readily concludes that the relation between the normalised slenderness values of columns $i$ and $j$ is given by

$$
\frac{\overline{\lambda_{i}}}{\overline{\lambda_{j}}}=\sqrt{\frac{N_{p l, i}}{N_{c r, i}} \frac{N_{c r, i}}{N_{p l, j}}}=\sqrt{\frac{N_{p l, i}}{N_{p l, j}} \frac{\overline{N_{j}}}{\overline{N_{i}}}}
$$

which shows that the $\bar{\lambda}$ values of all the frame columns are related to each other through their relative $\mathrm{N}_{\mathrm{pl}}$ and $\overline{\mathrm{N}}$ values. This leads to a quite curious result, namely that the column that is closer to reaching $\mathrm{N}_{\mathrm{pl}}$ is the most "slender" one, i.e., has the highest $\bar{\lambda}$ value. This result has the following implications:

(i) Among the members exhibiting the same $\mathrm{N}_{\mathrm{pl}}$ value, the one acted by the lowest axial force $\mathrm{N}_{\mathrm{Ed}}$ is the most "slender".

(ii) Among the members acted by the same axial force, the one exhibiting the highest $\mathrm{N}_{\mathrm{pl}}$ value is the most "slender".

Since high $\bar{\lambda}$ values imply low $\mathrm{N}_{\mathrm{b}, \mathrm{Rd}}$ values, such members are often regarded as "weak", in the sense of "highly susceptible to second-order effects", although this perception seems to disagree with the fact that they may be subjected to low $\mathrm{N}_{\mathrm{Ed}}$ values or display high $\mathrm{N}_{\mathrm{pl}}$ values. Although these (apparently) paradoxical conclusions are addressed and explained later in the paper, it is important to 
emphasise right away that, in the case of frame members, a high $\bar{\lambda}$ value does not necessarily imply a "low buckling resistance" or " high susceptibility to second-order effects" - it merely indicates that the member critical axial force is, in the specific context of the loaded frame under consideration, well below the associated plastic axial force (recall Eq. (3)). It follows that, in order to adequately assess the susceptibility of a given frame to second-order effects, it is necessary to define a "global" parameter. In the next section, such parameter, the "frame slenderness", is presented and discussed.

\subsection{The Concept of Frame Slenderness}

The concept of "normalised (non-dimensional) slenderness", traditionally used in the context of compressed structural elements (columns, beams, plates, etc.), can be readily extended to frames, by resorting to the definition $[18,21]^{2}$

$$
\overline{\lambda_{\mathrm{f}}}=\sqrt{\Lambda_{\mathrm{y}} / \Lambda_{\mathrm{cr}}}
$$

where $\Lambda_{\mathrm{cr}}$ is the frame critical load parameter and $\Lambda_{\mathrm{y}}$ is the frame "yielding" load parameter, which is associated with the yielding of the first compressed member in the whole frame, due to axial force alone (i.e., the one first reaching its plastic axial load), and is defined by

$$
\Lambda y=\min \left(\frac{\mathrm{A}_{\mathrm{i}} \mathrm{f}_{\mathrm{y}, \mathrm{i}}}{\overline{\mathrm{N}_{\mathrm{i}}}}\right)(\mathrm{i}=1, \ldots, \mathrm{n})
$$

where $\mathrm{n}$ is the number of frame compressed members ${ }^{3}$. Both $\Lambda_{\mathrm{cr}}$ and $\Lambda_{\mathrm{y}}$ must be related to the same load combination and, for an "ideal frame" (i.e., geometrically/materially perfect and with no first or second-order bending moments acting on its members), $\bar{\lambda}_{\mathrm{f}}>1(<1)$ indicates that frame buckling precedes (follows) the attainment of the plastic load in any member. Then, one may express the load-carrying capacity or "resistance" of an "ideal frame" $\left(\Lambda_{R}\right)$ in terms of the frame reduction factor $\chi_{\mathrm{f}}$

$$
\begin{gathered}
\Lambda_{\mathrm{R}}=\chi_{\mathrm{f}} \Lambda_{\mathrm{y}} \\
\chi_{\mathrm{f}}=\frac{\min \left(\Lambda_{\mathrm{y}} \Lambda_{\mathrm{cr}}\right)}{\Lambda_{\mathrm{y}}}=\min \left(1 ; \frac{1}{\bar{\lambda}_{\mathrm{f}}^{2}}\right)
\end{gathered}
$$

It is worth noting that the variation of $\chi_{\mathrm{f}}$ with $\bar{\lambda}_{\mathrm{f}}$ is analogous to its "ideal column" counterpart (Eq. (2), making $\alpha=0$ ). By incorporating (5) and (10) into (9), one concludes that

$$
\bar{\lambda}_{\mathrm{f}}=\min \left(\bar{\lambda}_{\mathrm{i}}\right)=\bar{\lambda}_{\min }(\mathrm{i}=1, \ldots, \mathrm{n})
$$

i.e., that $\bar{\lambda}_{\mathrm{f}}$ is precisely the smallest among the $\bar{\lambda}$ values of all frame columns.

A nice feature of the frame slenderness concept resides in the fact that, like for isolated columns, the designation "slender frame" means "frame susceptible to second-order effects", thus making it possible to circumvent the problems associated with the interpretation of the buckling lengths and normalised slenderness values of each individual column, which was explained in subsection 2.2. Moreover, the frame slenderness concept deserves a few important remarks:

\footnotetext{
${ }^{2}$ It is worth noting that this concept also appears in the EC3-prEN [4], defined as "relative slenderness of the structure".

${ }^{3}$ Although the tensile members can be taken into account when determining $\Lambda_{\mathrm{cr}}$, they must not be involved in the calculation of $\Lambda_{\mathrm{y}}$ - the safety checking of the tensile members has to be performed separately and independently.
} 
(i) Like for isolated members (e.g., columns, beam-columns), the calculation of $\bar{\lambda}_{\mathrm{f}}$ does not take into account the various member bending moments and shear forces. Moreover, it is theoretically possible to obtain any $\bar{\lambda}_{\mathrm{f}}$ value associated with a given $\Lambda_{\mathrm{cr}}$, by merely changing the plastic axial forces $\left(\mathrm{N}_{\mathrm{pl}}\right)$ of the frame members, i.e., changing $\Lambda_{\mathrm{y}}$.

(ii) Since, in most situations, the first and second-order member axial force values are almost identical, $\Lambda_{\mathrm{y}}$ can be determined from Eq. (10), which is based on first-order axial forces.

(iii) It might be argued that, since $\Lambda_{\mathrm{y}}$ underestimates the frame plastic load-carrying capacity, a "plastic load parameter" $\Lambda_{\mathrm{pl}}$, corresponding to the formation of a complete frame collapse mechanism, could be used instead. However, because the determination of such parameter is not at all easy and the main goal behind the use of $\bar{\lambda}_{\mathrm{f}}$ is just to assess the susceptibility of the frame to second-order order effects, one adopts only $\Lambda_{y}$ in this work.

(iv) It is important to check whether the compressed members that yield for $\Lambda=\Lambda_{\mathrm{y}}$ also participate in the frame critical buckling mode (associated with $\Lambda=\Lambda_{\mathrm{cr}}$ ). This ensures that $\Lambda_{\mathrm{cr}}$ and $\Lambda_{\mathrm{y}}$ concern the same structural system or sub-system.

The design or safety checking of columns integrated in a frame is performed by means of Eq. (1). Using Eqs. (2), (3), (5) and introducing the design load parameter $\Lambda_{\mathrm{Ed}}=\mathrm{N}_{\mathrm{Ed}, \mathrm{i}} / \overline{\mathrm{N}}_{\mathrm{i}}$, any frame column i must satisfy the condition

$$
\mathrm{n}_{\mathrm{b}, \mathrm{Rd}, \mathrm{i}}=\frac{\mathrm{N}_{\mathrm{Ed}, \mathrm{i}}}{\mathrm{N}_{\mathrm{b}, \mathrm{Rd}, \mathrm{i}}}=\frac{\Lambda_{\mathrm{Ed}} \overline{\mathrm{N}}_{\mathrm{i}}}{\frac{\chi_{\mathrm{i}} \mathrm{N}_{\mathrm{pl}, \mathrm{i}}}{\gamma_{\mathrm{M} 1}}}=\frac{2_{\gamma \mathrm{M} 1}}{\Psi_{\mathrm{i}}} \frac{\Lambda_{\mathrm{Ed}}}{\Lambda_{\mathrm{cr}}}=\frac{2_{\gamma \mathrm{M} 1}}{\Psi_{\mathrm{i}}} \mathrm{n}_{\mathrm{cr}} \leq 1(\mathrm{i}=1, \ldots, \mathrm{n})
$$

where $\mathrm{n}_{\mathrm{cr}}=\Lambda_{\mathrm{Ed}} / \Lambda_{\mathrm{cr}}$ and it is important to realise that the only parameter that changes from column to column is $\Psi_{\mathrm{i}}$. The curves depicted in Figure 2 provide the variation of $\Psi$ with $\bar{\lambda}$, for (i) an "ideal" column and (ii) the EC3 column buckling curves $a-d[3,4]$. Because $\Psi$ grows monotonically with $\bar{\lambda}$ in all these curves, one readily concludes from Eq. (14) that the column with the lowest $\bar{\lambda}(=\bar{\lambda}$ min $)$ is the one governing the safety checking of the whole frame - such column will be hereafter designated as "critical" and denoted by $(\cdot)_{c}{ }_{c}^{4}$. Moreover, from Eq. (13) one also deduces that the critical column $\bar{\lambda}$ value $\left(\bar{\lambda}_{\mathrm{c}}\right)$ is equal to the frame slenderness value (i.e., $\bar{\lambda}_{\mathrm{c}}=\bar{\lambda}_{\mathrm{min}}=\bar{\lambda}_{\mathrm{f}}$ ). Although, strictly speaking, the above conclusions are only one hundred per cent true whenever the same buckling curve applies to all columns, it seems quite safe to say that, when performing the design or safety checking of a given frame, columns with $\bar{\lambda}>>\bar{\lambda}_{\mathrm{f}}$ do not need to be checked - they do not govern the frame safety checking and should be viewed as "over designed", as far as strength is concerned.

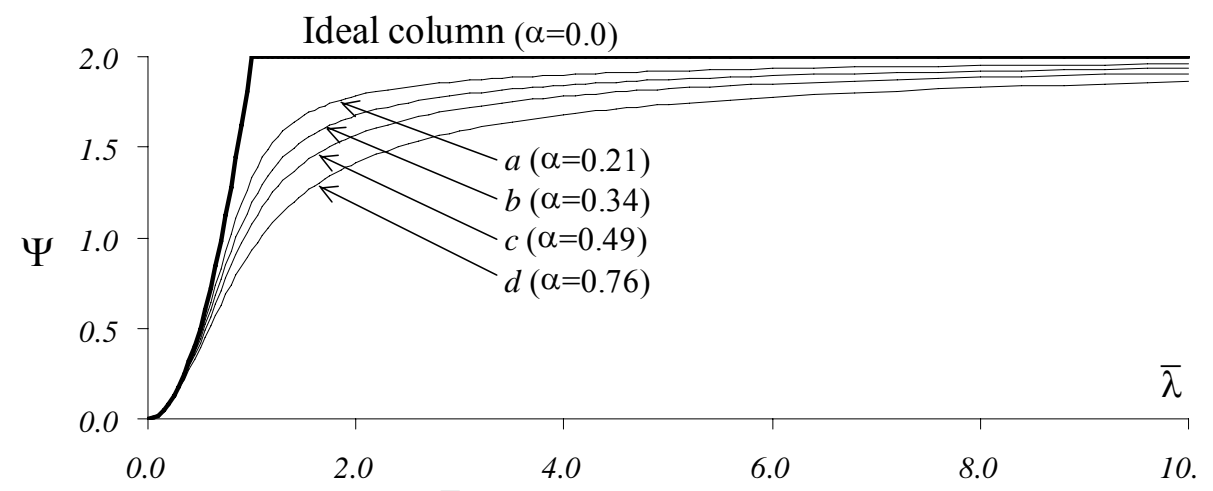

Figure 2. Variation of $\Psi$ with $\bar{\lambda}$ for (i) an "ideal" column and (ii) the EC3 curves $a-d$

\footnotetext{
${ }^{4}$ Obviously, a frame may have several critical columns, all of them sharing $\bar{\lambda}_{\text {min }}$.
} 
On the other hand, since the critical column always exhibits the lowest $\bar{\lambda}$ value (if the same buckling curve applies for all columns), it is possible to conclude, on the basis of Eqs. (5), (8), (13), that this critical column is the one closest to reaching the plastic axial force $\mathrm{N}_{\mathrm{pl}}=\mathrm{Af}_{\mathrm{y}}$. Indeed, one has

$$
\bar{\lambda}_{\mathrm{c}}=\lambda_{\min }=\min \left(\lambda_{\mathrm{i}}\right)=\sqrt{\min \left(\frac{\mathrm{A}_{\mathrm{i}} \mathrm{f}_{\mathrm{y}, \mathrm{i}}}{\Lambda_{\mathrm{cr}} \overline{\mathrm{N}}_{\mathrm{i}}}\right)}=\sqrt{\frac{1}{\Lambda_{\mathrm{cr}}} \min \left(\frac{\mathrm{A}_{\mathrm{i}} \mathrm{f}_{\mathrm{y}, \mathrm{i}}}{\overline{\mathrm{N}}_{\mathrm{i}}}\right)}(\mathrm{i}=1, \ldots, \mathrm{n})
$$

Consequently, a frame in which all columns (i) exhibit the same cross-section area and steel grade and (ii) are governed by the same buckling curve, the critical column is always the one acted by the highest axial force, regardless of its length.

If the columns are governed by different buckling curves (a usual case), one must consider the possibility that the critical column may have a $\bar{\lambda}$ value higher than $\bar{\lambda}_{\text {min }}=\bar{\lambda}_{\mathrm{f}}$. As an example, consider a column with $\bar{\lambda}=\bar{\lambda}_{\text {min }}=2.0$ and governed by curve $a(\Psi=1.783)$. This column will not be critical if, for instance, there is another column (i) governed by curve $d$ and (ii) having $\bar{\lambda}<6.2$ - one will then get $\Psi<1.783$. The charts shown in Figure 3 can be used to detect the situations in which $\bar{\lambda}_{\mathrm{c}}>\bar{\lambda}_{\min }=\bar{\lambda}_{\mathrm{f}}$ : each of them plots a set of curves providing the ratios between the $\bar{\lambda}$ values of any two columns (columns $i$ and $j$, such that $\bar{\lambda}_{i}<\bar{\lambda}_{j}$ ) that lead to identical $\Psi$ values, when column $i$ is governed by curve $a$ (left chart), $b$ (middle chart) or $c$ (right chart) - obviously, a column governed by curve $d$ is always the critical one, since it exhibits the lowest $\Psi$ function (see Figure 2), and no chart is needed. In the previous example, column i is governed by curve $a$, which means that one must consider the left chart, and column $\mathrm{j}$ by curve $d$. Then, the " $d$ " curve of the chart provides, for $\bar{\lambda}_{\mathrm{i}}$ $=2.0, \bar{\lambda}_{\mathrm{j}} / \bar{\lambda}_{\mathrm{i}}=3.10$, thus showing that column $\mathrm{j}$ is critical for $\bar{\lambda}_{\mathrm{j}}<3.10 \times 2.0=6.2$.

It is worth noting that the critical column concept provides a theoretical validation of the "frame stability curve" concept proposed by Cosenza et al. [18], which prescribes the use of a single buckling curve, together with $\bar{\lambda}_{\mathrm{f}}$, to estimate a frame load-carrying capacity by means of Eq. (11). It is now clear that both concepts are equivalent provided that (i) $\bar{\lambda}_{\mathrm{c}}=\bar{\lambda}_{\min }=\bar{\lambda}_{\mathrm{f}}$ and (ii) the critical column buckling curve is used to calculate $\chi_{\mathrm{f}}$.
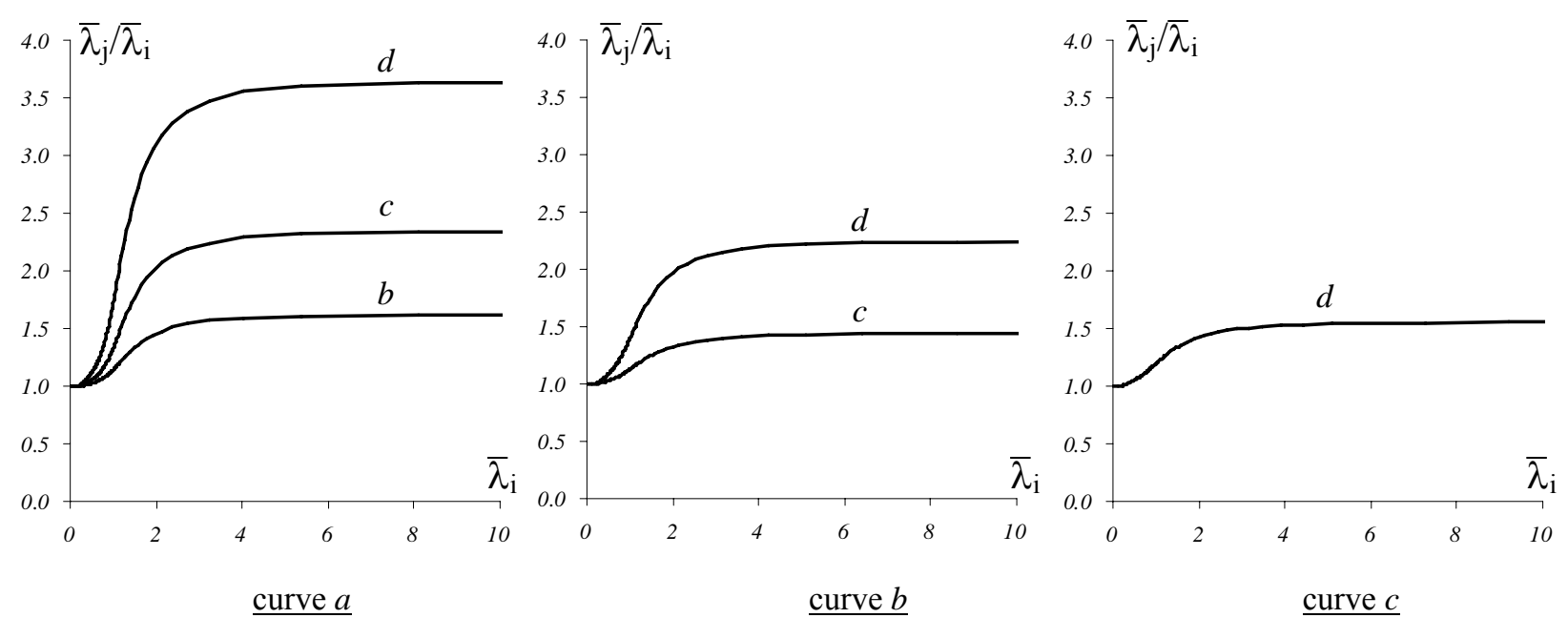

Figure 3. $\bar{\lambda}_{\mathrm{j}} / \bar{\lambda}_{\mathrm{i}}$ values associated with $\Psi_{\mathrm{i}}=\Psi_{\mathrm{j}}-$ column $\mathrm{i}$ corresponds to curves $a, b$ and $c$ 


\subsubsection{Frame optimisation procedure}

On the basis of the results just presented, one readily concludes that, in an efficiently (optimally) designed frame, all compressed members must satisfy the condition (see Eq. (14))

$$
\mathrm{n}_{\mathrm{b}, \mathrm{Rd}, \mathrm{i}}=\frac{2 \gamma_{\mathrm{Ml}}}{\Psi_{\mathrm{i}}} \mathrm{n}_{\mathrm{cr}}=1(\mathrm{i}=1, \ldots, \mathrm{n})
$$

which means that (i) they are all critical and also that (ii) their buckling resistances are being fully used (i.e., one has $\mathrm{N}_{\mathrm{Ed}, \mathrm{i}}=\mathrm{N}_{\mathrm{b}, \mathrm{Rd}, \mathrm{i}}$ ). Such a situation can be reached by adopting the following procedure:

(i) First, at the pre-design stage, one must try to ensure that the $n_{\mathrm{cr}}=\Lambda_{\mathrm{Ed}} / \Lambda_{\mathrm{cr}}$ values (one per load combination) are as low as possible - obviously, they must be lower than 1. Of course, this means that the $\Lambda_{\text {cr }}$ values must be as high as possible, which can be accomplished by properly bracing the members and/or by choosing sufficiently stocky cross-sections.

(ii) For each load combination (i.e., $\mathrm{n}_{\mathrm{cr}}$ value), select the optimum values of $\mathrm{N}_{\mathrm{pl}, \mathrm{i}}=\mathrm{A}_{\mathrm{i}} \mathrm{f}_{\mathrm{y}, \mathrm{i}}$ for all compressed members, which must satisfy Eq. (16)) - note that, by changing $\mathrm{N}_{\mathrm{pl}, \mathrm{i}}$, one alters $\bar{\lambda}_{\mathrm{i}}$ and, thus, also $\Psi_{\mathrm{i}}$. The chart shown in Figure 4(a) provides valuable help to perform this task, as it plots the optimum $n_{\mathrm{pl}, \mathrm{i}}=\mathrm{N}_{\mathrm{Ed}, \mathrm{i}} / \mathrm{N}_{\mathrm{pl}, \mathrm{i}}$ values as a function of $\mathrm{n}_{\mathrm{cr}}$, for an "ideal" column and the EC3 buckling curves $a-d$, adopting $\gamma_{\mathrm{M} 1}=1.1-$ a $\mathrm{n}_{\mathrm{pl}, \mathrm{i}}$ value above (below) the curve under consideration corresponds to an unsafe (safe) design ${ }^{5}$. On the other hand, the chart displayed in Figure 4(b) provides the optimum $\bar{\lambda}_{i}$ values $-\mathrm{a} \bar{\lambda}_{\mathrm{i}}$ value above (below) a given curve is associated with safe (unsafe) designs.

Since the above procedure must be carried out for each load combination, it is virtually impossible to design the frame so that Eq. (16) holds for all members and load combinations. However, the use of the concepts on which this approach is based enables a much more rational frame design and, in addition, provides valuable insight on the frame structural behaviour - e.g., the "critical" and "over-designed" compressed members can be easily spotted and, if necessary, efficiently redesigned.

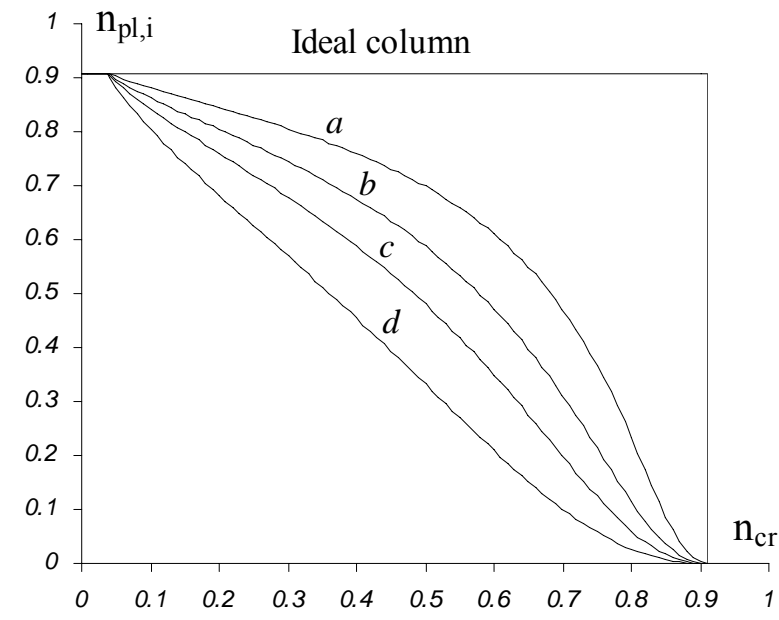

(a)

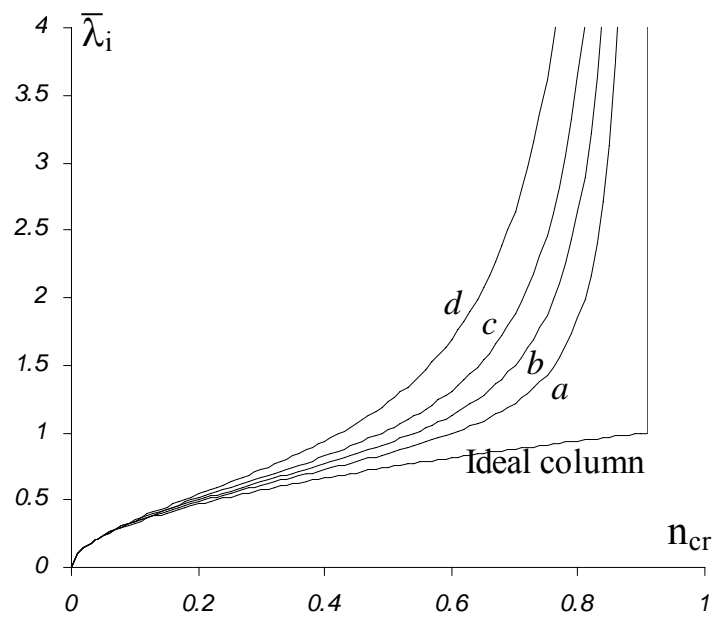

(b)

Figure 4. Variation of $\mathrm{n}_{\mathrm{pl}, \mathrm{i}}$ and $\bar{\lambda}_{\mathrm{i}}$ with $\mathrm{n}_{\mathrm{cr}}$ for (i) an "ideal" column and (ii) the EC3 curves $a-d$.

\footnotetext{
${ }^{5}$ Note that a low $\mathrm{n}_{\mathrm{cr}}$ value implies that the column can almost reach its plastic strength, i.e., that the corresponding optimum $\mathrm{n}_{\mathrm{p} 1, \mathrm{i}}$ value is very close to $1 / \gamma_{\mathrm{M} 1} \approx 0.9$.
} 
It is well known that, like in the case of isolated members, an efficiently designed frame exhibits members with cross-sections displaying high second moments of area I and low areas A (i.e., high radii of gyration). However, due to either limitations in the range of commercially available profiles, the occurrence of local buckling phenomena or even architectural demands, it is often not possible to obtain any desired I-A combination. Therefore, the member I values are inevitably modified during the performance of the optimisation procedure - if these modifications are significant, it will be necessary to recalculate $\Lambda_{\mathrm{cr}}$ and restart the whole procedure.

For illustrative purposes, let us consider the central column of the "simple construction" frame (continuous columns and hinged beam-to-column joints) depicted in Figure5, which comprises four equal-length uniformly compressed segments. Assuming that the column has been already pre-designed, the current goal is to reduce the cross-section area of each segment for the load case under consideration $\left(\overline{\mathrm{N}}_{1}=\mathrm{P}, \overline{\mathrm{N}}_{2}=2 \mathrm{P}, \overline{\mathrm{N}}_{3}=3 \mathrm{P}, \overline{\mathrm{N}}_{4}=4 \mathrm{P}\right.$ ). Supposing, for the sake of simplicity, that the same buckling curve governs all column segments, the optimisation procedure involves the following steps:

(i) Performance of a linear stability analysis of the whole column, thus obtaining $\Lambda_{\mathrm{cr}}$ and $\mathrm{n}_{\mathrm{cr}}$.

(ii) Calculation of all the segment $\bar{\lambda}$ values $\left(\bar{\lambda}_{1}-\bar{\lambda}_{4}\right)$. Since the same buckling curve applies, they are all critical if $\bar{\lambda}_{1}=\bar{\lambda}_{2}=\bar{\lambda}_{3}=\bar{\lambda}_{4}\left(=\bar{\lambda}_{\mathrm{f}}\right)-$ from Eq. (8), this holds true if $\mathrm{N}_{\mathrm{pl}, 2}=2 \mathrm{~N}_{\mathrm{pl}, 1}, \mathrm{~N}_{\mathrm{pl}, 3}=3 \mathrm{~N}_{\mathrm{pl}, 1}$ and $\mathrm{N}_{\mathrm{pl}, 4}=4 \mathrm{~N}_{\mathrm{pl}, 1,1}$, regardless of their lengths and support conditions.

(iii) Calculation of the "optimum" $\mathrm{n}_{\mathrm{pl}}$ value corresponding to $\mathrm{n}_{\mathrm{cr}}$ for just one (any) segment, by using the chart in Figure 4(a) - if the $\mathrm{N}_{\mathrm{pl}}$ ratios mentioned in the previous item are retained, no calculations involving the other column segments are necessary.

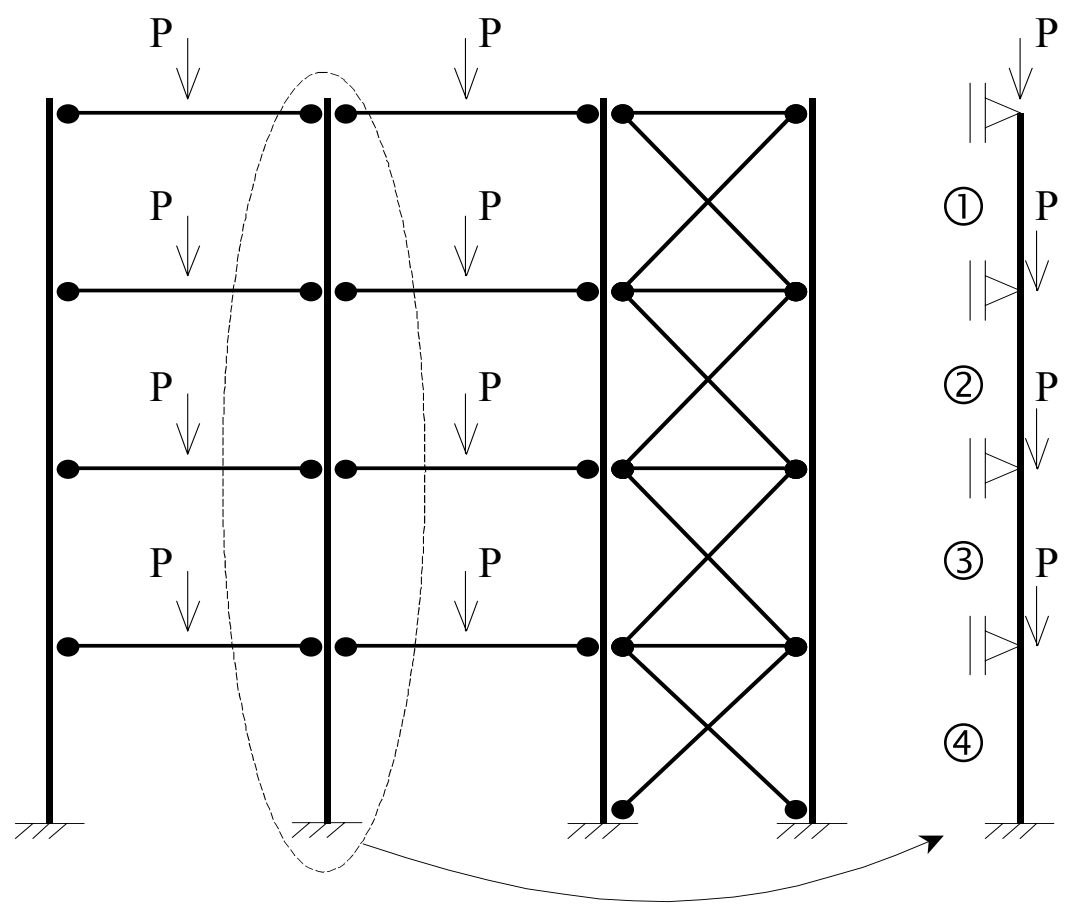

Figure 5. Illustrative example: simple construction frame

Notice, once more, that if the above procedure modifies the cross-sections I values significantly, it is indispensable to recalculate $\Lambda_{\text {cr }}$ and redo the whole procedure. Moreover, if the segments are governed by different buckling curves, some extra care is required because some of the segments may not be critical for $\bar{\lambda}_{1}=\bar{\lambda}_{2}=\bar{\lambda}_{3}=\bar{\lambda}_{4}$. Finally, it is important to stress again that the conclusions drawn 
here are exclusively based on the use of Eq. (16) with $\Psi_{\mathrm{i}}$ obtained from the EC3 buckling curves this means that they may not reflect the actual physical behaviour of real frames.

\subsubsection{Parametric study}

In order to assess the validity of the "critical column concept", a parametric study was carried out for the simple plane structural systems (or "frames") shown in Figure 6: (a) a simple construction unbraced frame with a rigid beam and (b) an L-shaped frame with both members compressed. The aim of this study consists of comparing the strength estimates obtained by means of the critical column concept with "exact" ultimate (collapse) loads $\Lambda_{\mathrm{u}}$, yielded by second-order plastic-zone finite element analyses, performed in the code ABAQUS [7]. The two flexible members in each frame (members 1 and 2) are HEB300 hot-rolled profiles made of S235 carbon steel and are acted by axial compressive forces $\mathrm{P}_{1}$ and $\mathrm{P}_{2}$. Only in-plane (major axis bending) behaviour was allowed and several geometry/loading combinations were considered, identified by the values of $\mu$ (length ratio), $\rho$ (axial load ratio) and $\bar{\lambda}_{\mathrm{f}}$ (frame slenderness), parameters defined as

$$
\mu=\frac{\mathrm{L}_{1}}{\mathrm{~L}_{2}} \quad \rho=\frac{\overline{\mathrm{N}}_{1}}{\overline{\mathrm{N}}_{2}} \quad \bar{\lambda}_{\mathrm{f}}=\sqrt{\frac{\Lambda_{\mathrm{y}}}{\Lambda_{\mathrm{cr}}}}
$$

For each pair of $\rho-\mu$ values, several $L_{2}$ and $L_{1}=\mu L_{2}$ values were considered, in order to obtain a sufficiently large set of $\bar{\lambda}_{\mathrm{f}}$ values. The frames analysed ranged from rather "stocky" $\left(\bar{\lambda}_{\mathrm{f}}=0.2\right)$ to quite "slender" $\left(\bar{\lambda}_{\mathrm{f}}=3.0\right)$ and over 280 cases were dealt with - all the selected pairs of $\rho-\mu$ values are given in Table $1^{6}$.

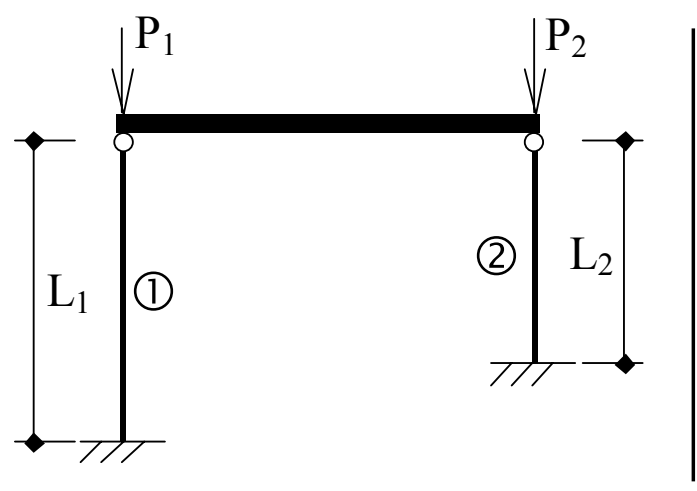

(a)

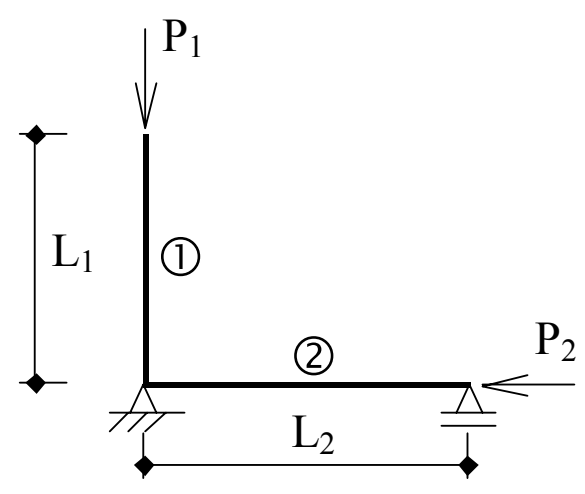

(b)

Figure 6. Structural systems employed in the parametric study:

(a) simple unbraced frame with a rigid beam and (b) L-shaped frame

Table 1. Selected pairs of $\rho-\mu$ values: (a) simple unbraced frame and (b) L-shaped frame

\begin{tabular}{c|c|c|c|c|c|c|c|c|c}
\hline$\mu$ & 0.1 & 0.3 & 0.5 & 0.6 & 0.66 & 1 & 1.5 & 2 & 3 \\
\hline $\mathbf{0 . 5}$ & & & (b) & & & (b) & & (b) & \\
\hline $\mathbf{1}$ & (a) & (a) & (a),(b) & (a) & (a) & (a),(b) & & (b) & \\
\hline $\mathbf{1 . 5}$ & (a) & (a) & & (a) & & (a) & (a) & (a) & (a) \\
\hline $\mathbf{2}$ & (a) & (a) & (b) & (a) & & (a),(b) & (a) & (a),(b) & (a) \\
\hline $\mathbf{3}$ & (a) & (a) & & (a) & & (a) & (a) & (a) & (a) \\
\hline $\mathbf{1 0}$ & (a) & (a) & & (a) & & (a) & (a) & (a) & (a) \\
\hline
\end{tabular}

\footnotetext{
${ }^{6}$ Due to the particular geometry of the sway frame, only cases corresponding to $\rho \geq 1$ were dealt with.
} 
The second-order plastic-zone analyses, performed in the finite element code ABAQUS [7], employed B31 beam elements and involved the specification of several cross-section integration points, indispensable to model the residual stresses distribution accurately [21]. All the frame members contained the initial bow imperfection and residual stress distribution shown in Figure 7 and an elastic-perfectly-plastic stress-strain law (i.e., with no strain hardening) was adopted to model the steel material behaviour $\left(E=210 \mathrm{GPa}, v=0.3\right.$ and $\left.\mathrm{f}_{\mathrm{y}}=235 \mathrm{MPa}\right)$. In order to avoid unnecessary modelling difficulties, the cross-section web-flange radii were neglected.
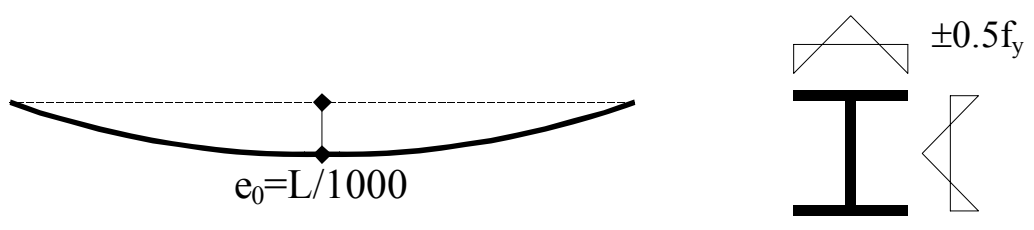

Figure 7. Frame member initial geometrical imperfection and residual stress distribution

The results obtained for the two frames are summarized in the diagrams presented in Figure 8. Each diagram shows all the results concerning each frame and provides the variation of the frame ultimate load reduction factor $\chi_{\mathrm{f}}=\Lambda_{\mathrm{u}} / \Lambda_{\mathrm{y}}$ with $\bar{\lambda}_{\mathrm{f}}$. Also depicted in each diagram are (i) the EC3 buckling curve governing the major axis flexural buckling behaviour of an HEB300 profile (curve $b$ ) and (ii) the "ideal" column/frame curve. Before analysing the results, one should recall that, since all columns exhibit identical cross-sections (same geometry, steel grade and buckling curve), the critical column is the one acted by the higher axial force - i.e., column 1 (column 2) if $\rho \geq 1(\rho \leq 1)$. Moreover, the frame reduction factor $\chi_{\mathrm{f}}$ is always equal to its critical column counterpart $\chi_{\mathrm{c}}$, i.e., one has

$$
\chi_{\mathrm{f}}=\frac{\Lambda_{\mathrm{u}}}{\Lambda_{\mathrm{y}}}=\frac{\Lambda_{\mathrm{u}}}{\min \left(\mathrm{Af}_{\mathrm{y}} / \overline{\mathrm{N}}_{\mathrm{i}}\right)}=\max \left(\frac{\Lambda_{\mathrm{u}} \overline{\mathrm{N}}_{\mathrm{i}}}{\mathrm{Af}_{\mathrm{y}}}\right)=\frac{\mathrm{N}_{\mathrm{u}, \mathrm{c}}}{\mathrm{Af}_{\mathrm{y}}}=\chi_{\mathrm{c}}
$$

which stems from the equivalence of the "critical column" and "frame stability curve" concepts, whenever the same buckling curve is adopted for all columns - recall subsection 2.4.

The observation of the results displayed in Figure 8 prompts the following remarks:

(i) Virtually all results lie "not too much" above the buckling curve $b$, which means that the use of this buckling curve leads to conservative and fairly accurate strength estimates. All the (very few) unsafe predictions occur for $\bar{\lambda}_{\mathrm{f}}<0.2$ and stem mostly from neglecting strain-hardening. On the other hand, some excessively conservative estimates take place for either $\bar{\lambda}_{\mathrm{f}} \approx 1$ or "odd" frame geometries (e.g., $\mu=0.1)$ - although these particular estimates cannot be sorted out from Figure 8, all the separate results are available in reference [21].

(ii) In view of the above results, it is fair to say that, at least for the particular cases investigated, the concepts of "critical column" and "frame stability curve" have been validated. This means that, if one performs only the safety check of the critical column, by means of the buckling curve that governs its behaviour (curve $b$ in this case), one is led to accurate and safe frame strength estimates and, therefore, no other column needs to be checked. It is worth noting that, as anticipated in subsection 2.4, this statement also holds true if the critical column is the shorter one - all the cases in which one has either (i) $\rho>1$ and $\mu<1$ or (ii) $\rho<1$ and $\mu>1$. 


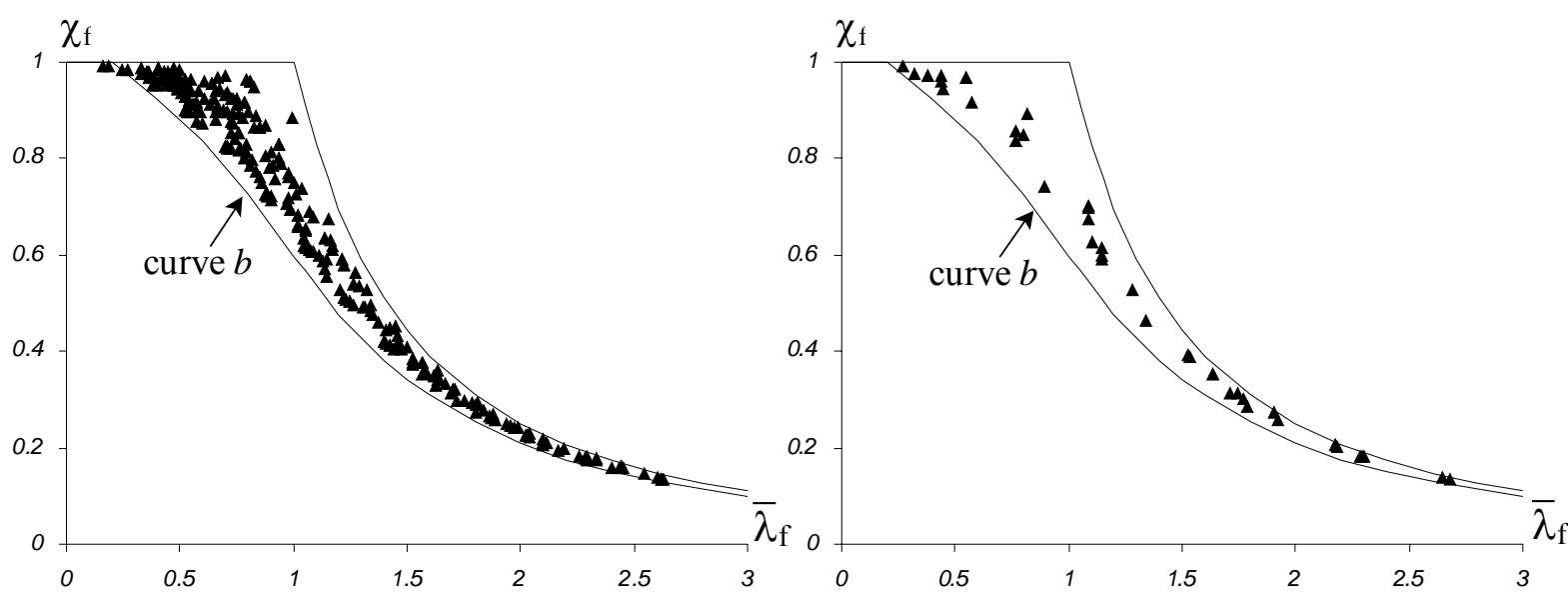

(a)

(b)

Figure 8. Critical column results: (a) simple unbraced frame and (b) L-shaped frame

Finally, one last word concerning the reduction factor of the non-critical column $\chi_{\mathrm{nc}}$, which has not been plotted in Figure 8 and can be calculated on the basis of $\chi_{c}$, by using the relations

$$
\frac{\chi_{n c}}{\chi_{c}}=\frac{N_{u, n c}}{\operatorname{Af}_{y}} \frac{\operatorname{Af}_{y}}{N_{u, c}}=\frac{\bar{N}_{n c}}{\bar{N}_{c}}=\min (\rho ; 1 / \rho)
$$

Therefore, one has always $\chi_{\mathrm{nc}}<\chi_{\mathrm{c}}$, which is a direct consequence of the fact that the non-critical column is acted by a lower axial force at collapse.

\subsubsection{Particular case: braced frames}

Let us now address the particular case of columns integrated in braced (non-sway) frames, for which it is routine practice to assume that their buckling lengths can be conservatively taken as equal to the distance between the corresponding lateral supports ("system length") - for instance, such a simplifying assumption is stated in clause 5.5.1.5(1) of the EC3-ENV [3] ${ }^{7}$. However, one should be aware that this approach is potentially dangerous when the critical member $\mathrm{N}_{\mathrm{cr}}$ value is overestimated, because it leads to lower (and, therefore, unsafe) $\bar{\lambda}_{\mathrm{c}}$ values - recall the inverted L-frame depicted in Figure 1(a), for which the K-factor can be considerably higher than 1.

For illustrative purposes, one analyses next the in-plane behaviour (major axis bending) of the inverted L-frame with hinged supports depicted in Figure 9. Once again, the frame members are HEB300 profiles made of $\mathrm{S} 235$ steel. In order to have medium $\bar{\lambda}$ values, $\mathrm{L}=10 \mathrm{~m}$ was adopted. By assuming $\mathrm{K}=1$ in both members, one is led to $\bar{\lambda}_{1}=0.819, \bar{\lambda}_{2}=1.639, \chi_{1}=0.7125$ and $\chi_{2}=0.2959$ and one would, therefore, believe that (i) the frame is able to withstand any loading if $\mathrm{N}_{\mathrm{Ed}} \leq \mathrm{N}_{\mathrm{b}, \mathrm{Rd}}$ holds for both members and (ii) the optimum loading is characterised by

$$
\overline{\mathrm{N}}_{2}=1 \quad \overline{\mathrm{N}}_{1}=\frac{\chi_{1}}{\chi_{2}}=2.408 \quad \rho=\frac{\overline{\mathrm{N}}_{1}}{\overline{\mathrm{N}}_{2}}=2.408 \quad \Lambda_{\mathrm{Rd}}=\frac{\mathrm{N}_{\mathrm{b}, \mathrm{Rd}, \mathrm{i}}}{\overline{\mathrm{N}}_{\mathrm{i}}}=0.2959 \frac{\mathrm{N}_{\mathrm{pl}}}{\gamma_{\mathrm{M} 1}}
$$

However, the performance of a linear stability analysis of the whole frame yields, for this particular loading, $\mathrm{K}_{1}=1.133, \mathrm{~K}_{2}=0.879, \bar{\lambda}_{1}=0.929, \bar{\lambda}_{2}=1.441, \chi_{1}=0.6428, \chi_{2}=0.3649$ and

\footnotetext{
${ }^{7}$ Note, however, that it does not appear in EC3-prEN [4].
} 


$$
\Lambda_{\mathrm{Rd}}=\min \left(\frac{\mathrm{N}_{\mathrm{b}, \mathrm{Rd}, \mathrm{i}}}{\overline{\mathrm{N}}_{\mathrm{i}}}\right)=0.2669 \frac{\mathrm{N}_{\mathrm{pl}}}{\gamma_{\mathrm{M} 1}}
$$

which indicates that the assuming $\mathrm{K}=1$ leads to an overestimation of the frame ultimate strength by about $11 \%$. Note also that one has $K_{1}=1.133>1$ for the critical member (member 1 , since $\bar{\lambda}_{\mathrm{f}}=\bar{\lambda}_{1}$ $<\bar{\lambda}_{2}$ ), which corresponds precisely to the potentially dangerous situation identified above. Moreover, higher errors are obtained if the length of member 1 is reduced - e.g., $19 \%$ for $\mathrm{L}_{1}=5 \mathrm{~m}$ and $24 \%$ for $\mathrm{L}_{1}$ $=2 \mathrm{~m}$.

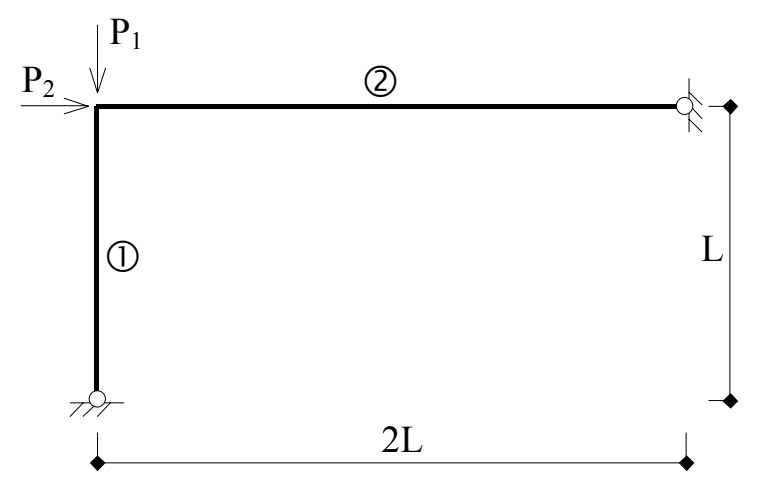

Figure 9. Braced frame illustrative example: inverted L-frame with hinged supports

The curves depicted in Figure 10 represent all the pairs of normalised ultimate load values $\mathrm{N}_{\mathrm{u}, 1} / \mathrm{N}_{\mathrm{pl}}-\mathrm{N}_{\mathrm{u}, 2} / \mathrm{N}_{\mathrm{pl}}$ obtained by (i) using curve $b$ and $\mathrm{K}=1$ in both members, (ii) using curve $b$ and "exact" $\mathrm{K}$ values (yielded by frame linear stability analyses) and (iii) performing in ABAQUS second-order plastic zone ("exact") analyses that incorporate member imperfections (see subsection 2.4.2). Moreover, in order to ensure a meaningful comparison between these three approaches, $\gamma_{\mathrm{M} 1}=1$ was adopted in the first two.

After observing the results presented in Figure 10, it is possible to conclude that:

(i) Assuming $\mathrm{K}=1$ leads to the dashed horizontal and vertical lines and, as already mentioned, the ultimate load of each member becomes independent of the loading ( $\rho$ value).

(ii) The comparison between the " $\mathrm{K}=1$ " and "exact $\mathrm{K}$ " curves shows that the former approach (ii $\left.{ }_{1}\right)$ mostly leads to extremely conserv ative strength estimates (particularly if $\mathrm{N}_{1}$ is small), but (ii ${ }_{2}$ ) also yields unsafe results in the vicinity of $\rho=2.408$.

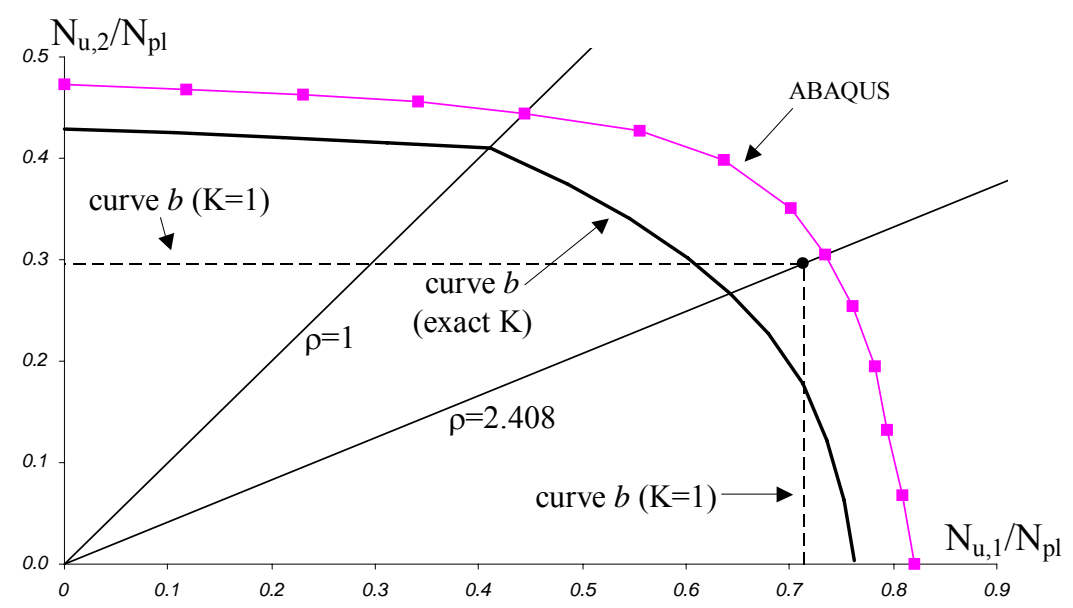

Figure 10. Inverted L-frame ultimate load values 
(iii) Since the frame is statically indeterminate and the buckling curve always underestimates the actual frame collapse load (see Figure 8), the "exact" analyses ("ABAQUS" curve) are somewhat higher than the "exact $\mathrm{K}$ " strength estimates and considerably higher than the " $\mathrm{K}=1$ " ones. This fact "masks" all the (theoretical) errors associated with the adoption of $\mathrm{K}=1$ - the authors investigated a large number of different frame geometries and loadings and found only a few slightly unsafe results, all of them corresponding to frames with odd geometries (e.g., one member much longer that the other).

(iv) In view of the above items, it can be successfully argued that the choice of $K=1$, although theoretically incorrect, does not lead to unsafe designs for situations of practical interest.

(v) Finally, it is still important to mention that the "kink" exhibited by the "exact K" curve at $\rho=1$ is due to the fact that this point corresponds to a critical member switch: member 1 is critical for $\rho>1$ and member 2 for $\rho<1$ (obviously, both members are critical for $\rho=1$ ).

\section{SAFETY CHECKING OF BEAM-COLUMNS INTEGRATED IN FRAMES}

\subsection{The Method 1 and Method 2 Beam-Column Interaction Formulae}

As far as Europe is concerned, the ongoing research on the design and safety checking of steel beam-columns has been taking place in the context of the activities of the Technical Committee 8 ("Stability") of the European Convention for Constructional Steelwork (ECCS). This research work led to the inclusion of two distinct sets of interaction formulae in EC3-prEN [4], which are identified by the designations "Method 1" and "Method 2"8. The Method 2 formulae, which were developed by an Austrian-German research team [22-24], aim mostly at a simple and user-friendly format and, thus, involve only a fairly small number of fully empirical parameters - they have no physical meaning and values are obtained through calibration procedures, i.e., the comparison with numerically (mostly) and experimental results. On the other hand, the aim of the Method 1 formulae, developed by a French-Belgian research team [25-27], are two-fold: (i) to achieve a higher accuracy and also (ii) to assign a clear physical meaning to as many parameters as possible. It seems fair to say that there is a kind of "trade-off" between simplicity (Method 2) and accuracy/transparency (Method 1). In the particular case of the in-plane behaviour of compact (class 1 or 2) I-section beam-columns subjected to major axis bending, the Method 1 and Method 2 interaction formulae read

Method 1:

$$
\begin{gathered}
\frac{\mathrm{N}_{\mathrm{Ed}}}{\chi_{\mathrm{y}} \mathrm{Af}_{\mathrm{y}} / \gamma_{\mathrm{M} 1}}+\frac{\mathrm{C}_{\mathrm{my}, 1} \mathrm{M}_{\mathrm{y}, \mathrm{Ed}}}{\left(1-\chi_{\mathrm{y}} \mathrm{N}_{\mathrm{Ed}} / \mathrm{N}_{\mathrm{cr}, \mathrm{y}}\right) \mathrm{C}_{\mathrm{yy}} \mathrm{W}_{\mathrm{pl}, \mathrm{y}} \mathrm{f}_{\mathrm{y}} / \gamma_{\mathrm{Ml}}} \leq 1 \\
\mathrm{C}_{\mathrm{yy}}=1+\left(\mathrm{w}_{\mathrm{y}}-1\right)\left(2-\frac{1.6}{\mathrm{~W}_{\mathrm{y}}} \mathrm{C}_{\mathrm{my}, 1}{ }^{2}\left(\bar{\lambda}_{\mathrm{y}}+\bar{\lambda}_{\mathrm{y}}{ }^{2}\right)\right) \frac{\mathrm{N}_{\mathrm{Ed}}}{\mathrm{Af}_{\mathrm{y}} / \gamma_{\mathrm{M} 1}} \geq \frac{\mathrm{W}_{\mathrm{el}, \mathrm{y}}}{\mathrm{W}_{\mathrm{pl}, \mathrm{y}}} \mathrm{w}_{\mathrm{y}}=\frac{\mathrm{W}_{\mathrm{pl}, \mathrm{y}}}{\mathrm{W}_{\mathrm{el}, \mathrm{y}}} \leq 1.5
\end{gathered}
$$

Method 2:

$$
\frac{\mathrm{N}_{\mathrm{Ed}}}{\chi_{\mathrm{y}} \mathrm{Af}_{\mathrm{y}} / \gamma_{\mathrm{M} 1}}+\frac{\mathrm{C}_{\mathrm{my}, 2} \mathrm{M}_{\mathrm{y}, \mathrm{Ed}}}{\mathrm{W}_{\mathrm{pl}, \mathrm{y}} \mathrm{f}_{\mathrm{y}} / \gamma_{\mathrm{M} 1}}\left(1+\frac{\mathrm{N}_{\mathrm{Ed}}}{\mathrm{Af}_{\mathrm{y}} / \gamma_{\mathrm{M} 1}}\right) \min \left(\bar{\lambda}_{\mathrm{y}}-0.2 ; 0.8\right) \leq 1
$$

where $\mathrm{W}_{\mathrm{el}, \mathrm{y}}$ and $\mathrm{W}_{\mathrm{pl}, \mathrm{y}}$ are the cross-section elastic and plastic moduli. Besides satisfying one of the above interaction formulae, the resistance of the member end sections must be checked by using

\footnotetext{
${ }^{8}$ The reader should be warned that these sets of beam-column interaction formulae have been often designated in the literature as "Level 1 formulae" and "Level 2 formulae". Unfortunately, the former correspond to "Method 2" and the latter to "Method 1" - failing to take this "switch" into account will lead to considerable misunderstanding.
} 
appropriate N-M plastic interaction formulae. However, when applying the interaction formulae defined by Eqs. (22) and (23) to frame members, the following two aspects deserve special attention:

(i) Although it was demonstrated that, in frames having only axially compressed members, the "critical column" may be easily and quickly identified, such feature no longer exists when the frame members are also subjected to bending moments (i.e., are beam-columns). This fact raises the question of whether it is necessary to calculate the exact buckling lengths required to apply the beam-column interaction formulae, particularly in the case of members acted by small axial forces - recall that large $\mathrm{L}_{\mathrm{cr}}$ and, therefore, low $\chi$ values will be obtained. This issue will be further addressed later in this paper.

(ii) The accuracy of the above interaction formulae is strongly dependent on the choice of an appropriate equivalent moment factor value $\mathrm{C}_{\mathrm{my}}$. However, it is very important to emphasise that the Method 1 and Method 2 formulae were developed on the basis of slightly different "equivalent moment" concepts. Indeed, for simply supported members, $\mathrm{C}_{\mathrm{my}, 1}$ and $\mathrm{C}_{\mathrm{my}, 2}$ concern sinusoidal and uniform equivalent moments, which means that one has, respectively",

$$
\mathrm{C}_{\mathrm{m}, 1}=\left(1-\mathrm{N}_{\mathrm{Ed}} / \mathrm{N}_{\mathrm{cr}}\right) \frac{\mathrm{M}_{\mathrm{Ed}}^{\mathrm{I}, \mathrm{max}}}{\mathrm{M}_{\mathrm{Ed}}^{\mathrm{I}, \max }} \mathrm{C}_{\mathrm{m}, 2}=\cos \left(\frac{\pi}{2} \sqrt{\mathrm{N}_{\mathrm{Ed}} / \mathrm{N}_{\mathrm{cr}}}\right) \frac{\mathrm{M}_{\mathrm{Ed}}^{\mathrm{II}, \max }}{\mathrm{M}_{\mathrm{Ed}}^{\mathrm{I}, \mathrm{max}}}
$$

where $\mathrm{M}_{\mathrm{Ed}}^{\mathrm{I}, \max }$ and $\mathrm{M}_{\mathrm{Ed}}^{\mathrm{II}, \text { max }}$ are the maximum first and second-order moments acting on the beam-column, for a given axial load $\mathrm{N}_{\mathrm{Ed}}$. Both the Method 1 and Method 2 formulae include a more or less extensive set of $\mathrm{C}_{\mathrm{m}}$ expressions or values, all of which have been derived in the context of isolated members (mostly simply supported) and, therefore, cannot be readily applied to members integrated in frames. In order to circumvent this difficulty and avoid the need to evaluate accurate $\mathrm{C}_{\mathrm{m}}$ values, an alternative approach is suggested here [28]: to incorporate each of the theoretical $\mathrm{C}_{\mathrm{m}}$ expressions defined by Eq. (24) directly into the associated interaction formulae (22)-(23), thus yielding

Method 1:

$$
\frac{\mathrm{N}_{\mathrm{Ed}}}{\chi_{\mathrm{y}} \mathrm{Af}_{\mathrm{y}} / \gamma_{\mathrm{M} 1}}+\frac{\left(1-\mathrm{N}_{\mathrm{Ed}} / \mathrm{N}_{\mathrm{cr}, \mathrm{y}}\right) \mathrm{M}_{\mathrm{y}, \mathrm{Ed}}^{\mathrm{II}}}{\left(1-\chi_{\mathrm{y}} \mathrm{N}_{\mathrm{Ed}} / \mathrm{N}_{\mathrm{cr}, \mathrm{y}}\right) \mathrm{C}_{\mathrm{yy}} \mathrm{W}_{\mathrm{pl}, \mathrm{y}} \mathrm{f}_{\mathrm{y}} / \gamma_{\mathrm{M} 1}} \leq 1
$$

Method 2: $\frac{\mathrm{N}_{\mathrm{Ed}}}{\chi_{\mathrm{y}} \mathrm{Af}_{\mathrm{y}} / \gamma_{\mathrm{M} 1}}+\frac{\cos \left(\frac{\pi}{2} \sqrt{\mathrm{N}_{\mathrm{Ed}} / \mathrm{N}_{\mathrm{cr}, \mathrm{y}}}\right) \mathrm{M}_{\mathrm{y}, \mathrm{Ed}}^{\mathrm{II}}}{\mathrm{W}_{\mathrm{p} 1} \mathrm{f}_{\mathrm{y}} / \gamma_{\mathrm{M} 1}}\left(1+\frac{\mathrm{N}_{\mathrm{Ed}}}{\chi_{\mathrm{y}} \mathrm{Af}_{\mathrm{y}} / \gamma_{\mathrm{M} 1}}\right) \min \left(\bar{\lambda}_{\mathrm{y}}-0.2 ; 0,8\right) \leq 1$

In these formulae, it is implicitly assumed that $\mathrm{M}_{\mathrm{y}, \mathrm{Ed}}^{\mathrm{II}}$ is the maximum bending moment acting on the beam-column (i.e., the superscript "max" is omitted), which is obtained from a frame second-order global analysis that does not incorporate member imperfections - they are already accounted for by the interaction formulae ${ }^{10}$. An additional benefit of this approach is related to the fact that either of the new formulae tend to the commonly used cross-section plastic moment check $\left(\mathrm{M}_{\mathrm{y}, \mathrm{Ed}} \gamma_{\mathrm{M} 1} / \mathrm{W}_{\mathrm{pl}, \mathrm{y}} \mathrm{f}_{\mathrm{y}} \leq 1\right)$ as $\mathrm{N}_{\mathrm{Ed}}$ approaches zero - this is in contrast with the original formulae, defined by Eqs. (22) and (23), which become

$$
\frac{\mathrm{C}_{\mathrm{my}} \mathrm{M}_{\mathrm{y}, \mathrm{Ed}}}{\mathrm{W}_{\mathrm{pl}, \mathrm{y}} \mathrm{f}_{\mathrm{y}} / \gamma_{\mathrm{M} 1}} \leq 1
$$

leading to the need to perform an additional end cross-section plastic checks when $\mathrm{C}_{\mathrm{my}} \leq 1$.

\footnotetext{
${ }^{9}$ An in-depth discussion about this matter can be found in a recent paper by the authors [32].

${ }^{10}$ If the member second-order axial forces differ substantially from their first-order counterparts (not the usual case), one should also replace $\mathrm{N}_{\mathrm{Ed}}$ by $\mathrm{N}_{\mathrm{Ed}}^{\mathrm{II}}$.
} 
In order to assess the performance of the proposed beam-column interaction formulae and also to investigate whether it is necessary to calculate exact buckling lengths, a second parametric study was carried out concerning the two simple frames analysed earlier and depicted in Figure 6. However, the frame loading now includes a lateral load Q that induces exclusively first-order bending moments in the members - see Figure 11. It is worth mentioning that the rather peculiar L-shaped frame was selected because of one specific and rather interesting feature: no first-order moments appear in member 1 (only second-order ones).

In this study, the strength estimates obtained by means of the proposed interaction formulae (25) are compared with "exact" results, obtained once more from second-order plastic-zone analyses performed in ABAQUS, which include the initial imperfections shown in Figure 7 in all members. Since the proposed formulae are based on second-order moments, it was also necessary to perform elastic second-order analyses of the two frames, a task that was undertaken resorting to a standard matrix structural analysis method using stability functions (e.g., [29,30]). One should still mention that both frames are classified, according to EC3-prEN, as "unbraced", which means that appropriate frame geometrical imperfections (or, alternatively, equivalent lateral forces) should be included in their global analyses. However, for the sake of simplicity and without any loss of generality (only the loading would change, due to the additional equivalent lateral forces), the influence of this type of geometrical imperfections was disregarded in this study.

Due to space limitations, only a selected (but representative) set of the results is presented in Figures 12 and 13, respectively for the simple unbraced and L-shaped frames - all the remaining results can be found in [31]. This set of results corresponds to the $\rho-\mu$ combinations given in Table 2 (recall Eqs. (17)) and it is worth noting that they are all Massociated with situations such that (i) member 1 is acted by the higher axial force $(\rho>1)$ and (ii) the maximum first-order bending moment occurs in member 2. As before, for each pair of $\rho-\mu$ values, several $L_{2}$ and $L_{1}=\mu L_{2}$ values were considered, thus making it possible to cover a sufficiently wide range of $\bar{\lambda}_{\mathrm{f}}$ values. Moreover, in order to keep the number of parameters involved low, it was decided (i) to take $\gamma_{\mathrm{M} 1}=1.0$ in the interaction formulae and (ii) to adopt "exact" $\chi$ values in member 1 (i.e., the one subjected to the higher axial force), extracted from the plastic-zone results presented in Figure 8. Concerning the last issue, it is obvious that the use of the column buckling curves would lead to slightly lower $\chi$ values, thus making the interaction formulae predictions somewhat safer.

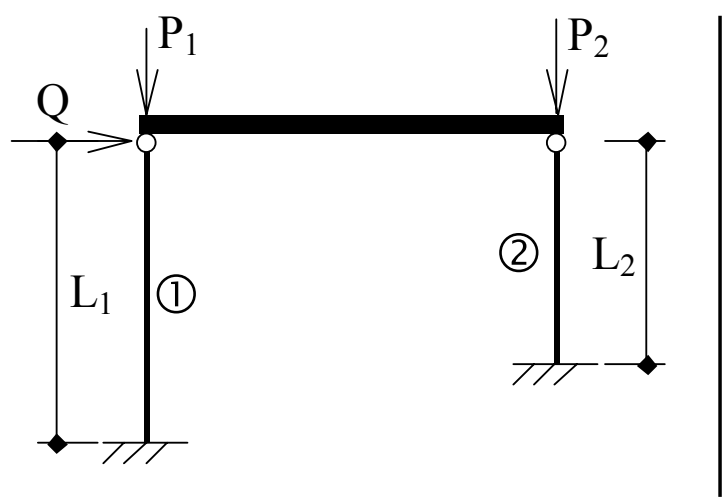

(a)

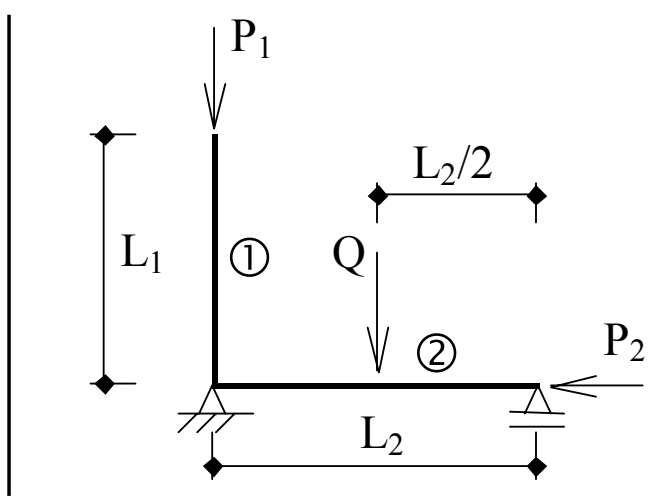

(b)

Figure 11. Structural systems employed in the beam-column parametric study:

(a) simple unbraced frame with a rigid beam and (b) L-shaped frame. 
Table 2. Selected pairs of $\rho-\mu$ values: (a) simple unbraced frame and (b) L-shaped frame

\begin{tabular}{c|c|c|c|c}
\hline$\mu$ & 0.5 & 1 & 2 & 3 \\
\hline 1.5 & & (a) & (a) & (a) \\
\hline 2 & (b) & (b) & (b) & (a) \\
\hline 3 & & (a) & (a) & \\
\hline
\end{tabular}

Each diagram in Figures 12 and 13 corresponds to a particular pair of $\rho-\mu$ values and provides, for several $\bar{\lambda}_{\mathrm{f}}$ values, the pair of ultimate $\mathrm{Q}-\mathrm{P}_{1}$ load values. The observation of the results leads to the following conclusions:

(i) The application of the proposed formulae (Eqs. (25)), which employs ( $i_{1}$ ) exact buckling lengths (obtained from linear stability analyses) and $\left(i_{2}\right)$ elastic second-order moments (obtained from genuine second-order global analyses), consistently leads to rather accurate frame ultimate strength estimates ${ }^{11}$. As expected, the Method 1 formula provides the more accurate load-carrying capacity predictions ${ }^{12}$, even if the differences between the two Methods are always rather minute - a similar assessment was made when both formulae were applied to isolated members, employing exact $\mathrm{C}_{\mathrm{my}}$ values [32].

(ii) For low axial forces, the application of either formula leads to rather conservative strength estimates. This is due to the fact that the second-order effects are almost negligible and, therefore, the structures are able to withstand a loading level very close to the one associated with the occurrence of a first-order rigid-plastic (plastic hinge) collapse mechanism [21]. Naturally, this effect is more relevant in frames exhibiting low $\bar{\lambda}_{\mathrm{f}}$ values ${ }^{13}$.

(iii) Finally, note that the majority of the (few) unsafe estimates concern the L-shaped frame and correspond to situations associated with high $\bar{\lambda}_{\mathrm{f}}$ and axial force values, i.e., situations in which moderate-to-large displacements are bound to occur - obviously, such situations are outside the range of validity of the elastic second-order global analyses performed (they were based on the use of standard stability functions).

\footnotetext{
${ }^{11}$ Note that this statement also applies to the L-shaped frame, where no first-order bending moments act in member 1. This would certainly lead to some difficulties, concerning the application of the original formulae - recall that Eqs. (22) and (23) involve first-order bending moments.

${ }^{12}$ Recall that Method 2 was developed with the explicit objective of achieving a high degree of simplicity and user-friendliness, even at the cost of some accuracy and transparency.

${ }^{13}$ Concerning this aspect, it is worth mentioning that the EC3-prEN states explicitly that the buckling effects may be ignored in columns for which $\mathrm{N}_{\mathrm{Ed}} / \mathrm{N}_{\mathrm{cr}} \leq 0.04$ - only the cross-section resistance needs to be checked.
} 

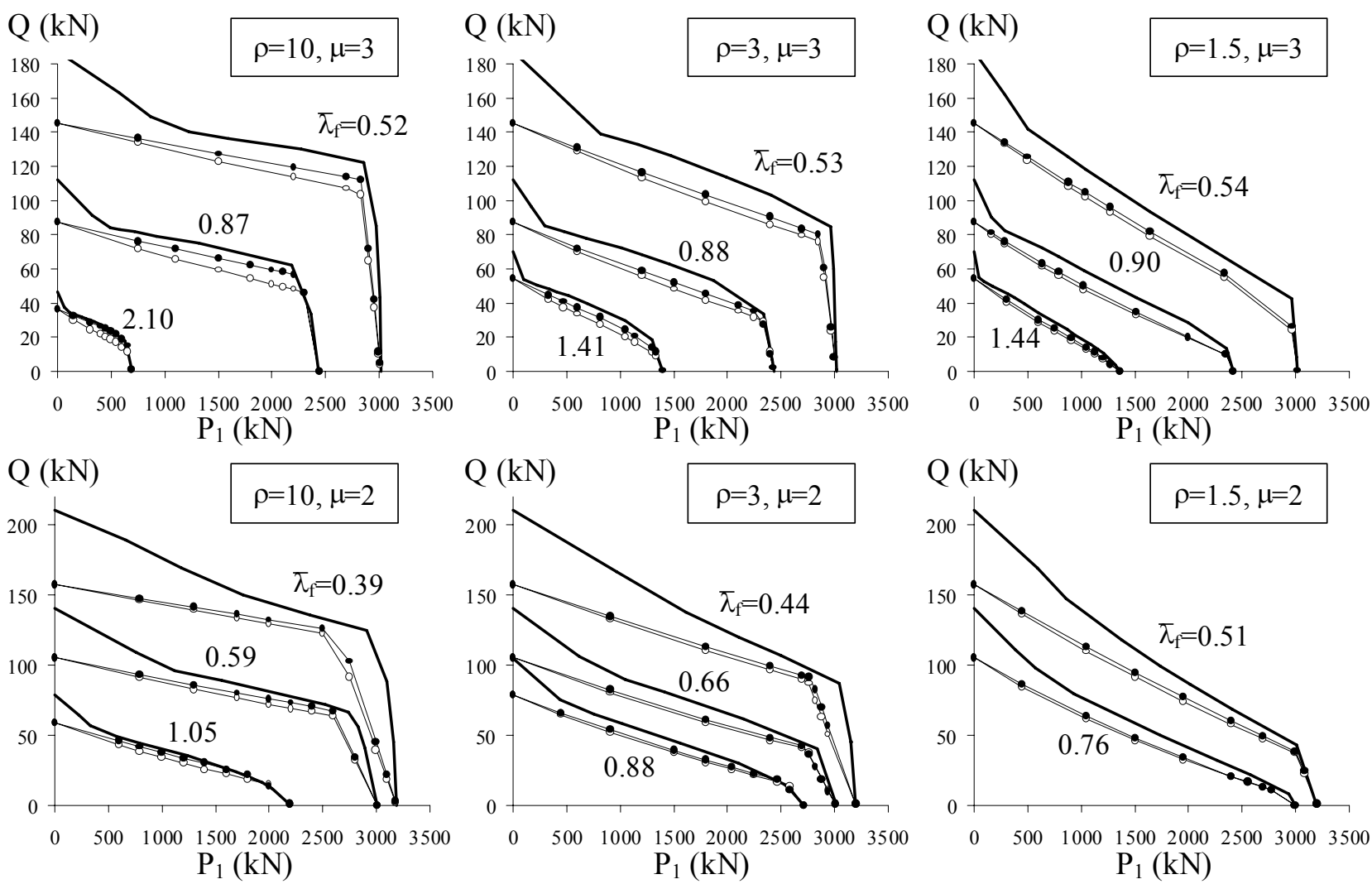

\section{$\longrightarrow$ ABAQUS $\longrightarrow$ METHOD $1 \multimap$ METHOD2}

Figure 12. Beam-column parametric study: simple unbraced frame results
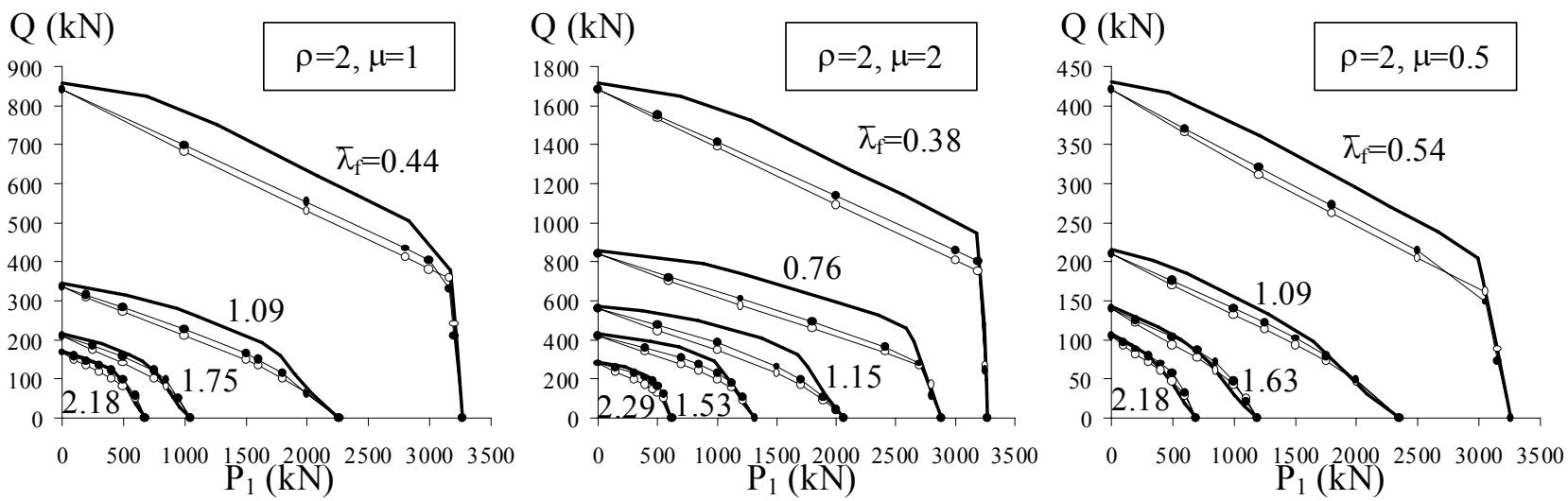

\section{ABAQUS $\longrightarrow$ METHOD $1 \multimap$ METHOD2}

Figure 13. Beam-column parametric study: L-shaped frame results

It is still worth mentioning that if one chooses to employ Eqs. (22) and (23), adopting tabulated $\mathrm{C}_{\mathrm{m}}$ values, rather than the proposed formulae given in Eq. (25), extreme caution is required since, as mentioned earlier, the overwhelming majority of the available $\mathrm{C}_{\mathrm{m}}$ values and expressions were determined for isolated and simply supported beam-columns [32] - the misuse of these values and expressions may lead to considerably unsafe strength estimates [31].

Finally, a few words concerning the choice of the buckling lengths to be incorporated in the beam-column interaction formulae. The results displayed in Figures 12 and 13 clearly show that accurate frame ultimate load values are consistently obtained if one adopts exact $\mathrm{L}_{\mathrm{cr}}$ values, even 
when these values are very large and "non intuitive", e.g., when $\rho>>1$ - from Eq. (7), one obtains $\mathrm{L}_{\mathrm{cr}, 2}=\sqrt{\rho} \mathrm{L}_{\mathrm{cr}, 1}$, which means that, for instance, one has $\rho=10$ and $\mathrm{L}_{\mathrm{cr}, 2}=\sqrt{10} \mathrm{~L}_{\mathrm{cr}, 1}$ if $\overline{\mathrm{N}}_{1}=10 \overline{\mathrm{N}}_{2}$. Although the authors have previously shown that underestimating such large $\mathrm{L}_{\mathrm{cr}}$ values may lead to extremely unsafe strength estimates $[21,31]^{14}$, it should be made absolutely clear that the underestimation of $\mathrm{L}_{\mathrm{cr}}$ corresponds, in fact, to an overestimation of $\mathrm{N}_{\mathrm{cr}}$, which often leads to serious safety problems. Therefore, the use of exact, albeit very large, buckling lengths is strongly recommended.

\section{CONCLUSION}

In this work, one discussed some fundamental concepts and presented a few illustrative results concerning the design and safety checking of columns and beam-columns integrated in plane steel frames - particular attention being paid to the provisions prescribed by the upcoming (European Norm) version of Eurocode 3. Initially, the paper addressed the ambiguities and surprising results that a designer may be faced with when he wishes to calculate the buckling lengths of compressed members belonging to frame structures. Besides clarifying a number of peculiar issues and showing that the "exact" buckling length values must be obtained from frame linear stability analyses, it was also demonstrated that a theoretically sound member safety checking procedure must necessarily incorporate those "exact" buckling lengths - moreover, the use of "intuitive" values (prompted by an "isolated member reasoning") may lead to considerably unsafe frame strength estimates.

Next, one introduced the concept of frame "critical column", i.e., the column that governs the frame strength and safety checking procedure, which (i) provides valuable insight into the frame overall behaviour (for instance, by making it easy to spot the frame "weak" members) and (ii) may be used to develop a frame optimisation procedure. After addressing the identification of the "critical column" of a given frame, it was shown that its normalised slenderness always supplies the value of the frame normalised slenderness, provided that all the frame columns are governed by the same buckling curve.

Finally, attention was devoted to the design and safety checking of beam-columns integrated in frames using the novel (Method 1 and Method 2) interaction formulae included in the upcoming version of Eurocode 3. It was shown that, at least for the simple frames dealt with in this paper, the inclusion of "exact" buckling lengths and equivalent moment factors $\left(\mathrm{C}_{\mathrm{m}}\right)$ consistently leads to frame ultimate load-carrying capacity predictions that are both safe and accurate. However, since (i) the accuracy of the strength estimates provided by the formulae is strongly dependent on the choice of appropriate $C_{m}$ values and (ii) it is rather difficult to obtain such values for frame members, an alternative approach to use the above formulae was proposed: to incorporate genuine second-order elastic bending moments, yielded by the analysis of "ideal" (initially perfect) frames.

In order to assess the validity and/or efficiency of the various concepts and procedures addressed in this work, several illustrative examples were presented and discussed throughout the paper. They dealt with simple two-bar frames and the numerical results obtained were compared with "exact" values, yielded by second-order plastic zone finite element analyses, performed by means of the code ABAQUS

\footnotetext{
${ }^{14}$ In particular, the following "intuitive" $\mathrm{K}$-factors were considered: (i) $\mathrm{K}=2$ for the simple unbraced frame member acted by the smaller axial load and (i) $\mathrm{K}=1$ for the L-shaped frame horizontal member. In both cases, the interaction formulae yielded several rather unsafe strength estimates.
} 
and including standard initial geometric imperfections and residual stresses - the proposed methodologies were shown to consistently yield safe and accurate strength predictions.

\section{REFERENCES}

[1] Chen WF, Toma S (eds). Advanced Analysis of Steel Frames. Boca Raton: CRC Press, 1994.

[2] Chan SL. Non-Linear Behaviour and Design of Steel Structures Journal of Constructional Steel Research 2001;57(12):1217-1231.

[3] Comité Européan de Normalization (CEN). ENV 1993-1-1 Eurocode 3: Design of Steel Structures, Part 1.1: General Rules and Rules for Buildings. CEN, Brussels; 1992.

[4] Comité Européan de Normalization (CEN). prEN 1993-1-1 Eurocode 3: Design of Steel Structures, Part 1.1: General Rules and Rules for Buildings (stage 49 draft, June 2004). CEN, Brussels; 2004.

[5] Sfintesco D. Fondement Expérimental des Courbes Européennes de Flambement. Construction Métallique 1970;3:5-12. (French)

[6] Beer H, Schulz G. Bases Théoriques des Courbes Européennes de Flambement, Construction Métallique 1970;3:37-56. (French)

[7] Hibbit, Karlsson \& Sorensen Inc. ABAQUS Standard (version 6.3-1); 2002.

[8] Wood R. Effective Lengths of Columns in Multi-Story Buildings (Parts 1-3). The Structural Engineer 1974;52(7):235-245; 52(8):295-302; 52(9):341-346.

[9] ASCE Task Committee on Effective Length. Effective Length and Notional Load Approaches for Assessing Frame Stability: Implications for American Steel Design, ASCE, New York; 1997.

[10] Cheong-Siat-Moy F. K-Factor Paradox. ASCE Journal of Structural Engineering 1986;112(8):1747-1760.

[11] Picard A, Beaulieu D, Kennedy D. Longueur de Flambement des Éléments en Compression. Construction Métallique 1992;2:3-15. (French)

[12] Maleck A, White D. A Modified Elastic Approach for the Design of Steel Frames. Proceedings of the SSRC Annual Technical Session \& Meeting (Ft. Lauderdale), 2001:43-62.

[13] Canadian Standards Association (CSA). CAN/CSA S16.1 M89 Limit States Design of Steel Structures. Canadian Standards Association, Toronto; 1998 
[14] Surovek-Maleck A, White D. Alternative Approaches for Elastic Analysis and Design of Steel Frames (Part I: Overview and Part II: Verification Studies). Journal of Structural Engineering (ASCE) 2004;130(8):1186-1197 and 1197-1205.

[15] Fang LX, Chan SL. Advanced, Second-Order and Modified First-Order Analyses for Design of 2-Bay Portals. In: Hancock G, Bradford M, Wilkinson T, Uy B, Rasmussen K, editors. Advances in Structures, ASSCCA'03 Sydney, Rotterdam, 2003:517-520.

[16] Chan SL, Huang HY, Fang LX. Advanced Analysis of Imperfect Portal Frames with Semi-Rigid Base Connections. Journal of Engineering Mechanics (ASCE) 2005;131. (in press)

[17] De Luca A, Mele E, Faella, C. Advanced Inelastic Analysis: Numerical Results and Design Guidelines for Rigid and Semi-Rigid Sway Frames. In: White D, Chen WF, editors. Plastic Hinge Based Methods for Advanced Analysis and Design of Steel Frames: An Assessment of the State-of-the-Art. Bethlehem: SSRC, 1993:41-63.

[18] Cosenza E, De Luca A, Faella C. The Concept of "Frame Slenderness" for the Definition of "Frame Stability Curves". Proceedings of SSRC Annual Technical Session and Meeting, 1988:59-70.

[19] Chen WF, Atsuta T. Theory of Beam-Columns: Vol. 1 - In Plane Behaviour and Design. New York: McGraw-Hill, 1976.

[20] Barreto V, Camotim D. Computer-Aided Design of Structural Steel Plane Frames According to Eurocode 3. Journal of Constructional Steel Research 1998;46(1-3):367-368.

[21] Gonçalves R. Member Imperfections in Steel Structures: Concepts, Results and Thoughts, MASc Thesis (Structural Engineering), Technical University of Lisbon, 1999. (Portuguese)

[22] Greiner R. Background Information on the Beam-Column Interaction Formulae at Level 1. Report TC8-2001-002 from the ECCS Technical Committee 8, 2001.

[23] Greiner R. Recent Developments for the New Rules for Member Stability in Eurocode 3. In: Iványi M, editor. Stability and Ductility of Steel Structures (Budapest). Akademia Kiadó, 2002:23-30.

[24] Lindner J. Design of Beams and Beam-Columns. Progress in Structural Enginering and Mechanics 2003;5:38-47.

[25] Maquoi R, Boissonnade N, Muzeau JP, Jaspart JP, Villette M. The Interaction Formulae for Beam-columns: A New Step of a Yet Long Story. Proceedings of the SSRC Annual Technical Session \& Meeting (Ft. Lauderdale), 2001:63-88.

[26] Boissonnade N, Jaspart JP, Muzeau JP, Villette M. Improvement of the Interaction Formulae for Beam-Columns in Eurocode 3. Computers \& Structures 2002;80(27-30):2375-2385. 
[27] Boissonnade N, Jaspart JP, Muzeau JP, Villette M. New Interaction Formulae for Beam-Columns in Eurocode 3. Journal of Constructional Steel Research 2004;60(3-5):421-431.

[28] Gonçalves R, Camotim D. On the Use of Beam-Column Interaction Formulae to Design and Safety Check Members Integrated in Steel Frame Structures. In: Iványi M, editor. Stability and Ductility of Steel Structures (Budapest). Akademia Kiadó, 2002:283-291.

[29] Livesley R, Chandler D. Stability Functions for Structural Frameworks. Manchester University Press; 1956.

[30] Chen WF, Lui EM. Stability Design of Steel Structures. Boca Raton: CRC Press, 1991.

[31] Camotim D, Gonçalves R. Comparison Between Level 1 / Level 2 Interaction Formulae and FEM Results for Frame Members. Report TC8-2002-024. Technical Committee 8 (TC8) of the European Convention for Constructional Steelwork (ECCS); 2002.

[32] Gonçalves R, Camotim D. On the Application of Beam-Column Interaction Formulae to Steel Members with Arbitrary Loading and Support Conditions. Journal of Constructional Steel Research 2004;60(3-5):433-450. 
[Blank Page] 


\title{
FLEXURAL BEHAVIOUR OF STEEL PANELS COMPOSED OF BOLTED MODULAR UNITS
}

\author{
H.T. Wong ${ }^{1}$, J.G. Teng ${ }^{1, *}$, Z.C. Wang ${ }^{2}$, Y. Zhao ${ }^{3}$ and S.L. Dong ${ }^{3}$ \\ ${ }^{1}$ Department of Civil and Structural Engineering \\ The Hong Kong Polytechnic University, Hong Kong, China \\ ${ }^{2}$ Research Centre for Spatial Structures, Shanghai Jiaotong University, Shanghai, China \\ ${ }^{3}$ Department of Civil Engineering, Zhejiang University, Hangzhou, China \\ *Corresponding author. Email: cejgteng@polyu.edu.hk; Fax: +852 2334 6389; Tel: +852 27666012
}

\begin{abstract}
Steel-concrete composite shell roofs (Comshell roofs) are formed by pouring concrete on a thin stiffened steel base shell which serves as both the permanent formwork and the tensile steel reinforcement. The thin steel base shell, constructed by bolting together open-topped modular units consisting of a base plate and surrounding edge plates, are required to carry the wet concrete loading safely during construction. The behaviour of these bolted shells is complicated by the presence of many bolted joints, so the use of finite element analysis is necessary in order to accurately predict their behaviour. For any such finite element model, the key issue is the accurate modelling of the behaviour of the bolted connections within a bolted steel base shell in which bending and membrane actions exist in both directions. In this paper, bolted flat panel specimens under transverse loading are studied to develop a good understanding of the behaviour of such bolted connections and to assess the validity of a relatively simple finite element connection model developed in a previous study. Experimental results obtained from a series of flexural tests on model bolted panels are presented together with those from finite element analyses in which the existing simplified connection model was employed. Comparisons of results from these two approaches confirm that the simplified connection model proposed in a previous study leads to accurate predictions of the flexural behaviour of these present bolted panels.
\end{abstract}

Keywords: Shell roofs, bolted steel panels, buckling, bolted connections, finite element analysis, bolted steel shells

\section{INTRODUCTION}

Many thin concrete shells have been built around the world as large span roofs, but their use has gradually declined over the past few decades. This decline has been due mainly to the high cost of construction and removal of temporary formwork and associated falsework for concrete casting in the construction of a thin concrete shell. This labour intensive and costly process of construction, coupled with the increasing ease in analysing complex skeletal spatial structures offered by advances in computer technology, has made concrete shells much less competitive than they were a few decades ago.

Over the past few decades, there have been several attempts aimed at eliminating the need for temporary formwork in constructing thin concrete shell roofs, but these have met with only limited success. An excellent review of these attempts and other developments of thin concrete shell roofs was given by Medwadowski [1], who concluded that forming "remains the great, unsolved problem of construction of concrete thin shell roofs. Any and all ideas should be explored, without prejudice.” The latest development in the forming of thin concrete shell roofs is the Comshell roof system proposed by Teng [2] which is believed to be a very promising solution to this difficult problem (Teng et al. [3]).

The Comshell roof is a steel-concrete composite shell roof formed by pouring concrete on a thin stiffened steel base shell which serves as both the permanent formwork and the tensile steel 
reinforcement. The steel base shell is constructed by bolting together modular steel units in the form of an open-topped box consisting of a flat or slightly curved base plate surrounded by edge plates (Figure 1). By adopting modular units of different shapes, different shell forms can be achieved, but current research is limited to cylindrical shell roofs only (Figure 2) as they are the easiest to construct by this modular approach (Teng et al. [3]). A brief description of the system and its advantages is given here, but further details are available elsewhere (Teng [2]; Teng et al. [3]).

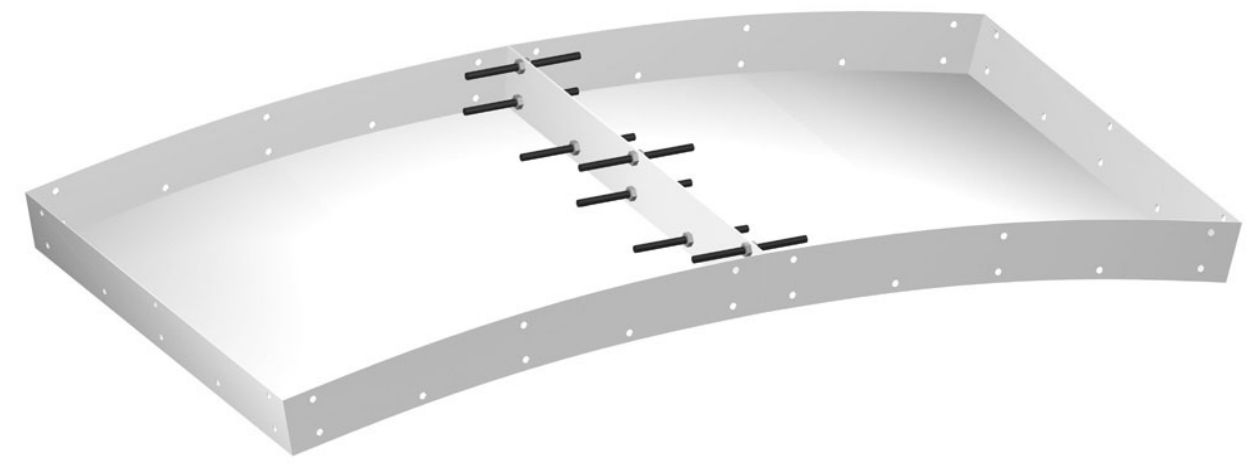

Figure 1. Modular units and bolted connection

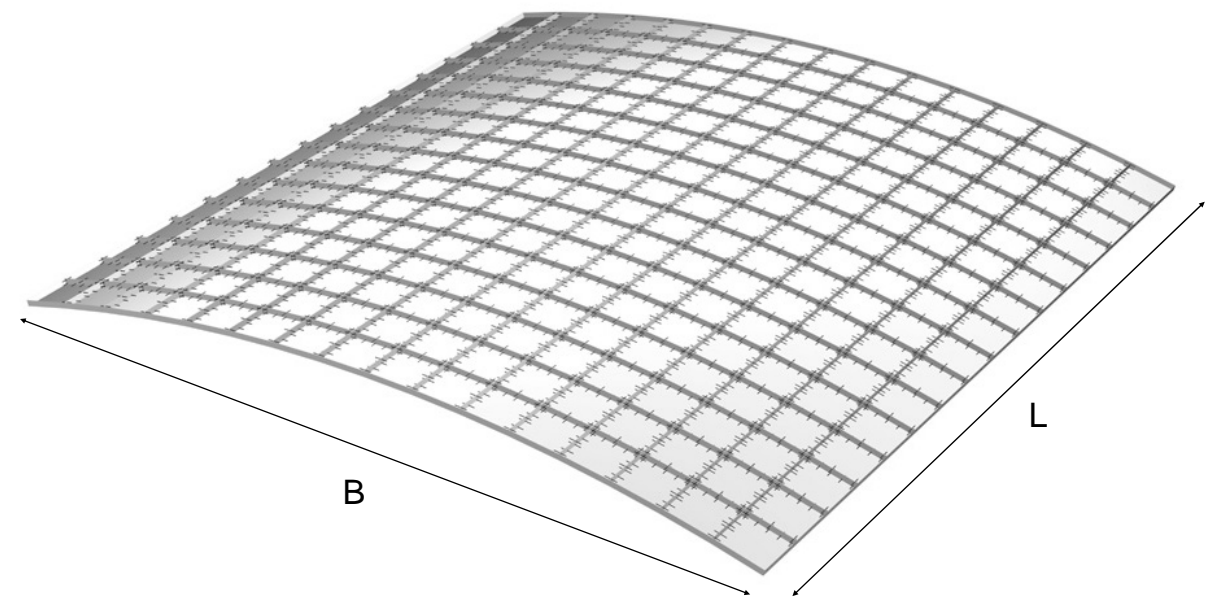

Figure 2. Steel base shell formed from modular units

The modular units for cylindrical shell roofs are made with two of the edge plates slightly inclined, so that when they are assembled using bolts, a curved profile of desired curvature results (Figures 1 and 2). Holes are drilled on the edge plates for bolt connections to adjacent units, and the bolted-together edge plates form stiffeners in both directions (Figure 2). The circular profile of the shell can be either approximated by flat bases, or exactly followed by slightly curved bases with all edge plates being perpendicular to the base. In fact, the base of modular units can have curvatures which differ from the global curvature of the roof, and can be either convex or concave, if desired.

This system has many distinct advantages: (a) mass factory production of the units of a few standard sizes and curvatures is possible, so shells of desired spans and curvatures can be built easily; (b) transportation to and handling on site is easy, and units can be bolted together to form big panels on the ground (e.g. half-span arch panels) for lifting; (c) the steel shell so built has many rib stiffeners formed from edge plates, and as a result, its buckling resistance is substantially enhanced so shoring during construction can be substantially reduced; (d) the ribs can prevent wet concrete 
from flowing down the shell surface; (e) the ribs together with bolts act as shear connectors between the steel shell and the concrete, so additional welded shear connectors are not required; and (f) the ribs can be used as spacers to ensure accurate positioning of steel reinforcing bars/wire meshes for controlling cracks or for hogging moment resistance. It may be noted that the edge plates of the modular units fulfil many useful roles.

Steel sheets with a thickness of around $2 \mathrm{~mm}$ are expected to be sufficient for the base plate of the modular unit to carry wet concrete loading without excessive deformations, stresses or premature local buckling, particularly if small corrugations are used in the base to enhance its out-of-plane stiffness (Teng et al. [3]). Due to this small thickness, the units can be press-formed easily with precise geometric control. The units can be assembled into arch panels on ground before lifting, ensuring a tight control of the geometric shape of the assembled shell and limiting shoring requirement.

For the Comshell system to be widely used in practice, many issues have to be studied to establish a sound understanding of the behaviour and strength of these shells, and to develop suitable design methods. At the present, a number of failure modes have been identified (Teng et al. [3]), and each needs a great amount of research. A main design issue of Comshell roofs is the buckling strength of the bolted steel base shell during the construction stage under wet concrete loading. Due to the many bolted connections, the behaviour of these bolted base shells is complicated, so the use of finite element analysis is necessary at the present in order to accurately predict their behaviour, although a simpler method may be established in the more distant future. For any such finite element model, the key issue is the accurate modelling of the behaviour of the bolted connections within a bolted steel base shell, in which bending and membrane actions exist in both directions.

The aim of the present study was to develop a good understanding of the behaviour of the bolted connections in Comshell roofs under one-way or two-way bending and to assess the validity of a relatively simple finite element connection model developed in a previous study (Teng et al. [3]). Experimental results obtained from a series of flexural tests on model bolted flat panels are presented together with those from finite element analyses in which the existing simplified connection model was employed. The use of bolted flat panels simplified the experimental work and allowed attention to be focused on the flexural behaviour of the connections. This then forms a solid basis for further research into the behaviour and modelling of these bolted connections in a curved bolted steel base shell of the Comshell roof.

\section{GENERAL EXPERIMENTAL CONSIDERATIONS}

During the construction stage, the wet concrete acts as loading on the bolted steel base shell which can fail by either local buckling or overall buckling (Teng et al. [3]). Local buckling can be in one of two modes: buckling of the bolted stiffeners formed from edge plates with or without stiffening lips, and buckling of the base plates of the modular units. Overall buckling of the bolted base shell involves global shape changes, while local buckling only involves deformations of either the stiffeners or the base plates or both.

With the availability of powerful computer software for nonlinear analysis of shells, the purpose of experiments is mainly to calibrate numerical models instead of providing a parametric behavioural 
study. Such calibration is essential when there are theoretical uncertainties in numerical modelling. Typical uncertainties in modelling the nonlinear and buckling behaviour of steel structures include geometric imperfections, residual stresses and connection behaviour. All these aspects are present in the bolted base shell of a Comshell roof, but the uncertainty of the connection behaviour is the predominant aspect. Therefore, the accurate modelling of the behaviour of the bolted connections is the key to the accurate prediction of the buckling load of bolted steel base shells.

As a first step towards understanding the behaviour and modelling of these bolted connections, simple cantilever connection tests were previously conducted, and experimental results together with results from numerical simulations are given in Teng et al. [3]. This study led to the development of a relatively simple connection model in addition to a refined model. The simpler model, referred to as the simplified connection model, was shown to be efficient and sufficiently accurate, and thus has the potential to be used in the nonlinear analysis of bolted steel base shells of the Comshell roof system. The connections investigated in the study of Teng et al. [3] were not "complete" connections, in the sense that the edge plate of a modular unit was bolted to a rigid support plate, but in real bolted steel base shells, a connection is formed by connecting two deformable edge plates of adjacent modular units by bolts. An obvious difference between these two types of connections is that buckling of the bolted edge plate cannot occur in the former type of connection. While the cantilever tests provided useful test data for understanding the connection behaviour and for the development of a simplified finite element connection model, the natural next step of this research would be to examine the behaviour and modelling of more realistic bolted connections. This paper therefore presents such a study in which the flexural behaviour of bolted stiffened panels were tested and modelled, with particular attention to connection behaviour and buckling phenomena.

\section{FABRICATION OF SPECIMENS}

This series of tests, referred to as the BP series, consisted of four tests on three bolted panel specimens. The three panel specimens were of two configurations and subjected to different loadings. The three panels are referred to as specimens BP1, BP2 and BP3. Two tests were conducted on specimen BP3, which are referred to as test BP3-1 and test BP3-2.

The three panel specimens were constructed from two types of modular units. Specimen BP1 was formed by bolting together two modular units, each of which had a $300 \mathrm{~mm}$ x $300 \mathrm{~mm}$ base plate and four $30 \mathrm{~mm}$ high edge plates each stiffened with a $10 \mathrm{~mm}$ wide lip (Figure 3a). This height of the edge plates meant that only one row of bolts with washers could be accommodated. Specimens BSP2 and BSP3 were constructed by bolting together nine modular units into a square panel, with the central unit being surrounded by other modular units on all four sides and representing closely a modular unit in a much larger panel in terms of interaction with adjacent modular units. The modular units for specimens BSP2 and BSP3 had a $500 \mathrm{~mm}$ x $500 \mathrm{~mm}$ base plate and four $60 \mathrm{~mm}$ high edge plates (Figure $3 b$ ). The greater height of the edge plates of these two specimens allowed the use of two rows of bolts with washers at connections. All four edge plates were perpendicular to the flat base in these modular units. The choices of dimensions were made, taking into account the requirements of the corresponding model base shell tests (Wong and Teng [4]). 


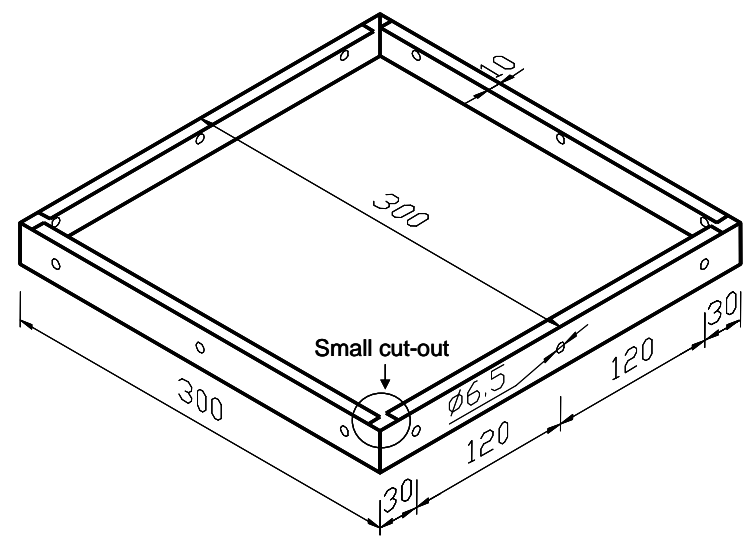

(a) Unit for specimen BP1

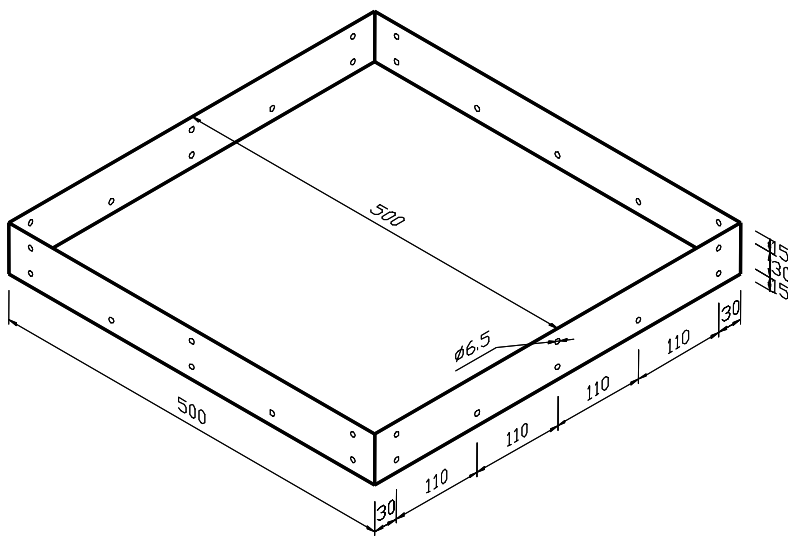

(b) Unit for specimen BP2 and BP3

Figure 3. Dimensions of modular units

Zinc-galvanized cold-formed steel sheets with a nominal thickness of $1 \mathrm{~mm}$ were used to fabricate the modular units. This thickness was chosen because sheets of this thickness are commonly available and are suitable for the necessary welding involved in the fabrication process. Material properties of the steel sheets were determined by tensile tests according to BSEN1002-1 [5]. Table 1 provides the material properties of the steel sheets averaged from the results of three tensile tests, where the percentage elongation after fracture is for a $50 \mathrm{~mm}$ gauge length. Selected stress-strain curves of the steel sheets used in the fabrication of these specimens are shown in Figure 4. The tensile stress-strain curves from other tests not shown herein are very similar to these selected curves. These tensile test results were used to define the material behaviour in the subsequent finite element analyses. The material properties were calculated using the sheeting thicknesses that included coatings, which partly explains why the elastic moduli of the steel sheets found from the tensile tests are on the lower side of values for steels.

Table 1. Material properties of steel sheets

\begin{tabular}{c|c|c|c|c|c}
\hline Panel specimen & $\begin{array}{c}\text { Thickness } \\
\mathbf{t}(\mathbf{m m})\end{array}$ & $\begin{array}{c}\text { Young's } \\
\text { modulus } \\
E \mathbf{( G P a )}\end{array}$ & $\begin{array}{c}\text { Yield stress } \\
\sigma_{y} \mathbf{( M P a )}\end{array}$ & $\begin{array}{c}\text { Tensile strength } \\
\sigma_{u}(\mathbf{M P a})\end{array}$ & $\begin{array}{c}\text { Ultimate Elongation } \\
\boldsymbol{\varepsilon}_{u}(\mathbf{\%})\end{array}$ \\
\hline BP1 & 1.03 & 183.68 & 282 & 344 & 29.6 \\
\hline BP2 and BP3 & 1.03 & 189.01 & 278 & 323 & 26.3 \\
\hline
\end{tabular}

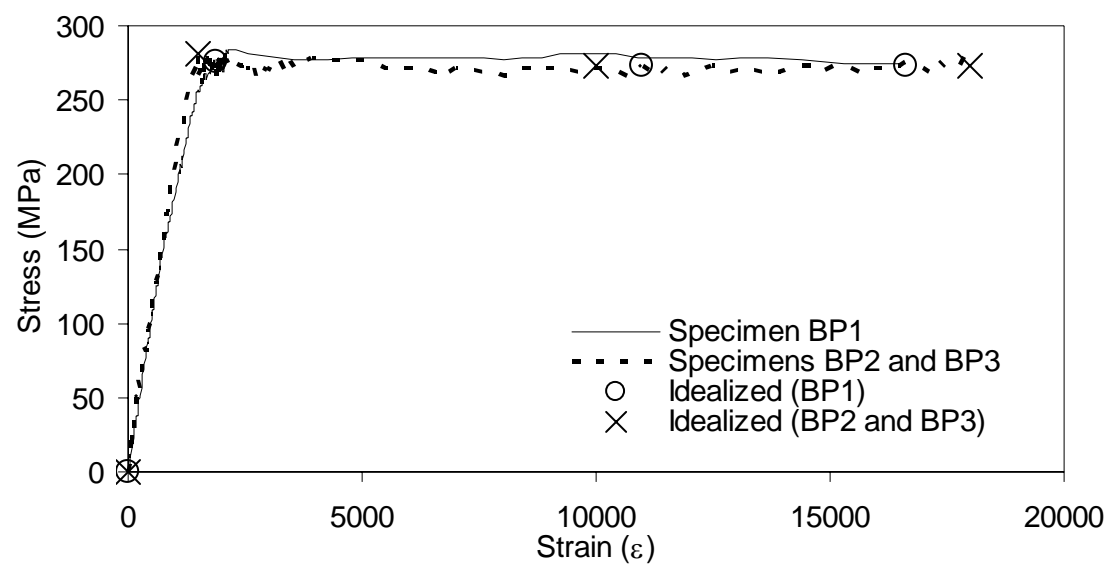

Figure 4. Typical stress-strain curves of steel sheets from tensile tests 
While stamping is expected to be the forming process for the modular units in future practical applications, and can be easily realized by a commercial manufacturer if a large number of units are required, the fabrication of the experimental modular units had to follow a simpler approach. The fabrication of these experimental modular units involved the steps of cutting, drilling, bending and welding. First, a square steel sheet with four corner cut-outs and pre-drilled holes were obtained. Second, a numerically controlled bending machine was employed to fold the four edge plates to form a $90^{\circ}$ angle. Third, the four corners were welded to obtain a modular unit in the form of an open-topped box (Figure 3). To achieve high quality welding, a TRANSTIG 16Pi pulsed TIG (Tungsten Inert Gas) welding machine was employed. Finally, the excess welding deposits were ground away to provide smooth and clean edges. Despite much care exercised in the fabrication process, it was noticed that the modular units so produced had slightly convex or concave base plates. In addition, in fabricating specimens BP2 and BP3, the bolt holes, which were manually drilled, were not as accurately positioned as initially expected, which led to slight unevenness between the modular units after their assembly into a panel. Modifications to the fabrication process to avoid this problem were subsequently implemented in a follow-on series of tests on bolted steel shells (Wong and Teng [4]).

\section{EXPERIMENTAL SET-UP}

\subsection{Test BP1}

A simply supported one-way panel test was first conducted on specimen BP1 (Figure 5) to study the behaviour of a bolted steel panel. Loading was applied by weights hung at the mid-span corners of the modular unit at an increment of $10 \mathrm{~N}$ per loading point (Figure 5). Three linear variable differential transformers (LVDTs) were placed at the mid-span for the measurement of vertical displacements. Strain gauges were not installed, as the test was intended to provide a preliminary assessment of connection behaviour in a panel.

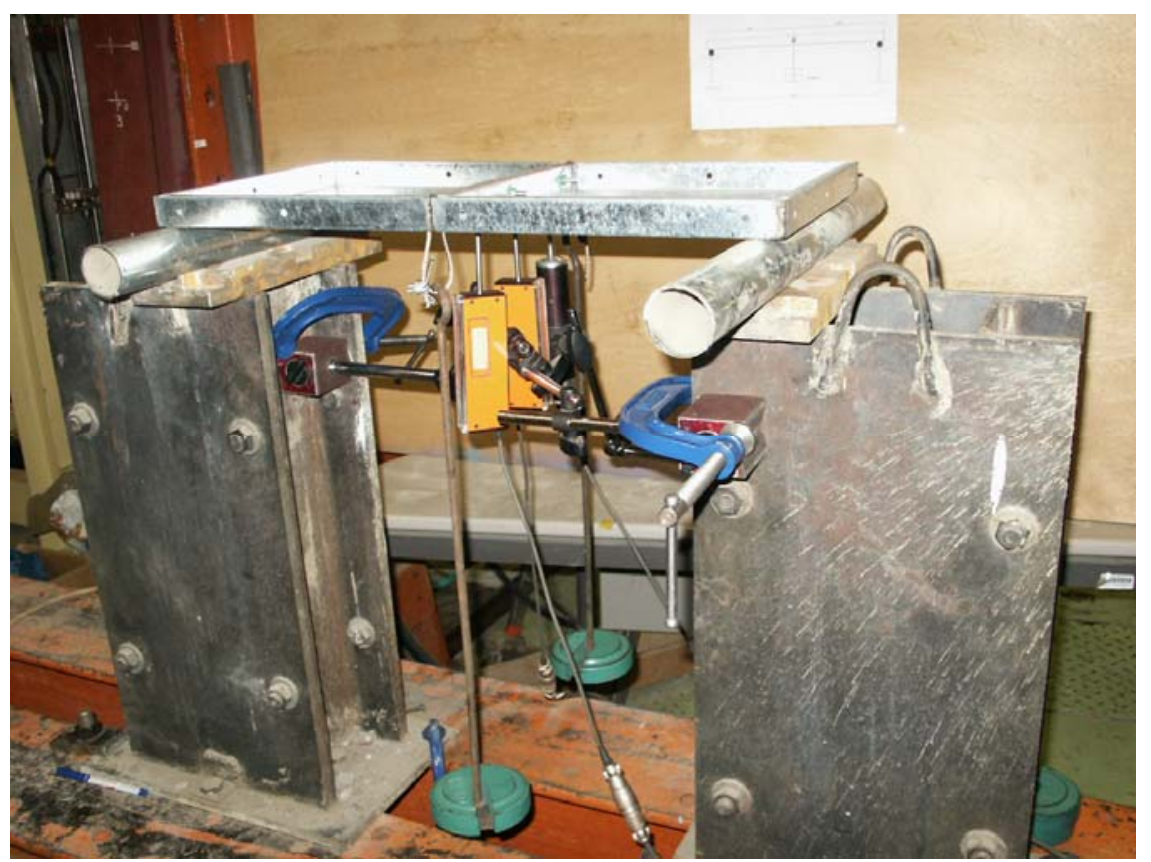

Figure 5. Experimental set-up for specimen BP1 
The experimental set-up for test BP2 is shown in Figure 6, where three components can be identified: the loading boxes, the supporting system and the bolted steel panel specimen. The square panel specimen rested on roller supports on all four sides. It is well-known that square plates so supported will experience uplifting movements in the corner regions (Timoshenko and Woinowsky-Kreieger [6]), so the edges were not strictly simply-supported. These supports were used as they could be easily achieved and could also be dealt with in the numerical modelling work.

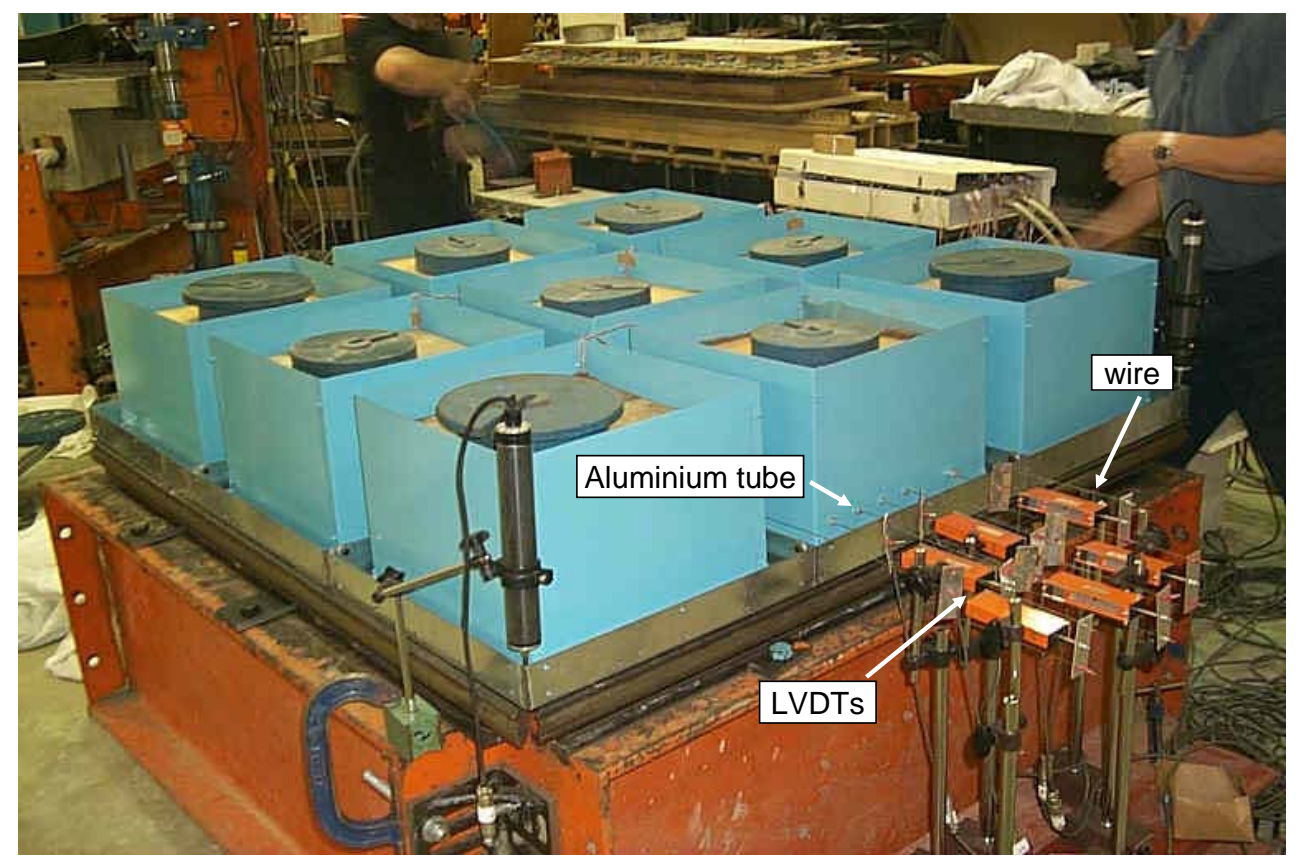

Figure 6. Experimental set up for BP2

The loading boxes were filled with sand, on the top of which dead weights were added, to simulate a uniformly distributed load corresponding to wet concrete loading during construction. In test BP2, a loading box with a plan size of $400 \mathrm{~mm} \times 400 \mathrm{~mm}$ and a height of $300 \mathrm{~mm}$ was placed in each modular unit (Figure 6), so the loading box was a little smaller than the base plate to avoid possible contact between the edge plates and the loading box. The smaller boxes also allowed the deformations of the stiffeners to be observed and measured during the test.

Two tests were conducted on specimen BP3: test BP3-1 and test BP3-2. An overall view of the set-up for test BP3-1 is shown in Figure 7. In this test, loading was applied to the central unit only through a single loading box with a plan size of $500 \mathrm{~mm} \times 500 \mathrm{~mm}$ and a height of $400 \mathrm{~mm}$, and vertical supports were provided at the four corners of the central unit (Figure 8). This test was to approximately simulate the unfavourable condition of a single modular unit being loaded while all adjacent units are still empty. In a curved shell, the edges of the loaded unit are unlikely to experience significant translational displacements due to the presence of curvature, which explains the provision of vertical supports to the central unit in test BP3-1. This test also provided a relatively simple check of the numerical model. 


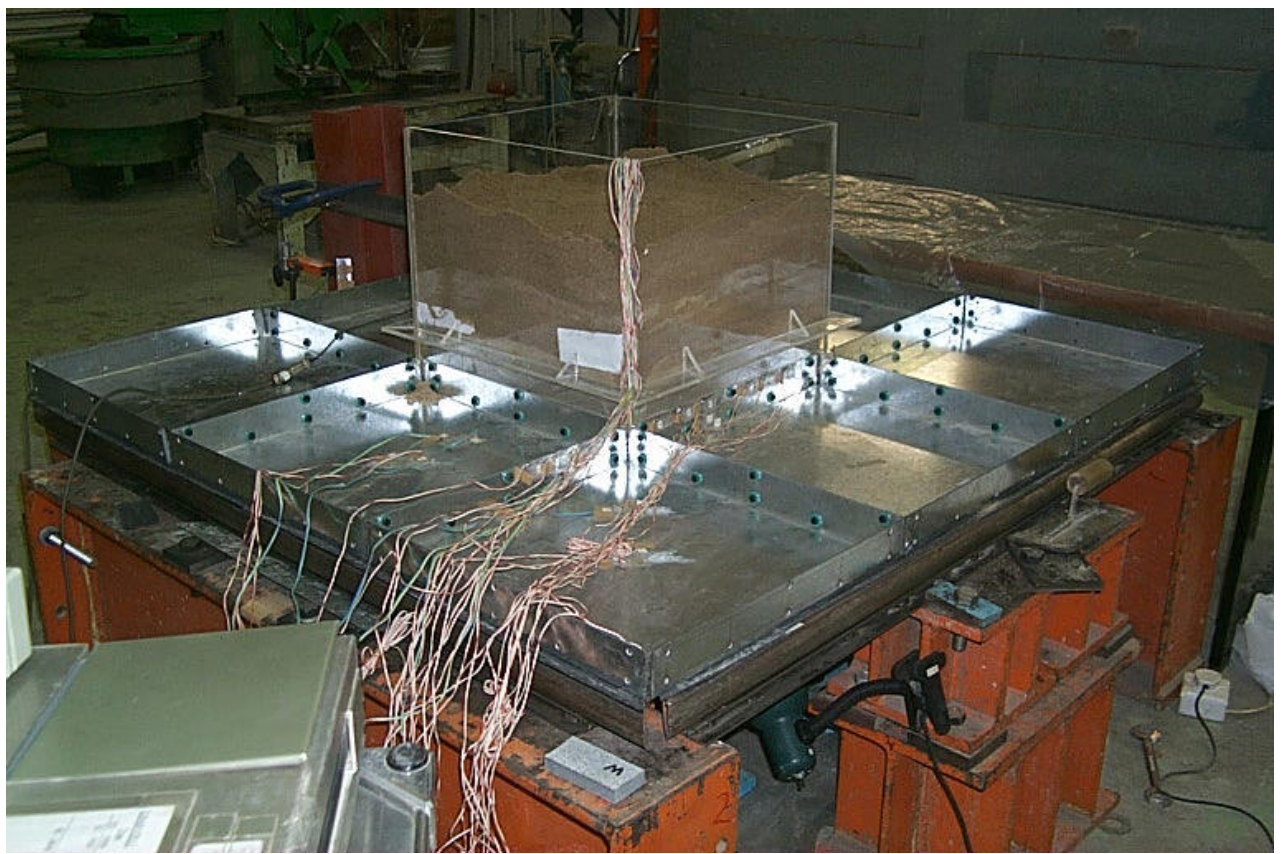

Figure 7. Experimental set-up for test BP3-1

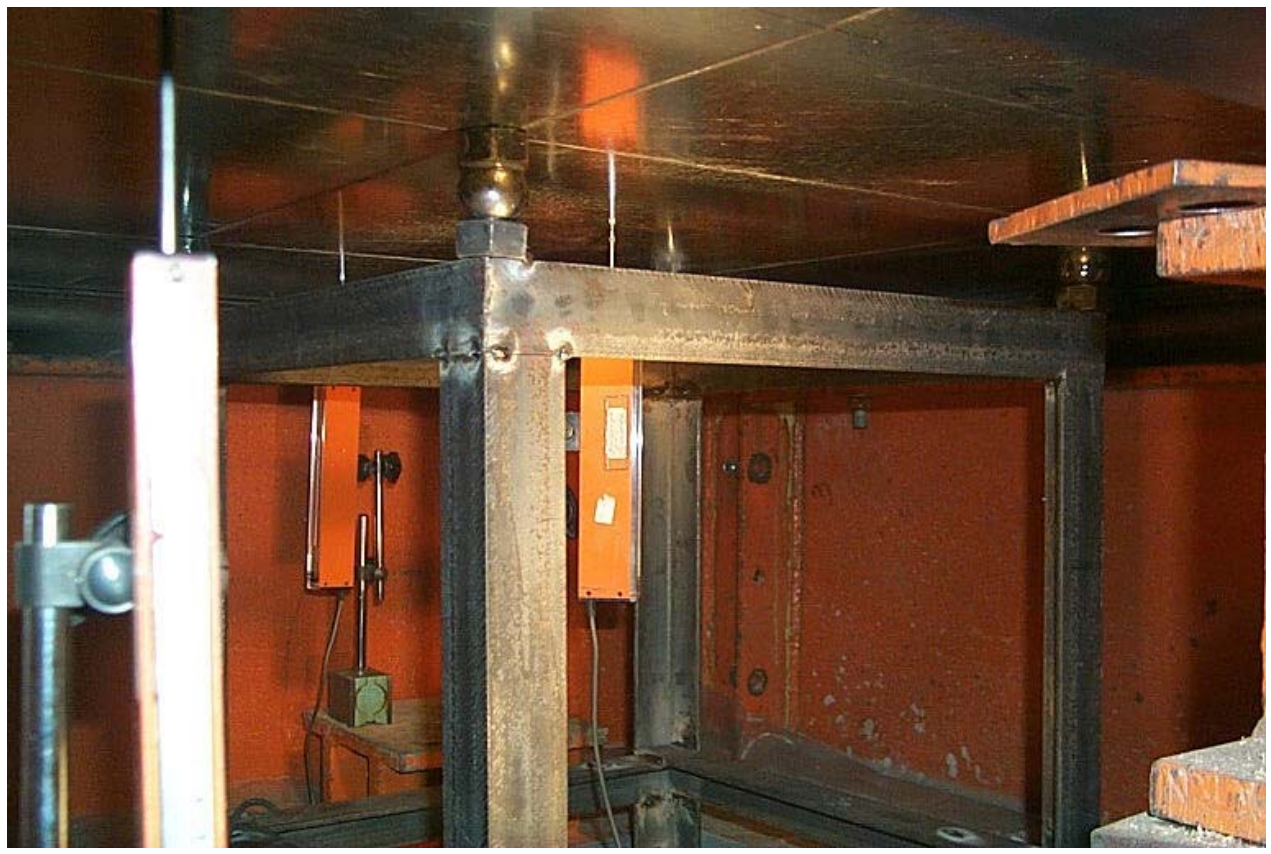

Figure 8. Support frame for the central unit in test BP3-1

The set-up for test BP3-2 is similar to that for test BP2 shown in Figure 6. The only difference is that a uniform layer of sand was applied to the entire specimen. The sand was contained by a single loading box with a plan size of $1500 \mathrm{~mm} \times 1500 \mathrm{~mm}$ and a height of $300 \mathrm{~mm}$. If the loading on specimen BP2 can be approximated as being uniformly distributed over the entire panel and that the sand did not provide a significant restraint to the deformation of the bolted stiffeners, the difference between tests BP2 and BP3-2 is expected to be small. As tests BP3-1 and BP3-2 were conducted on the same panel, in test BP3-1, yielding of steel and excessive deformations were avoided. 
The supporting frame was fabricated mainly using $533 \mathrm{~mm} \times 210 \mathrm{~mm}$ x $20 \mathrm{~mm}$ universal I-section beams (Figure 9). Along each of the four edges, the test panel rested on a bearing plate welded to a steel tube ( $\mathrm{D}=60 \mathrm{~mm}$ ) directly. This support arrangement allowed the up-lifting of the panel at the corners. Lubricating oil was applied to both surfaces of the steel angle and the bearing tube to minimize any friction to allow the steel tube to rotate freely. As some slight unevenness between the modular units existed in the panel, the specimen and the support bearing plate were not in complete contact over some small parts of the edges. These small gaps tended to close up as the applied loading increased.

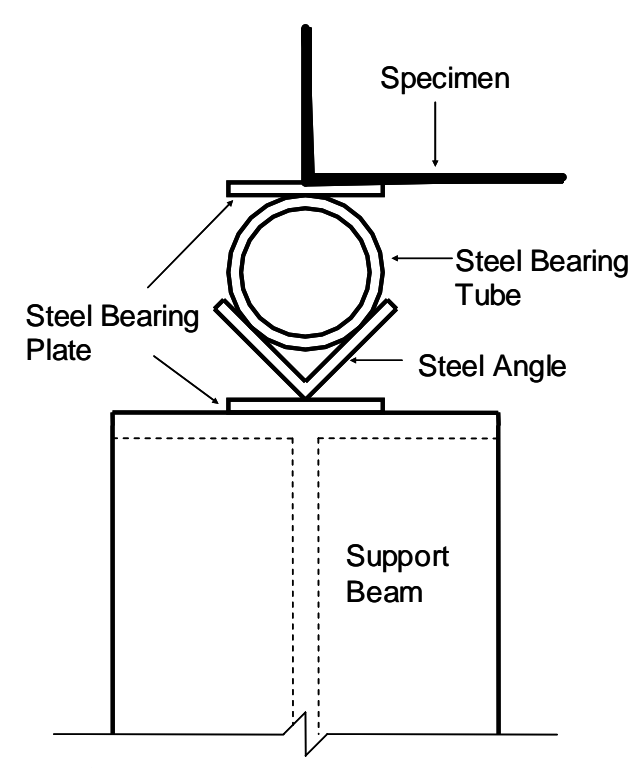

Figure 9. Cross-section of the support

A number of LVDTs were used to measure the vertical displacements in all three tests, with most of them being placed under the base plates. Although it was desirable to measure the deformed shapes of the stiffeners of specimen BP2, which were available for observations, there was not enough space to install LVDTs or dial gauges. As a result, an indirect method was adopted for the measurement of stiffener deformations in the present study. In this method, a set of wires with aluminium tube covers were led through one of the loading boxes located near the edge (Figure 6). Each wire was connected to the top edge of the selected stiffener (stiffener II in Figure 10b) at one end and to an LVDT at the other end, and the LVDTs were placed on the ground nearby the panel (Figure 6). The aluminium tubes, which kept the sand sway from the wires, were fixed onto the loading box and the wire and the tube did not come into contact during the loading process. With this method, the six LVDTs placed nearby the specimen provided measurements of the out-of-plane deformations of stiffener II. The positions measured by these six LVDTs are shown in Figure 10. No stiffener deformations were measured in test BP3-1 as local buckling was unlikely to occur and in test BP3-2, the stiffeners were buried under the sand.

Strain gauges were installed on each panel specimen to measure strain distributions on both the stiffeners and the base plates. Figures 10 and 11 show the layouts of the main strain gauges on specimens BP2 and BP3 respectively; readings from strain gauges of lesser are not discussed here. The strain gauges are simply numbered but indicated with a starting letter " $\mathrm{S}$ " when referred to in the text. Most of the strain gauges installed on the base plates were two-element and three-element rosettes, with some of them being placed at the same locations on both sides of the steel sheet. As shown in Figures 10 and 11, the main strain gauges were placed on a one-eighth portion of the specimen. The arrangements of strain gauges on the two specimens were slightly different. In specimen BP2, most of the strain gauges were placed on the soffit of the panel and those on the upper surfaces of the base plates are represented by the '*' symbol (Figure 10). In specimen BP3, all strain gauges were placed on the upper surfaces of the base plates. 


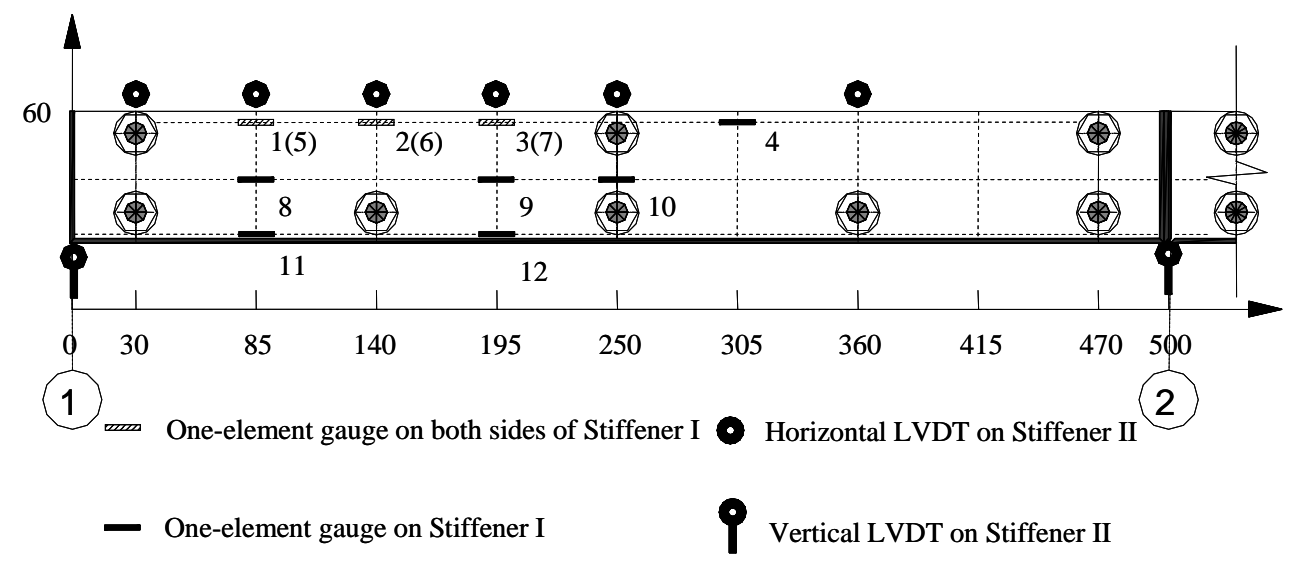

(a) Strain gauges and LVDTs on Stiffeners I and II (Section A-A)

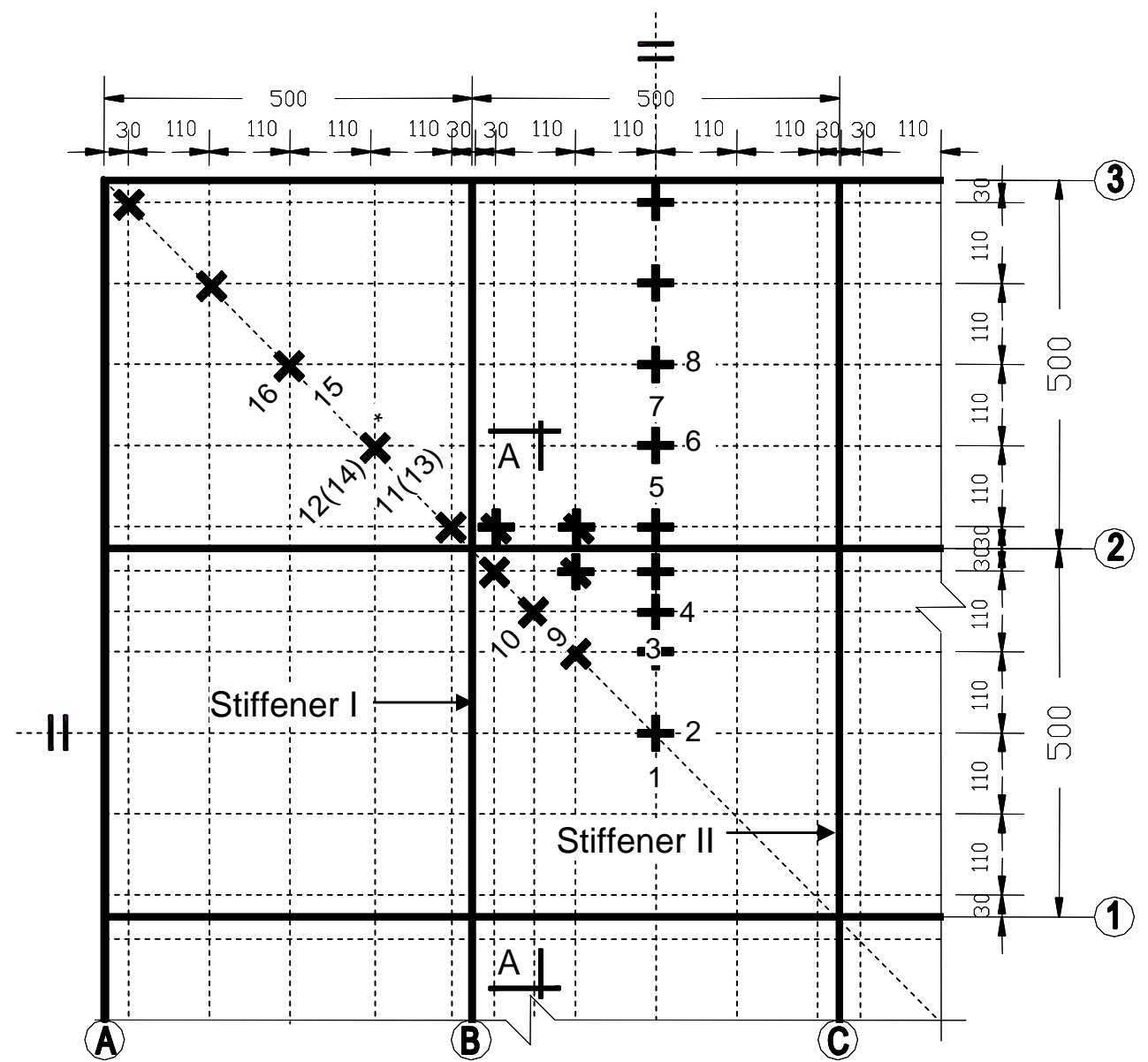

(b) Strain gauges on the base plates

Figure 10. Layouts of strain gauges and LVDTs on specimen BP2 


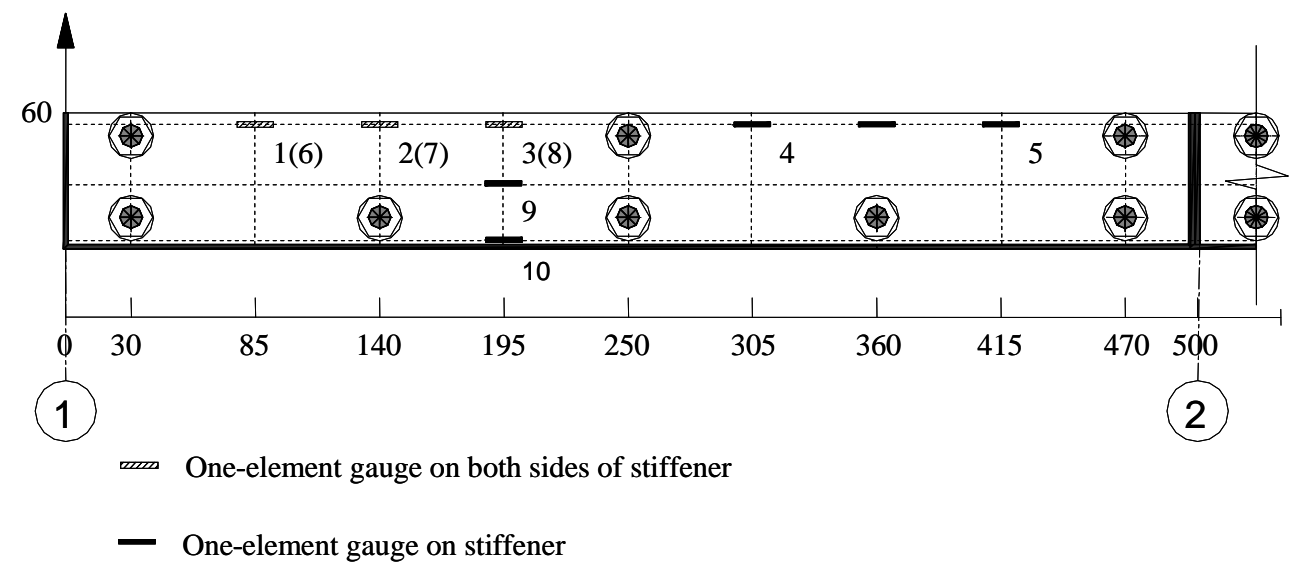

(a) Strain gauges on the selected stiffener (Section B-B)

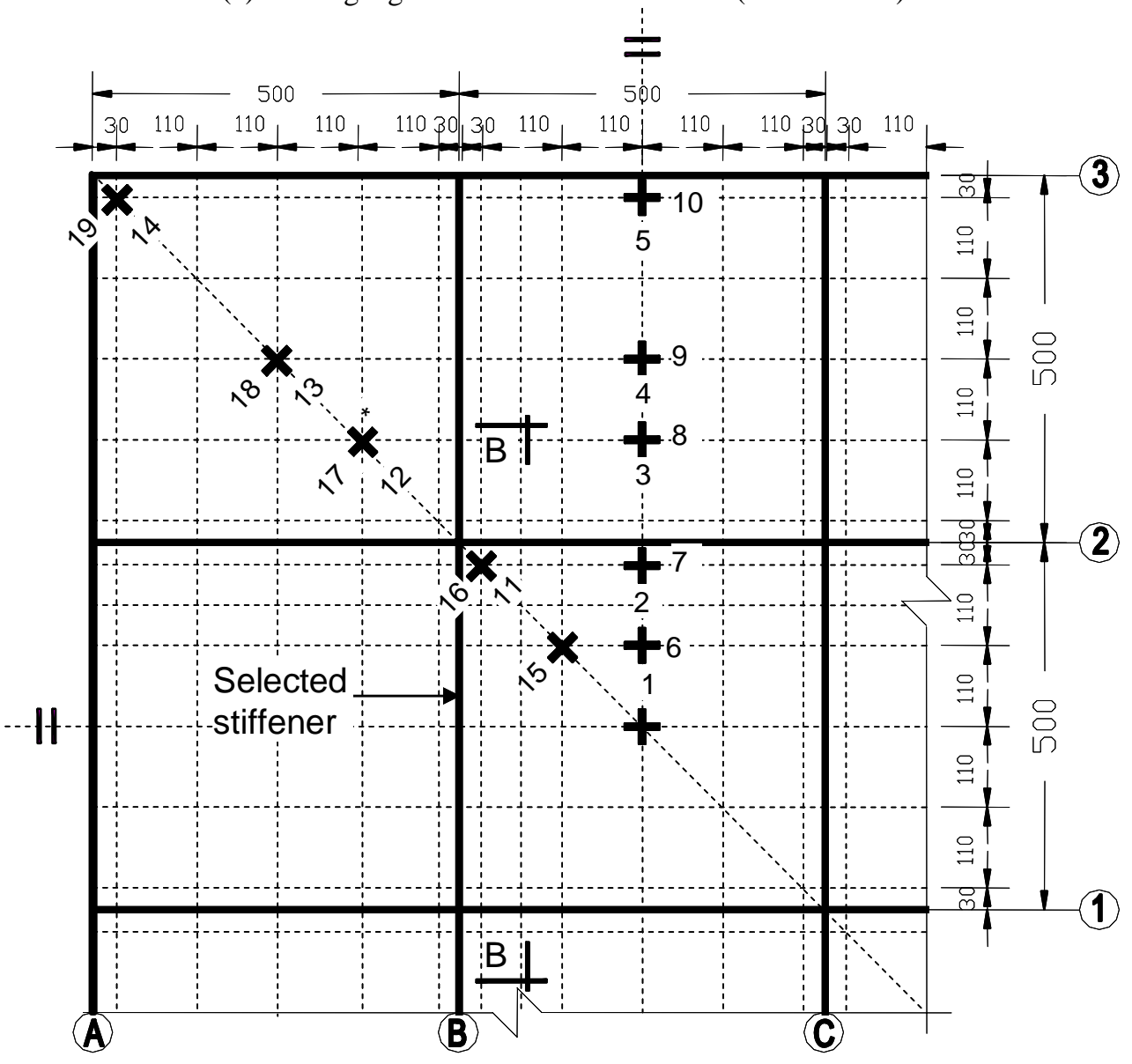

(b) Strain gauges on the base plates

Figure 11. Layouts of strain gauges on specimen BP3 


\section{EXPERIMENTAL RESULTS}

\subsection{Specimen BP1}

This was a simple experiment. The specimen was loaded until its sudden collapse. Almost throughout the entire loading process of this test, lateral deformations could not be observed on the edge plates by naked eyes. These edge plates were each stiffened with a lip, while those in specimens BP2 and BP3 were not. As a result of the stiffening lips, the edge plates in specimen BP1 had a relatively high local buckling resistance. When the applied load reached about $250 \mathrm{~N}$ per loading point, short-wave buckles were noticeable on the edge plates by naked eyes at the mid-span, where the lip stiffeners did not exist. Final collapse soon followed at a load of $270 \mathrm{~N}$ per loading point. Specimen BP1 after failure is shown in Figure 12, while the load-displacement curve of the panel centre (i.e. mid-width of the mid-span) is shown in Figure 13. No strain readings were taken during this simple test.

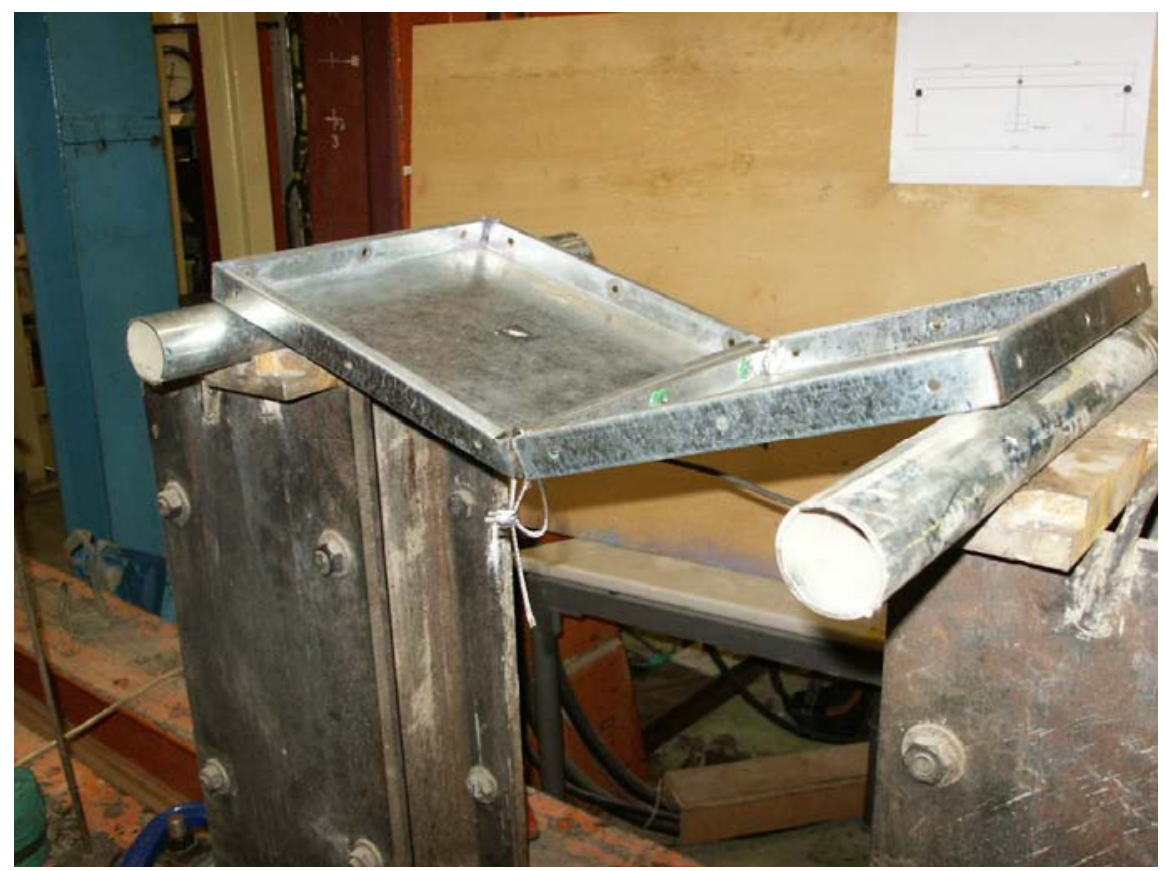

Figure 12. Failure mode of specimen BP1

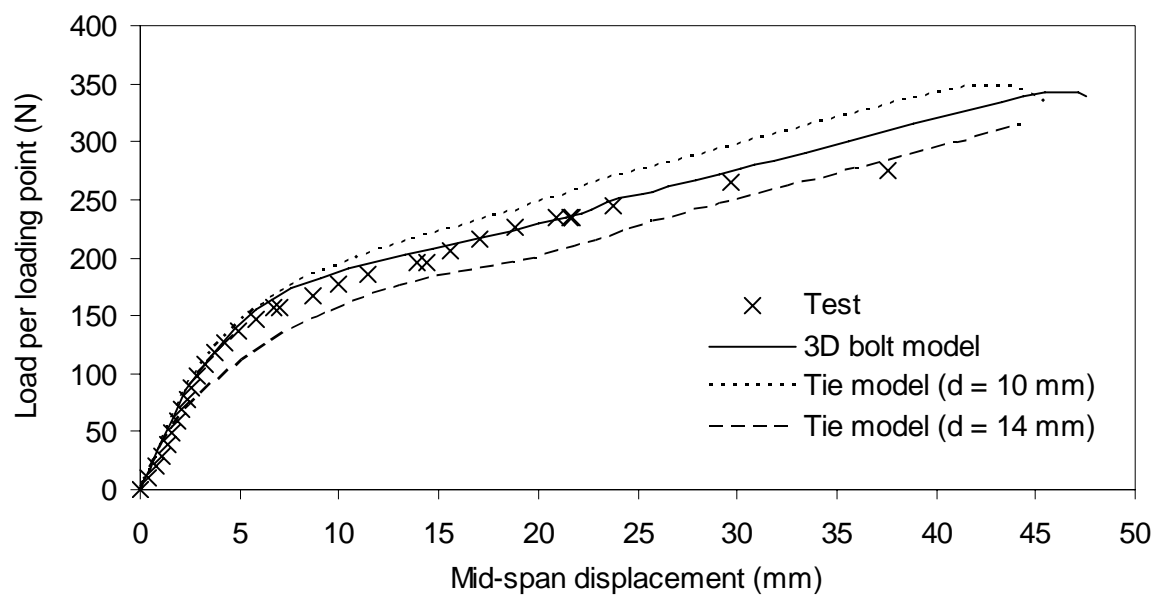

Figure 13. Load-displacement curves of specimen BP1 


\subsection{Specimen BP2}

According to the chosen loading scheme, sand was pre-packed and then filled into the loading boxes. To avoid excessive sand filling and emptying work and to limit the height of the loading boxes, standard steel weights were added to the top of the sand to apply additional loading. It was expected that through the sand layer, the steel weights produced a pressure on the modular unit which was close to being uniform, although this could not be checked. It may be noted that a higher box does not automatically mean a more uniform transfer of the steel weights to the base plate of the modular unit as a distributed pressure, as a higher box is also more like to lead to arching actions in the sand.

At a pressure of about $1.5 \mathrm{kPa}$ on the base areas of the boxes, small lateral deformations could be observed on the stiffeners around the central unit by naked eyes. These deformations continued to grow with further loading and propagated to other stiffeners outside the central unit, leading to obvious short-wave buckles of roughly similar wavelengths. These buckles grew with load increases. Some of the initial load increments proved to be too large as each step caused a large increase in deformation. The load increments were later reduced.

Figure 14 shows the variations of strains measured on stiffener I versus the total applied pressure (including those from the surcharge load and the self-weight of the filled sand). The solid lines represent the readings from those strain gauges installed close to the top edge, while the dashed and the dashed-dotted lines represent the readings from the strain gauges located at the mid-height and near the bottom edge of the stiffener, respectively. The local buckling of stiffener I is reflected by these readings, particularly those from the strain gauges near the top-edge (Figure 14). Most of the strain readings increase almost linearly with the applied load until the load reaches around $2.7 \mathrm{kPa}$. Above this load level, rapid increases are then seen in some of the strain readings, while other readings show a trend reversal. This is the load level corresponding to the local buckling of the stiffeners. Moreover, it is clear that the strains recorded near the top-edge are significantly higher than those at the mid-height and near the bottom edge.

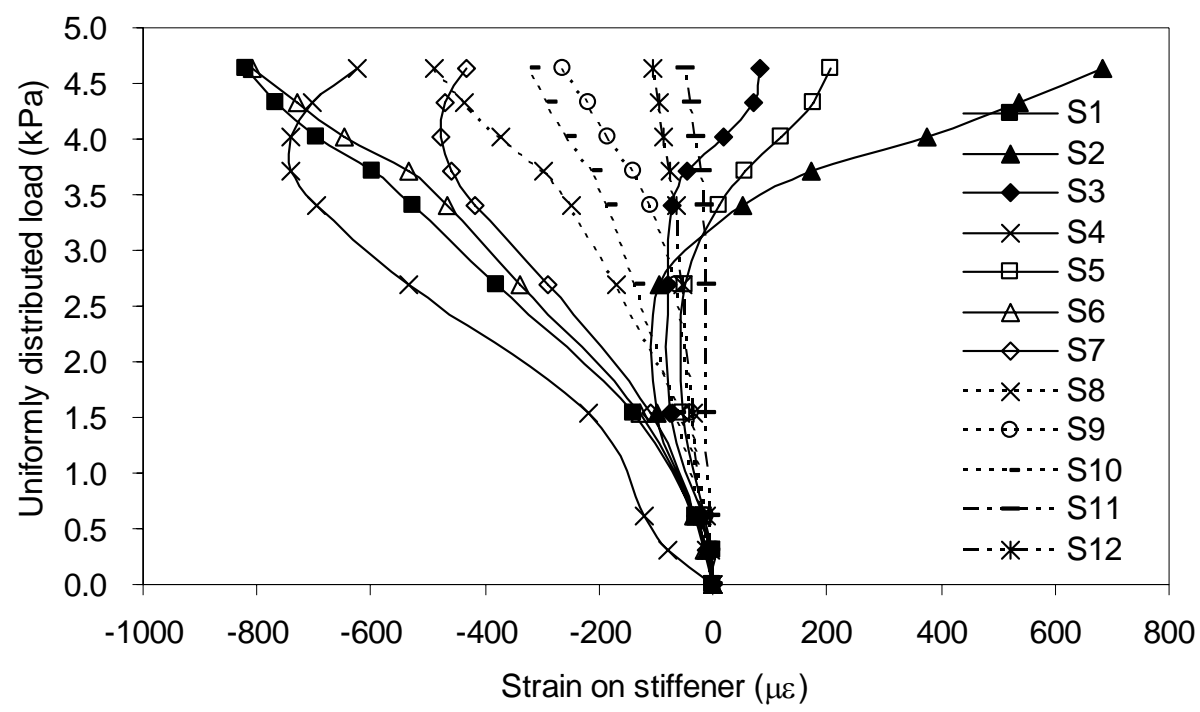

Figure 14. Load-strain curves of stiffener I in specimen BP2 
The strain readings recorded on the base plates are shown in Figures 15a and 15b. Most of these strain gauges were located on the bottom surfaces of the base plates. Figure 15a shows readings from strain gages along the vertical axis of symmetry, while Figure 15b shows those along a diagonal. These strain readings suggest that the bottom surfaces of base plates were generally in tension. This can be easily understood, as the specimen was subject to uniformly distributed loading that led to bending tensile strains (as well as membrane tensile strains at significant deflections) on the bottom surfaces of the base plates. The jumps in the strain values during the initial load steps might have been caused by the imperfect initial shapes of the base plates. Local buckling at a load of around $2.7 \mathrm{kPa}$ is reflected in these readings as at this load level, some of the strain readings show a change in the trend of variation.

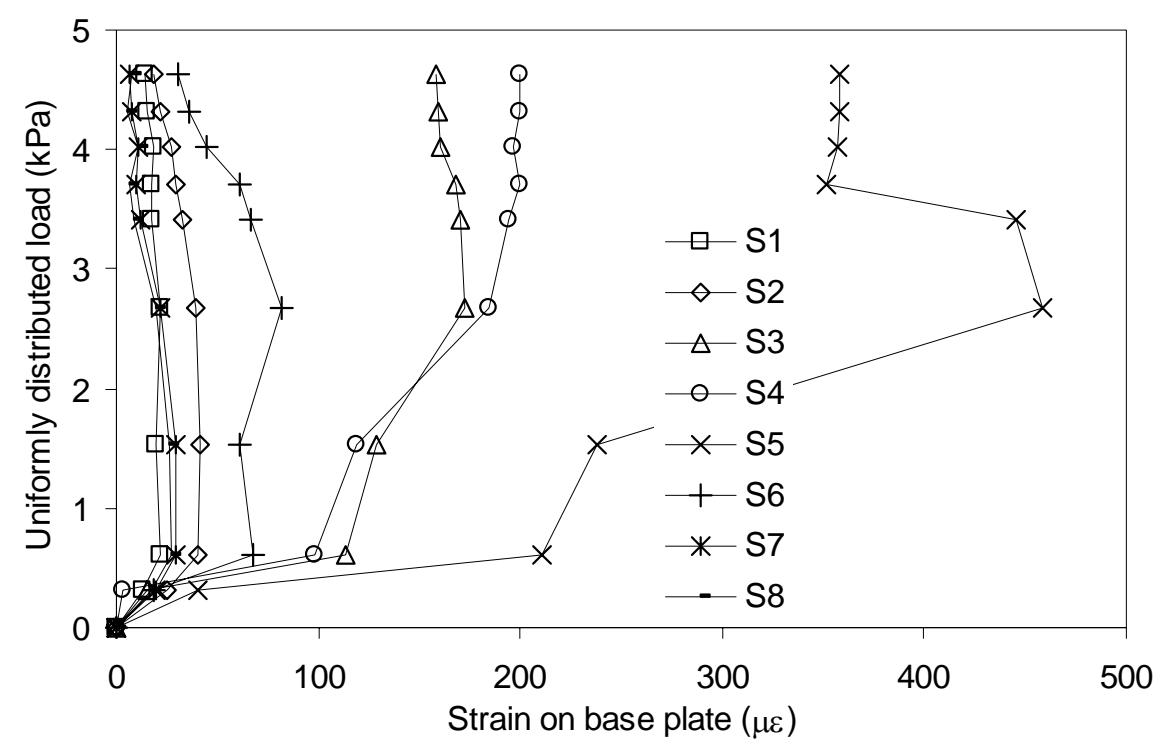

(a) Strain gauges S1-S8

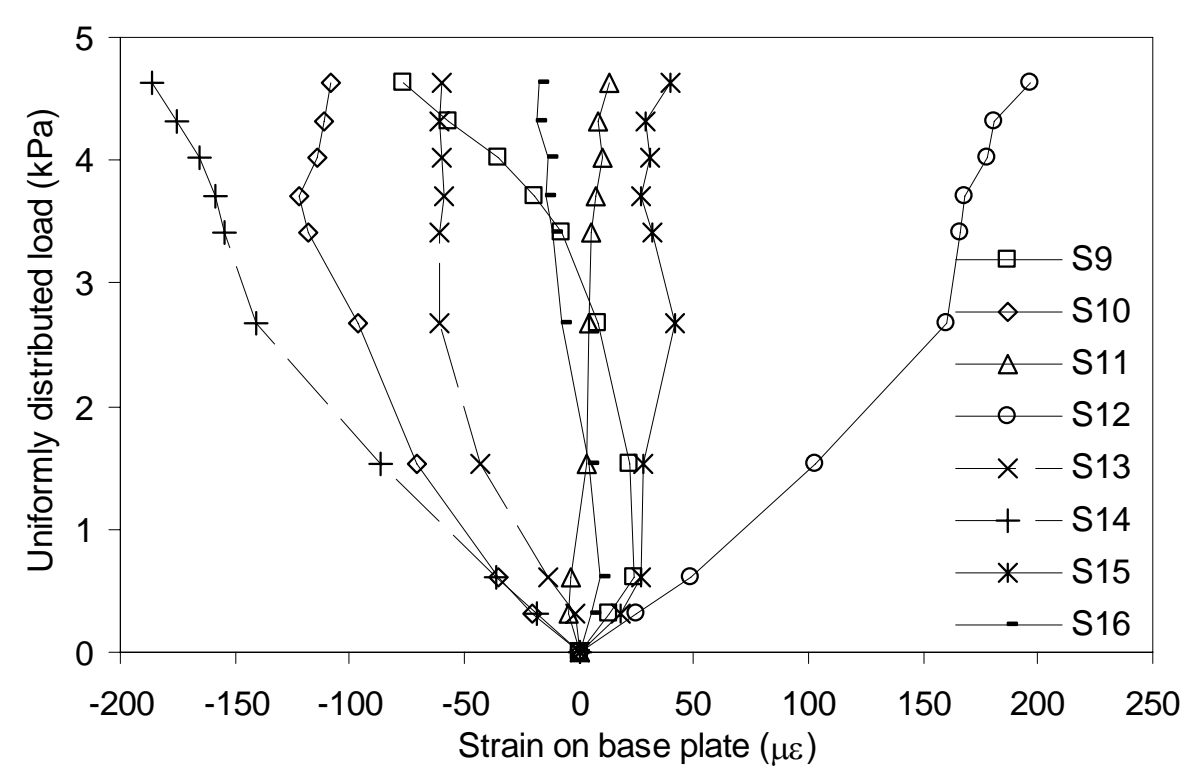

(b) Strain gauges S9-S16

Figure 15. Load-strain curves of base plates in specimen BSP2 
Figure 16 shows the horizontal deformation profile at selected load steps along stiffener II which was selected for displacement monitoring (Figure 10). These readings indicate that before local buckling, the stiffener had almost uniform horizontal displacements along its top edge. Local buckling deformations can be seen at a load of $2.68 \mathrm{kPa}$, which was followed by a stable post-buckling deformation process, during which short-wave buckles continued to grow. These observations are consistent with the strain readings shown in Figure 15.

At the load level of $4.6 \mathrm{kPa}$, plastic deformations in the stiffeners ended the stable post-buckling deformation process, which triggered a large reduction in the overall stiffness of the panel. Final collapse soon followed during the process of adding weights to achieve a load of $4.9 \mathrm{kPa}$. Due to an unexpected problem with the LVDT, the central displacement of panel BP2 was not recorded. As an alternative, the vertical displacement at the intersection of axes B and 2 (Figure 10) is shown against the applied load in Figure 17. An overall view of specimen BP2 after failure is shown in Figure 18a. Figure 18b shows two close-up views of the failure mode, where torsional deformations are seen at the corner joints of modular units.

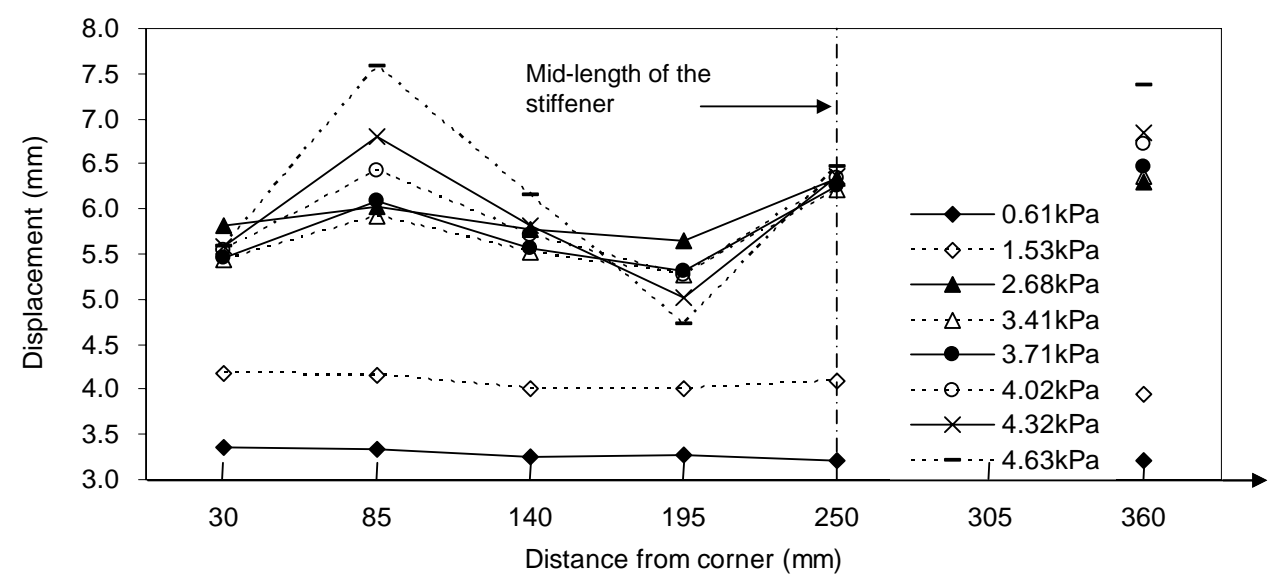

Figure 16. Displacement profiles along stiffener II of specimen BP2

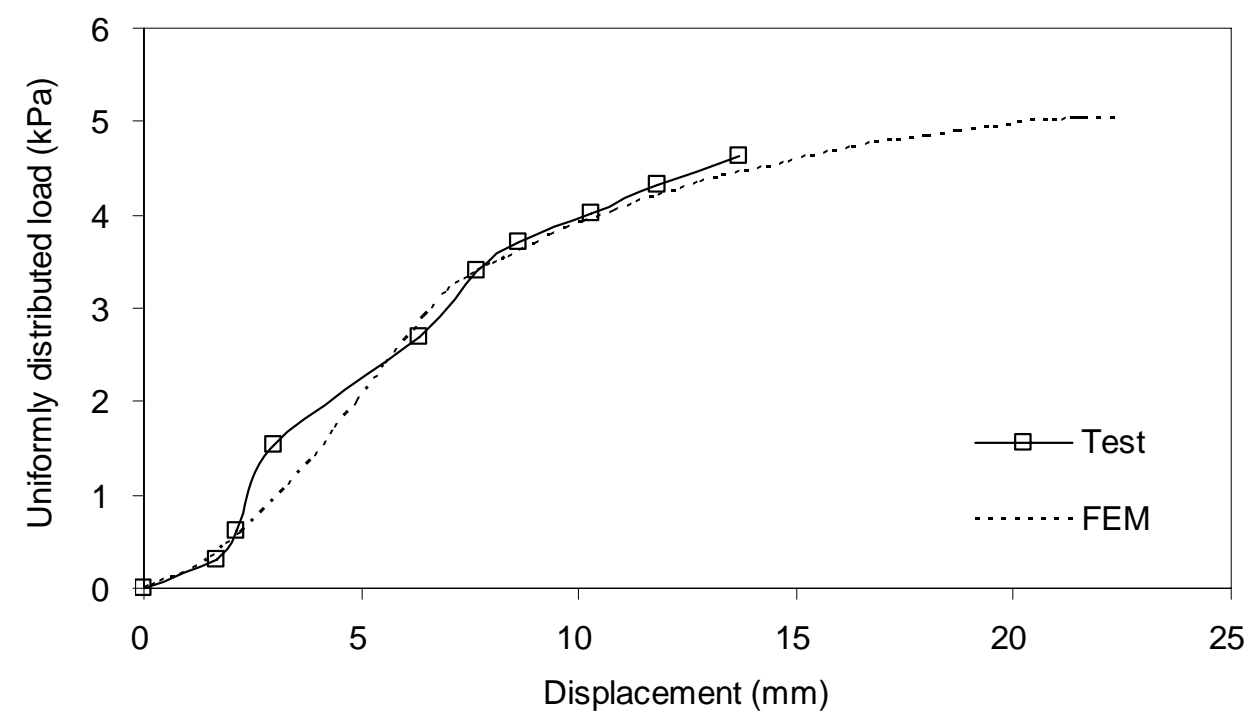

Figure 17. Load-displacement curves of specimen BP2 


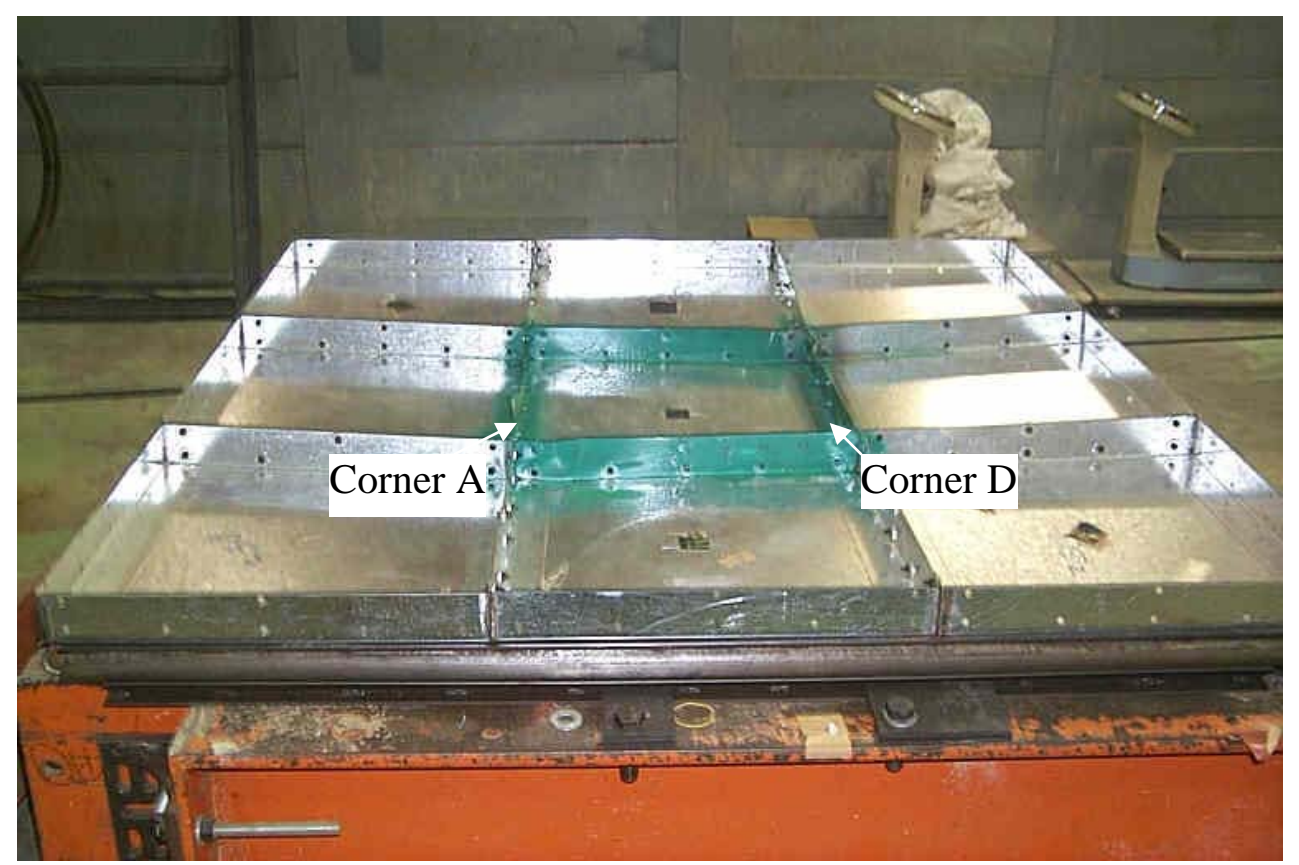

(a) Overall view

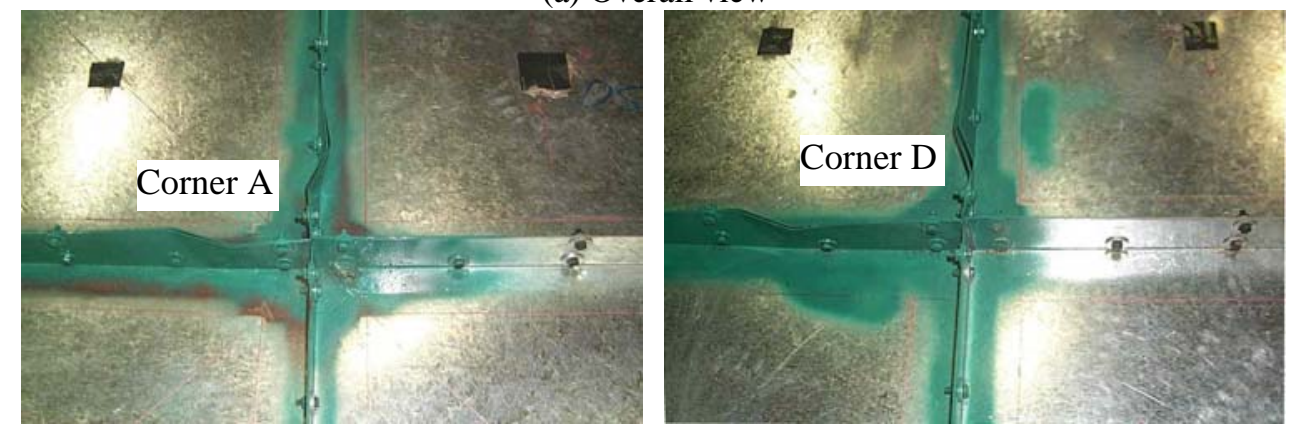

(b) Close-up view

Figure 18. Failure mode of specimen BP2

\subsection{Specimen BP3}

Two tests were conducted on specimen BP3. Strain gauge readings from test BP3-1 are not reported herein, as their readings remained very small during the entire loading process. These readings, however, provided a means for monitoring the structural behaviour and controlling the loading process. Test BP3-1 was stopped at a load of $10.5 \mathrm{kPa}$. The maximum strain recorded in the specimen reached 490, which is well below the yield strain of the steel. The load-deflection curve of the centre of the specimen is shown in Figure 19, which is typical of a plate which stiffens with lateral deflections.

Deformations of the stiffeners were not measured during the BP3-2 test, as the stiffeners were buried in the sand. Figure 20 shows the variations of strains measured on the selected stiffener (Figure 11b). It is clear that these load-strain curves are significantly different from those shown in Figure 14, despite that they were recorded at similar locations. The former are almost linear up to the buckling load, while the latter are more nonlinear and diverge from each other much earlier in the loading process. In test BP3-2, the strains experienced a sudden jump at a load of around $3 \mathrm{kPa}$. 
In particular, several strain gauges recorded abrupt changes from compressive to tensile values (S4, S7, S8 and S10). These changes in strain readings clearly indicate the occurrence of buckling. Moreover, a loud noise was heard at this load level, which was further evidence that buckling had occurred. Subsequently, the specimen entered its post-buckling stage and continued to carry additional loading at the expense of additional deformations. Final collapse happened during the process of adding weights to achieve a load of $4.75 \mathrm{kPa}$.

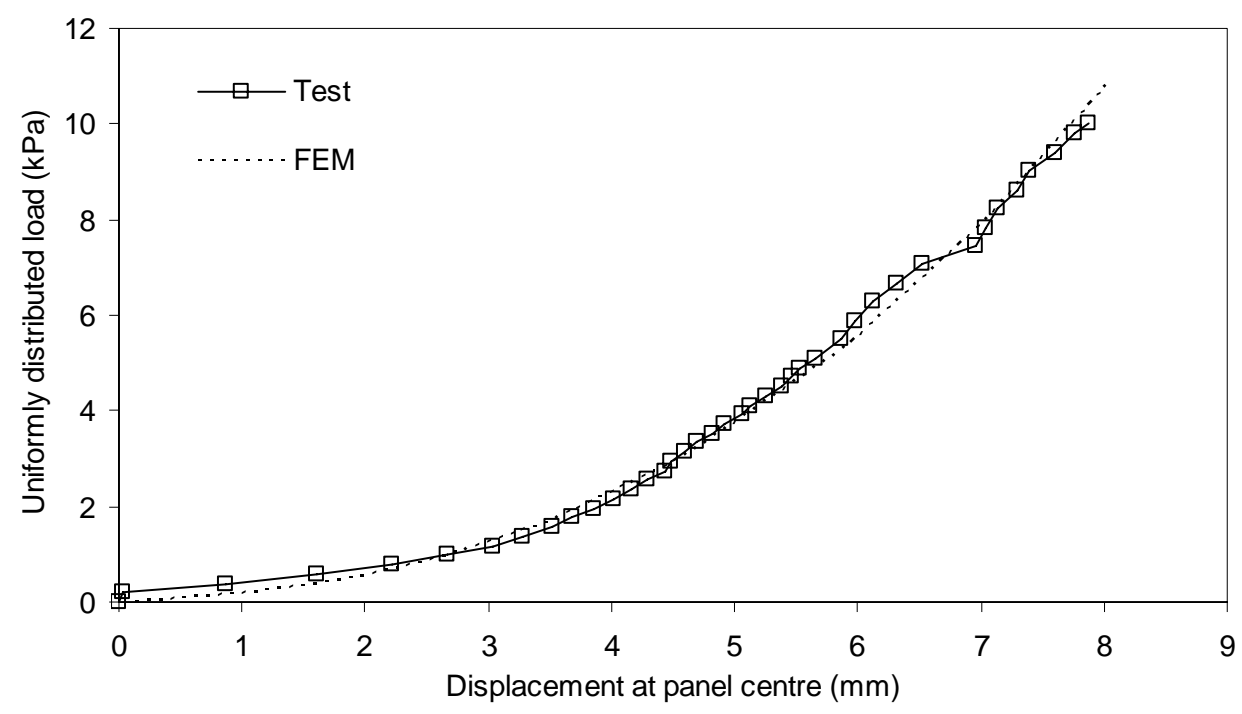

Figure 19. Load-displacement curves of specimen BP3 in test BP3-1

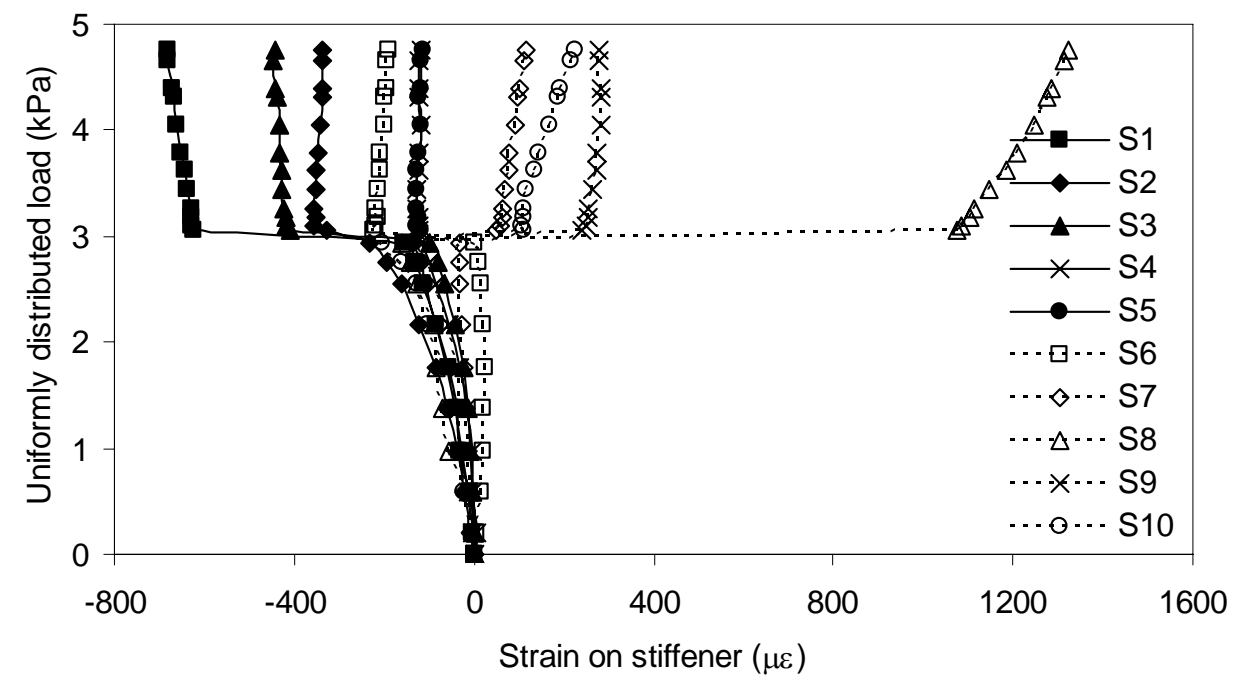

Figure 20. Load-strain curves of selected stiffener in test BP3-2

Figure 21a shows the load-strain responses from strain gauges installed on the base plates (S1-S10). Different from those shown in Figure 15, negative readings were recorded by almost all these strain gauges, as they were attached at the upper surfaces of the base plates. Local buckling of the stiffeners is reflected in these curves by a jump in the strain values at a load level of about $3 \mathrm{kPa}$. The strains on one half of a diagonal of the specimen are shown in Figure 21b (strain gauges S11-S19). It can be seen that except for S16 near a corner, compressive strains developed in the diagonal direction, while tensile strains occurred perpendicular to the diagonal direction. The 
buckling phenomenon of the specimen is also reflected by a sudden jump in these load-strain curves.

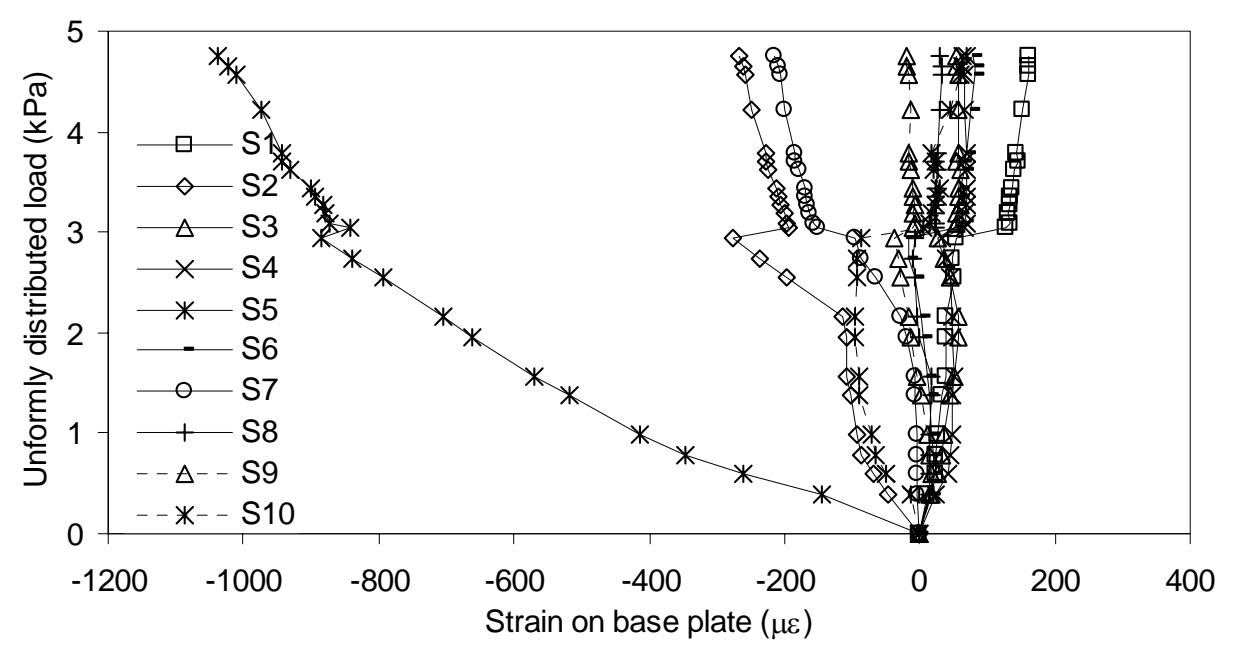

(a) strain gauges S1-S10

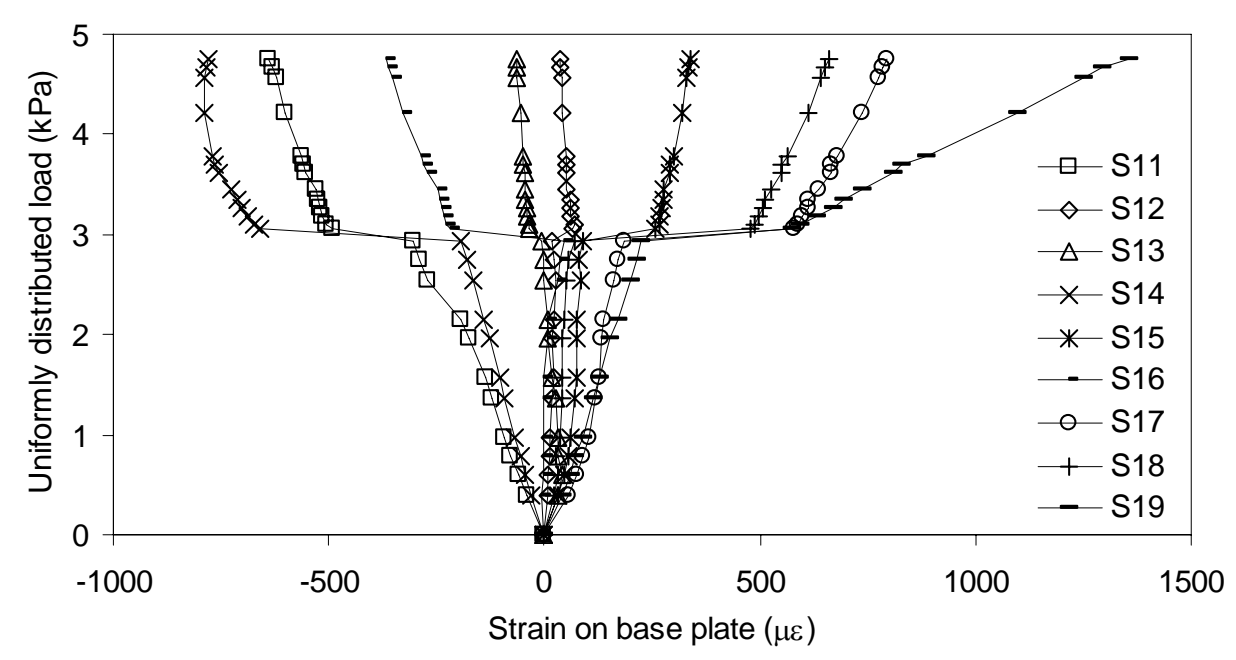

(b) Strain gauges S11-S19

Figure 21. Load-strain curves of base plates in test BP3-2

Figure 22 shows the load-displacement curve of the centre of the specimen, where a sudden increase in the displacement is seen at a load of about $3 \mathrm{kPa}$. This sudden increase in deformation is the result of a snap-though buckling process in a load-controlled test. An overall view of specimen BS3 after the test is shown in Figure 23a. Close-up views of two corner joints are given in Figure 23b, where local buckling of the stiffeners is clearly seen.

The difference in behaviour between test BP2 and test BP3-2 can be attributed to the restraining effect of the sand in test BP3-2. The elastic support of sand reduced the lateral deformations and enhanced the buckling resistance of stiffeners. The stiffeners can be idealized as beams on elastic foundations, which have buckling characteristics similar to those of axially compressed cylindrical shells. This means that when buckling of these elastically restrained stiffeners occurs, the stress level the stiffener can carry has to reduce, leading to the snap-through buckling process. During the 
removal of sand from the panel following the test, it was found that the sand, particularly the bottom layer of the sand, was highly compacted and was difficult to remove.

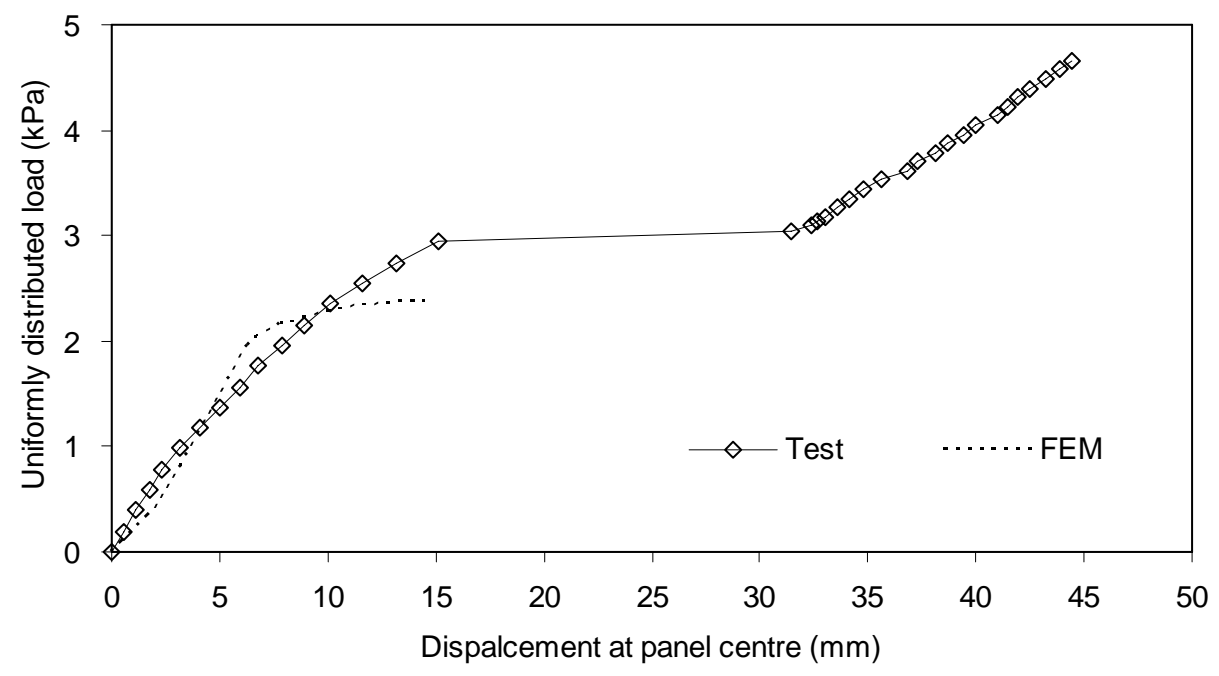

Figure 22. Load-displacement curves at panel centre in test BP3-2

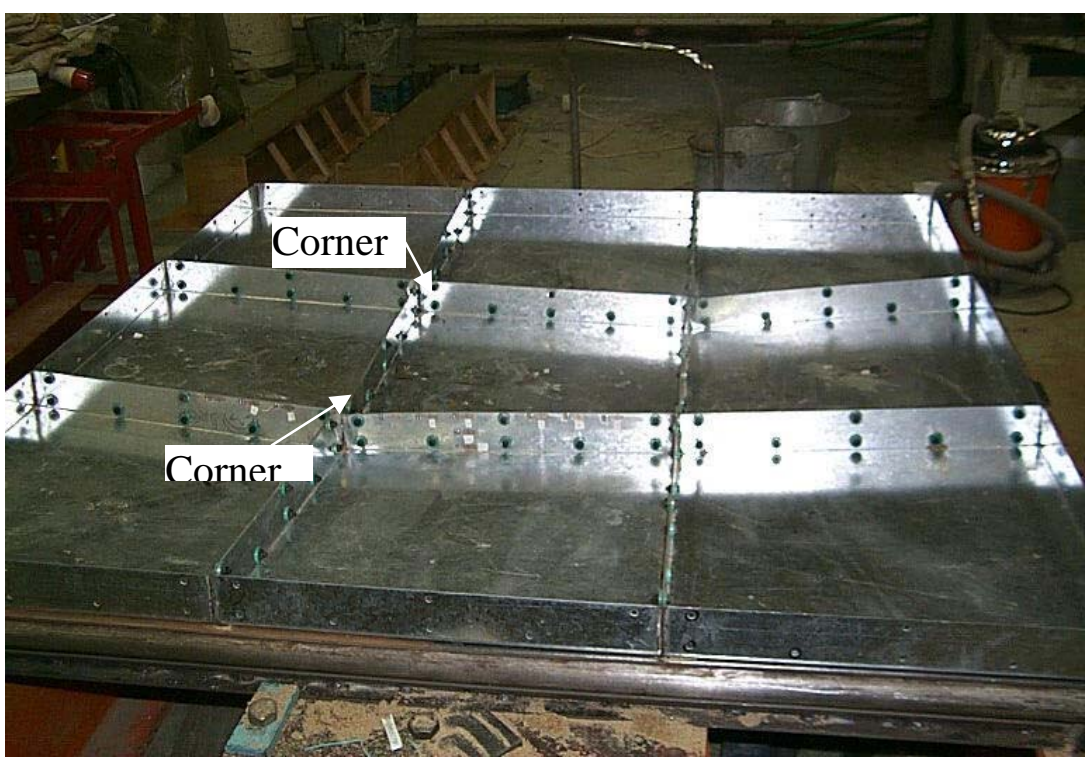

(a) Overall view
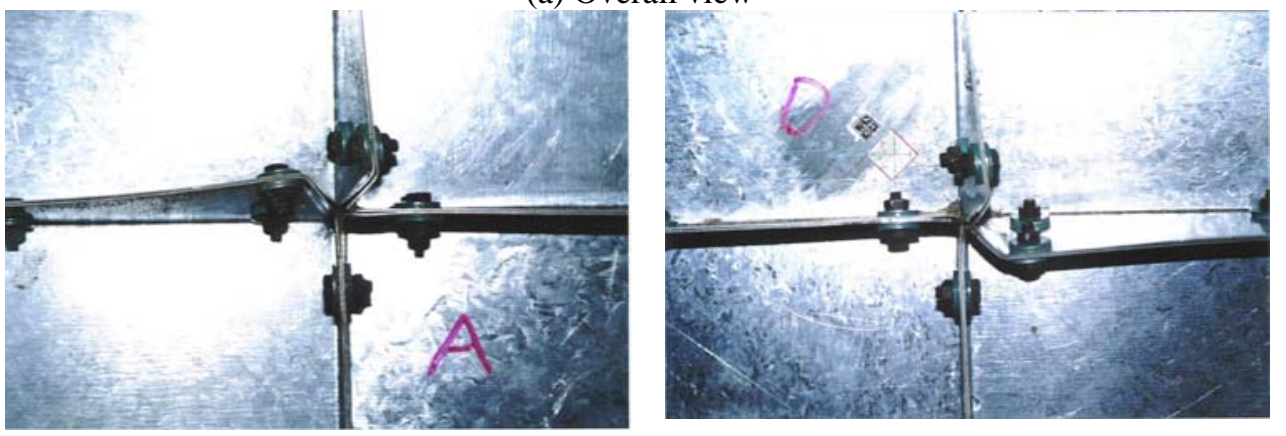

(b) Close-up view

Figure 23. Failure mode of specimen BP3-2 


\section{FINITE ELEMENT MODELLING}

\subsection{General}

The general-purpose finite element package ABAQUS [7] was employed to model the panel tests described above. The boundary condition and method of loading adopted in the finite element analysis followed closely those used in the tests.

Material nonlinearity was included in the finite element model by specifying a stress-strain curve in terms of the true values of stress and strain. The engineering stresses and strains obtained from the tensile tests were converted to true stresses and strains for this purpose. The idealized stress-strain curves adopted in the finite element analysis are multi-linear and were averaged from the tensile tests; they are indicated in Figure 4 using circles and crosses respectively. The primary objective of the finite element study was to arrive at a simple yet accurate connection model which can be used in modelling the buckling behaviour of bolted steel base shells of Comshell roofs. For comparison, a refined finite element model of specimen BP1 with explicitly defined bolts and washers was first investigated and then a simplified approach was explored. Numerical simulations of tests BP2, BP3-1 and BP3-2 were then carried out using the simplified model only. The load-displacement response was traced using the arc-length method (i.e. 'Riks' method). It should be noted that the radius of the round corner between the edge plate and the base plate was not taken into account in the finite element model, as this is believed to have a small effect. Mesh convergence studies were carried out to arrive at accurate meshes (Wong [8]).

\subsection{Refined Bolted Connection Model}

The refined finite element model for specimen BP1 is shown in Figure 24. In this model, the modular unit, bolts and washers were all modelled with deformable elements. These bearing tubes with a diameter of $50 \mathrm{~mm}$ were taken as rigid bodies and prevented from any movements. The panel and the tubes were defined to interact following the hard contact condition with no friction, but rigid body motions of the panel were prevented by appropriate restraints. The hexagon bolt head was modelled as a circular bolt head that circumscribes the original hexagon and this circular bolt head had a diameter of $10 \mathrm{~mm}$. The bolt shank had a nominal diameter of $6 \mathrm{~mm}$ including the threads. In the finite element model, the details of the threads on the shank were neglected but an effective diameter of $5 \mathrm{~mm}$ was used. As the washer generally remained in close contact with the bolt head during the entire loading process, the washer with a diameter of $18 \mathrm{~mm}$ and the bolt head together was treated as an integral component, which simplified the model. The bolt head, washer and shank were all modelled using eight-node hybrid linear solid elements (C3D8H). The performance of this element in modelling bolted connections has been validated by other researchers (Bursi et al. [9]; Wheeler et al. [10]). In particular, this element does not suffer from possible problems of volume strain locking, which can occur with the C3D8 linear element (Bursi et al. [9]. The modular unit was constructed using linear four-node thin shell elements (S4R), with a thickness of $1.03 \mathrm{~mm}$ determined by laboratory measurements made on the steel sheets used in the tests. 


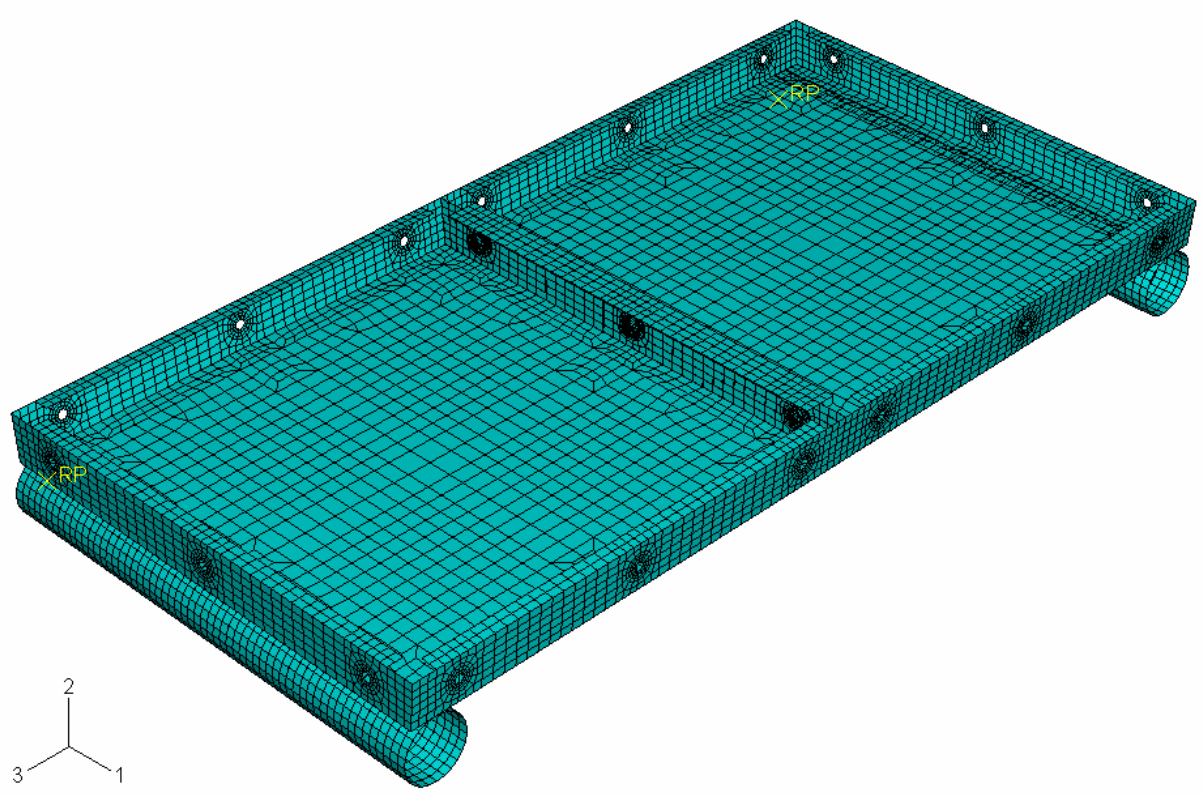

Figure 24. Finite element model for specimen BP1

Contact between adjacent parts was explicitly modelled, including the contact conditions between the washer and the edge plate and between the edge plate pair respectively. Depending on the type of contact problem, two approaches were available in ABAQUS [7] for modelling contact conditions with finite sliding between adjacent parts: (a) defining the contact condition by identifying and pairing potential contact surfaces, and (b) using contact elements. A careful study of the capability of the ABAQUS [7] program revealed that ABAQUS [7] did not include a contact element appropriate for the present purpose, so the surface-based contact modelling technique was adopted. To activate the defined contact condition, the potential contact surfaces were paired up using the "CONTACT PAIR" option provided by ABAQUS [7]. As the shell elements modelling the modular units were surface elements while the bolts and shanks were modelled using solid elements, the possible contact and bearing interaction between the bolt shank and the bolt hole was ignored, which is believed to be acceptable as the diameter of the bolt hole $(6.5 \mathrm{~mm})$ was slightly larger than the diameter of the shank $(5 \mathrm{~mm})$. Moreover, the small-sliding formulation was employed to reduce the computational cost. In this formulation, the corresponding contact surfaces are assumed to undergo only comparatively small relative sliding but arbitrary rotations. A numerical comparison showed that the difference between the general finite-sliding formulation and the small-sliding formulation is negligible for the present problem, but the former is computationally much more efficient.

A "hard" contact condition was defined to model the interaction normal to the two contact surfaces. With this definition, pressures can be transmitted between the two surfaces when they are in contact but disappear when they separate. Two different approaches were employed when considering the interaction tangential to the surfaces. A classical Coulomb friction model, with an assumed coefficient of 0.3 was used in modelling the bolt-to-edge plate interaction. A value of 0.3 or a similar value for the frictional coefficient is commonly used for modelling contact between normal smooth steel surfaces (e.g. Al-Emrani and Kliger [11]). The tangential contact condition between the edge plates was assumed to be perfectly smooth with no inter-surface friction. 
To circumvent the numerical problem of 'overclosure' of the two edge plates, a small gap of $0.1 \mathrm{~mm}$ was introduced between the contact pair of edge plates, through the "ADJUST" and "CLEARANCE" options in ABAQUS [7]. The selected gap magnitude was the result of a large number of trial-and-error calculations aimed at an optimum balance between accuracy and ease for convergence.

The pretension forces in the bolts and the surface-to-surface friction are important parameters in a bolted connection model. The pretension forces in the bolts lead to normal pressures which determine the magnitude of the surface-to-surface frictional force. In the experiments, the bolts were tightened with a spanner by hand. Each bolt was assumed to be subject to a pretension force of $2 \mathrm{kN}$ (around $100 \mathrm{MPa}$ tensile stress in the bolt shank with an effective diameter of $5 \mathrm{~mm}$ ). A parametric study on the effect of the pretension force on the connection behaviour in a simple cantilever connection test (Wong [7]) showed that within the range of $1 \mathrm{kN}$ to $5 \mathrm{kN}$, the actual value of the assumed pretension force has little effect on the predicted response of the connection. To model the complete behaviour of the connection, the analysis was carried out in two stages. In the first stage, the pretension force in the bolt was applied through the "BOLT LOAD" option in ABAQUS [7]. In the second stage, two concentrated loads were applied to the two mid-span corners of the modular unit as was done in the tests. To avoid the rigid body motions of the bolts, additional vertical restraints were applied at the centres of the bolts during the first stage of analysis. These restraints were removed at the beginning of the second stage as the bolts were adequately constrained after the pretensioning.

\subsection{Simplified Bolted Connection Model}

In the simplified bolted connection model, a node within a specified circular area (i.e. tied area) of one edge plate surrounding the bolt hole is assumed to have the same displacements as those of a corresponding node of the other edge plate of the contact pair. That is, these nodes were paired up and constrained using the "TIE" option provided by ABAQUS [7]. Details of the connection such as the bolts and the washers are therefore ignored in this simplified model. In the finite element implementation, three circular layers of elements around each bolt hole were defined. The outer diameter of these three circular layers coincided with diameter of the washer, while that of the innermost layer coincided with the diameter of the bolt head (Figure 25). Two different tied areas were explored for specimen BP1: a diameter of $14 \mathrm{~mm}$ covering two circular layers of elements and a diameter of $10 \mathrm{~mm}$ cover the innermost layer of elements. For specimens BP2 and BP3, only the latter option was used. With such an arrangement, both the translational and rotational degrees of freedom of the tied nodes have the same displacement values during the deformation process. Over the remaining parts, the pair of edge plates was coupled using the surface-based contact definition (ABAQUS [7]) (Figure 25).

The finite element model for specimens BP2 and BP3 is shown in Figure 26. By eliminating the details of the bolts and the washers from the finite element model, only around 10,600 and 110,000 elements were required to model specimens BP1 and BP2 or BP3 respectively in the simplified approach. As a result, a single numerical simulation of specimen BP1 using the simplified model only took about 50 minutes instead of around 180 minutes required by an analysis using the refined model on the same computer, which represents a dramatic reduction in the computational cost as a result of the simplifications. 


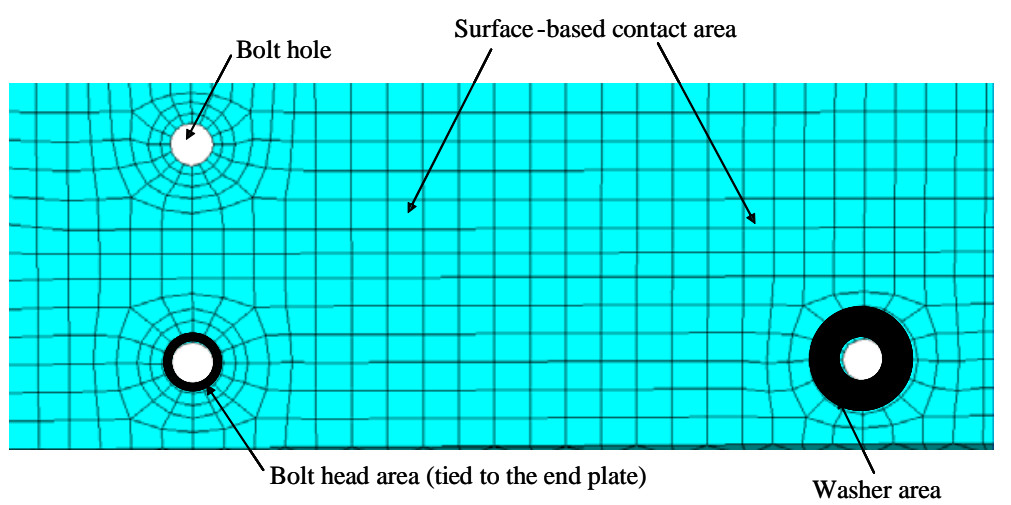

Figure 25. Contact definitions in the simplified model

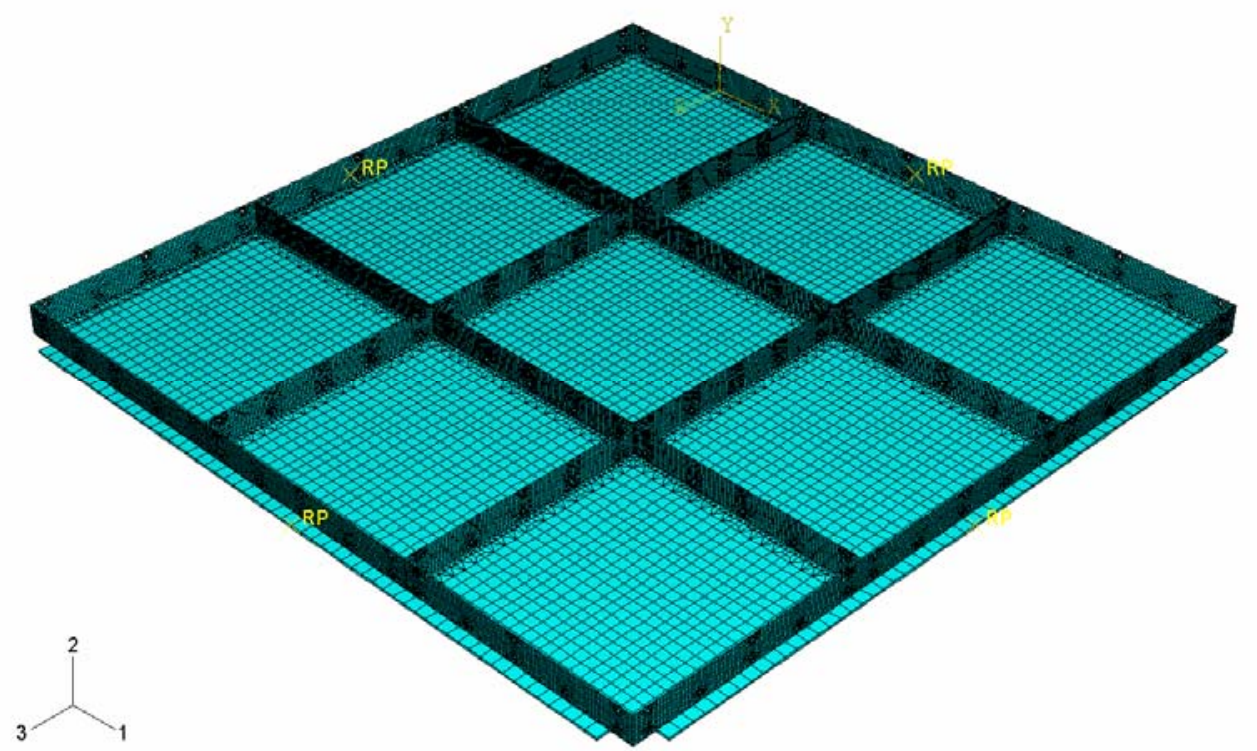

Figure 26. Finite element model for specimens BP2 and BP3

\section{COMPARISON BETWEEN TEST AND FINITE ELEMENT RESULTS}

\subsection{Refined Bolted Connection Model}

The finite element load-displacement curve for the centre of the BP1 specimen is compared with the test curve in Figure 13. In general, the numerical results are in close agreement with the test results. However, the finite element model tends to overestimate the structural resistance in the final stage of deformation. This softer behaviour of the test specimen can be attributed to the slight relative twisting between the two modular units at the connection observed in the test. These non-symmetric deformations were due to the small geometric distortions in the test specimen which were not included in the finite element model.

The deformed shape superimposed with the contours of the von Mises equivalent stress at the maximum load predicted by the refined finite element model is shown in Figure 27. It is clear that 
the finite element deformed shape agrees well with that from the experiment.

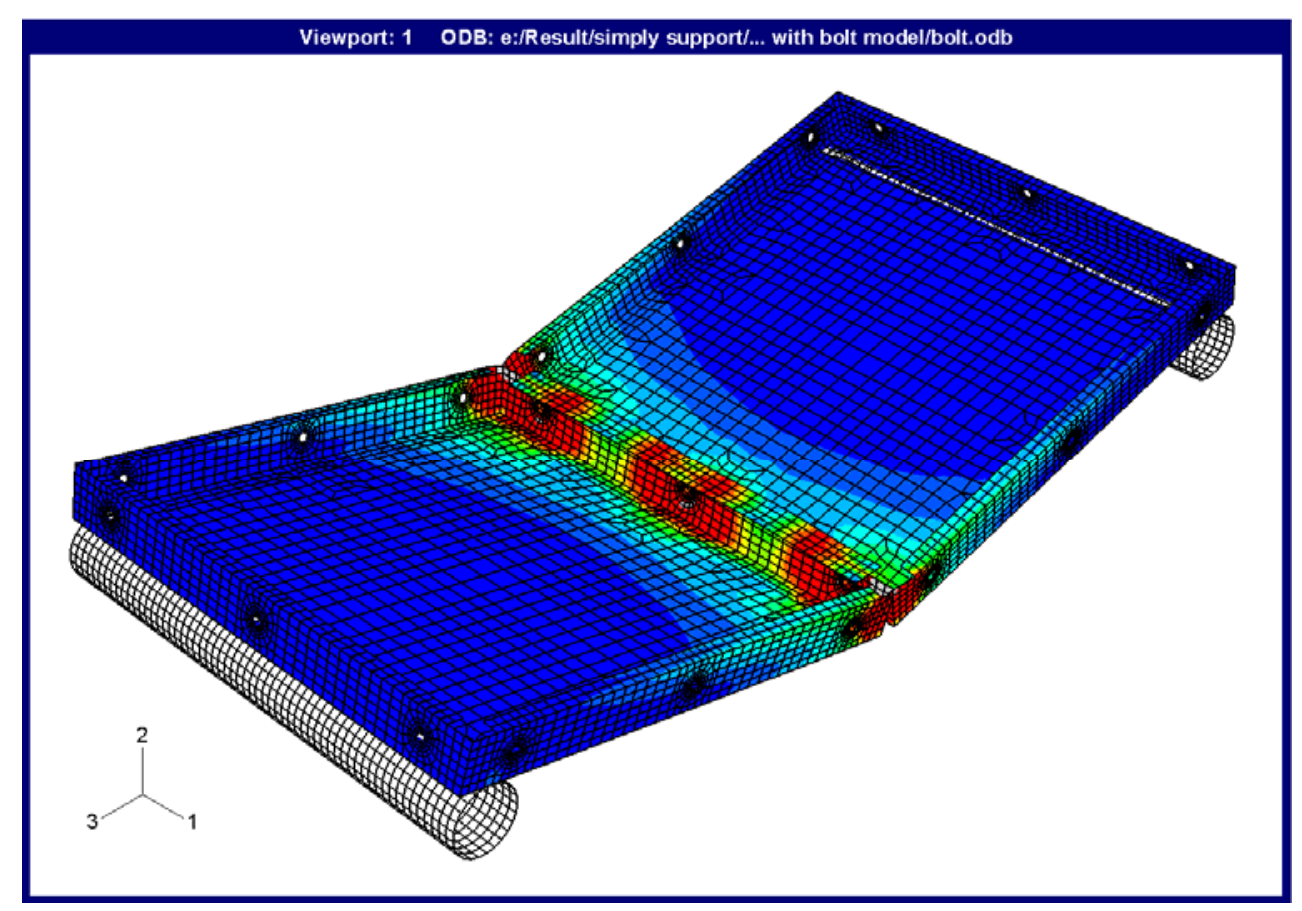

Figure 27. Deformed shape and stress distribution from finite element analysis for test BP1

\subsection{Simplified Bolted Connection Model}

\subsubsection{Test BP1}

The results of the two finite element simulations using the simplified model are also shown in Figure 13. It is seen that the load-displacement curves from the numerical analyses with two different tied areas agree well with the experimental curves in the initial stage. At higher loads, the finite element curves deviate from the test curve. In the modelling of specimens BP2 and BP3, only the more conservative option of a tied area of $10 \mathrm{~mm}$ in diameter was adopted.

Again, the numerical models overestimate the structural resistance significantly in the final stage of deformation. The deformed shapes superimposed with the contour plots of the von Mises equivalent stress from the simplified finite element models at the maximum load are similar to that predicted by the refined model and are not shown here.

\subsubsection{Test BP3-1}

The load-displacement response at the centre of the panel predicted by ABAQUS [7] is shown in Figure 19, which is seen to be in prefect agreement with the experimental results. Figure 28 presents the predicted failure mode and the corresponding stress distribution at the ultimate load (42.6 kPa), while the experiment stopped at the load of $7.8 \mathrm{kPa}$.

\subsubsection{Tests BP2 and BP3-2}

The load-displacement curve for the point of intersection between axes B and 2 (Figure 10b) from test BP2 is given in Figure 17. The numerical simulation was stopped due to the divergence of the 
iterative solution process. Figure 17 shows that the load-displacement curve predicted by ABAQUS [7] is in good agreement with that from the test.

For test BP3-2, Figure 22 shows that the load-displacement response predicted by ABAQUS [7] is significantly different from the experimental curve. In fact, they are significantly different right from the beginning of loading. Both the buckling load and the deep post-buckling path obtained form the test could not be predicted by the numerical model. Since the effect of the sand during the test was omitted in the numerical model, the fact that finite element buckling load is lower than the experimental value may be interpreted to imply that the sand enhanced the buckling strength of the panel. The discrepancies observed between the numerical and the experimental behaviour can thus be attributed to the presence of the sand during the test. Figures 29 and 30 show the deformed shapes and the corresponding distributions of the von Mises equivalent stress at the maximum load for tests BP2 and BP3-2, respectively.

As the load increased, material yielding firstly occurred within the bolted area. However, the panel continued to deform with its global behaviour little affected by such local stress concentration and yielding. The magnitude of stresses continued to grow with further loading, leading to obvious concentration of yielding in certain regions on the stiffeners. It should be noted that the stress distribution is much more uniform on specimen BP2 than specimen BP3-2. High stresses are mainly observed at the four corners of the central unit, which agrees well with the test observation (Figures 18b and 23b). Despite this discrepancy, the deformed shapes of specimen BP2 and BP3-2 predicted by ABAQUS [7] are similar. The stresses in the base plates from the finite element analyses remain small during the loading process, which are consistent with the measurements from the test. These comparisons show that the ultimate failure of the specimens occurred as a result of the buckling of stiffeners. In addition, the finite element models are able to accurately capture the buckling behaviour observed in the tests (Figures 18 and 23).

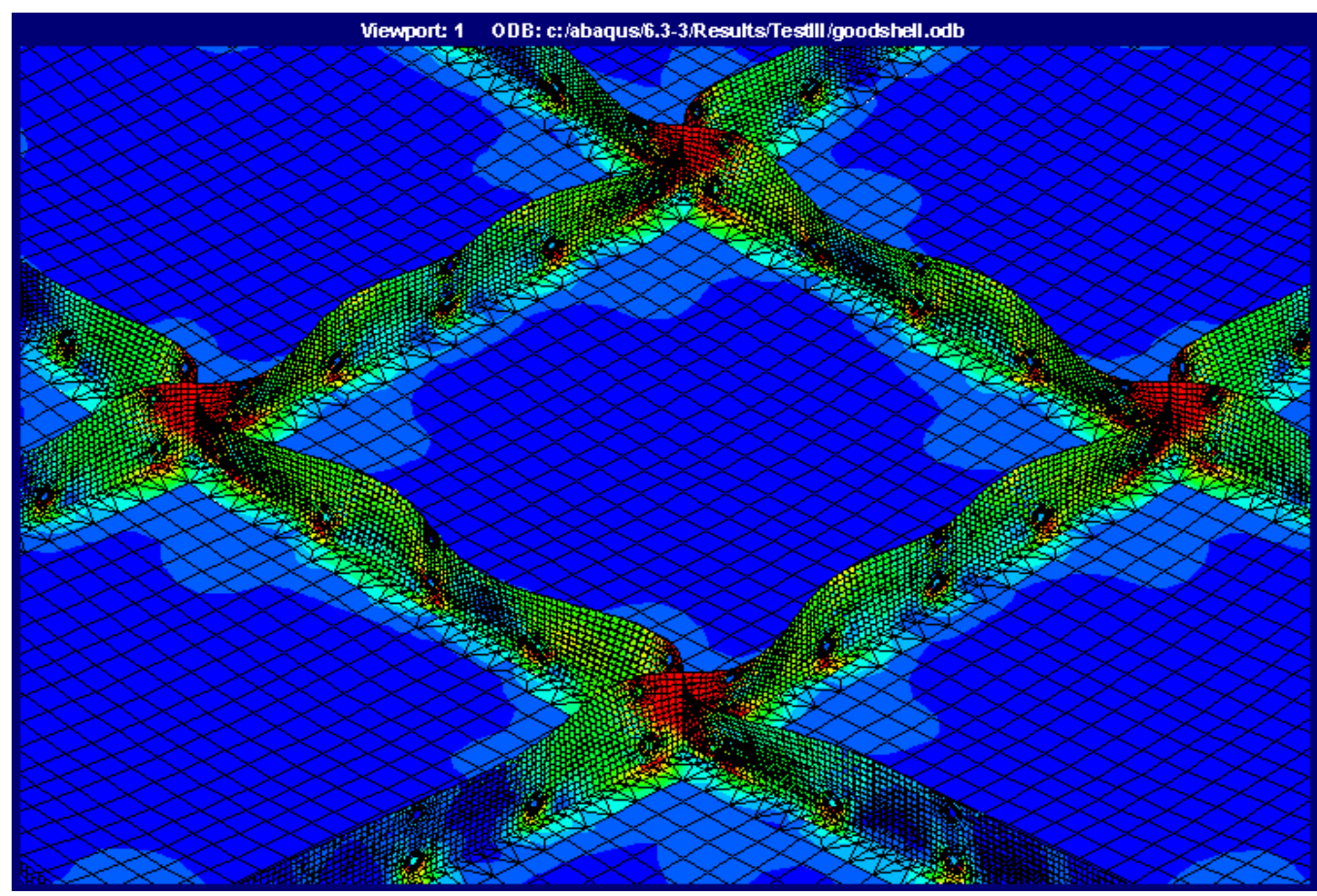

Figure 28. Deformed shape and stress distribution from finite element analysis for test BP3-1 


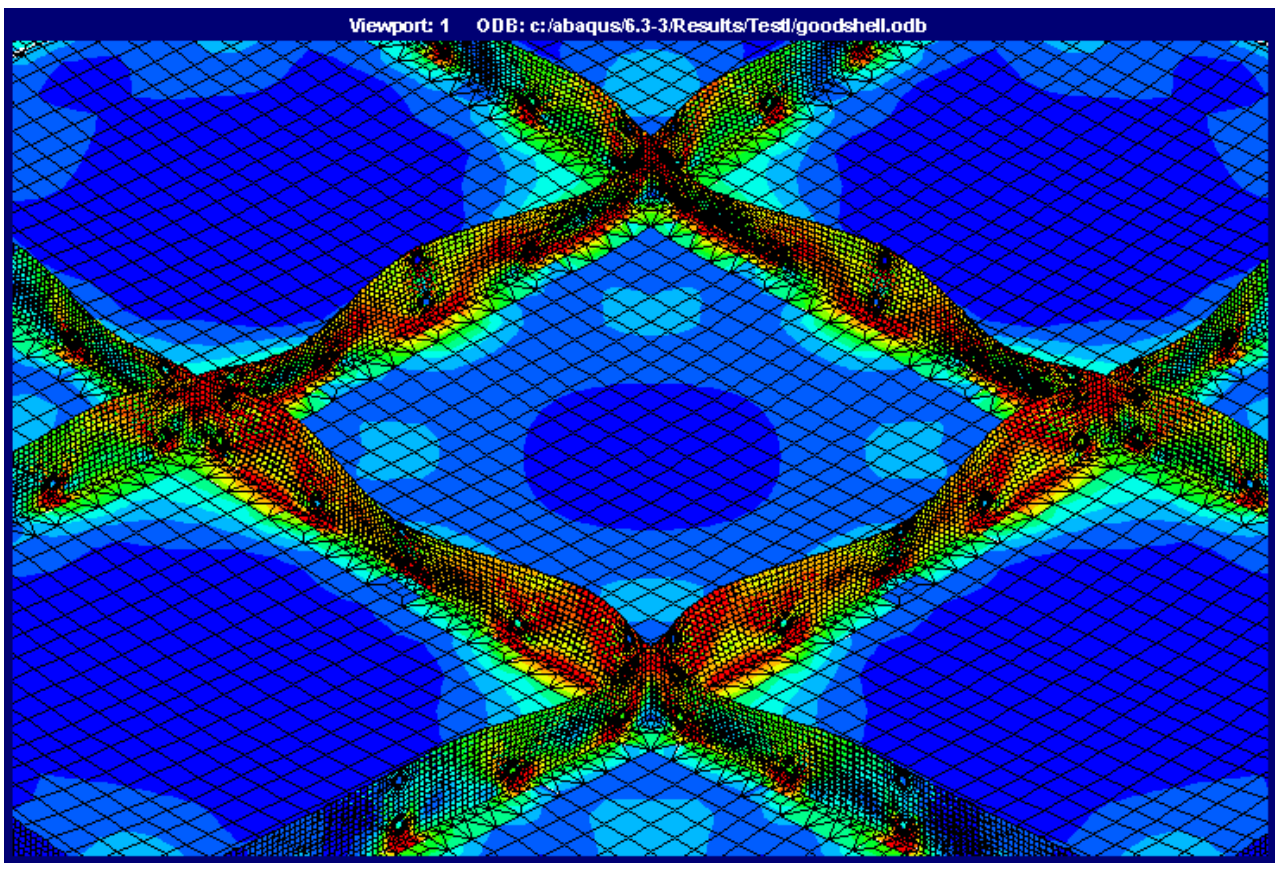

Figure 29. Deformed shape and stress distribution from finite element analysis for test BP2

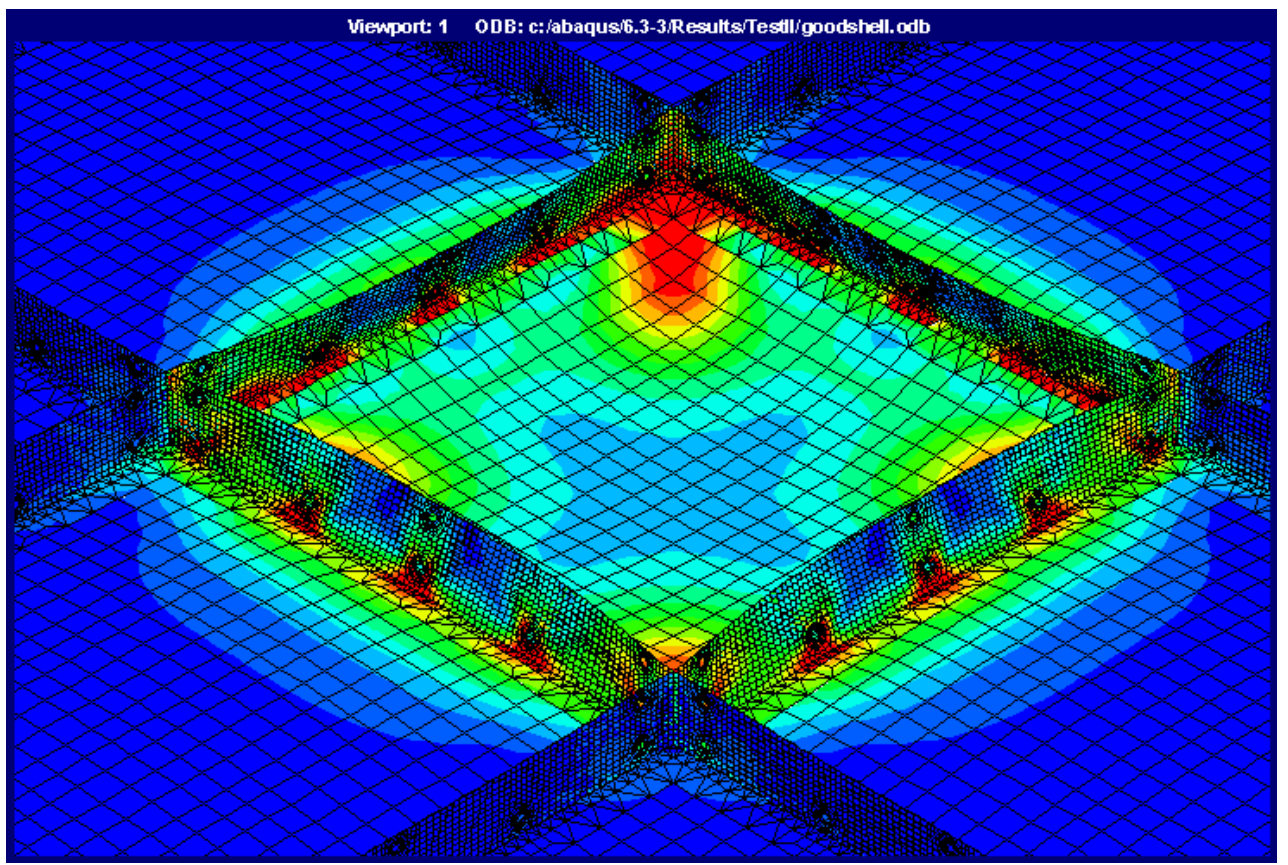

Figure 30. Deformed shape and stress distribution from finite element analysis for test BP3-2

\section{CONCLUSIONS}

A Comshell roof consists of a bolted steel base shell and cast in-situ concrete in composite action. A key design issue of Comshell roofs is the buckling strength of the steel base shell under wet concrete loading during construction. The behaviour of these bolted shells is complicated by the presence of many bolted joints, so the use of finite element analysis is necessary in order to accurately predict their behaviour. This paper has been concerned with the flexural behaviour of these bolted joints through a series of tests conducted on bolted flat panels featuring such joints and the numerical modelling of this behaviour. 
The tests showed that the main failure mode of bolted panels under transverse loading is the buckling of the stiffeners as the upper part of the stiffeners is subject to longitudinal compression. It was also found that this buckling behaviour was affected by the presence of filled sand used to apply loading. The sand enhanced the buckling load of the panel but also led to sudden a snap-through buckling failure.

Finite element analyses incorporating a simplified connection model were developed for modelling the behaviour of the test panels. The finite element results were first compared with those from a simple two-unit panel test, and then compared with those from nine-unit panel tests. These comparisons showed that the simplified connection model, in which the bolt connections were simulated using the "TIE" option of the ABAQUS [7] program, led to accurate results with the choice of an appropriate tied area and without the presence of filled sand. Based on these comparisons, it can be concluded that the simplified connection model has the potential to be used in modelling bolted base shells of real shell roofs.

\section{ACKNOWLEDGEMENTS}

This work has been supported by the Research Grants Council of the Hong Kong Special Administrative Region, China (Project No: PolyU 5059/99E), with additional support from The Hong Kong Polytechnic University. The authors are grateful for this support.

\section{REFERENCES}

[1] Medwadowski SJ. Concrete thin shell roofs at the turn of the millennium. Current and Emerging Technologies of Shell and Spatial Structures. Proceedings of an IASS Symposium, April, 1998:9-22.

[2] Teng JG. Steel-concrete composite shells for enclosing large spaces. Proceedings, International Conference on Steel and Composite Structures, Pusan, Korea, 14-16 June, 2001:403-409.

[3] Teng, JG, Wong HT, Wang ZC, Dong SL. Steel-concrete composite shell roofs: structural concept and feasibility. Advances in Structural Engineering 2005:8(3), in press.

[4] Wong HT, Teng, JG. Buckling behaviour of model steel base shells of the Comshell roof system. Journal of Constructional Steel Research; 2005, in press.

[5] BSEN1002. Metallic Materials-Tensile Testing-Part 1: Method of Test at Ambient Temperature. European Committee for Standardization, Brussels; 2001.

[6] Timoshenko SP, Woinowsky-Krieger S. Theory of Plates and Shells, 2nd Edition. McGraw-Hill Book Company, 1959.

[7] ABAQUS. ABAQUS standard user’s manual, version 6.3; 2003. 
[8] Wong HT. Behaviour and Modelling of Steel-Concrete Composite Shell Roofs. PhD Thesis, The Hong Kong Polytechnic University; 2005.

[9] Bursi OS, Jaspart JP. Calibration of a finite element model for bolted end plate steel connections. Journal of Constructional Steel Research 1997;44:225-262.

[10] Wheeler AT, Clarke MJ, Hancock GJ, FE Modeling of four-bolt, tubular moment end-plate connections. Journal of Structural Engineering, ASCE 2000;122:1307-1316.

[11] Al-Emrani M, Kliger R. FE analysis of stringer-to-floor-beam connections in riveted railway bridges. Journal of Constructional Steel Research 2003;59:803-818. 


\title{
SECOND-ORDER P- $\Delta-\delta$ ANALYSIS AND DESIGN OF ANGLE TRUSSES ALLOWING FOR IMPERFECTIONS AND SEMI-RIGID CONNECTIONS
}

\author{
S.L. Chan* and S.H. Cho \\ *Department of Civil and Structural Engineering, \\ The Hong Kong Polytechnic University, Hong Kong \\ Email: ceslchan@polyu.edu.hk Fax: (852) 23346389
}

\begin{abstract}
Single angle members have a broad range of applications, such as web members in roof trusses and bracing members in latticed towers. The structural behaviour of a single angle compression member in a truss is complicated. It is not uncommon to connect one angle member to another through their legs. Therefore, in practice, the member is under an eccentric force which introduces a pair of end moments. However, in most design codes such as BS5950 (2000) and Eurocode 3 (2003), these end moments are often ignored. To compensate for this load eccentricity, the Robertson constant in the Perry-Robertson formula is amplified so that the compressive strength is reduced for the negligence of end eccentricities. In this method of analysis, all connections are assumed to be pin-jointed; while in the design, the effective length is assumed on the basis of connection types (e.g. single-bolted, double-bolted or welding) which violates the assumption in the analysis. This paper proposes a design method for angle trusses using nonlinear analysis which eliminates the inconsistency between the analysis and the design. Laboratory tests of angles as web members of a truss were carried out. The test results are compared with the proposed theoretical and code design loads. In the proposed design method, there is no need to consider any effective length. The second-order P- $\Delta$ and P- $\delta$ effects are considered automatically by geometry update. The proposed method is readily applicable to design of practical steel trusses made of angle sections.
\end{abstract}

Keywords: Eccentricity, effective length, initial curvature, nonlinear analysis, second-order effects

\section{INTRODUCTION}

Second-order and advanced analysis of steel buildings has been extensive with its concept is well established (Chen and Lui [1]), but this type of analysis for angle trusses is limited. Single angle members in compression have a broad range of applications, such as web members in roof trusses, members in latticed towers and bracing members, etc. Single angles are widely used because of their ease of fabrication, erection and transportation. It is not uncommon to connect one angle member to a gusset or another member through one leg. Therefore, in practice, the member is under an eccentric force which introduces a pair of end moments reducing the load capacity of the angle member. However, the connection at ends normally provides restraining moments which are beneficial to the compressive resistance of the angle. The above-mentioned features are unique to angle sections making the analysis of angle members complicated. Moreover, the sections are either mono-symmetric for equal-leg angles or asymmetric for unequal-leg angles, the principal planes are almost always inclined to the loading planes. They may fail in a complex mode involving bending about both principal axes with simultaneous twisting about the shear centre. To achieve the exact elastic solution of an angle with end restraints and eccentric compressive load, a close-form solution is hardly possible and numerical methods must be adopted. Trahair [2] carried out a theoretical investigation on elastic biaxial bending and torsion of beam-columns with symmetric end loading and restraints. These end conditions are close to the ones in practical structures. The differential equilibrium equations for principal major axis bending, principal minor axis bending and torsion have been given by Goodier [3,4], and the problem was solved by using the finite integral method 
(Trahair, [2]). The structural behaviour of eccentrically loaded end restrained single angle struts was studied and compared with experimental data reported by Foehl [5]. It was shown that the first yield loads are quite close to the failure load and may be used as conservative estimates of the ultimate strengths of the single angle struts. It should be noted that when using the interactive formula for axial force and moment in conjunction with the use of elastic modulus, the checking becomes the first-yield load check. When the plastic modulus is used, the checking then becomes section capacity check.

Kitipornchai and Chan [6] employed an alternative approach based on the finite element method to solve the problem of elastic analysis of restrained beam-columns. The total potential energy for thin-walled beam-column was formulated, incorporating member geometrical nonlinearity. The element geometric stiffness matrix for angles was derived. The equilibrium paths were then determined from the incremental and the total force-deformation equilibrium equations. The influence of the pre-buckling deformations was incorporated in the analysis by modifying the structural tangent stiffness continuously through geometry updates. The results were compared with those reported by Trahair [2]. It was found that when the geometry was not updated, the results were found to agree well with the finite integral solutions by Trahair [2]. However, when the geometry was updated, the influence of the pre-buckling deformations was apparent in some orientation of the restraint plane indicating that the conventional numerical procedure may grossly overestimate the actual member capacity. This indicates the importance considering the finite deflection effect. However, these two approaches were seldom used in practice as they were time consuming and thus unsuitable for designing large scale trusses. Instead, the linear analysis in annotation with the effective length method was adopted conventionally.

On top of theoretical studies, a great deal of research has been conducted on testing of angle members in compression and the results were compared with some of the American design codes. Trahair et al. [7] carried out theoretical and experimental studies on the design of eccentrically loaded single-angle steel columns. The tests were performed on equal and unequal angles under various end restraint conditions. The theoretical solutions of elastic analysis were found to agree well with the test results and can be used as a lower bound estimate of the actual failure loads. Adluri and Madugula [8] compared experimental results on eccentrically loaded single angle members free to rotate in any directions at ends with the available literature with AISC LRFD [9] and AISC ASD [10] specifications. The experimental investigations, which cover a wide spectrum of single angle struts, were carried out by Wakabayashi and Nonaka [11], Mueller and Erzurumlu [12], and Ishida [13]. It was concluded that the interaction formulas given in AISC LRFD [9] and AISC ASD [10] are highly conservative when applied to eccentrically loaded single angle members. Bathon et al. [14] carried out 75 full-scale tests which cover a slenderness ratio ranging from 60 to 210. The test specimens were unrestrained against rotation and twist at the end supports. It was noted that the ASCE Manual 52 [15] under-predicts the capacities of single angle struts. The conservatism of the interaction formulas are due to the fact that these formulas were derived primarily for doubly symmetric sections and the moment ratios in these formulas are evaluated for the case of maximum stresses about each principal axis. This practice does not pose a problem on doubly symmetric sections such as I sections because the four corners are critical for moments about both principal axes simultaneously. However, for angle sections, as they are mono-symmetric or asymmetric, the points of maximum bending stress about both principal axes usually do not coincide. As a consequence, the load capacities of the sections calculated from these interaction formulas are underestimated (Adluri and Madugula [8]). 
The above-mentioned research work focuses only on isolated members with ideal end conditions. Although different end conditions were considered (e.g. pinned or fixed-end), the actual end conditions may not be truly reflected. To model accurately the actual end conditions, Elgaaly et al. [16] conducted an experimental program to investigate the structural behaviour of non-slender single angle struts as part of three-dimensional trusses. The specimens cover a range of slenderness ratio from 60 to 120. Results also show that both the ASCE Manual 52 [15] and AISC LRFD [9] are over-conservative for single angle members with low slenderness ratio.

In this paper, a new design method for angle trusses is derived and incorporated into a nonlinear analysis computer program (NIDA [17]), which allows for the practical nature of external forces and structures such as load eccentricity and initial imperfections. Because of the availability of low-cost personal computers, this computer method can be applied to design of a wide range of angle trusses to-date. The validity and the accuracy of the proposed method are demonstrated through two laboratory tests of trusses with single angles as web members. The test results are compared with the theoretical solutions and with the current design method to BS5950 [18]. The advantage of the proposed method lies on its accurate computation of moment and axial force on a section due to eccentric moments about the two principal axes and its flexibility of modelling the equivalent initial imperfection in substitution for the combined effect of geometrical imperfection and residual stresses. The results reported in this paper may provide reference to member imperfection for this type of asymmetric sections recommended in steel design codes with advanced topics, which include the latest Euro-code 3 [19] and the Hong Kong Steel Code [20], on second-order and advanced analysis.

\section{CONVENTIONAL DESIGN METHOD - BS5950 (2000)}

When angles are used as web members of trusses, the members are usually attached to gusset plates or to the chord members through one leg. In addition, the principal axes are often inclined to the loading axes. Therefore, the load acting to the angle is always away from the centroid of the section such that these members are subject to end eccentricities about two principal axes in practice. As a result, theses angles may fail in a complex mode involving axial shortening, biaxial bending and twisting. Despite the wide-spread use of single angles as compression members, the design procedures in many national design codes such as BS5950 [18] and Euro-code 3 [19] are often over-simplified. To simplify the design procedure, in BS5950 [18], Clause 4.7.10 allows the engineers to design these members as simple compression members without end eccentricity. Instead, the end eccentricity is represented qualitatively by amplifying the Robertson constant in the Perry-Robertson formula so that the compressive strength is reduced in order to compensate the effect due to end eccentricity. There are basically two stages in the design procedure. In the analysis stage, a linear analysis is performed and deformation is assumed small so that the load-deformation relationship can be neglected and the connections are pin-jointed. With the output of member forces, the "effective length" of individual member is assumed in the second design stage in accordance with the connection type. Summarizing the consideration of effective length recommended in BS5950 [18], the "effective length" factor is 1.0 for single-bolted end connection and 0.85 for end connection with two or more bolts. The compressive resistance of the member is calculated from this assumed "effective length". The structure is deemed to be adequately safe if the compressive resistance is larger than the applied force. However, the "effective length" assumption in the design stage contradicts with the pin-jointed connection assumption in the analysis stage. It is realized that 
any gross under-estimation of effective length may lead to a catastrophic collapse. On the other hand, material will be wasted if the compressive strength is under-estimated.

\section{SECOND-ORDER P- $\Delta-\delta$ DESIGN METHOD}

In the proposed design method, the nonlinear analysis software NIDA [17] is modified. As indicated in its user manual [17]. A few assumptions have been made for the computer analysis as follows.

(1) The assumed failure mode is flexural buckling about the principal minor axis. Therefore the initial imperfection is imposed about the principal minor axis so that bending about the principal minor axis is initiated. The other failure mode like the flexural-torsional buckling is not directly considered in the investigation but they may be included by separated member check since their behaviour has little interaction with other members in the frame.

(2) The effect of local buckling is ignored. Only Class 3 semi-compact or above angle sections are considered with only the extreme fibre in compression can be loaded to the design strength. However, if slender sections are used, it is suggested the equivalent sectional properties accounting for local plate buckling can be used and the remaining procedure can be followed.

One of the important features of software NIDA [17] is the initial curvature can be incorporated into the element. To the authors' knowledge, this inclusion of member imperfections is suggested explicitly in only two currently available design codes, the Euro-code 3 [19] and the Hong Kong Steel Code [20]. In this model, when the element is under pure axial load, both the axial shortening and bending due to member imperfection and curvature due to load will occur. In contrast, if a linear analysis is performed, only axial shortening can be modeled. During the nonlinear analysis, the $\mathrm{P}-\delta$ effect is taken into account by the imposition of the load-induced curvature to initial curvature throughout the analysis. Further, the P- $\Delta$ effect depending on nodal movement is considered by continuous modification of the structural geometry. The advantages of using the $\mathrm{P}-\Delta-\delta$ method include the followings.

(1) Effective length is not required to be guessed for computation of compressive strength of members of which a reliable "guess" for some buckling modes like snap-through buckling is not possible;

(2) The effective length approach of accounting for P- $\delta$ moment can only deal with the effect arisen from initial imperfection and the $\mathrm{P}-\delta$ moment induced by external load on member curvature cannot be allowed for by the effective length method. Additional reduction such as $\mathrm{B}_{1}$ factor in LRFD [9] is required and the design becomes tedious;

(3) Only one element per member is required for modeling since the element possesses curvature to mode $\mathrm{P}-\delta$ effect, leading to much convenience in model construction and in modeling of imperfect member required by the Euro-code 3 [19] and the Hong Kong Steel Code [20]; and

(4) The design is completed simultaneously with the analysis, thus time and effort spent by the design engineer can be greatly reduced. 


\section{MEMBER IMPERFECTIONS}

In BS5950 [18], the end eccentricity is replaced by an equivalent value of the Robertson constant. Similarly, in NIDA (2002), the end eccentricity is simulated by an equivalent value of initial curvature of the element. The value of initial curvature-to-length ratio $\left(\delta_{0} / \mathrm{L}\right)$ is controversial but generally in the same order across different codes. In this paper, the following formula derived basically from the Perry-Robertson formula is used (Chan and Cho, [21]).

$$
\frac{\delta_{0}}{L}=0.001 \times \frac{5.5}{y / r}
$$

in which $\quad \delta_{0}$ is the initial imperfection of the element

$\mathrm{L}$ is the element length

$\mathrm{y}$ is the distance from the centroid to the extreme fibre of the section

$r$ is the radius of gyration of the section

According to Eq. (1), depending on the sizes and leg ratios of angles, there are different values of $\delta_{0} / \mathrm{L}$ to account for the P- $\delta$ effect. However, for similar geometrical cross-sections, the values of $y / r$ are roughly constant. Therefore, for practical design purpose, only one single value of $\delta_{0} / \mathrm{L}$ is adopted for each section type (equal angle and unequal angle) for convenience which is obtained from the section having the smallest value of $\mathrm{y} / \mathrm{r}$ and thus the largest value of $\delta_{0} / \mathrm{L}$ so that the buckling strength calculated using this $\delta_{0} / \mathrm{L}$ value is slightly conservative to the actual buckling strength. Table 1 summarizes the design values of $\delta_{0} / \mathrm{L}$ for both equal and unequal angles.

Table 1. Recommended design values of initial imperfection about the minor axis

\begin{tabular}{c|c}
\hline Section Type & $\delta_{0} / L$ \\
\hline Equal Angle & $1 / 360$ \\
\hline Unequal Angle & $1 / 400$ \\
\hline
\end{tabular}

\section{CONNECTION SPRING ELEMENT}

In the convention design approach, the double-bolted connection of the compression angle is considered by assuming the "effective length" as 0.85 of the actual length of the member; while in the proposed approach, the double-bolted connection is modelled as a connection spring element shown in Figure 1 and inserted to the end of the angle member. Therefore, the rotational stiffness due to the double-bolted connection can be considered at the early stage of the analysis rather than at the design stage as in the linear analysis and effective length design method. Only the rotational deformation of the connection spring element is considered for design because the effects of the axial and shear forces in the connection deformations are small when compared with that of bending moments.

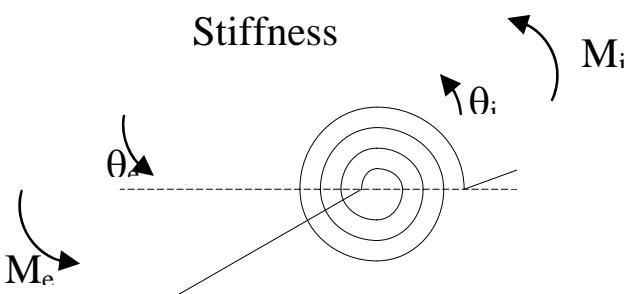

Figure 1. Connection spring element at one end of an element 
Referring to Figure 1 and considering equilibrium, the vector sum of moments on two ends of a connection spring element vanishes.

$$
M_{e}+M_{i}=0
$$

in which $M_{e}$ and $M_{i}$ are the external and internal moments at two ends of a connection. The external node refers to the one connected to the global node and the internal node is joined to the angle element. The stiffness of the connection, $S_{c}$, can be related to relative rotations at the two ends of the connection spring as

$$
S_{c}=\frac{M_{e}}{\theta_{e}-\theta_{i}}=\frac{M_{i}}{\theta_{i}-\theta_{e}}
$$

in which $\theta_{e}$ and $\theta_{i}$ are the conjugate rotations for the moments $M_{e}$ and $M_{i}$.

Eq. (3) can be re-written to an incremental tangent stiffness matrix form as

$$
\left[\begin{array}{l}
\Delta M_{e} \\
\Delta M_{i}
\end{array}\right]=\left[\begin{array}{rr}
S_{c} & -S_{c} \\
-S_{c} & S_{c}
\end{array}\right]\left[\begin{array}{l}
\Delta \theta_{e} \\
\Delta \theta_{i}
\end{array}\right]
$$

Eq. (4) will be superimposed to the element stiffness matrix so that the flexural rigidity of the connection can be accounted for during analysis.

\section{ANALYSIS PROCEDURE}

To determine the design and buckling load of a structure, approximately $1 \%$ to $10 \%$ of the predicted failure load is applied incrementally until the sectional capacity factor, $\varphi$, in Eq. (5) below is greater than 1 .

$$
\frac{P}{p_{y} A}+\frac{M_{y}+P\left(\Delta_{y}+\delta_{y}+\Delta_{0 y}+\delta_{0 y}\right)}{p_{y} Z_{y}}+\frac{M_{z}+P\left(\Delta_{z}+\delta_{z}\right)}{p_{y} Z_{z}}=\varphi
$$

in which $\quad p_{y}$ is the design strength normally taken as the yield stresses of the section,

$P$ is the external force in the section

$A$ is the cross-sectional area

$M_{y}$ and $M_{z}$ are the external moments about the y- and the z- axes

$M_{r y}$ and $M_{r z}$ are the moment resistance about the $\mathrm{y}$ - and the z- axes

$P\left(\Delta_{y}+\delta_{y}\right)$ and $P\left(\Delta_{z}+\delta_{z}\right)$ are the second-order $\mathrm{P}-\Delta-\delta$ moments about the $\mathrm{y}$ - and the $\mathrm{z}$ axes for large deflection effect and member bowing effect as well as their imperfections of which the consideration allows us to include automatically the effect of "effective length"

To be more accurate for economical design, Equation 5 should be applied to various points across the section using the corresponding moduli of those points considered with allowance for the sign of stress.

The Newton Raphson method combined with the minimum residual displacement iterative scheme (Chan, [22]) of solving the following set of nonlinear simultaneous equation as follows is utilized with the iterative scheme illustrated in Figure 2. 


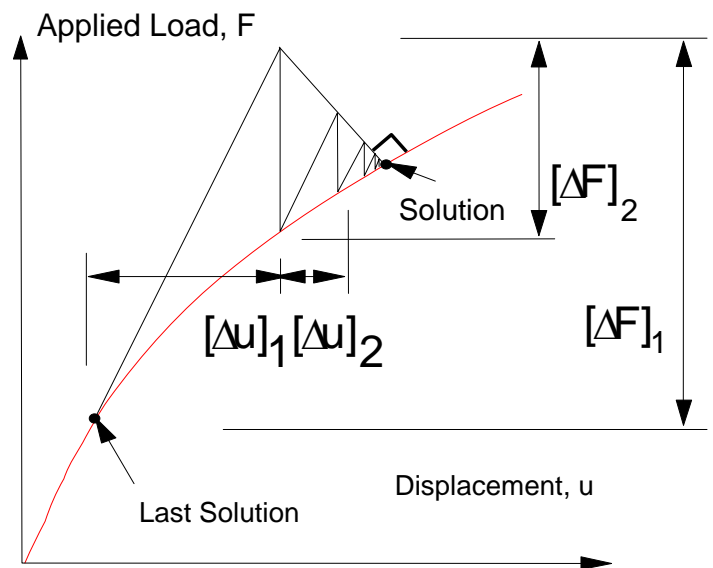

Figure 2. The Minimum Residual Displacement method

$$
\begin{aligned}
& {[\Delta \tilde{u}]=\left[K_{T}\left(u, \delta_{0}, F\right)\right]^{-1}[\Delta F]} \\
& {[\Delta \bar{u}]=\left[K_{T}\left(u, \delta_{0}, F\right)\right]^{-1}[\Delta \bar{F}]}
\end{aligned}
$$

The displacement incremental is determined as,

$$
[\Delta u]=[\Delta \tilde{u}]+\lambda[\Delta \bar{u}]
$$

in which $[\Delta \widetilde{u}],[\Delta \bar{u}]$ and $[\Delta u]$ are the displacement increments due to unbalanced force, applied load and summed displacement increment for calculation of unbalanced force. $\lambda$ is a parameter satisfying the minimum residual displacement condition (Chan [22]). Figure 3 shows the compressive strength curves of both equal and unequal angles of slenderness ratio ranging from 0 to 350 derived from NIDA [17] using the initial curvature values shown in Table 1, together with the BS5950 [18], compressive strength curve c (Table 24c) for comparison. It is found that, in lower slenderness range, the difference between the NIDA [17] curve and the BS5950 [18] curve is about 10\% but at the higher slenderness range two curves tend to be identical. It should be noted that practical angle struts usually belong to the intermediate to high slenderness range between 50 to 150 . This degree of accuracy is considered to be adequate for practical design.

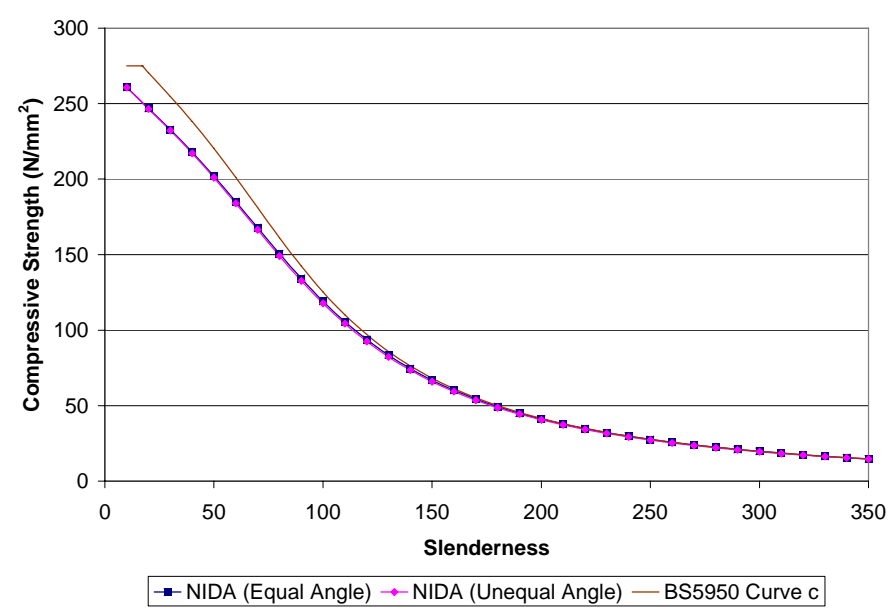

Figure 3. Compression strength curves 
To validate the accuracy of the method proposed in this paper and to study the structural behaviour of a slender angle web member of a truss, two $2000 \mathrm{~mm}$ long $65 \times 65$ x 6 single angle specimens of Grade S275 steel and slenderness ratio about 150 were tested as web members of a two dimensional simply supported truss shown in Figure 4. The leg length-to-thickness ratio meets the BS5950 [18] requirements so that local buckling can be ignored. Each end of the member is connected to a $240 \mathrm{x}$ $180 \times 8$ gusset plate. The two specimens were tested under single-bolted and double-bolted end conditions. The trusses were loaded in pair and sufficient lateral restraints were provided to ensure out-of-plane buckling at connecting nodes between chords and webs is fully avoided. Load was applied through a hydraulic jack. As shown in Figures 5 and 6, twelve strain gauges were mounted at the mid length of targeted member and the tested truss was so designed that the targeted member fails first. At the targeted member, two displacement transducers were placed in the in-plane and out-of-plane directions and transducers were also used to monitor the movements of the top and the bottom joints of the targeted member so that its movement relative to the truss can be measured. At the load where the target member buckled or failed, the deformations of the remaining parts of the truss were small and reversible. Thus, after the first test, the failed member was replaced by another new specimen so that the second test could be carried out under the almost the same conditions except with different bolting details at member ends.

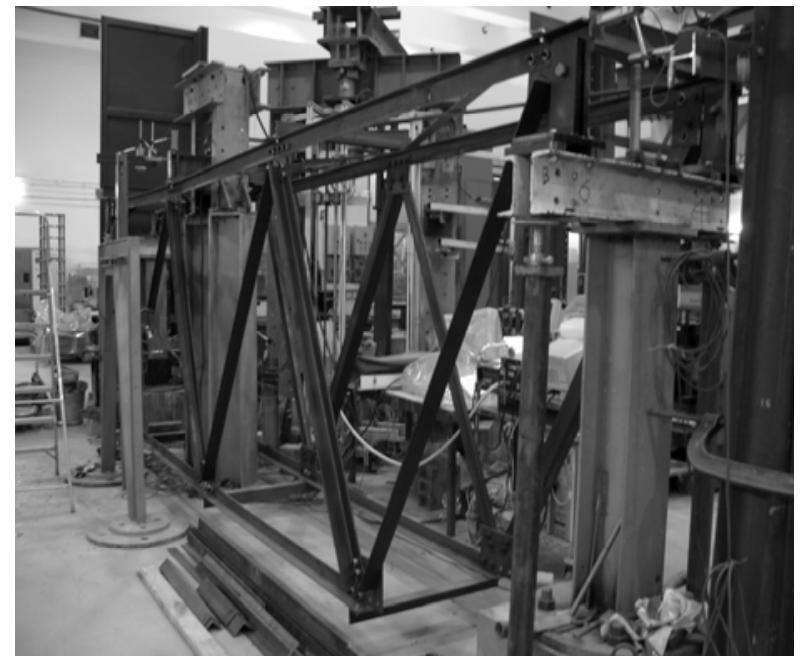

Figure 4. Truss before test

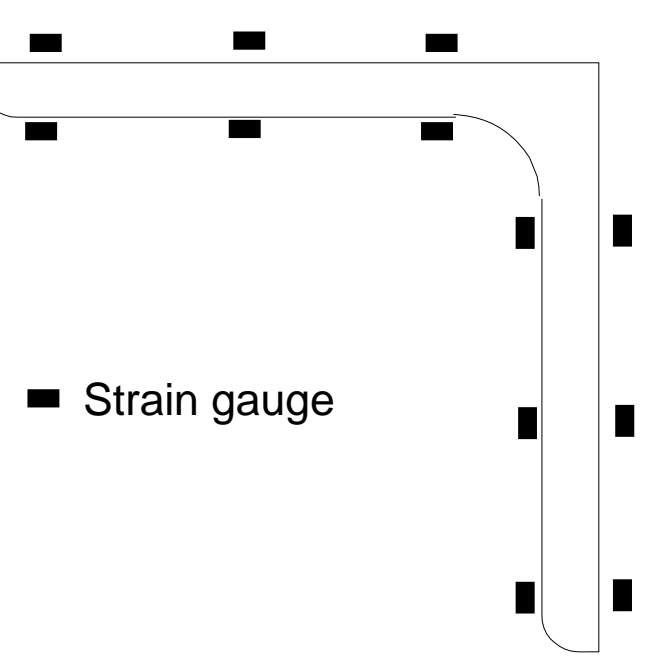

Figure 5. Locations of strain gauges

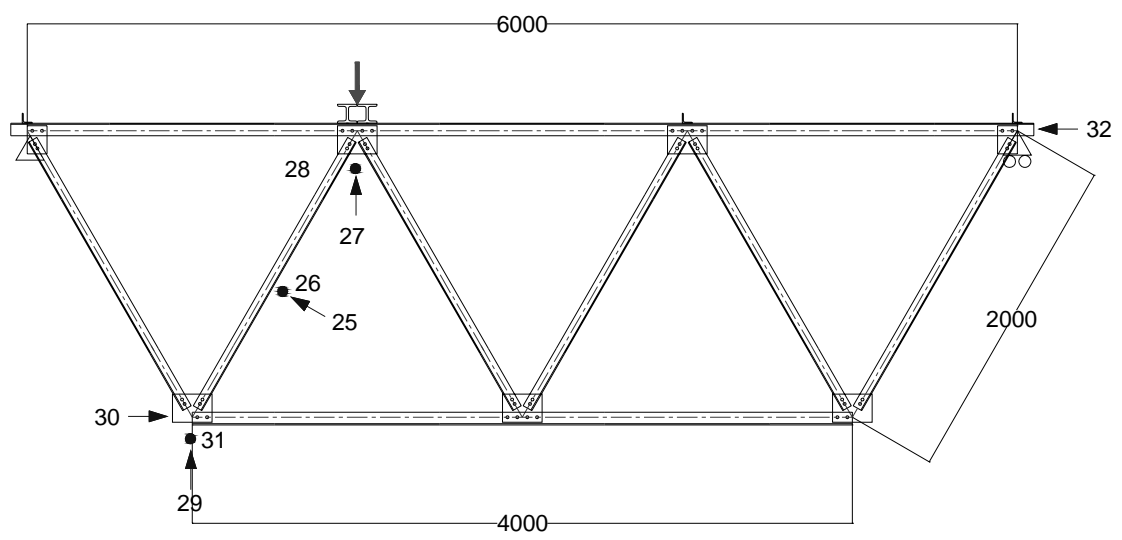

- Out-of-plane direction

$\rightarrow$ In-pane direction

Figure 6. Locations of the transducers 


\subsubsection{Material Properties}

Two coupon tests were performed to determine the material properties of the steel used in the test specimens following the procedure given in BS EN 10002-1 [23]. The tests gave consistent results which are summarized in Table 2.

Table 2. Coupon test results

\begin{tabular}{|c|c|c|}
\hline Coupon & $\begin{array}{c}\text { Young's modulus, E } \\
\left(\mathrm{kN} / \mathrm{mm}^{2}\right)\end{array}$ & Yield stress, $\sigma_{y}\left(\mathrm{~N} / \mathrm{mm}^{2}\right)$ \\
\hline 1 & 347.0 & 216.9 \\
\hline 2 & 347.6 & 211.8 \\
\hline Mean & 347.3 & 214.4 \\
\hline
\end{tabular}

\subsubsection{Test Results}

The observed failure modes are flexural buckling about the principal minor axis for both of the tests as shown in the photos (Figures 7 and 8). Figure 7 shows the failure mode of Specimen 1, of which each end is connected by one single bolt, making it to behave as if pin-ended. Figure 8 shows the failure mode of Specimen 2 of which each end is connected by two bolts. The gusset plate connected at each end provides some flexibility making it to behave as if partially restrained in the out-of-plane direction. Figure 9 shows the in-plane deformations while Figure 10 shows the out-of-plane deformations of the two specimens. Their response patterns are almost identical. As can be seen from the curves, the out-of-plane deformations are always more severe than the in-plane deformations. The member failure loads are calculated using numerical integration of the stress over the cross-sectional area and listed in Table 3. The failure load of the specimen with double-bolted end condition is approximately $12 \%$ higher than that with single-bolted end condition.

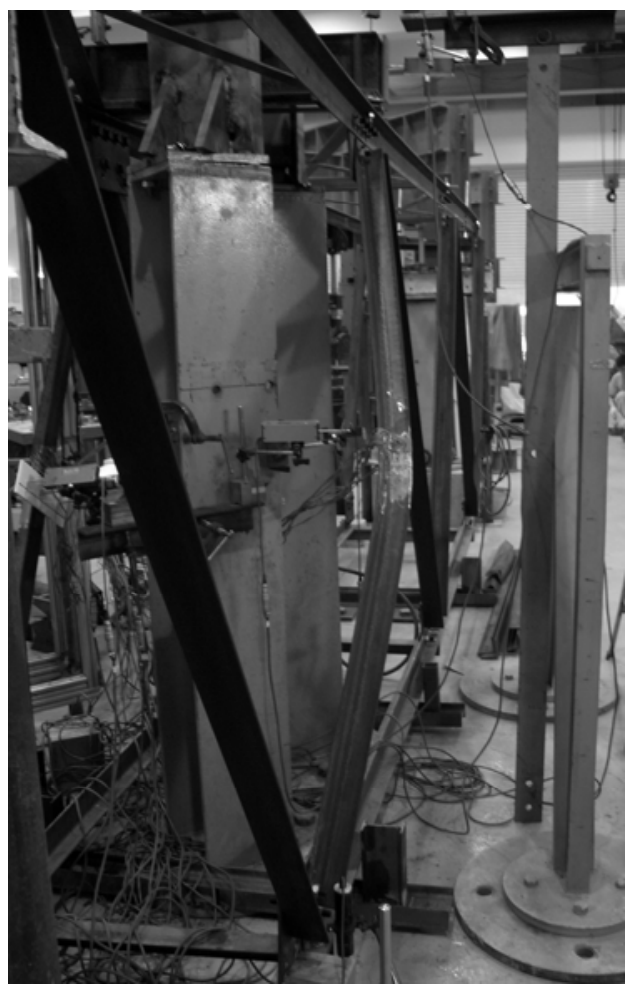

Figure 7. Flexural-buckling about the principal minor axis of Specimen 1

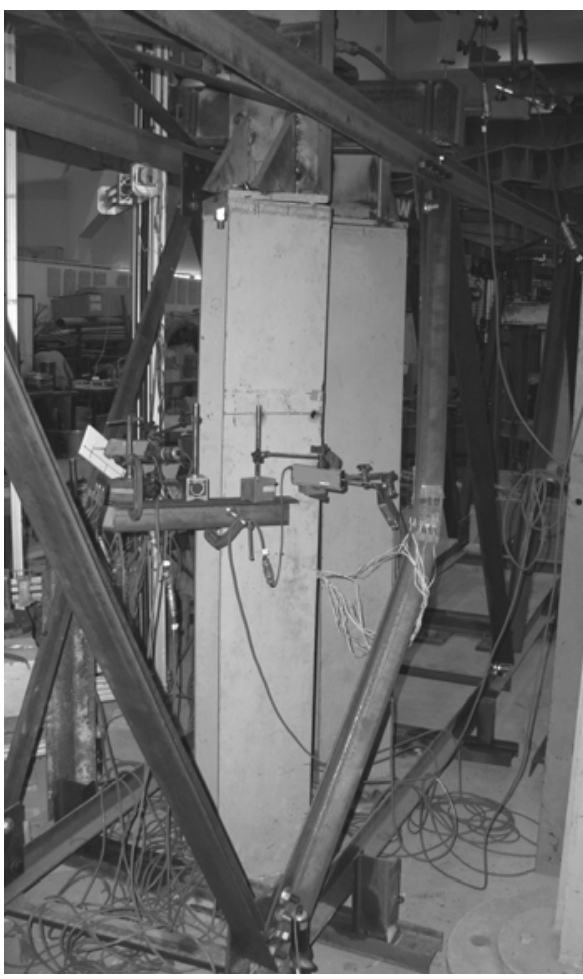

Figure 8. Flexural-buckling about the principal minor axis of Specimen 2 


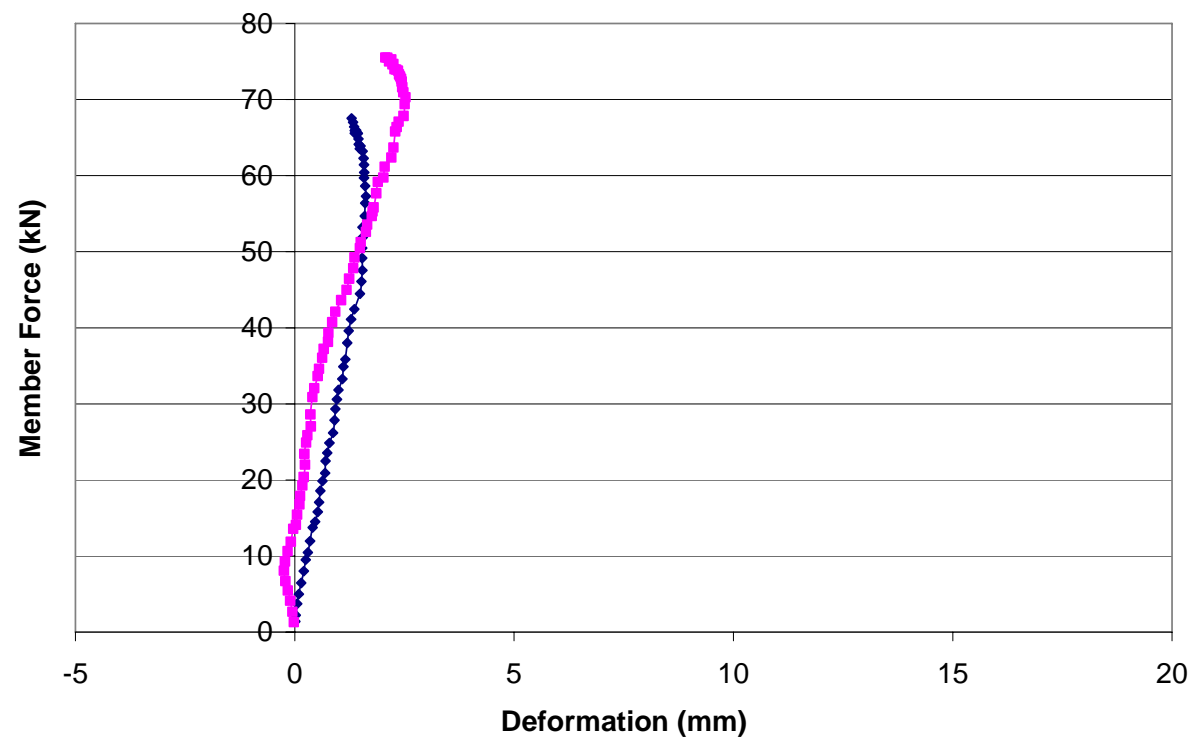

- Single-bolted Connection $-\backsim$ Double-bolted Connection

Figure 9. In-plane deflection of Specimens 1 and 2

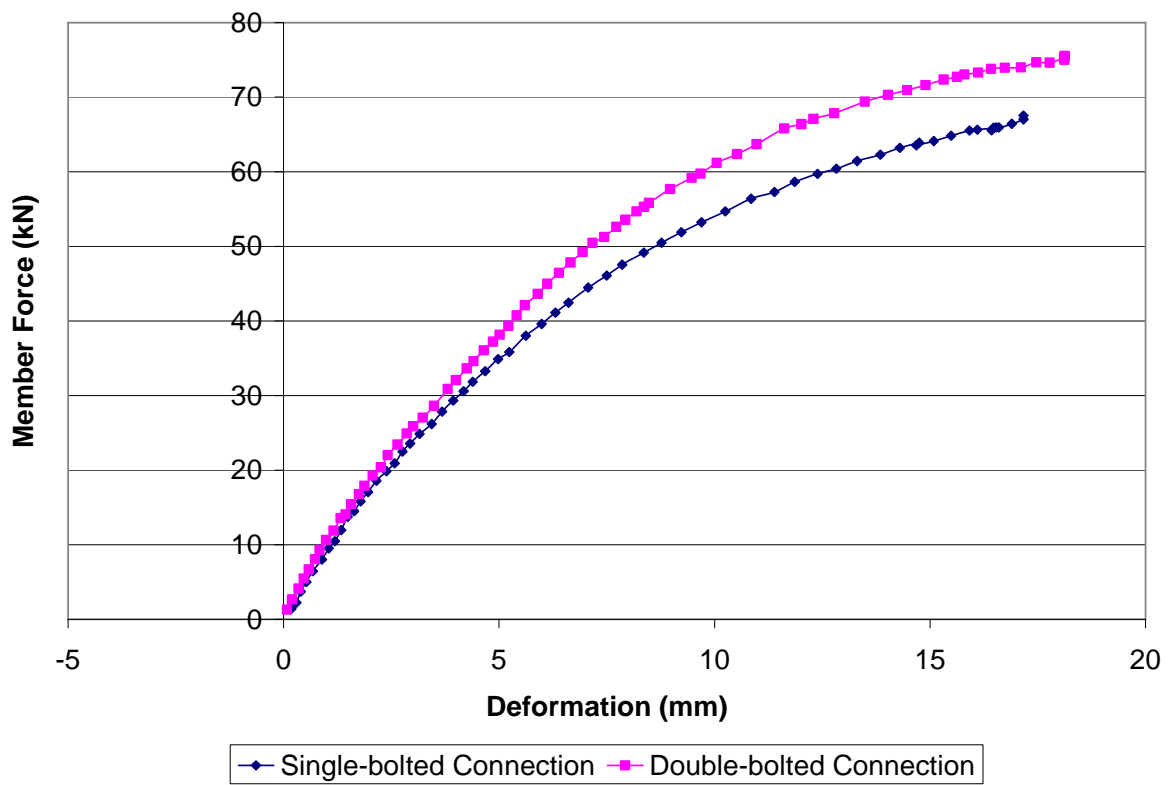

Figure 10. Out-of-plane deflections of Specimens 1 and 2

Table 3. Test failure loads of specimens 1 and 2

\begin{tabular}{c|c|c}
\hline Specimen & End Condition & Failure Load (kN) \\
\hline 1 & Single-Bolt & 67.5 \\
\hline 2 & Double-Bolt & 75.5 \\
\hline
\end{tabular}

The design loads from BS5950 [18] are compared with the experimental failure loads and the predicted failure loads by NIDA [17]. In predicting the failure load of the double-bolted specimen (Specimen 2) by NIDA [17], rotational springs of stiffness equal to the stiffness of the gusset plate are inserted to both ends of the element and the results are summarized in Table 4. It is found that the BS5950 [18] predicted failure loads are $40.6 \%$ and $11.8 \%$ lower than the tested failure load for 
single-bolted and double-bolted end conditions respectively. In other words, the BS5950 [18] provides a conservative but acceptable design loads for both cases.

Table 4. BS5950 [18] Failure Loads vs Experimental and NIDA [17] Failure Loads

\begin{tabular}{c|c|c|c|c|c|c}
\hline Specimen & $\begin{array}{c}\text { End } \\
\text { Condition }\end{array}$ & $\begin{array}{c}\text { BS5950 } \\
\text { Design } \\
\text { Load (kN) }\end{array}$ & $\begin{array}{c}\text { Experimental } \\
\text { Failure Load } \\
\mathbf{( k N )}\end{array}$ & $\begin{array}{c}\text { BS5950 \% } \\
\text { Difference } \\
\text { with Test }\end{array}$ & $\begin{array}{c}\text { NIDA } \\
\text { Failure } \\
\text { Load (kN) }\end{array}$ & $\begin{array}{c}\text { NIDA \% } \\
\text { Difference } \\
\text { with } \\
\text { BS5950 }\end{array}$ \\
\hline 1 & Single-Bolt & 40.1 & 67.5 & 40.6 & 39.3 & 2.0 \\
\hline 2 & Double- Bolt & 66.6 & 75.5 & 11.8 & 63.1 & 5.2 \\
\hline
\end{tabular}

The design load allowing for flexible end connection by NIDA [17] is $2 \%$ and $5 \%$ below the code results for single and double bolted conditions respectively.

In the current design method based on codes, isolated member behaviour and design are the normal focus. The analysis and design are carried out in two separated and independent stages. The calculation of the compressive strength of a single angle relies heavily on the assumption of the effective length factor $\left(\mathrm{L}_{\mathrm{e}} / \mathrm{L}\right)$ which is, however, limited to 1.0 and 0.85 respectively for single and double-bolted end conditions. In fact, if the two end nodes of the member move, the "effective length" factor is always larger than 1.0 and thus the conventional linear analysis method becomes unsafe.

\subsection{Example 2: Second-order analysis in a portal - an illustrative example for advantages}

The accuracy of the proposed approach using imperfect element has been demonstrated and the advantage of the present method over the conventional effective length method is illustrated in the example here. To allow clarity in this demonstration, a very simple portal braced by a pair of angle members is studied by the two approaches, the code method based on a linear analysis and the second-order $\mathrm{P}-\Delta-\delta$ analysis. As shown in Figure 11, the portal is 2 $\mathrm{m}$ high by $3 \mathrm{~m}$ wide with beams and columns of the same section of $305 \times 305 \times 240$ UC of

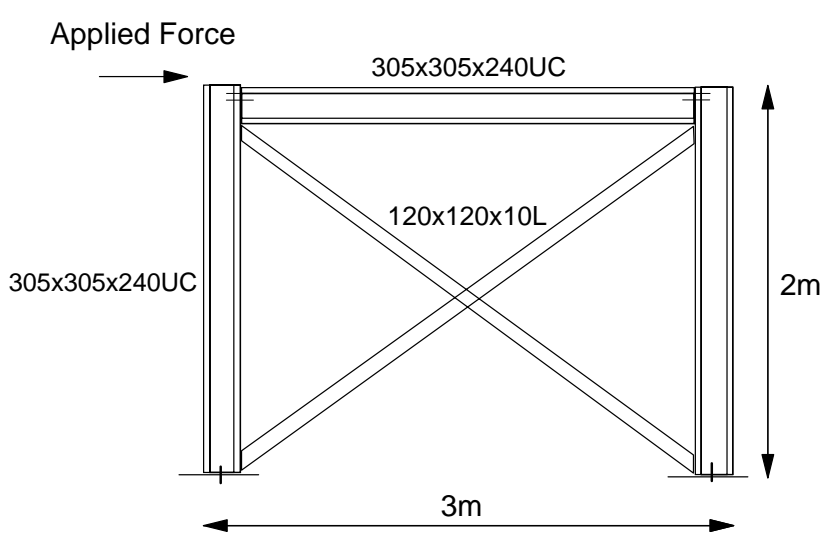

Figure 11. Simple portal with cross-braces S275 steel grade. The bracing angles are taken as sections 120 x 120 x 10 L grade S275 steel with both ends pin-connected to the columns by a single bolt. For simplicity, the gusset plate is assumed thin with negligible flexural stiffness so that rotational spring at connection is ignored. The portal is pinned to ground and the beam is pinned to column, which represents the simplest case of simple construction with beams simply supported on columns and lateral force resisted by a bracing system.

In conventional linear analysis, the compressive angle member is commonly ignored because of its high slenderness. Thus, two linear analyses were carried out as ignoring and considering the presence of compression member. For second-order analysis, again two assumptions are made on using (1) imperfection of L/360 recommended in this paper and (2) a very small imperfection of $\mathrm{L} / 7600$ for comparison. In all design, the design load is assumed when the first member fails except 
in an elastic-plastic analysis where analysis is continued until the load cannot further be increased with increment of displacement. Below is the summary of the design loads of the truss. The results are summarized in Table 6 and Figure 12 presents a load-deflection curve of the node at which the load is applied to.

From this example, a few interesting points are noted as follows.

(1) The conventional approach ignoring bracing members in compression yields a result more conservative than the second-order analysis by 28\%. Apart from this over-designing, the approach is difficult to apply when many bracing members are present and the error depends on the slenderness ratio of the braces. As $\mathrm{L} / \mathrm{r}$ for the brace is in a typical range of 153 here, the error is considered to be representative of a typical braced truss.

(2) The error considering compression member in a linear analysis and second-order analysis based on perfect geometry are both unacceptable in accuracy. This shows a second-order analysis without consideration of imperfections should not be used with section capacity check or even in a second-order analysis.

(3) The common concept that the compression bracing member cannot take much load and therefore ignored in a linear analysis is not correct when the present slenderness ratio is considered. Compression members even as bracings can be considered in an analysis with allowance for their strength and stiffness reductions due to high slenderness and imperfections.

The advantage of the present method over the linear analysis is obvious in this example. The contribution of the compression member can be considered when using the second-order analysis and the actual failure mode in the structure can be manifested, both of the considerations are not possible to consider in a linear analysis with the effective length method.

Table 5. Design Loads of various analysis types

\begin{tabular}{|c|c|c|c|}
\hline Analysis Type & $\begin{array}{l}\text { Design Load at } \\
\text { First Yield } \\
(\mathbf{k N})^{1} \\
\end{array}$ & $\begin{array}{c}\text { Corresponding Force } \\
\text { at } \operatorname{Compression~}^{\operatorname{Brace}^{2}(\mathbf{k N})} \\
\end{array}$ & $\begin{array}{c}\text { Corresponding Force } \\
\text { at Tension Brace }{ }^{2} \\
(\mathrm{kN})\end{array}$ \\
\hline $\begin{array}{l}\text { Linear analysis with design } \\
\text { load assumed at failure of } \\
\text { compression brace }\end{array}$ & 207 & 124 & 124 \\
\hline $\begin{array}{l}\text { Linear analysis ignoring the } \\
\text { presence of compression } \\
\text { brace }\end{array}$ & 430 & / & 517 \\
\hline $\begin{array}{l}\text { Second-order using very } \\
\text { small imperfection (L/7200) }\end{array}$ & 840 & 506 & 504 \\
\hline $\begin{array}{l}\text { Second-order analysis using } \\
\text { L/360 as imperfection }\end{array}$ & 595 & 358 & 357 \\
\hline Elastic-plastic analysis ${ }^{4}$ & 726 & 358 & 517 \\
\hline \multicolumn{4}{|c|}{$\begin{array}{l}\text { Note: 1. Design load is taken as the lateral load causing the bracing member to yield. } \\
\text { 2. The compression or tension force at the design load. } \\
\text { 3. This is the design load calculated from the recommended imperfection in this paper. } \\
\text { 4. Elastic-Plastic buckling load is obtained by simple maintenance of the maximum resistance of the compressive brace } \\
\text { with the external load continues to increase until a mechanism is reached. This method accounts for force and moment } \\
\text { re-distribution among members and its load deflection curve is indicated in Figure 12. }\end{array}$} \\
\hline
\end{tabular}




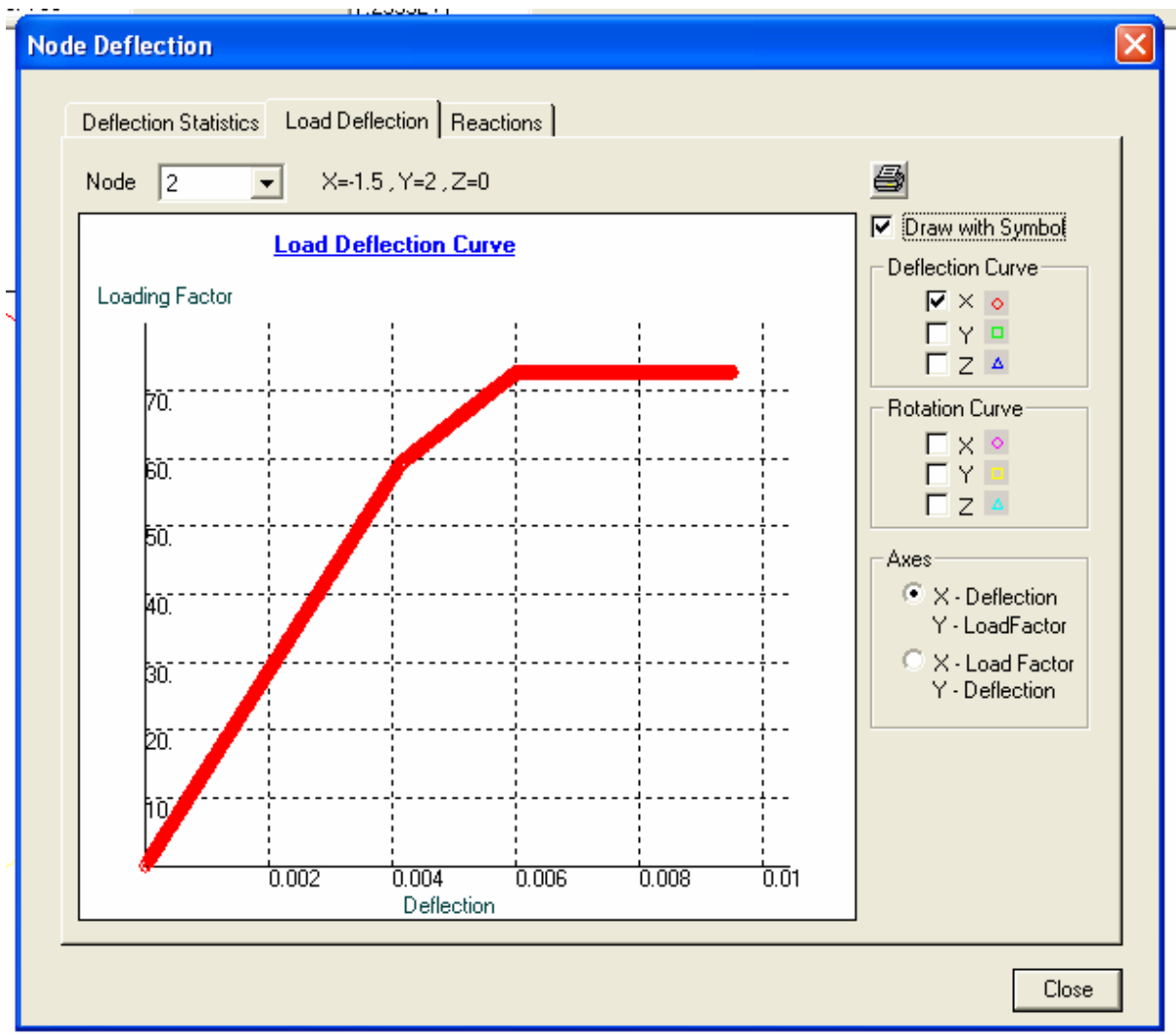

Figure 12. Theoretical Load vs. deflection plot of the portal

\section{CONCLUSIONS AND RECCOMENDATIONS}

In this paper, a second-order $\mathrm{P}-\Delta-\delta$ analysis is developed for angle trusses comprised of slender members. The P- $\Delta$ and P- $\delta$ effect is considered respectively by geometry and curvature updates, with code allowance of imperfections as imperfect frame geometry and initial member curvature. The values of $\delta_{0} / \mathrm{L}$ for equal and unequal angles are suggested and verified by comparison with laboratory tests of angle trusses. It is found that the proposed method gives a conservative design in fulfillment of the code requirements and the same calibrating procedure can obviously be applicable to other national steel structure design codes. The second-order $\mathrm{P}-\Delta-\delta$ method was noted to be a reliable, robust, efficient and convenient design method for steel frames as well as angle trusses. It considers and designs the framed structure as a whole instead of designing members in isolation and separately. The method requires no assumption on effective length and the rotation stiffness of the connection is accounted for by adding rotational spring elements at member ends. This method is more rational when compared with the effective length method. In the present investigation, the stiffness of the rotational spring element can be taken as the stiffness of the gusset plate.

\section{ACKNOWLEDGEMENT}

The authors acknowledge the financial support of "Second-order Analysis and Design of Angle Trusses and Frames” by the Research Grant Council grant from the Hong Kong SAR Government. 


\section{REFERENCES}

[1] Chen WF and Lui EM. Stability design of steel frames. Boca Raton, Florida: CRC Press, 1991.

[2] Trahair, NS. Restrained elastic beam-columns. Journal of the Structural Division, ASCE 1969;95(12):2641-2664.

[3] Goodier, JN. The buckling of compressed bars by torsion and flexure. Cornell Univ Engineering Experimental Station Bulletin, 1941;27 Dec.

[4] Goodier, JN. Flexural-torsional buckling of bars of open section, under bending, eccentric thrust or torsional loads. Cornell Univ Engineering Experimental Station Bulletin 1942; 28 Jan.

[5] Foehl FP. Direct method of designing single angle struts in welded trusses, Design Book of Welding. Lincoln Electric Co., Cleveland, OH; 1948.

[6] Kitipornchai S, Chan SL. Nonlinear finite element analysis of angle and tee beam-columns. Journal of Structural Engineering, ASCE 1987;113(4):721-739.

[7] Trahair NS, Usami T, Galambos TV. Eccentrically loaded single angle columns. Research Report No. 11. Structural Division, Civil and Environmental Engineering Department, School of Engineering and Applied Science, Washington University, St Louis, Missouri, USA; 1969.

[8] Adluri SMR, Madugula MKS. Eccentrically loaded steel angle struts. Engineering Journal, AISC 1992;31(3):59-66.

[9] AISC. Load and resistance factor design specification for structural steel buildings. AISC Inc, Chicago; 1986.

[10] AISC. Specification of allowable stress design. AISC Inc, Chicago; 1989.

[11] Wakabayashi M, Nonaka T. On the buckling strength of angles in transmission towers. Bulleting of the Disaster Prevention Research Institute, Kyoto University, Japan, Nov 1965;15(2):1-18.

[12] Mueller WH, Erzurumlu H. Behaviour and strength of angles in compression: an experimental investigation. Research Report of Civil-Structural Engineering. Division of Engineering and Applied Science. Portland State University, Oregon, USA; 1983.

[13] Ishida A. Experimental study on column carrying capacity of "SHY” steel angles. Yawata Technical Report. Yawata Iron and Steel Co Ltd, Tokyo, Japan; Dec, 1968;265:8564-8582, 8761-8763.

[14] Bathon L, Mueller WH, Kempner L. Ultimate load capacity of single steel angles. Journal of Structural Engineering 1993;119(1):279-300. 
[15] ASCE. Manuals and reports on engineering practice no 52. Guide for Design of Steel Transmission Towers, ASCE, New York; 1988.

[16] Elgaaly M, Davids W, Dagher H. Non-slender single angle struts. Engineering Journal, AISC 1992;31(3):49-59.

[17] NIDA. Non-linear integrated design and analysis computer program manual version 7 ElePlast, NAF Series, User’s Manual. The Hong Kong Polytechnic University, Hong Kong; 2005.

[18] BSI. Structural use of steelwork in building - Part 1: Code of practice for design - Rolled and welded sections”, BS5950, BSI, London; 2000.

[19] CEN. Eurocode 3 Design of steel structures - Part 1-1: General rules and rules for building. CEN, BSI, London; 1992.

[20] Code of practice for structural design of steel structures - A limit state approach. Buildings Department, Hong Kong; 2005.

[21] Chan SL, Cho SH. Design of steel frames using calibrated design curves for buckling strength of hot-rolled members. In: Chan SL, Teng JG, Chung KF, editors. Proceedings of Advances in Steel Structures. Elsevier, 2002. Elsevier Science. 1193-1199

[22] Chan SL. Geometric and material nonlinear analysis of beam-columns and frames using the minimum residual displacement method. International Journal for Numerical Methods in Engineering 1988;26:2657-2669.

[23] BSI. Metallic Materials - Tensile Testing - Part 1: Method of Test at Ambient Temperature, BS EN 10002. BSI, London; 2000. 
[Blank Page] 


\section{ADVANCED STEEL CONSTRUCTION}

\section{An International Journal}

\section{Volume 1 Number 1 June 2005}

\section{CONTENTS}

\section{Technical Papers}

Effects of Concrete Slab on Ductility of Steel Moment Connections C.B. Joh and W.F. Chen

Compressive Performance of Cold-formed Thin-walled Steel Channel Sections in Fire Y.C. Wang, M.Q. Feng and B. Salhab

An Equilibrium Approach for Flexural-Torsional Buckling of Elastic Steel Arches Y.L. Pi, M.A. Bradford and Y.Y. Chen

Steel Framed Structures Subjected to the Combined Effects of Blast and Fire Part 1: State-of-the-Art-Review

H.X. Yu and J.Y.R. Liew

Steel Framed Structures Subjected to the Combined Effects of Blast and Fire -

Part 2: Case Study

H.X. Yu and J.Y.R. Liew

Design of Plane Steel Frames - Towards a Rational Approach

R. Gonçalves and D. Camotim

Flexural Behaviour of Steel Panels Composed of Bolted Modular Units H.T. Wong, J.G. Teng, Z.C. Wang, Y. Zhao and S.L. Dong

Second-order P- $\triangle-\delta$ Analysis and Design of Angle Trusses Allowing for Imperfections and Semi-rigid Connections

S.L. Chan and S.H. Cho 